\title{
Diffusion or Dissent: Examining International Family Planning Frames and Domestic Policy Divergence
}

\author{
Gillian C. Beach
}

Follow this and additional works at: https://researchrepository.wvu.edu/etd

\section{Recommended Citation}

Beach, Gillian C., "Diffusion or Dissent: Examining International Family Planning Frames and Domestic Policy Divergence" (2017). Graduate Theses, Dissertations, and Problem Reports. 5167.

https://researchrepository.wvu.edu/etd/5167

This Dissertation is protected by copyright and/or related rights. It has been brought to you by the The Research Repository @ WVU with permission from the rights-holder(s). You are free to use this Dissertation in any way that is permitted by the copyright and related rights legislation that applies to your use. For other uses you must obtain permission from the rights-holder(s) directly, unless additional rights are indicated by a Creative Commons license in the record and/ or on the work itself. This Dissertation has been accepted for inclusion in WVU Graduate Theses, Dissertations, and Problem Reports collection by an authorized administrator of The Research Repository @ WVU.

For more information, please contact researchrepository@mail.wvu.edu. 


\title{
Diffusion or Dissent:
}

Examining International Family Planning Frames and Domestic Policy Divergence

\author{
Gillian C. Beach \\ Dissertation submitted \\ to the Eberly College of Arts and Sciences \\ at West Virginia University \\ in partial fulfillment of the requirements for the degree of \\ Doctor of Philosophy in \\ Political Science
}

\author{
Erik Herron, Ph.D., Co-chair \\ Cyanne Loyle, Ph.D., Co-chair \\ Robert Duval, Ph.D. \\ Jeffrey Worsham, Ph.D.
}

Department of Political Science

Morgantown, West Virginia

2017

Keywords: issue framing, diffusion, advocacy, family planning, Iran, Cuba Copyright 2017 Gillian Beach 


\begin{abstract}
Diffusion or Dissent:

Examining International Family Planning Frames and Domestic Policy Divergence

Gillian C. Beach

This dissertation explores how issue framing within an international advocacy movement influences and is influenced by the framing of the same issue within politically differentiated regimes, and examines this question through an analysis of the international family planning movement. Existing work on both policy diffusion and international advocacy presents strong evidence that the international community has a powerful effect on the framing and development of domestic policy. However, there is room for refinement of the literature in addressing how international actors affect policy trajectories within dissenting regimes - that is, regimes that espouse explicitly anti-Western ideologies, but which are nevertheless active in the international community. To examine this relationship, I employ a comparative case study of the Cuban and Iranian family planning movements, using content analysis of archival data and process tracing methods. While both Cuba and Iran have developed strong family planning programs and have actively sought international support in the process, they have also promoted family planning frames consistent with their own national ideologies. Thus, these movements offer the opportunity to explore the dynamics of dissenting regime policy framing and its interactions with the international arena, and to enhance understanding of the relationship between international activism and domestic policy development.
\end{abstract}


For Joe,

My love and support in all of life's adventures. 


\section{Table of Contents}

Chapter 1 - Introduction: International Advocacy and Dissenting Regimes .............................. 1

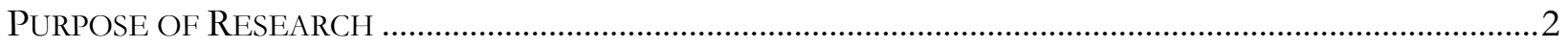

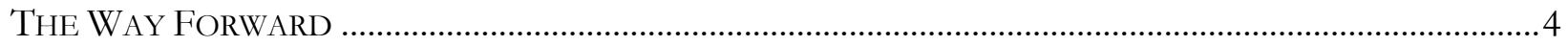

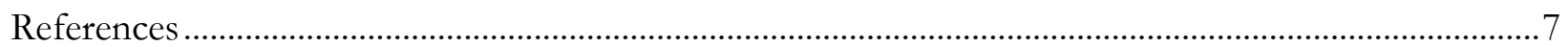

Chapter 2 - Literature Review: The Intersection of Framing, Diffusion, Social Movements

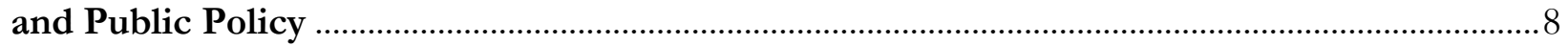

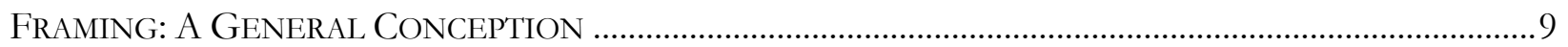

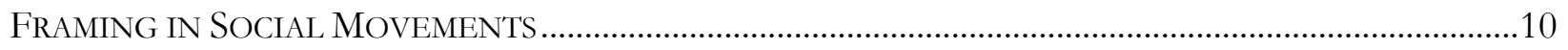

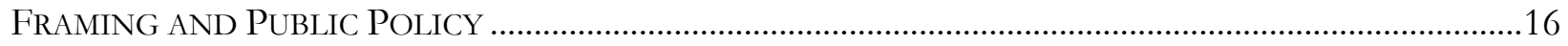

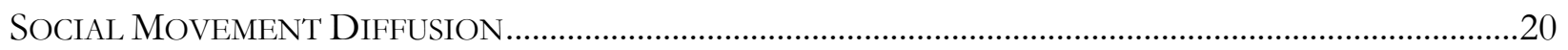

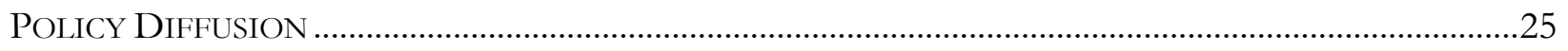

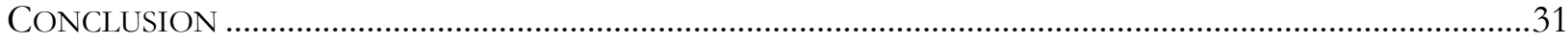

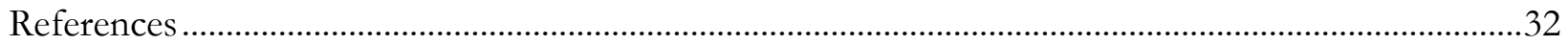

Chapter 3 - Theory and Methods: Toward Explaining the Behavior of Dissenting Regimes

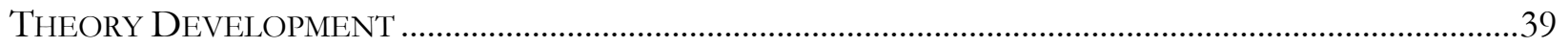

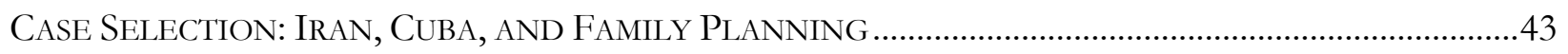

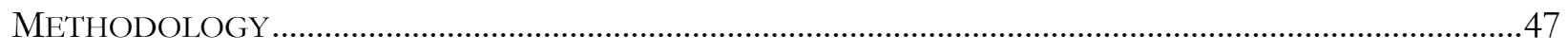

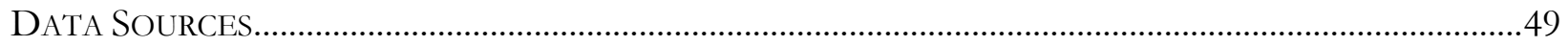

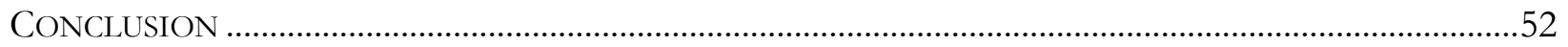

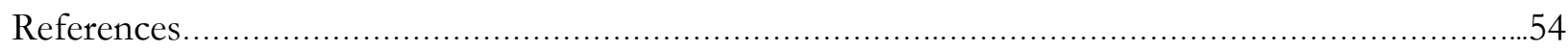

Chapter 4 - The International Movement: Tracing Family Planning Frames Across Time and

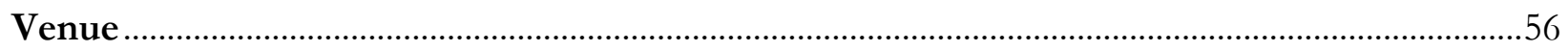

History of THE International FAMiLy Planning MOVEMENT: A MAINSTREAM

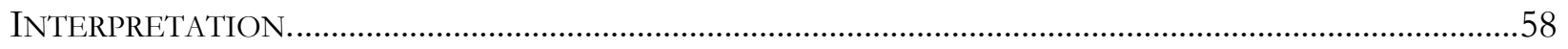

FAMILY PlanNING HiSTORY: AN ALTERNATIVE INTERPRETATION ...................................................64

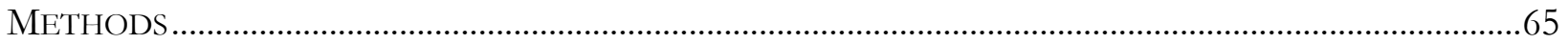

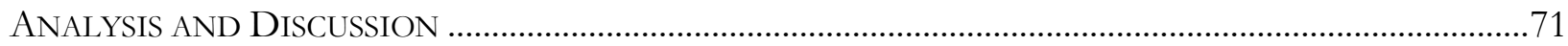

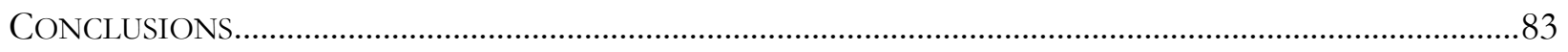

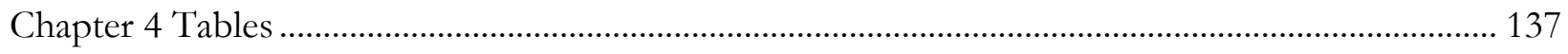

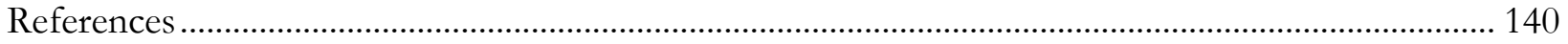




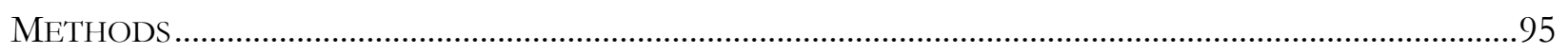

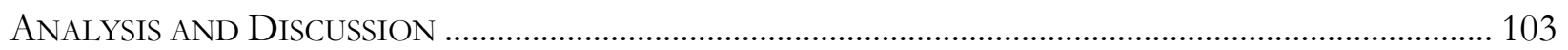

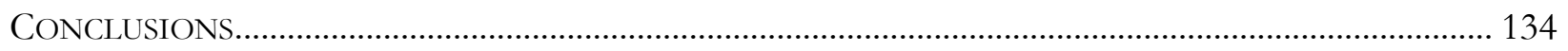

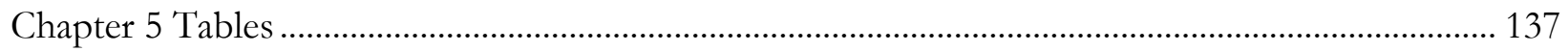

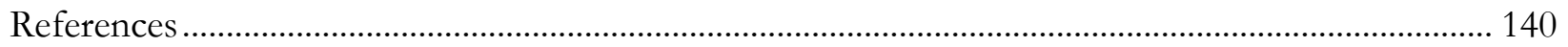

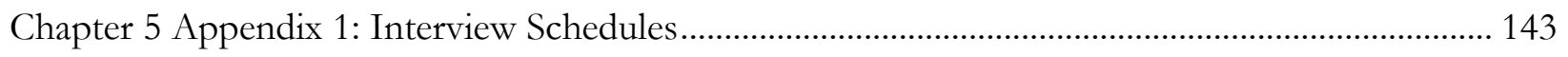

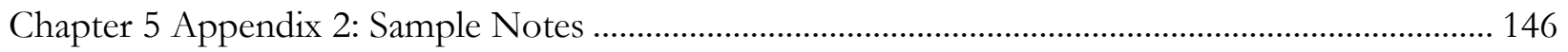

Chapter 6 - Family Planning in Iran: Frame Convergence and Divergence in the Islamic

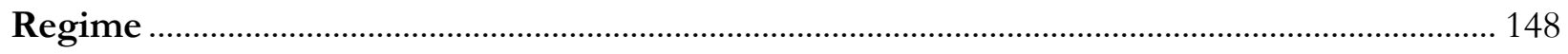

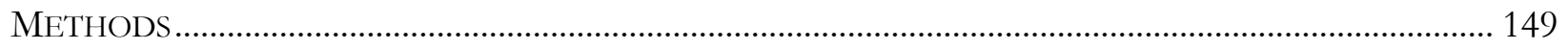

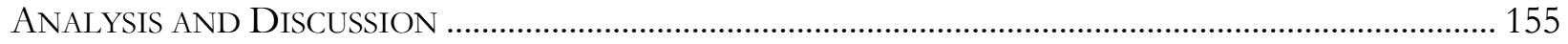

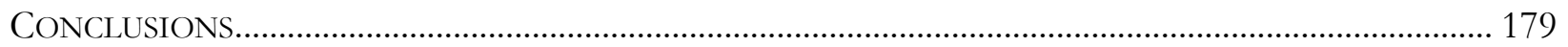

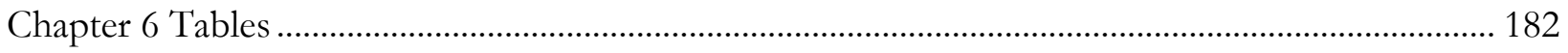

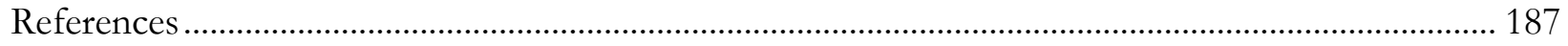

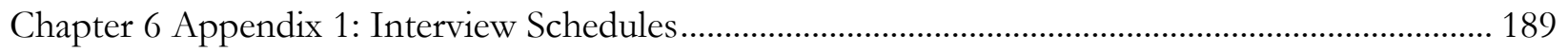

Chapter 7 - Conclusion: Dissent and Diffusion in Policy and Advocacy ................................ 191

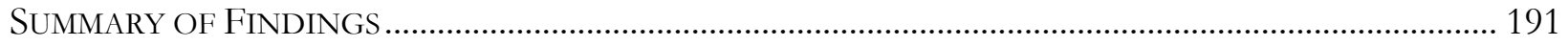

REVIEW OF HYPOTHESES AND THEORETICAL IMPLICATIONS............................................................. 193

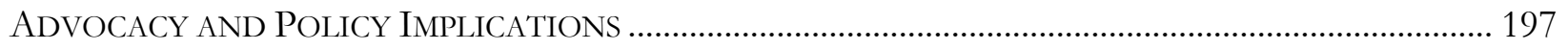

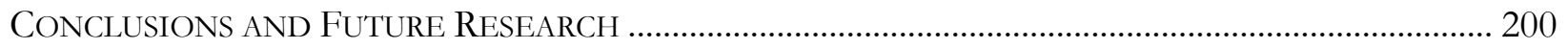




\section{Chapter One}

\section{Introduction: International Advocacy and Dissenting Regimes}

In 1974, representatives from 135 nations met at the $3^{\text {rd }}$ UN World Population Conference in Bucharest to discuss global family planning advocacy, policies, and programs. An international social movement promoting family planning-financially and ideologically led predominantly by US-based actors - had been gaining momentum since the 1960s, and by 1974 the ideas that framed the international family planning dialog were firmly established. Family planning was widely viewed as a means for limiting population growth and promoting economic development (Blanc and Tsui 2005; Seltzer 2002), and the 1974 UN Plan of Action reiterated the belief "that population policies and objectives are an integral part of socio-economic development policies". Although this statement reflects majority opinion about the role of family planning, not every nation was comfortable with the focus on population control and development. Among these nations, Cuba stands out for its open dissent to UN framing of family planning at Bucharest. Cuban conference delegates vocally rejected the conference's dominant neo-Malthusian ideology, asserting that population growth did not cause poverty and was merely being used as a distraction from the true causes of underdevelopment—that is, neocolonialism (Sanders 1974, 5). However, despite its objection to the UN's approach to family planning, at the close of the conference, Cuba negotiated a $\$ 3.8$ million grant agreement with the United Nation Fund for Population Activities (UNFPA), which was used to help establish an industry for the local manufacture of oral contraceptives and provided equipment and personnel training for maternal healthcare facilities (IPPF 1980).

1 See the World Population Plan of Action, http://www.un.org/en/development/devagenda/population.shtml 


\section{PuRPose of RESEARCH}

Cuba's activity at the 1974 Bucharest conference poses an interesting challenge to current theories on advocacy, aid-seeking, and domestic policymaking. Existing work argues that international advocates seeking to influence domestic policies must frame policy goals in a way that increases their compatibility with domestic belief systems (Benford and Snow 2000; Keck and Sikkink 1998; Noaks and Johnston 2005; Tarrow 2005). The literature also predicts that, in order to engage the international community and receive support for local programs, domestic advocates must portray their movements as compatible with international agendas (Bob 2005). Over time, interaction between domestic and international actors promotes the further convergence of policy frames and similarities across resulting policies (Bennett 1991; Harsin 2010, 165; James and Lodge 2003, 182; Koopmans 1999, 67; Newmark 2002, 164). Thus, a lack of congruence between domestic frames and the frames forwarded by transnational activists-which does not impede international support, collaboration, and successful, internationally-endorsed policy programs—requires further explanation.

In more general terms, existing literature fails to account for the policy and advocacy trajectories of dissenting regimes—that is, regimes that espouse non-Western ideologies, but which are nevertheless active in the global community. ${ }^{2}$ Rather than isolating themselves from the international community, dissenting regimes choose to actively participate in international social movements even when domestic priorities diverge from the issue frames being promoted by international policy advocacy—when these frames conflict with stated domestic ideologies or cultural values. Furthermore, this discord does not always negatively impact the ability of dissenting regimes to draw international support and to construct progressive policies. Thus, a revised understanding of these dynamics of participation and dissent is critical to increasing our ability to successfully include dissenting regimes in policy advocacy efforts and to build better policy programs.

\footnotetext{
${ }^{2}$ Here, I intentionally make a distinction between these dissenting regimes and closed regimes, such as North Korea,
} which more fully isolate themselves from the international community. 
Within the context of the international family planning movement, Iran and Cuba are examples of dissenting regimes. Both the Republic of Cuba and the Islamic Republic of Iran actively participated in this international movement, attending UN meetings and seeking international aid and legitimacy for their eventually-successful and robust programs. However, narrative accounts of this participation suggest a conscious refusal to re-frame their domestic family planning movements to match international framing strategies. Through an analysis of these cases, my research investigates how dissenting regimes participate in international movements, affirming overall movement policy goals while simultaneously promoting these goals through seemingly irreconcilable frames. Specifically, through this dissertation, I examine the following research questions: How do international and domestic actors negotiate the tension between divergent framing tactics in both domestic and international venues? Does the international movement shift to accommodate these divergent frames, or do the dissenting regimes themselves conform? Does prolonged engagement eventually lead to frame convergence?

In answering these questions and working to increase understanding of how US-based advocacy and policymaking directly impacts public policy development across different domestic contexts, my research specifically focuses on policy and advocacy frames. In their comprehensive review of policy diffusion studies within political science, Graham et al. (2012) note that while much research has been conducted on the diffusion of actual policy adoption, there is a paucity of studies that examine the spread of policy ideas (689). By shifting the focus from the programmatic content of family planning policies to the diffusion of framing messages underpinning those policies, my dissertation directly addresses this deficiency. In order to analyze the framing strategies used in various contexts, I rely on the following sources of data: UN conference reports; US, Iranian, and Cuban media reports; international and domestic NGO reports; domestic public policy documents; and government and advocate interviews and statements regarding family planning. These form the core of three distinct 
case studies that examine frame development and change in the international family planning movement, in the Cuban movement, and the Iranian movement.

Through analysis of these three cases, this dissertation helps to demonstrate where and when domestic frame matching is required in order to garner international support, and whether prolonged engagement with the international community eventually leads to frame convergence. Moreover, this research offers an explanation of how dissent from international norms and progressive policy change can coexist. As a result, we will be more fully prepared to enable groups with diverse values to work together to bring about positive social change in an increasingly globalized world, and to develop advocacy strategies and policy programs that more consciously and effectively account for the impacts of these underlying differences.

\section{THE WAY FORWARD}

In order to establish a foundation based in the current understanding of relevant theories, Chapter Two examines two larger bodies of literature on issue framing and diffusion as they relate to both social movement mobilization and public policy. Discussions of frame narratives and the framing process are integral to both social movement and policy theories; however, these literatures have largely developed independently of one another. Although there are some specific distinctions in how framing influences mobilization and policy processes, this chapter takes the opportunity to begin to unify these two fields of thought. Similarly, diffusion mechanisms have been a central topic of concern to policy and social movement scholars alike, and this is another area where there is room for the integration of two often-distinct literatures. Here again, this chapter draws upon the contributions of both fields in order to construct a more comprehensive understanding of diffusion processes.

Chapter Three builds on the work reviewed in Chapter Two and proposes an extension of these theories that may be applied to the behavior of dissenting regimes and international activists. From 
this theoretical development follows a set of hypotheses to be tested in the empirical portion of the dissertation. This chapter concludes with a broad overview of the methods employed in each case study.

Chapter Four provides an empirical analysis of the framing strategies pursued by the international family planning movement between 1960 and 2010. Specifically, this chapter traces the levels of use of 6 frames employed to promote family planning-population, development, environment, women's welfare, health, and human rights-in media, NGO, and United Nations venues. This analysis of frame use establishes the baseline for understanding where and how international movement framing tactics have shifted over time. In order to identify processes of convergence or divergence among dissenting regimes, it is first necessary to develop a firm understanding of the frames that dominated the international arena in each decade. Thus, this analysis of the international movement provides the critical measures of international frame use that form the basis for comparison in later chapters.

In Chapter Five, I develop an in depth case study of family planning frame use in Cuba between 1960 and 2010. Using archival resources and participant interviews, this chapter first documents trends in frame use across multiple domestic and international venues. In the second part of the chapter, I examine the theoretical implications of these frame use strategies with regard to the processes of dissent to and convergence with international movement norms.

Similarly, Chapter Six contains a detailed case study of Iranian family planning framing from 1979 to 2010, and also relies on both archival materials and participant interviews to construct an analysis of framing tactics employed in both domestic and international venues. Again, this analysis is followed by an examination of the lessons that can be draw from this case with regard to the ways in which dissenting regimes express objection while building collaborative partnerships, and what this means for diffusion processes. 
Finally, in Chapter Seven, I conclude with a summary of the theoretical insights offered by this dissertation with regard to the ways in which dissenting regimes engage in a strategic balancing of dissent and conciliation in their relationships with international activists, who in turn shift to accommodate divergent frames. Here, I also take the opportunity to reflect on several methodological points of interest, and to suggest possible avenues of future work on this topic.

In sum, the theory and analysis presented within these chapters establishes a fuller understanding of the behavior of dissenting regimes and their interactions with the international activist community. 


\section{References}

Benford, R. D., \& Snow, D. A. (2000). Framing Processes and Social Movements: An Overview and Assessment. Annual Review of Sociology, 26, 611-639.

Bennett, C. J. (1991). What is Policy Convergence and What Causes It? British Journal of Political Science, 1991, 215-233.

Blanc, A, \& A Tsui. (2007). "The Dilemma of Past Success: Insiders' views on the future of the international family planning movement". Sage Family Studies Abstracts. 29 (1): 263.

Bob, C. (2005). The Marketing of Rebellion: Insurgents, Media, and International Activism. Cambridge; New York: Cambridge University Press.

Graham, E. R., Shipan, C. R., \& Volden, C. (2013). The Diffusion of Policy Diffusion Research in Political Science. British Journal of Political Science, 43, 3, 673-701.

Harsin, J. (2010). "Diffusing the Rumor John Kerry is French, i.e. Haughty, Cowardly, Foppish, Socialist and Gay". In R. Given and S. Soule eds. The Diffusion of Social

Movements. New York: Cambridge University Press.

International Planned Parenthood Federation (IPPF). 1980. Family planning in Cuba: A profile of the development of policies and programmes. London, England: International Planned Parenthood Federation.

James, O. and Lodge, M. (2003). The Limitations of 'Policy Transfer' and 'Lesson Drawing' for Public Policy Research. Political Studies Review, 1, 2, 179-193.

Johnston, H., \& Noakes, J. A. (2005). Frames of protest: Social movements and the framing perspective. Lanham: Rowman \& Littlefield Publishers.

Keck, M. E., \& Sikkink, K. (1998). Activists Beyond Borders: Advocacy networks in international politics. Ithaca, N.Y: Cornell University Press

Koopmans, R. (1999). "Globalization or Still National Politics? A Comparison of Protests Against the Gulf War in Germany, France, and the Netherlands". In: Hanspeter Kriesi, Donatella della Porta and Dieter Rucht, eds. Social Movements in a Globalizing World. Houndmills, Basingstoke: Macmillan.

Newmark, A. J. (2002). An Integrated Approach to Policy Transfer and Diffusion. Review of Policy Research, 19, 2, 151-178.

Tarrow, S. (2005). The New Transnational Activism. New York: Cambridge University Press.

Sanders, T. G. 1974. Cuba and the Bucharest Conference. American Universities Field Staff Reports: North America 2 (4): 1-11.

Seltzer, J. R. (2002). The origins and evolution of family planning programs in developing countries. Santa Monica, CA: Rand. 


\section{Chapter Two}

\section{Literature Review: The Intersection of Framing, Diffusion, Social Movements and Public Policy}

With a focus on the nexus between international advocacy and domestic public policy development, this dissertation draws heavily on literature from both comparative politics and public policy. Specifically, this dissertation is built on the literature concerning two broad theoretical concepts that are equally relevant to studies of both social movements and policy processes, but which are not frequently applied to both areas within the context of a single study. The first of these is the vast literature on the subject of framing. Framing is a critical concept in a range of disciplines, and it is a key component of both social movement and policy development literature alike. The first section of this review gives a brief overview of the concept of framing in its most general form, and then details how framing has been centrally employed to explain both the nature of social movements and the formation of public policy. The second core theoretical concept is diffusion. Both social movement and policy research have focused extensively on the spread of movements and policies from one area to another, and the second half of this review examines the literature pertaining to each similar but distinct body of diffusion theory.

The purpose of this review is not only to establish the theoretical foundation for the development of this dissertation, but also to demonstrate the compatibility of policy and social movement literature on framing and diffusion. Although these two framing and diffusion literatures have evolved separately within the field of comparative politics and public policy, my dissertation will draw on their similarities and work to integrate their ideas more seamlessly in the formation of my own theoretical and empirical contributions. 


\section{FRAMING: A GENERAL CONCEPTION}

In his central work on frame theory, Entman (1993) states that "to frame is to select some aspects of a perceived reality and make them more salient" (52). Gamson and Modigliani (1989) define frames themselves as an ideational 'package' or "a central organizing idea" (3). Thus, framing is the construction of a specific interpretation of reality around a core idea-making frames narrower in focus than either discourses or ideologies (Polletta and Ho 2006, 8). At the most basic level, frames work to organize information and make the world more intelligible (Chong and Druckman 2007, 106; Gamson and Modigliani 1989, 3; Polletta and Ho 2006, 2; Scheufele and Iyengar forthcoming, 13). However, the effect of framing is much more powerful that this simple understanding suggests. As Entman (1993) elaborates, by organizing a particular vision of reality, frames critically work to identify and define social problems, diagnose the causes of those problems, make moral evaluations of both causes and effects, and prescribe appropriate remedies (52). Thus, framing tells us 'what is at issue' and what ought to be done about it (Gamson and Modigliani 1989, 3). As new information becomes available, frames evolve to accommodate it (Chong and Druckman 2007, 108). Thus, framing should be conceptualized as a dynamic process, and frames themselves have somewhat fuzzy boundaries (Chong and Druckman 2007, 108; Gamson and Modigliani 1989, 4; Polleta and Ho 2006, 5).

In the effort to 'diagnose, evaluate and prescribe', not all frames have equal authority, and the strength of a frame is largely determined by its resonance. Resonance, as articulated by Scheufele and Iyengar (forthcoming), is produced when a frame interprets reality in a way that is consistent with an individual's preexisting cognitive schema (13). These schema, in turn, are heavily conditioned by cultural contexts, which contain a range of shared symbols and meanings that can be incorporated in the construction of frames (Entman 1989, 53; Gamson and Modigliani 1989, 5; Scheufele and Iyengar forthcoming, 15). Framing efforts that capitalize on shared cultural experiences make frames seem "natural and familiar" (Gamson and Modigliani 1989, 5). However, frames that are culturally 
inconsistent are less likely to produce resonance. More narrowly, ideology, individual values, and personal experiences influence individual-level frame resonance, and frames that cannot be reconciled with personal values, knowledge, or ideological leanings will have difficulty in generating acceptance and credibility (Chong and Druckman 2007, 111-112; Polletta and Ho 2006, 23).

Strong frames elevate the ideas they promote to a position of social or political salience, making them "more noticeable, meaningful and memorable to audiences" (Entman 1993, 53). Eventually, such frames may become dominant - that is, the problem definitions, evaluations and remedies they prescribe have "the highest probability of being noticed, processed and accepted by the most people" (Entman 1993, 56). In other words, certain frames become widely accepted as the 'best rationale' concerning a given issue (Chong and Druckman 2007, 116). While these dominant frames are not immune to opposition and may be challenged by 'counterframes', alternative interpretations will have a hard time gaining traction (Entman 1993, 56). Critically, once strong frames become accepted, they have a profound effect on opinions, attitudes, and behavior around an issue (Chong and Druckman $2007,104,109)$. That is to say, frames direct thought and beliefs in a particular direction, and are thus a powerful tool. As a result, a wide range of actors have an interest in creating and disseminating frames, and framing efforts play a pivotal role in social and political processes. The role of framing in two such processes_-social movement activism and policymaking-is the subject of the sections that follow.

\section{FRAMING IN SOCIAL MOVEMENTS}

While the concept of framing was developed in the 1950s, frames did not become an integral part of social movement theory until several decades later, and were first introduced to the field in Todd Gitlin's 1980 study of media and activism, The Whole World is Watching (Noakes and Johnston 2005, 3). The application of frame theory to social movement research was further developed throughout the 1980s, most notably by sociologists William Gamson, Robert Benford, and David Snow (Noakes and 
Johnston 2005, 3). By the end of 1990s, framing had "come to be regarded, alongside resource mobilization and political opportunity processes, as a central dynamic in understanding the character and course of social movements" (Benford and Snow 2000, 612; see also McAdam et al. 1996).

Although the framing processes studied within social movement research serve the same interpretive function as other frames, collective action frames are distinct in that they are explicitly and fundamentally 'action-oriented' (Benford and Snow 2000, 614). These frames diagnose problems and prescribe solutions, but the key to their importance lies in their ability to mobilize a collective response that serves as the foundation for generating social movement activity (Benford and Snow 2000, 615). Thus, social movement actors are critical frames-developers, and frames themselves act as the "call to arms" that helps to explain the role of human agency in mobilization (Benford and Snow 2000, 617).

Clearly, not all collective action frames are successful in mobilizing collective action, and as with other types of frames, the variation in frame success can be explained by the level of frame resonance. Within social movement research, the concept of resonance has been more precisely developed as a measure of both frame credibility and frame salience (Benford and Snow 2000, 619). Credibility depends upon the consistency of the frame with a movement's beliefs and actions, the frame's empirical credibility or correspondence with 'real' external indicators, and the credibility of the claimsmakers or movement entrepreneurs (Benford and Snow 2000, 619; Noakes and Johnston 2005, 7). Salience, by contrast, captures the elements of centrality, or the importance of the issue to would-be participants, the commensurability or relatability of the issue as it is framed, and the 'narrative fidelity' or 'cultural resonance' of the frame (Benford and Snow 2000, 621-622). However, because collective action frames, by definition, seek to alter some aspect of the society in which they are developed, frames must reach a "balance between resonating with the existing cultural repertoire and challenging the status quo" (Hewitt and McCammon 2005, 34). That is, they must be simultaneously resonant and radical (Hewitt and McCammon 2005, 48). In part, framing efforts can achieve this balance by 
pointing out and emphasizing longstanding cultural contradictions that have lain "dormant" in a society - the language of freedom in the US constitution versus the practice of holding slaves, for example (Zald 1996, 266).

In the effort to uses frames specifically as a mobilizing tool, cultural compatibility is especially important. Movements make claims within "extant, culturally legitimate, boundaries" (Noakes and Johnston 2005, 10). Frames "amplify" beliefs associated with existing ideologies, and thus "ideology [serves] as a cultural resource for framing activity" (Benford and Snow 2005, 209). Cultural resonance increases issue salience, which, in turn, increases the likelihood of mobilization (Benford and Snow 2000, 622). Thus, cultural compatibility and the essential action-oriented component of collective action frames are tightly linked. As movements grow and spread, movement actors engage in the "strategic selection" and "fitting" of frames for new audiences, which allows for the "cross-cultural promotion" of ideas (Benford and Snow 2000, 627). Finally, movement framing adds to culture as "the frames of winning movements get translated into public policy and into the slogans and symbols of the general culture” (Zald 1996, 271).

Movements do not operate in a vacuum and it is critical to note that as movements work to mobilize support with resonant frames, they face challenges from counter-claimants. This may or may not include opposition movements, who engage in parallel framing activities; however, for many movements, the state is a powerful oppositional force (Noakes and Johnston 2005, 17). In their bid to maintain 'cultural supremacy', states forward what Noakes (2005) labels official frames-the state-sanctioned interpretations of social movement grievances (91). Attention to state framing activity is important because an "understanding of official frames is central to understanding the context in which social movements rise, prosper and decline" (Noakes 2005, 101). In other words, in addition to producing resonant collective action frames that mobilize support, a successful movement must also develop frames that override the state's competing frames. Additionally, although the state does not 
always fiercely oppose movement goals, and movements may merely be seeking to get their issue on the government's limited agenda, appealing to official frame narratives is critical to this process (McAdam et al. 1996). The importance of framing to agenda setting will be discussed in greater detail below.

In this competition between official and collective action frames, movements are often at a disadvantage because the organs of the states are generally more organized and possess greater cultural and material resources (Noakes 2005, 102; Tarrow 2005, 62). Although 'the state' is not (and does not operate as) a perfectly unified entity — and may, as a result, struggle internally to develop a coherent frame narrative — states are generally better positioned to ensure that their official frames are efficiently and accurately disseminated through culturally legitimate sources, such as respected media venues (Noakes 2005, 105). In addition, states and their official frames usually start from a position of greater political legitimacy, and movements must work to both credibly challenge this legitimacy while promoting their own frames (Noakes 2005, 104). Because the relative resonance of collective action frames vis-à-vis official frames is an important factor in determining social movement success, the role of official frames in movement development cannot be ignored.

As "privileged providers of information", the media also plays a key role in development of collective action frames (Walgrave and Manssens 2005, 117). Media framing and public frame interpretations are tightly bound in a mutually influential relationship where "media discourse is part of the process by which individuals construct meaning, and public opinion is part of the process by which journalists and other cultural entrepreneurs develop and crystallize meaning in public discourse" (Gamson and Modigliani 1989, 2). Thus, social movements rely on the media to promote collective action frames among the general public, as well as to attract the attention of political and social elites, and to boost movement morale (Klandermans and Goslinga 1996, 319). As movements work both to access the media and to forward their framing of an issue through media channels, 
several distinct challenges emerge. First, accessing the media agenda is difficult, as the media has limited time and space and nearly infinite possible stories (McAdam et al. 1996, 296). As a result, whether the media picks up a story depends on the news-gathering routines of reporters, whether the story is deemed 'interesting' or 'newsworthy', and whether the story is in line with the news agency's commercial (consumer and advertiser) interests (McAdam et al. 1996, 296-297). Movements with limited resources have a particularly difficult time getting on the media agenda, and many movements are never able achieve media access (McAdam et al. 1996, 306).

Even if media access is achieved, there is no guarantee that the media interpretations of events will favor movement goals, since the media will promote its own transformed version of the story (Klandermans and Goslinga 1996, 320). The media uses its own frames to "convey information, evoke emotional response, dramatize events, and focus attention" (Zald 1996, 270; see also Walgrave and Manssens 2005, 117). These frames may coincide with the frames the movement wishes to forward, or it may clash with movement frames. Consequently, movements try to influence the media discourse by carefully, explicitly, and strategically conveying their frames in news venues (Klandermans and Goslinga 1996, 324). Nevertheless, the media often serves as another competitor in a movement's quest to take control of issue framing (Walgrave and Manssens 2005, 116).

In addition to using collective action frames to target the general public, the media, and the state, social movements also use framing techniques to draw domestic and international NGO support (Bob 2005). NGO support can be very valuable for social movements, as it provides resources — such as monetary funding, supplies, and expertise-visibility, and legitimacy (Bob 2005, 15). In addition, NGO backing gives the movement leverage against opponents, and helps boost a movement's morale. However, the number of movements far exceeds the number of potential NGO partners, which creates a market with low supply and high demand, and results in a fierce competition for movement funding and support (Bob 2005, 15). 
Although not all movements seek such support, movements that do follow "two simultaneous but discrete steps" (Bob 2005, 179). One step is to raise awareness about the movement itself_or simply getting their movement on an NGO's agenda. Movements go about this in two ways: lobbying for support and enacting displays to draw media attention. Depending on the structure of the movement, either or both tactics may be employed with varying levels of success. Once agenda access has been achieved, the second critical step involves "framing their causes to match key NGO characteristics" (Bob 2005, 22). In determining which causes to support, NGOs balance altruistic goals and pragmatic strategizing to select among causes for the most promising ones that most closely match their interests (Bob 2005 14, 21). Therefore, a movement's ability to frame their cause as compatible with the goals and interests of the NGO from which support is desired is essential. Like other interpretive framing activities, this movement framing activity can involve simply highlighting certain appealing substantive or cultural angles of a movement, or also shifting movement tactical, organizational or ethical strategies to align with NGO principles. That is, a movement forwards particular interpretations that "blend realistic and opportunistic elements" in a rationally calculated effort to better market itself for support (Bob 2005, 27).

Because the effort to draw support from NGOs generally crosses international boundaries, movements also use the previously mentioned 'cross-cultural fitting' techniques, and domestic movements are incentivized to adopt internationally salient, NGO-endorsed frames (Bob 2005). Thus, domestic movements are encouraged to 'buy in' to the frames and messages of the international community as they market themselves for international financial aid or support. Overall, participation by domestic actors in the international arena is likely to be most successful (in terms of generating support) when domestic frames 'match' international ones, and it is possible for marketing efforts to "hijack" the movement's original trajectory and force it to change its goals and frames to win support (Bob 2005, 185). Thus, the dynamics of framing efforts hold a critical influence over a movement's 
overall development and success.

\section{FRAMING AND PUBLIC POLICY}

Within the policymaking process, issue framing is an important element of problem identification and definition, agenda setting, policy development and change, and policy implementation strategies. Additionally, there are similarities and overlap between framing processes in social movement activities and in policymaking-particularly in the problem definition and agenda setting stages — as a SMO activists are one of many groups who strive to influence the policy process through framing activities. However, a policy-specific discussion of the importance of framing extends beyond collective action frames to include other elements of political activity across the policy stages.

In the problem identification and definition stages, claims-makers use frames that emphasize "a particular version of reality" in order to both locate new issues and characterize them as problems (Rochefort and Cobb 1994,11). In this process Stone (1989) describes the importance of causal stories, which redefine simple events or situations as issues or problems-moving them from a fact of fate to a place of agency_by assigning blame and locating causal mechanisms. 'The question of culpability' is critical to setting up an issue as an actionable problem, as it establishes the cause that a particular policy solution may address (Rochefort and Cobb 1994, 15). The framing of these causes and solutions is reflective of the "interests and assumptions" of the claims-makers, as well as the culture, norms, and institutional constraints in which they are developed (Rochefort and Cobb 1994, 8; Bosso 1994, 192). Thus, problem definition and its related framing efforts are "time, place and context bound" (Seidman and Rappaport 1986, cited by Rochefort and Cobb 1994, 6).

As with other types of framing, producing resonant frames is necessary for drawing public support and media attention, but here the policy-specific goal of problem identification and definition is to access the formal policy agenda. Simply put, the way in which problems are framed affects the 
probability of agenda access (Rochefort and Cobb 1994, 9). Although other factors, such as resource allocation and political power, certainly help to determine agenda access, these alone are inadequate for explaining whether an issue reaches the formal agenda (Cobb and Ross 1997, 3). Rather, the "cultural and symbolic forces" that serve as the foundation for frame activity also help to determine whether an issue can be ignored by policymakers (Cobb and Ross 1997, 4). Problems with solutions that are framed (or counter-framed) as culturally incompatible, or politically or economically infeasible are more likely to be denied a place on the formal agenda (Bosso 1994, 187; see also Cobb and Ross 1997). By contrast, issues that are successfully promoted through resonant frames are more likely to find a place on the formal agenda.

Agenda access does not ensure policy change, as many agenda items do not become translated into policy, but framing efforts also help to determine whether policy change does occur. In understanding why policy formation may not result from formal agenda consideration, it is important to recognize that routine, predictable and nondiscretionary activities make up the majority of the policy process, and most policy change occurs in a predictable, incremental, equilibrium-inducing fashion (Jones 1994, 172). Although a range of forces work to maintain equilibrium, Sabatier's Advocacy Coalition Framework (ACF) of the policymaking process helps to explain how ideas and beliefs — and their resulting frames-reinforce the rule of incremental change. Briefly, his framework describes the organization of policy subsystems according to coalitions with similar beliefs. These beliefs sort hierarchically from the most fundamental and entrenched 'deep core beliefs', which are nearly impossible to change, to 'policy core preferences' that form the salient and stable base of coalition formation, to 'secondary beliefs' which deal with program-specific implementation preferences and are limited in scope and most changeable (Sabatier and Jenkins-Smith 2007, 194-196). According to the ACF, most policy change must be incremental because coalition beliefs-the shared interpretations of reality — and the alliances formed around them are difficult to alter (Sabatier and 
Jenkins-Smith 2007, 192, 194). Thus, "when advocates, public officials, journalists, and researchers chose an issue frame, they are intentionally or not aligning themselves with a particular coalition in a contest for political support "(Gormley 2012, 146). Within these coalitions, beliefs and ideology, as well as a notion of sunk costs and the desire to maintain credibility, discourage radical reframing efforts that could spur substantial policy change (Gormley 2012, 41).

Nevertheless, framing tactics can also be used in "an effort to restructure political alliances," and the success of new frames is essential to moving from agenda setting to real policy change (Gormley 2012, 146). In order for dramatic policy change to occur, equilibrium must be upset and there are many forces_-both exogenous and endogenous to the policymaking process — that can work to upset equilibrium. In the exogenous category, equilibrium can be disrupted by issue expansion, or a crisis or 'shock' to the system (Baumgartner and Jones 2009, 88-89). From within the policymaking system, both tipping points and policy entrepreneurs and their efforts at issue framing can work to break equilibria.

According to Schattschneider (1960), a new pattern of alignment is created by expanding the scope of conflict (17). In this process, conflict is publicized and new players are brought into the debate, creating a "mobilization of bias" that tips the scales of power away from their previous balance $(30,37,39)$. In this process of mobilization, it is the inclusion of new people-and their ideas and interests — which upset equilibrium. As Cobb and Ross (1997) note, the ability to win over these new 'hearts and minds' depends not only on "money, access and experience," but also "the skill to package an issue in cultural terms that will appeal to large numbers of people" (15). Thus, the ability to expand the scope of conflict, 'restructures political alliances,' upset equilibrium and enact dramatic policy change is dependent on effective framing.

Beyond intentional efforts to disrupt an existing equilibrium, sudden, unexpected "shocks" or exogenous crises can also destabilize a system. Anthony Downs (1972) describes these as part of an 
"issue-attention cycle", where "some dramatic series of events"—for example, a catastrophic oil spill or grave economic depression-catapults a previously ignored issue into the limelight (39). Crises do not possess inherent meaning on their own, but present an excellent opportunity for framers to strategically forward their interpretations of a highly visible, salient event. As these frames gain traction and attention in policymaking shifts to rapidly address this "new" issue, old configurations of power break down and equilibrium is disrupted by the formation of new policies and the implementation of new programs (Baumgartner and Jones 2009, 88).

In the category of endogenous change, entrepreneurial activity and tipping points may also play a role in upsetting equilibrium. Entrepreneurs are actors who devote themselves to locating policy solutions for particular problems, and toward that end "the development and refinement of policy frames" is one of their principal activities (Fischer 2003, 145). Specifically, entrepreneurs actively use framing to define issues, push their own pet solutions, and set the overall terms of the debate (Sheingate 2003, 188). As entrepreneurs promote their preferred frames, they form coalitions around their policy goals, and frame selection and resonance also help to determine the type and number of members an entrepreneur's coalition is likely to attract. Additionally, entrepreneurs are critical frame diffusers, as even the most well-crafted, resonant framing strategy still needs an actor to help spread it to relevant populations (Wood 2006, 224). Thus, entrepreneurs can work not only to creatively develop frames, but to also make sure they reach their intended audiences.

Even without the occurrence of a dramatic event, these seemingly small framing activities undertaken by the entrepreneur can have a powerful snowballing effect that eventually leads to an issue 'tipping point' (Wood 2006). Tipping points occur when the accumulation of small changes suddenly produce a shift that results in non-incremental policy change. For example, Wood (2006) describes the processes through which many small framing efforts in tobacco policy changed how the issue was understood and eventually lead to a shift in balance and non-incremental policy change 
without the occurrence of a crisis. Thus, persistent, strategic framing efforts can result in sudden changes in how policymakers interpret an issue, and can provide a powerful source of equilibrium disruption and dramatic new policy outcomes.

Finally, with regard to policy formulation and resulting implementation strategies, framing also matters in the social construction of the population targeted by proposed policy (Schneider and Ingram 1993). Specifically strong populations that are framed in a positive light are more likely to be on the receiving end of beneficial policy formulation and effective implementation strategies, while weak, negatively framed populations are likely to bear the undesirable costs of policy decisions (Schneider and Ingram 1993). Additionally, the effectiveness of framing strategies determines whether policy outcomes are "favorable to advocates of the issue" (who are not necessarily program targets), or whether entrepreneurial messages and goals are co-opted in later stages of the policy process (Rochefort and Cobb 1994, 9). Thus, the successful translation of policy problems into desired policy outcomes requires a strong framing tactics that help to steer policy through each policy stage toward the desired goals.

\section{SOCIAL MOVEMENT DifFUSION}

The term diffusion describes the "spread of some innovation through direct or indirect channels across members of a social system" (Givan et al. 2010, 1). Within the study of social movements, diffusion research examines the ways in which collective action spreads across space and time. The tendency of movements in one area to come to resemble movements in another is a long-recognized phenomenon, but was originally theorized as a nonstrategic process of "contagion" that omitted human agency or complex causal relationships (Stobaugh and Snow 2010, 35). However, since the 1990s, scholars have moved beyond this perspective to understand social movement diffusion as a largely intentional processes driven by the interaction of various concrete causal mechanisms, and 
which requires the participation of many levels of socio-political actors (Givan et al. 2010, 3; Stobaugh and Snow 2010, 35). The dynamics of this process and its outcomes will be the focus of the following section.

In the discussion of diffusion, it is helpful to first locate what precisely is being diffused. With regard to social movements, the diffused elements fall into two broad categories: ideas and the collective action frames into which they are packaged, and collective action repertoires (Givan el al. 2010, 5, 7). While the latter category deals more precisely with mobilization tactics-both what movements do and "what they know how to do" (Tarrow 2011, 39)—the former reflects the goals and grievances of a movement. Thus, either or both of these characteristics of a given movement can be subject to diffusion, but given the topic of my research, this section will focus primarily on the diffusion of ideas and frames.

Not all movements are prone to diffusion, and for diffusion to occur, there are several necessary preconditions (Givan et al. 2010, 3; Snow and Benford 1999, 24). Specifically, the diffusers and receivers must see value in the elements that are being diffused; the diffusers and receivers must have enough shared cultural and structural reference points to be able to identify the meaning and use of the diffused elements; and, importantly, a channel or pathway for diffusion must exist (Snow and Benford 1999, 24). These pathways can be divided into three categories-relational, non-relational, and mediated — and are each associated with a particular set of diffusion mechanisms (Chabot 2010, 101; Givan et al. 2010, 9; Tarrow 2010, 211). Briefly, relational pathways rely on the direct interaction between individuals and organizations, where the diffusion occurs in the overt contact and exchange between two (or more) parties (Givan et al. 2010, 2). Here, the mechanisms that promote diffusion include network ties, trust, communication, and attribution of similarity (Chabot 2010, 101; Tarrow 2010, 211). By contrast, non-relational diffusion occurs without explicit interaction as the result of media coverage or other indirect global communication and cross-cultural linkages (della Porta and 
Kriesi 1999, 6; Givan et al 2010, 2, 11). In this case theorization-“"rational mimicking" or "the simplified interpretations of protest by unfamiliar people in another country"-is the mechanism that promotes social movement diffusion (Chabot 2010, 102; Givan et al. 2010, 11). Finally, mediated diffusion occurs when two parties are connected only through a third party, such as an NGO or international organization, which "brokers the spread of tactics or frames" (Givan et al. 2010, 2, 12). As suggested, brokerage or mediation is the primary mechanism for this pathway (Chabot 2010, 102; Givan et al. 2010, 12). In each pathway, these mechanisms lead to emulation, and although "each adopter will modify these protest ideas and practices 'at the margins' to suit its specific social context,...[diffusion] primarily involves imitation of the innovator" (Chabot 2010, 103). Thus, the extent to which each pathway leads to emulation determines the extent of diffusion.

Diffusion along these pathways can result in both horizontal diffusion, or diffusion among actors at the same analytical level of conflict, or in vertical diffusion, also referred to as scale shift (Roggeband 2010, 20; Tarrow 2010, 214-215). Tarrow (2005) defines scale shift as "a change in the number and level of coordinated contentious actions to a different focal point, involving a new range of actors, different objects, and broadened claims" (121). In this case, social movements diffuse either when local or domestic movements shift claims upward, in order to engage new audiences at the national or international level, or when larger (trans)national movements shift downward to target actors at the local level (Tarrow 2011, 193). In addition, movements that have shifted upward can later be shifted downward to different local areas, thus spreading movements to other domestic contexts (Tarrow 2005, 128).

This change in venues — and particularly upward scale shift—can be very advantageous to movements, as it allows groups to bypass resistant domestic targets and provides new allies, resources, visibility, political opportunity structures and leverage, which in turn changes domestic government perceptions about the costs and benefits of making concessions (Marks and McAdam 1999; 
Roggeband 2010, 34; Smith 1999, 183; Tarrow 2011, 193, 254). Thus, international diffusion through upward scale shift is an intentional strategy employed by movements and is "one of the most significant processes in contentious politics" (Tarrow 2010, 215). Keck and Sikkink (1998) describe how this process leads to a cyclical pattern of advocacy, or 'boomerang effect', wherein transnational advocacy networks (TANs) work through external states and international organizations to pressure the target regime for change. According to their theory, this process is particularly successful when TANs effectively: 1 generate and spread credible information about a problem, 2 . frame problems to appeal to relevant audiences, 3. provide international leverage against domestic elites, and 4. monitor compliance with agreements and policies (16). However, while movements seek to place their claims within an international frameworks, they also continue to seek the support of domestic constituents. As a result, movements are often engaged in a "two-level game", wherein different strategies, frames and repertoires are employed simultaneously in order to engage both the international community and local actors (della Porta and Kriesi 1999, Passy 1999, 152).

While international actors and organizations provide movements with certain advantages, foreign governments, international organizations, and NGOs also depend on domestic movements to meet their own altruistic or strategic goals. Specifically, these transnational actors rely on local movement actors to provide them with the 'practical' or local and specialized knowledge required to meet their own particular objectives (Passy 1999, 155; Smith 1999, 183). In addition, local movements act as efficient disseminators of information and provide "channels for the diffusion of UN [or other international] norms" (Passy 1999, 156; Smith 1999, 183). Therefore, domestic social movements and international actors are mutually beneficial allies, and as a result, international diffusion through scale shift is encouraged by both international actors and movements alike.

As scale shifting strategies lead to international diffusion of social movements, the diffusion of collective action frames is affected in two opposite directions, in processes Tarrow (2011) labels global 
framing and domestication (251, 252). Global framing translates or re-frames domestic messages for the global arena by using "external symbols to orient local or national claims" (Tarrow 2005, 60). Through this process, "challengers try to frame their protest in global terms, through a series of discursive actions, with the aim of finding a compromise or even consensus that allows them to speak with a common voice" (Passy 1999, 161). Thus, strategic re-framing allows international actors to identify with local claims, harmonizes domestic and international goals, and encourages international support (Tarrow 2005, 76; see also Bob 2005). Although the compromises required to re-frame a movement for a global audience can potentially result in fundamental changes to movement goals, it also gives movements access to those valuable benefits of scale shift (Tarrow 2005, 76; see also Bob 2005). Therefore, global framing remains a central element of social movement strategy.

By contrast, domestication involves the transformation of international norms and their accompanying frames for use in domestic contexts (Tarrow 2005, 251). Because both domestic culture and structure constrain the creation of resonate frames, not all international frames can be directly imported to domestic contexts (della Porta and Kriesi 1999, 9; Stobaugh and Snow 2010, 54; Snow and Benford 1999, 36). Instead, activists strategically and selectively fit outside ideas to domestic claims by demonstrating the compatibility and utility of foreign frames to a local cause (Benford and Snow 1999, 34, 36). While activists may be aware of internationally salient frames, they may reject them for more domestically compatible messages that produce more resonance (Ferree and Gamson 1999, 55) As a result, local frames for global issues may vary widely as activists "work within the power structures and political cultures of their own countries" to balance international frames with domestic claims (Tarrow 2005, 75-76). Therefore, as issues are translated back and forth between international and domestic contexts and movements diffuse from one region or level to the next, the most effective framing of the same issue may be expected to take many different forms.

In light of increased globalization, the importance of monitoring these diffusion processes cannot 
be overstated. Some researchers argue that through enhanced communications and mobility, the world is moving toward a more globally homogenized 'convergence culture' where supranational structures exert more power (Koopmans 1999, 67; Harsin 2010, 165). Transnational social movement organizations are on the rise, with the number of groups increasing at a growth rate of 80 to 90 percent in the 1980s and 1990s (Rucht 1999, 211; see also Tarrow 2011, 239). Thus, the networks that support transnational mobilization and social movement diffusion are strengthening as well. Although social movement diffusion and eventual frame convergence cannot be taken as a given (see Ferree and Gamson 1999), the dynamics of diffusion are likely to continue to have a powerful impact on the future of mobilization.

\section{POLICY DIFFUSION}

When applied to theories of policymaking, diffusion can be defined as the "process by which 'knowledge about...policies, administrative arrangements, institutions and ideas in one political setting (past or present) is used in the development of policies, administrative arrangements, institutions and ideas in another political setting"' (Stone 2004, 2, citing Dolowitz and Marsh 2000, 5). Thus, policy diffusion should not be imagined as a simple binary-the adoption or non-adoption of external policy models (Marsh and Sharman 2009, 278). Rather, comprehensive policy diffusion studies must focus on a broader conception of diffusion that captures a fuller range of the processes at work. For example, the object of diffusion may be actual policy content, but may also extend to incorporate specific institutions that shape policy development and policy outcomes; the ideologies, justifications and frames that bolster certain policy decisions; the attitudes, ideas and norms that characterize certain policy choices and policy targets; and the negative lessons that cause certain policy options to be avoided (Stone 2004, 2, see also Finnemore and Sikkink 1998; Grossback et al 2004; Schneider and Ingram 1988). 
As with other types of diffusion, policy diffusion is a strategic and boundedly rational process that is shaped by both individual initiative and structural and cultural constraints (Marsh and Sharman 2009, 274; Stone 2004, 4). Individuals may also work to shift these constraints, and as Marsh and Sharman note (2009), "agents are faced with a structural context which may privilege certain decisions. However, they interpret that structural context and in acting change it" (275). Thus, while diffusion may be more likely or common among countries that are geographically, ideologically, culturally, politically, or economically 'proximate' (see Newmark 2002, 158-159; Stone 2004, 12), these contextual characteristics do not necessarily predict where diffusion will or can occur. This then begs the question, what are the motivations and mechanisms of diffusion? Although terminology differs slightly, the literature identifies four central mechanisms of diffusion: learning, competition, coercion, and socialization (Graham et al. 2012, 690). A discussion of each follows below.

As Dolowitz (1997) asserts, a primary cause of policy diffusion is "dissatisfaction with the status quo” (26; see also Rose 2007, 2). Once a problem's identification and definition has transformed an issue into an actionable problem and agenda access is achieved, the search for a solution begins. However, innovation of new policy solutions can be both costly and unpredictable, both in terms of policy outcomes and public and elite reactions to policy (Berry and Berry 2007, 236; Grossback et al. 2004, 525). Thus, policymakers may rely on policy learning-or looking to the successfully implemented policy solutions for a similar problem employed in other political contexts-to formulate new policy (Shipan and Volden 2008, 841). This can be a particularly useful strategy, as it allows policymakers to more accurately anticipate not only how a policy solution will function, but also what political implications a policy may have (Graham et al. 2012, 691). Although not all external contexts provide equally applicable lessons, and learning from ideologically, culturally, economically and politically similar systems is often preferred (see Grossback et al. 2004, 525; Rose 2007, 9, 47), effective learning still requires the significant adaptation of foreign policies to domestic contexts (Rose 
2007, 121). Thus, the learning mechanism results in the diffusion of similar policies that have been slightly and strategically altered for each unique setting.

Similarly, competition can cause governments and policymakers to look outward for new policy solutions, but the motivation behind this mechanism is somewhat different from learning. Rather than focusing on effectively solving specific problems and predicting political effects, competition results in the emulation of external policies in order to "achieve an economic advantage over other states or avoid being disadvantaged" (Berry and Berry 2007, 225). On one hand, states may strive to imitate policies that have led to strong economic growth and economic investment. On the other hand, the costs of policy divergence from would-be international trade alliances or supranational structures like the European Union can be economically costly (Stone 2004, 13). Finally, it should be noted that while researchers have largely focused on the economic component of this mechanism, competition could also be at work in other policy areas, such as national security policy, for example. In either case, the determination not to lag behind other areas or nations motivates competition, and subsequent emulation and policy diffusion.

As the term suggests, coercion involves outside pressure or intervention in the externally compelled application of policy solutions (Graham et al. 2012, 692). Coercion can be applied both vertically (from supranational organizations) or horizontally (from one government to another), and commonly takes forms such as "aid conditions, pre-emptive laws, sanctions regimes, or use of military force" (Graham et al. 2012, 692-693). As Stone (2004) notes, coercive diffusion processes bear several unique characteristics that help to distinguish it from the other types of diffusion (14). Specifically, coerced regimes are induced to adopt policies that they would have otherwise avoided; they are selectively chosen as targets of outside pressure based on externally designated criteria; they are often shaped by a paternalist allocation of goods; they are restrained from reversing externally imposed policy decisions; and they are directly incentivized to perform in accordance with external expectations 
(Stone 2004, 15). Thus, this diffusion mechanism promotes a version of policy diffusion that is involuntary on the part of the adopter and that may more often result in negative policy and political consequences.

Similarly, socialization does not involve the active or direct pursuit of policy diffusion by the adopting regime, but is somewhat "softer" than coercion (Graham et al 2012, 692). Whereas coercion explicitly imposes external policy choices, socialization refers to the incremental and less overt process of externally shifting the domestic norms and preferences that underpin domestic policy decisions (Graham et al. 2012, 693). As domestic regimes become more involved with the international community, attitudes and ideologies tend to converge, and domestic policy choices reflect this deeper level harmonization. Some level of socialization is required for diffused policy to really take root, as a lack of compatible local knowledge and norms will cause the effects of new policy to remain 'superficial' (Stone 2004, 12). Thus, the diffusion of policy-related norms, frames and knowledge through socialization generally precedes the diffusion of actual policy programs (Finnemore and Sikkink 1998, 896; Graham et al. 2012, 683; Stone 2004, 7). Finally, although the line between coercion and socialization may be fuzzy at times-and in the real world we would likely find multiple mechanisms simultaneously at work-understanding how these mechanisms function within varying contexts and constraints is critical to analyzing policy diffusion and convergence.

A focus on mechanisms should not cause us to lose sight of the fact that "policies are chosen by real people who have varying preferences, goals and capabilities" (Graham et al. 2012, 684). These actors fall into three categories: internal actors who work within the government to which policies are being diffused, external actors who work within the diffusing government, and 'go-betweens' who act across multiple governments (Graham et al. 2012, 684). While external and internal government actors may be more frequently identified in the workings of the learning, competition and coercion mechanisms, go-betweens are particularly critical to socialization processes. Go-betweens include a 
wide range of actors - from government elites and policy entrepreneurs active in the international community, to the media, NGO and international organization activists, or migrants and international students who move back and forth over international borders_-and may facilitate diffusion from the bottom-up or the top-down (Dolowitz 1997, 127; Graham et al. 2012, 687; Perez-Armendariz and Crow 2010, 121; Newmark 2002, 157; Stone 2004, 9). These are the actors that not only form the transnational networks that promote awareness of outside solutions and serve as transmitters of the attitudes, ideas, frames and knowledge that underpin policy choices, but who also work to "synthesize and tailor such knowledge into products and 'best practices' that is then marketed and advocated" even within contexts that seem unlikely to be sites of diffusion (Stone 2004, 16; see also Dolowitz 1997, 31; True and Mintrom 2001, 28, 38). In many cases, this has resulted in the "rapid, global diffusion" of controversial policy changes that have occurred without coercion (True and Mintrom 2001, 33). Often times, this 'rapid, global diffusion' is the result of reaching a tipping point or threshold, wherein a few 'pioneer' nations first adopt a new policy and then a wave of global adoption follows (Finnemore and Sikkink 1998, 901; Marsh and Sharman 2009, 273). Thus, the socializing activities of go-betweens can have a dramatic and profound effect on global policy diffusion.

Within the study of diffusion, researchers should be attentive not only to the spread of certain policies, but also to the question of possible policy convergence (Graham et al. 2012, 680). As defined by Bennett (1991), convergence is "the tendency of societies to grow more alike, to develop similarities in structures, processes, and performances" (215). With regard to policy, the focus lies more specifically on the convergence of policy goals, policy content, policy instruments, policy outcomes, and policy styles (Bennett 1991, 218). Additionally, Bennett (1991) notes that policy convergence should be conceptualized not as a discrete status, but as a continuous process (219). As policies are individually adapted for domestic contexts, the degree to which these elements converge will vary, and Axelrod (1997) argues that the greatest degree to which convergence occurs depends on how similar 
societies are at the outset (222). Bennett (1991) adds that policy convergence is particularly likely to occur when domestic governments and transnational actors and supranational institutions recognize their interdependence in the effort to achieve certain policy goals (225). Nevertheless, as some nations converge together, they may become more distinct from other nations, and thus global policy convergence is neither uniform nor absolute (Axelrod 1997, 223). Therefore, diffusion studies should not take the convergence of diffused policies as a given, but rather study diffusion and convergence as two closely interrelated but distinct processes.

Like social movement diffusion, policy diffusion is potentially on the rise, as globalization further increases the opportunities for diffusion to occur (Newmark 2002, 164; see also James and Lodge 2003 , 182). Thus, attention to the effects of diffusion on policy development is essential and, moving forward, researchers have identified specific areas within diffusion studies that could benefit from further development. First, Marsh and Sharman (2009) advise that too much focus in policy diffusion research has been placed on diffusion among Western nations (270). Thus, more work focusing on the characteristics and processes of diffusion in both non-Western and developing nations-where the influence of supranational structures and international organizations is particularly powerful—is needed (Marsh and Sharman 2009, 270, 280; see also Ogden et al. 2003, 179). Second, in their comprehensive review of policy diffusion studies within political science, Graham et al. (2012) note that while much research has been conducted on the diffusion of actual policy adoption, there is a scarcity of studies that examine the spread of policy ideas (689). Marsh and Sharman (2009) echo this critique in their assertion that the multitude of research that studies diffusion as a discrete “adopt/don't adopt" policy outcome oversimplifies the nuanced and multi-leveled process (278). Thus, additional research that moves the focus from the mere adoption policies to the diffusion of ideas, norms and framing messages underpinning those policies is necessary. 


\section{CONCLUSION}

Taken together, the literature reviewed here describes a political system in which ideas and the frames in which they are packaged hold a profound influence over social movement development and policymaking processes. Although frames function somewhat differently in each area, the literature on framing is characterized by many similarities and unifying ideas. Principal among these are the ideas that 1. framing strategies help to determine whether issues become translated into actionable problems — addressed either by social movements or policy proposals—and, 2. the selection of salient, resonant frames is critical to the success of either policy or advocacy. With regard to diffusion, although the mechanisms of diffusion differ, the translation of frames for various contexts by a range of actors plays a similarly central role in determining how both social movements and policy spread. Thus, there is ample overlap to aid in the integration of these two literatures, through which the power of both bodies of theory may be magnified.

Moreover, through the integration and expansion of these theories, we can develop a clearer understanding of the ways in which regimes with anti-Western orientations but non-isolationist tendencies engage with international social movements and use them as a catalyst of domestic policy development. This is an area of research that has not been well-developed in the existing literature, but which bears a clear relationship to theories of framing and diffusion. The following chapter outlines the theoretical propositions forwarded in this dissertation, which seek to account for the behavior of dissenting regimes in both social movement and policy framing and diffusion. 


\section{References}

Axelrod, Robert. 1997. "The Dissemination of Culture: A Model with Local Convergence and Global Polarization". Journal of Conflict Resolution. 41 (2): 203-226.

Baumgartner, Frank R., and Jones, Bryan D. 2009. Agendas and Instability in American Politics. Chicago: University of Chicago Press.

Benford, Robert. D., and Snow, David. A. 2000. "Framing Processes and Social Movements: An Overview and Assessment". Annual Review of Sociology, 26: 611-639.

Benford, Robert. D., and Snow, David. A. 2005. "Clarifying the relationship between framing and ideology," in Frames of Protest: Social Movements and the Framing Perspective, ed. John Noakes and Hank Johnston. Lanham: Rowman \& Littlefield Publishers.

Bennett, Colin J. 1991. "What is policy convergence and what causes it?" British Journal of Political Science. 1991: 215-233.

Berry, F.S. \& Berry, W. 2007. "Innovation and Diffusion Models in Policy Research," Theories of the policy process, ed. Paul Sabatier. Boulder: Westview Press.

Bob, Clifford. 2005. The Marketing of Rebellion: Insurgents, Media, and International Activism. Cambridge; New York: Cambridge University Press.

Bosso, C. 1994. "The contextual bases of problem definition," in The politics of problem definition: shaping the policy agenda, ed. Rochefort, David A., and Roger W. Cobb. eds. Lawrence: University Press of Kansas.

Chabot, Sean. 2010. "Dialogue Matters: beyond the transmission model of transnational diffusion between social movements," in The Diffusion of Social Movements: Actors, mechanisms, and political effects, ed. Rebecca Givan, Kenneth Roberts, and Sarah Soule. Cambridge: Cambridge University Press.

Chong, D., and J. N. Druckman. 2007. "Framing Theory". Annual Review of Political Science. 10: 103-126.

Cobb, Roger W., and Marc Howard Ross. 1997. Cultural strategies of agenda denial: avoidance, attack, and redefinition. Lawrence: University Press of Kansas.

Entman, R. M. 1993. "Framing: Toward Clarification of a Fractured Paradigm". Journal of Communication, 43 (4) 51-58. 
Della Porta, Donatella, and Hanspeter Kriesi. 1999. "Social Movements in a Globalizing World: an Introduction," in Social Movements in a Globalizing World, ed. Donatella della Porta, Hanspeter Kriesi, and Dieter Rucht. London and New York: St. Martin's and Macmillan.

Dolowitz, David P. 1997. "British Employment Policy in the 1980s: Learning from the American Experience". Governance. 10 (1): 23-42.

Downs, Anthony. 1972. Up and Down with Ecology: The Issue-Attention Cycle. Public Interest, 28: 38-50.

Ferree, Myra Marx, and William Gamson. 1999. "The Gendering of Abortion Discourse: Assessing Global Feminist Influence in the United States and Germany," in Social Movements in a Globalizing World, ed. Donatella della Porta, Hanspeter Kriesi, and Dieter Rucht. London and New York: St. Martin's and Macmillan.

Finnemore, Martha, and Kathryn Sikkink. 1998. "International Norm Dynamics and Political Change". International Organization. 52 (4): 887-917.

Fischer, Frank. 2003. Reframing Policy Analysis. Oxford, UK: Oxford University Press

Gamson, William A., and Andre Modigliani. 1989. "Media Discourse and Public Opinion on Nuclear Power: A Constructionist Approach". American Journal of Sociology. 95 (1).

Givan, Rebecca, Kenneth Roberts, and Sarah Soule. 2010. "Introduction: the dimensions of diffusion," in The Diffusion of Social Movements: Actors, mechanisms, and political effects, ed. Rebecca Givan, Kenneth Roberts, and Sarah Soule. Cambridge: Cambridge University Press.

Gormley, William T. 2012. Voices for children: rhetoric and public policy. Washington, D.C.: Brookings Institution Press.

Graham, Erin R., Charles R. Shipan, and Craig Volden. 2013. "The Diffusion of Policy Diffusion Research in Political Science". British Journal of Political Science. 43 (03): 673-701.

Grossback, Lawrence J., Sean Nicholson-Crotty, and David A. M. Peterson. 2004. "Ideology and Learning in Policy Diffusion". American Politics Research. 32 (5): 521-545.

Harsin, Jayson. 2010. "Diffusing the rumor bomb 'John Kerry is French' i.e., haughty, foppish, elitist, socialist, cowardly and gay," in The Diffusion of SocialMovements: Actors, mechanisms, andpolitical effects, ed. Rebecca Givan, Kenneth Roberts, and Sarah Soule. Cambridge: Cambridge University Press.

Hewitt, Lyndi, and Holly McCammon. 2005. "Explaining Suffrage Mobilization : Balance, neutralization, and range in collective action frames," in Frames of Protest: Social Movements and the Framing Perspective, ed. John Noakes and Hank Johnston. Lanham: Rowman \& Littlefield Publishers. 
James, Oliver, and Martin Lodge. 2003. "The Limitations of 'Policy Transfer' and 'Lesson Drawing' for Public Policy Research". Political Studies Review. 1 (2): 179-193.

Jones, Bryan D. 1994. Reconceiving decision-making in democratic politics: attention, choice, and public policy. Chicago: University of Chicago Press.

Keck, Margaret E., and Sikkink, Kathryn. 1998. Activists Beyond Borders: Advocacy networks in international politics. Ithaca, N.Y: Cornell University Press

Klandermans, Bert, and Sjoerd Goslinga. 1996. "Media Discourse, Movement Publicity and the Generation of Collective Action Frames: Theoretical and Empirical Exercises in Meaning Construction," in Comparative perspectives on social movements: political opportunities, mobilizing structures, and cultural framings, ed. Doug McAdam, John D. McCarthy, and Mayer, N. Zald. Cambridge: Cambridge University Press.

Koopmans, Ruud. 1999. "A Comparison of Protests against the Gulf War in Germany, France and the Netherlands," in Social Movements in a Globalizing World, ed. Donatella della Porta, Hanspeter Kriesi, and Dieter Rucht. London and New York: St. Martin's and Macmillan.

Passy, Florence. 1999. "Supranational Political Opportunities as a Channel of Globalization of Political Conflicts. The Case of the Rights of Indigenous Peoples," in Social Movements in a Globalizing World, ed. Donatella della Porta, Hanspeter Kriesi, and Dieter Rucht. London and New York: St. Martin's and Macmillan.

Pérez-Armendáriz, Clarisa, and David Crow. 2010. "Do Migrants Remit Democracy? International Migration, Political Beliefs, and Behavior in Mexico". Comparative Political Studies. 43 (1): 119-148.

Polletta, Francesca, and M. Kai Ho. 2006. "Frames and Their Consequences," in The Oxford Handbook of Contextual Political Analysis, ed. Robert E. Goodin and Charles Tilly. Oxford: Oxford University Press. Available: http://www.socsci.uci.edu/ polletta/Articles and Book Chapters_files/2006 polletta and ho frames and their consequences.pdf [21 July 2015].

Marks, Gary, and Doug McAdam. 1999. "On the Relationship of Political Opportunities to the Form of Collective Action: The Case of the European Union," in Social Movements in a Globalizing World, ed. Donatella della Porta, Hanspeter Kriesi, and Dieter Rucht. London and New York: St. Martin's and Macmillan.

Marsh David, and Sharman J.C. 2009. "Policy diffusion and policy transfer". Policy Studies.30 (3): 269-288.

McAdam, Doug, John D. McCarthy, and Mayer, N. Zald. 1996. Comparative perspectives on social 
movements: political opportunities, mobilizing structures, and cultural framings. Cambridge: Cambridge University Press.

Newmark, Adam J. 2002. "An Integrated Approach to Policy Transfer and Diffusion". Policy Studies Review. 19 (2): 151.

Noakes, John. 2005. "Official frames in social movement theory : the FBI, HUAC, and the communist threat in Hollywood" in Frames of Protest: Social Movements and the Framing Perspective, ed. John Noakes and Hank Johnston. Lanham: Rowman \& Littlefield Publishers.

Noakes, John, and Hank Johnston. 2005. "Frames of Protest: A Roadmap to a Perspective," in Frames of Protest: Social Movements and the Framing Perspective, ed. John Noakes and Hank Johnston. Lanham: Rowman \& Littlefield Publishers.

Ogden, Jessica, Gill Walt, and Louisiana Lush. 2003. "The politics of 'branding' in policy transfer: the case of DOTS for tuberculosis control". Social Science \& Medicine. 57 (1): 179-188.

Rochefort, D. A. and Cobb, R. W. 1994. The Politics of Problem Definition: Shaping the policy agenda. Lawrence: University Press of Kansas.

Roggeband, Conny. 2010. "Transnational networks and institutions: how diffusion shaped the politicization of sexual harassment in Europe," in The Diffusion of Social Movements: Actors, mechanisms, and political effects, ed. Rebecca Givan, Kenneth Roberts, and Sarah Soule. Cambridge: Cambridge University Press.

Rose, Richard. 2007. Learning from Comparative Public Policy: a practical guide. London: Routledge.

Rucht, Dieter. 1999. “The Transnationalization of Social Movements: Trends, Causes, Problems” in Social Movements in a Globalizing World, ed. Donatella della Porta, Hanspeter Kriesi, and Dieter Rucht. London and New York: St. Martin's and Macmillan.

Sabatier, Paul, and Hank Jenkins-Smith. 2007. "The Advocacy Coalition Framework: An Assessment," in Theories of the policy process, ed. Paul Sabatier. Boulder: Westview Press.

Schattschneider, E. E. 1960. The semisovereign people: a realist's view of democracy in America. New York: Holt, Rinehart and Winston.

Scheufele, D. A., \& Iyengar, S. (forthcoming). The state of framing research: A call for new directions. In K. Kenski \& K. H. Jamieson (Eds.), The Oxford handbook of political communication theories. New York: Oxford University Press. Available: http://pcl.stanford.edu/research/2011/scheufele-framing.pdf [21 July 2015]. 
Schneider, Anne, and Helen Ingram. 1988. "Systematically Pinching Ideas: A Comparative Approach to Policy Design". Journal of Public Policy. 8 (1): 61-80.

Schneider, Anne, and Helen Ingram. 1993. "Social Construction of Target Populations: Implications for Politics and Policy". The American Political Science Review. 87(2): 334-347.

Sheingate, Adam D. 2003. "Political Entrepreneurship, Institutional Change, and American Political Development". Studies in American Political Development. 17 (2): 185-203.

Shipan, Charles R., and Craig Volden. 2008. "The Mechanisms of Policy Diffusion". American Journal of Political Science. 52 (4): 840-857.

Smith, Jackie. 1999. "Global Politics and Transnational Social Movements Strategies: The Transnational Campaign Against International Trade in Toxic Wastes," in Social Movements in a Globalizing World, ed. Donatella della Porta, Hanspeter Kriesi, and Dieter Rucht. London and New York: St. Martin's and Macmillan.

Snow, David, and Robert Benford. 1999. "Alternative Types of Cross-National Diffusion in the Social Movement Arena," in Social Movements in a Globalizing World, ed. Donatella della Porta, Hanspeter Kriesi, and Dieter Rucht. London and New York: St. Martin's and Macmillan.

Stobaugh, James, and David Snow. 2010. "Temporality and frame diffusion: the case of the creationist/intelligent design and evolutionist movements from 1925-2005," in The Diffusion of Social Movements: Actors, mechanisms, and political effects, ed. Rebecca Givan, Kenneth Roberts, and Sarah Soule. Cambridge: Cambridge University Press.

Stone, Deborah. A. 1989. Causal Stories and the Formation of Policy Agendas. Political Science Quarterly. 104, 2, 281-300.

Stone, Diane. 2004. "Transfer agents and global networks in the 'transnationalization' of policy". Journal of European Public Policy. 11 (3): 545-566.

Tarrow, Sidney. 2005. The new transnational activism. New York: Cambridge University Press.

Tarrow, Sidney. 2010. "Dynamics of diffusion: mechanisms, institutions, and scale shift." in The Diffusion of Social Movements: Actors, mechanisms, and political effects, ed. Rebecca Givan, Kenneth Roberts, and Sarah Soule. Cambridge: Cambridge University Press.

Tarrow, Sidney. 2011. Power in Movement: social movements and contentious politics. Cambridge: Cambridge University Press.

True, Jacqui, and Michael Mintrom. 2001. "Transnational Networks and Policy Diffusion: The Case of Gender Mainstreaming". International Studies Quarterly. 45 (1): 27-57.

Walgrave, Stefaan, and Jan Manssens. 2005. "Mobilizing the white march: media frames as alternatives 
to movement organizations," in Frames of Protest: Social Movements and the Framing Perspective, ed. John Noakes and Hank Johnston. Lanham: Rowman \& Littlefield Publishers.

Wood, Robert S. 2006. "Tobacco's Tipping Point: The Master Settlement Agreement as a Focusing Event". Policy Studies Journal. 34 (3): 419-436.

Zald, Mayer. 1996. "Culture, Ideology, and Strategic Framing," in Comparative perspectives on social movements: political opportunities, mobilizing structures, and cultural framings, ed. Doug McAdam, John D. McCarthy, and Mayer, N. Zald. Cambridge: Cambridge University Press. 


\section{Chapter Three}

\section{Theory and Methods: Toward Explaining the Behavior of Dissenting Regimes}

As review of the literature demonstrates, existing theories of activist framing and diffusion are focused on the need for domestic actors to frame their movement goals in ways that resonate with external targets in order to generate support and recognition. However, this pattern of engagement fails to account for the policy trajectories of dissenting regimes. Rather than isolating themselves from the international community, dissenting regimes choose to actively participate in international social movements even when they openly object to the issue frames being promoted by international policy advocacy, or when these frames conflict with stated domestic ideologies or cultural values. The behavior of dissenting regimes is exemplified by Cuba and Iran's engagement with the international community on the issue of family planning. In particular, it appears that Cuba and Iran both consciously_ and perhaps even confrontationally_promoted their own, non-resonate frames while simultaneously seeking international support. Thus, a reconceptualization of existing theory is required to accommodate and explain the behavior of these dissenting regimes. Toward that end, I propose an adjustment to current theories, which maintains that the relative importance of maintaining a cohesive and resonant frame narrative varies as social movements progress through distinct stages of development. The details of this theory will be elaborated in the following section. From this follows a series of hypotheses that predict the nature of framing strategies during different movement phases and contexts and their impacts on policy diffusion. I conclude with a general description of the methods and cases that will be employed to test these hypotheses. 


\section{THEORY DEVELOPMENT}

Theories of social movement development commonly recognize several conceptually distinct stages of a movement's lifecycle, which can be generally categorized as incipiency, coalescence, institutionalization, fragmentation and demise, illustrated in Figure 3.1 (Mauss 1975, 61; see also della Porta and Diani 1999; Gamson 1975, 30-32; Tilly 1978, 216-217). During incipiency, the movement first emerges as an uncoordinated interest in a particular issue, and lacks a formal structure or leadership (Mauss 1975, 61). In this stage, the construction of a common identity around a well-defined problem is critical to the advancement of the movement, since co-optation by society-at-large through "conciliation, compromise and absorption" is a particular threat (Mauss 1975, 62). By using targeted efforts at problem definition to create strong movement boundaries, the movement is better equipped to overcome co-optation and progress to the next stage (Mauss 1975, 62). In the next stage, coalescence, the movement begins to formalize its structure and leadership, form far-reaching alliances, and generate "sustained activity" (Mauss 1975, 62-63). Here, organized movement interests around a particular problem definition become more entrenched and effective repression of the movement requires a highly concerted effort (Mauss 1975, 63). After coalescence, a movement may progress to institutionalization, when elite venues are compelled to address the issue-at-hand, and they begin to respect and accommodate the movement (Mauss 1975, 63). In this stage, both the media and political elites take the movement seriously and take real action on its behalf, publishing favorable reports and formulating legislation to address movement issues (Mauss 1975, 63). According to Mauss (1975), this is when a movement enjoys its greatest power and prestige (64). The final phases, fragmentation and demise, may occur when uneven achievement of goals leads to leadership in-fighting and movement radicalization, which may alienate the general public and cause a movement to die out (Mauss 1975, 64-65). Additionally, 'buying off movement leaders or more overtly repressing the movement may also cause its demise (Mauss 1975, 65). However, in other instances, fragmentation 
and demise may occur when movement demands are met, and individuals begin to drop out of the movement. Thus, a certain measure of 'success' in terms of achieving movement goals and shifting popular norms is often a reason for social movement demise, and movements may end because their reform programs have been satisfactorily incorporated into formal political structures and public dialogs.

Figure 3.1

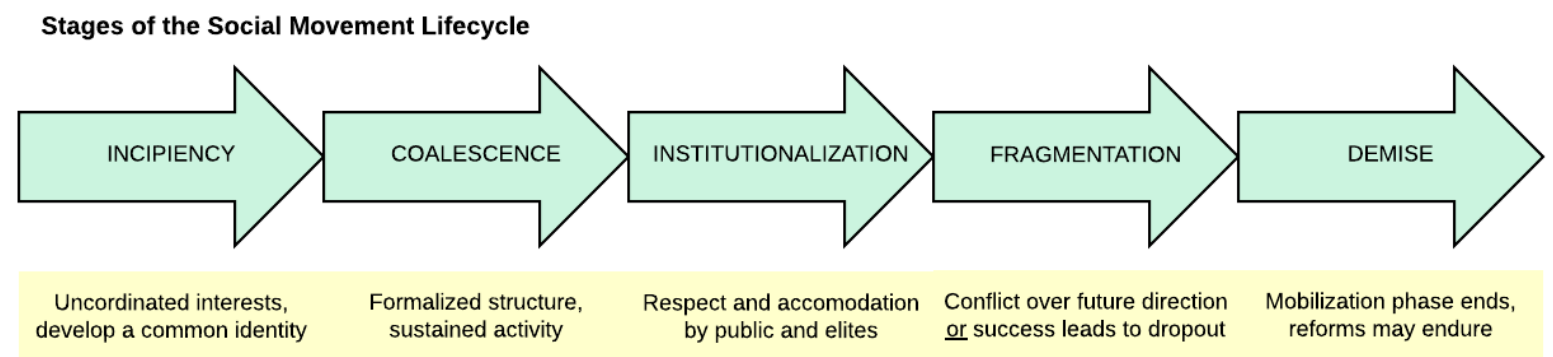

Although these social movement stages have been broadly theorized and well-defined, this literature does not specifically theorize variation in the role of framing strategies during each stage, nor is it attentive to how frame matching between domestic and international movements may vary depending on which stage of development each movement occupies. Nevertheless, it is clear from a description of these stages that while the incipiency and coalescence stages are visibly characterized by targeted efforts at strategic issue framing as a mobilization and agenda setting tactic, during the institutionalization stage, the movement "enjoys a large base of supporters, has plentiful resources, is organized and coordinated with a well-developed division of labor, and has gained respectability" (Blanc and Tsui 2005, 264). Therefore, I proposed that while the development and implementation of a unified framing strategy would be critical during incipiency and coalescence, once an international movement has become broadly institutionalized and its demands are being consistently and favorably addressed, the divergent framing tactics of dissenting regimes would prove less threatening to a stable 
and established movement. Moreover, once a movement has successfully utilized a targeted framing strategy to mobilize broad-based support and legitimacy for movement goals, and social norms have shifted to more readily accept the importance of these goals, the frames themselves become less relevant. As a result, institutionalized movements would be more likely to incorporate groups with diverging frame strategies, and a commitment to the movement's now-solidified programmatic goals_-such as the desire to implement a family planning program—should take precedence over the framing tactics used to promote them. Thus, a movement that demonstrates commitment to these goals would be more readily accepted, regardless of the framing strategies it uses. Domestically, this same pattern should be observed. As domestic activists work to promote both individual behavioral shifts and effective policy development and implementation, the use of frames with a high degree of resonance would be essential. However, after the messages, frames and norms promoted by a movement become institutionalized, a frame's 'mobilizing potency' is less important.

In extending this theory to the relationship between framing in international and domestic movements, it is essential to recognize that related movements do not often progress through these stages simultaneously. Rather, as the literature notes, movements diffuse from one area to another in a way that causes them to initiate and progress through the varying stages at different times. For example, in the case of the international family planning movement, Blanc and Tsui (2005) argue that family planning moved from incipiency to coalescence in the 1960's, and then to broad institutionalization in the 1970s and 1980s. In Cuba, narrative histories suggest that public action on family planning only arose several years after the 1959 revolution. Although Iran was an early participator in the international movement, the 1979 revolution marked a sharp turning point in family planning development, and the Islamist family planning movement did not emerge until the 1980s. Thus, it appears that each movement moved through the social movement stages of development during different periods. Consequently, if the importance of maintaining a cohesive and resonate 
frame narrative varies according to movement stage, then frame matching between domestic and international movements would be critical during incipiency and coalescence. However, diverging framing tactics may not hinder collaboration between movements with similar goals during institutionalization (see Figure 3.2). In other words, although earlier phases of the international social movement would limit inclusion and support to those domestic movements with compatible framing strategies, the institutionalization of the international movement allows space for the inclusion of divergent framing tactics from dissenting regimes as their own domestic movements are emerging. Thus, in contrast to theories which argue that frame matching between domestic groups and the international community is unilaterally expected when domestic movements seek international support, I argue that the stage of social movement development will help determine how rigidly a movement adheres to its own framing messages, and how likely frame matching is to occur between international and domestic contexts.

Figure 3.2

Domestic Movement

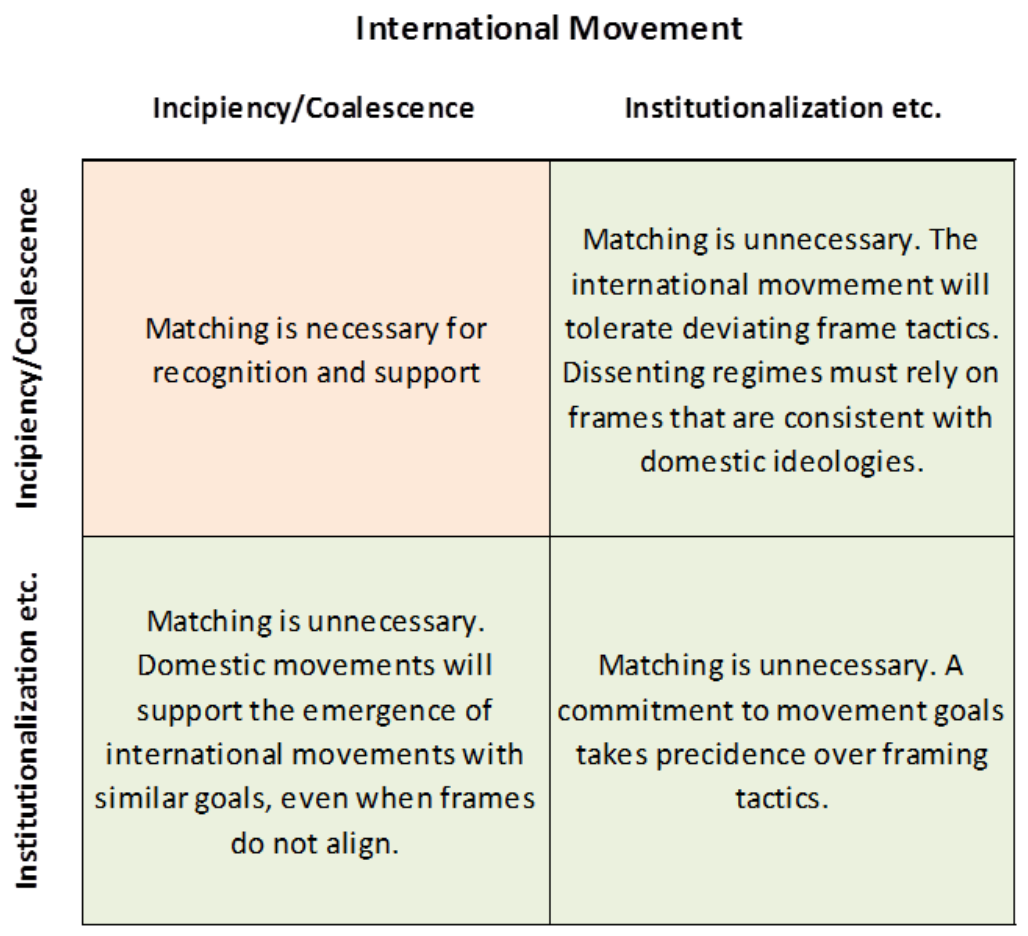


Applying this theory specifically to the relationship between international movements and dissenting regimes, I predict that:

H1: During the international movement's incipiency and coalescence, when the movement is working to focus, coordinate, and develop its messages and strategies, dissenting framing tactics will not be recognized or supported by the international movement. Funding and technical support will not be granted and collaborative partnerships will not develop. Thus, any international recognition and support of dissenting regimes that does occur during this phase requires frame matching by the dissenting regime. However, given the need for dissenting regimes to market themselves through ideologically inconsistent frames to draw international support, it is more likely that no relationship of support will develop during this phase.

H2: As the international movement institutionalizes, support will be extended to dissenting regimes despite divergent framing tactics. This is both because the institutionalized movement-having achieved high levels of support, resources, and legitimacy — is less threatened by dissenting framing tactics, and because domestic adherence to domestically salient (and ideologically divergent) frames is critical as the dissenting regimes themselves move through movement incipiency and coalescence.

Despite the prediction of divergent framing tactics during the early phases of the Cuban and

Iranian movement, both theories of policy and social movement diffusion predict that mechanisms such as brokerage, cooperation, socialization and persuasion eventually lead to harmonization between domestic and international strategies (see for example, Checkel 2005; Tarrow 2010). Additionally, after institutionalization, adherence to a single, particular framing strategy becomes less critical. Finally, then, I predict:

H3: As dissenting regimes continue to interact with the international movement and its related organizations, and their own movements become institutionalized, both activist and policy frames will converge with those employed by the international community.

A fuller description of the cases employed to test this theory and resulting hypotheses follows in the next section.

\section{Case Selection: Iran, Cuba, and FAmily Planning}

In order to test these hypotheses, I proceed with a qualitative analysis of family planning policy and activism in Iran and Cuba, and compare these to the development of the international family planning movement. For qualitative case studies, Bradshaw and Stratford (2010) suggest the selection 
of cases that are "practical and appropriate" through a strategy of purposive sampling (74). For the study of social movement frame diffusion across varying international and domestic contexts, the family planning movement fits these criteria very well. First, the dramatic impact of this social movement has been felt in nearly every corner of the world. In describing what they term the 'quiet revolution', Robinson and Ross (2007) note that in the course of less than two decades, both the use of contraceptives and the norms and ideas surrounding their use were globally transformed in a variety of domestic contexts by a powerful international movement (421). Second, analyzing the ways movements problematize issues is critical to my study, and the family planning movement provides an excellent opportunity to examine how coordinated framing strategies converged with scientific developments to move the inability to determine human fertility—which for millennia was just a fact of the human condition - to the position of a problem that needed to be solved. Additionally, varied framing approaches across different historical periods problematize unmanaged fertility in different ways, and despite broad scale implementation of domestic family planning programs, the international movement has been largely responsible for developing and disseminating the frames through which family planning is discussed (Blanc and Tsui 2005). Therefore, the family planning movement allows for an examination of both shifting international framing tactics and the domestic responses to these frames. Finally, from a practical perspective, the historical trajectory of this movement has been well-documented and there is a wealth of archival material available for empirical analysis.

In order to explore the effect of international movement framing on domestic frames within dissenting regimes, it is both necessary and appropriate to select country cases with both active domestic family planning movements and a degree of political, social, and economic contention based on their promotion of non-Western ideologies. The list of non- or anti-Western regimes that support popular, successful ${ }^{3}$ and voluntary family planning programs is not long. However, both Cuba and

\footnotetext{
${ }^{3}$ Where success is measured in terms of contraceptive prevalence rates and levels of access to high quality reproductive
} 
Iran collaborated with the international movement in the development strong family planning programs, while simultaneously espousing a commitment to Communist and Islamic nationalist values, respectively. Importantly_and most relevantly_ideological dissent is particularly evident in the development of their family planning initiatives. In Cuba, family planning advocates decried the international movement's focus on population control and development. They argued that the promotion population frames was being used as a distraction from the true neocolonial and imperialist causes of underdevelopment. In Iran, activists noted that family planning should be used as a tool to promote a more Islamic society and to keep Iran free from Western dominance.

With regard to the development of family planning policy and programs, these nations took an outwardly anti-Western approach. At the same time, this approach is complicated by the fact that these nations are not fully rejecting the international arena in which Western family planning norms are being developed and disseminated. Both nations have relied on international aid in the development of their family planning programs; both Iran and Cuba regularly attended UN population and development conferences and accepted international money and technical support for their family planning programs. In sum, both nations actively pursued productive, collaborative partnerships with the international movement in the construction of domestic programs that were based on frames that often conflicted with those employed in the international arena. Thus, both of these cases offer a 'practical and appropriate' opportunity to empirically examine whether non-Western regimes are forced to amend their framing tactics as they enter the international community, and whether the messages and values of these regimes remain intact as they develop their domestic policies and programs.

Manifestations of dissent, coupled with the ability to maintain control of domestic frame strategies while developing international partnerships, contrasts with the experience of other nations

health care. 
with distinct cultural, political, and socioeconomic contexts that have yielded to the frame narratives and tactics promoted by the international movement. Bangladesh provides a good example of the experience of non-dissenting, non-Western regimes. In Bangladesh, the first demands for family planning policy came from a domestic NGO, the Family Planning Association of Pakistan (FPAP). This NGO was founded in 1953, before Bangladesh gained its independence from Pakistan, by a coalition of wealthy, well-connected Pakistani women who wanted a family planning policy to improve women's health and well-being (Khan, 1996). However, Western-led NGOs were beginning to take an interest in family planning policy from the perspective of population and development, and it was this latter perspective that drew the attention of Pakistan's president, who realized that international pressures to curb population dovetailed with his own political platform for development and would also satisfy FPAP's demands for access to family planning services. Thus, a domestic movement that was initially framed by a concern for women's rights and health was soon overtaken by the internationally dominant population and development frame. Given the receptive political environment, international NGOs took a lead role in Pakistani development projects. Although government rhetoric supported family planning, the actual family planning program_—including research, and financial and logistical support for family planning services_-rested almost exclusively on a slowly growing coalition of international NGOs. After the 1971 civil war, the new Bangladeshi government briefly resisted some NGO innovations, disapproving of new contraceptive methods and contraceptive delivery structures. In the mid-1980's, the government called for the nationalization of all NGO family planning programs. However, by the 1980s, a network of about four hundred NGOs was directly active in the family planning program, and NGOs had powerful influence. The NGOs resisted and won, as "ministry officials came to see that cooperating and building on the approaches and structures that were leading to such irrefutable results were in everyone's best interests" (Robinson 2007, 336). 
In the example from Bangladesh, there are many features that are common to family planning movements in other non-Western, non-dissenting regimes. Specifically, we see early acquiescence to international framing and program strategies, and domination of domestic family planning by a powerful network of international organizations that form the backbone of domestic program structures. The contrast here with dissenting regimes like Cuba and Iran-which both intentionally maintain control over both the divergent frames used to promote family planning and the programs that result, while at the same time receiving international support and recognition-is evident.

\section{MeTHODOLOGY}

To analyze these cases, I employ process tracing methodologies, and specifically 'explaining-outcome' process tracing (Beach and Pedersen 2013, 18). Process tracing methods and an emphasis on causal mechanisms have proven fruitful in advancing an understanding of both policy diffusion and social movement development (see for example, Checkel 2005; Kollman 2007; Tarrow 2010; Tilly 2003; Wood 2003). Additionally, the goal of explaining-outcome process tracing is to produce a "minimally sufficient explanation of a puzzling outcome" (Beach and Pedersen 2013, 3), which is my objective in the case of explaining the relationship between dissenting regimes and transnational activist networks. As detailed by Beach and Pedersen (2013), this type of case-centric process tracing relies on the identification of often nonsystematic causal mechanisms to supplement existing theories that are, on their own, insufficient to explaining case outcomes (19). In practice, these mechanistic explanations are developed by synthesizing eclectic ideas and existing mechanisms in an iterative process that produces a fuller account of a particular outcome (64). Bennett and Checkel (2014) describe the resulting analysis as closely resembling a legal case, wherein evidence within a case is assembled piece by piece in order to construct a compelling explanatory narrative.

The effort to explain 'puzzling outcomes' necessitates an ability to account for the motivations 
and rationales of the actors guiding these outcomes. To that end, an empirical focus on framing and frame analysis provides a useful method for "penetrating the 'black box' of mental life" (Johnston 1995, 219). As Johnston (1995) asserts:

It has been shown that there is a fundamental relationship between the structures of mental life and the production of written or verbal discourse (Bartlett 1932; Kintsch and van Dijk 1978; Thorndyke 1977; Rumelhart 1975; Buschke and Schaier 1979), and because social movement frames are cognitive structures, a window of access exists through the spoken words of participants and written texts of social movement organizations (221).

Thus, the frames that various actors use can be employed as fairly reliable measures of the ways in which these actors understand social or policy problems, and can give us insight into the cognitive interpretations they may rely on to both internally and externally justify action on these problems. However, this approach does not advocate a simplified understanding that the intent behind framing language can be taken at face value. Rather, attention to the context in which frames are used-specifically, to the role of the actor employing the frame, to the venue in which is it forwarded, to the structure and intent of the document in which it is located, and to the broader culture in which it was constructed-is critical to correctly interpreting the intent behind framing choices (Johnston 1995). Attentiveness to these shifts in actors, venues, and intent are therefore critical to my efforts to accurately explain advocacy and policy outcomes. Overall, tracing the use of frames over space and time allows me to "approximate the underlying cognitive organization that structures experience and influences behavior," in order to construct an explanation of movement and policy outcomes (Johnston 1995, 235).

From a practical perspective, Kollman's (2007) work on the diffusion of the human rights frame from the international LGBT movement to varying domestic contexts serves as a guide to the application of these process tracing techniques in frame analysis. Through both interviews with key activists and content analysis of relevant documents, Kollman identifies the use of movement frames. To capture the sequencing of frames adoption, Kollman then uses a timeline to trace a "norm 
cascade". This process codes each frame according to the group who forwarded it and places it on the timeline, visually organizing an analysis that traces where frames originate, in which venues and by which actors they are used, and where evidence of diffusion emerges over time. My dissertation utilizes this process in the study of family planning movements.

\section{DATA SOURCES}

Applying this technique to the study of family planning frames in order to address the questions proposed in my dissertation requires an analysis of documents from both domestic and international sources. Because of variation between cases in the types of data sources employed and the methods used to analyze them, detailed methods sections are included within each case study chapter. However, each the case study analyses are centered on the examination of data sources that reflect framing tactics within several critical venues, described below.

Public Discourse and Media Framing. Bob (2005) emphasizes the importance of the public discourse is in shaping the trajectory of NGO activity, and, in turn, social movement activity. Specifically, Bob argues that successful NGOs must remain extremely attentive to how the general public - their potential support base_characterizes the issues the NGO seeks to address (Bob 2005, 41). In addition, public discourse helps to determine whether issues appear on the policy agenda and how those agenda items are translated into policy (Cobb and Ross 1997). For this reason, attention to shifts in the public framing of family planning is a critical first step to tracing frame development over time. As Gamson and Modigliani (1989) argue, public discourse framing and media framing are tightly intertwined, as the public frames are shaped by the media, and the media, in turn, utilizes frames that resonate with the public. In the absence of longitudinal survey data, an analysis of media framing is perhaps the best means of capturing changes in public discourse framing over time. Thus, each case study includes an analysis of family planning frames in the media. 
Civil Society Frames. NGOs are a cornerstone of activist networks, and analysis of the framing strategies forwarded by this sector is important to understanding the frames development in family planning. NGOs have been integral to the operations of the international movement, and have also been used to promote family planning in Cuba; NGO sources are included in both of these cases. In Iran, NGO sector guidance has been more absent from family planning, but religious leaders have been responsible for shaping civil society discourses on the topic. Thus, this chapter instead utilizes an analysis of Iran's Friday Prayers.

Framing at the United Nations. The UN has been a critical agenda setting venue throughout the history of the family planning movement, and UN population and women's conference Plans of Action and summary reports are written for the purpose of transmitting the details of proceedings, goals, strategies and priorities of the UN conference to an international audience, and setting the international family planning policymaking agenda. Importantly, these reports dedicate a substantial section to recording the specific reservations of individual nations to UN goals, and contain entries from both Cuba and Iran. These reservations are written largely to communicate contrasting national perspectives to the international forum, and to make divergences in domestic strategy a matter of public record. Therefore, I utilize the summary reports and Plans of Action from UN conferences to trace international movement frames, and employ the statements from Cuba and Iran to document domestic responses to international framing in this central international venue.

Official State Frames. To understand how movement frames are reflected in policy outcomes, state-level documents must be analyzed for frame content, and for domestic movements, official policy frames give key insight into how the government is constructing family planning. Thus, for both Cuba and Iran, I include a measure of government frames. The reports from Cuba's Communist Party Congresses do not mention family planning, but Fidel Castro gives attention to family planning in his formal addresses. These speeches are utilized to represent top-down state framing of family planning. 
In the Iranian case, both official family planning policy documents and Ministry of Health and Medical Education (MOHME) reports are employed to capture government frames.

Street-level Frames. Within domestic programming, an accurate depiction of each movement requires some understanding of how family planning frames are constructed and translated in programmatic outcomes. Thus, I incorporate insights from interviews with Cuban and Iranian patients and service providers in order to get a sense of on-the-ground operations.

Table 3.1 provides a list of the sources selected for analysis for each case and venue. 


\begin{tabular}{|c|c|c|c|}
\hline Case & $\begin{array}{l}\text { Venue } \\
\text { Category }\end{array}$ & Data Source & Purpose \\
\hline \multirow{4}{*}{ International } & UN & UN conference reports & $\begin{array}{l}\text { Determine international movement framing at } \\
\text { each conference }\end{array}$ \\
\hline & Media & NYT articles & $\begin{array}{l}\text { Track media frames influencing the international } \\
\text { movement }\end{array}$ \\
\hline & \multirow{2}{*}{ NGO } & $\begin{array}{l}\text { Population Council annual } \\
\text { reports }\end{array}$ & Determine INGO frames \\
\hline & & IPPF annual reports & Determine INGO frames \\
\hline \multirow{9}{*}{ Cuba } & UN & Cuba's statements to the UN & $\begin{array}{l}\text { Determine domestic framing in international } \\
\text { venues }\end{array}$ \\
\hline & \multirow{2}{*}{ NGO } & FMC reports & $\begin{array}{l}\text { Determine domestic NGO framing used within } \\
\text { Cuba }\end{array}$ \\
\hline & & $\begin{array}{l}\text { Mujeres magazine (FMC } \\
\text { Publication) }\end{array}$ & Determine domestic NGO framing within Cuba \\
\hline & \multirow{4}{*}{ Media } & Mujeres magazine & Determine domestic media framing within Cuba \\
\hline & & Bohemia magazine & Determine domestic media framing within Cuba \\
\hline & & Somos Jovenes magazine & Determine domestic media framing within Cuba \\
\hline & & Granma newspaper & Determine domestic media framing within Cuba \\
\hline & Government & Castro's addresses & Determine state-propagated frames in Cuba \\
\hline & Street-level & $\begin{array}{l}\text { Interviews with Cuban } \\
\text { women and doctors }\end{array}$ & Determine patient and provider frames in Cuba \\
\hline \multirow{7}{*}{ Iran } & UN & Iran's statements to the UN & $\begin{array}{l}\text { Determine domestic framing in international } \\
\text { venues }\end{array}$ \\
\hline & \multirow{2}{*}{ Media } & FBIS articles & Determine media framing in Iran \\
\hline & & Tehran Times articles & Determine media framing in Iran \\
\hline & $\begin{array}{l}\text { Religious } \\
\text { Leaders }\end{array}$ & Friday Prayers & $\begin{array}{l}\text { Determine frames forwarded by religious } \\
\text { authorities }\end{array}$ \\
\hline & Government & Iran's 5 Year Plans & Determine official policy framing in Iran \\
\hline & Government & $\begin{array}{l}\text { MOHME family planning } \\
\text { reports }\end{array}$ & Determine state-propagated frames in Iran \\
\hline & Street-level & $\begin{array}{l}\text { Interviews with Iranian } \\
\text { women and doctors }\end{array}$ & Determine patient and provider frames in Iran \\
\hline
\end{tabular}

\section{CONCLUSION}

By identifying and tracing the development of family planning frames across domestic and international contexts, this dissertation produces a richly detailed picture of the relationship between the framing tactics of dissenting regimes and international advocates. In so doing, I seek to augment 
existing theory in order to explain the puzzling dynamics of dissenting regimes' simultaneous rejection of and participation in the global community, and to reconcile the implications of this behavior with existing theories of international engagement and policy and social movement diffusion. Specifically, the following chapters will help to demonstrate where and when domestic frame matching is required in order to garner international support, and whether prolonged engagement with the international community eventually leads to frame convergence. 


\section{References}

Afary, Janet. 2009. Sexual politics in modern Iran. Cambridge, UK: Cambridge University Press.

Beach, Derek, and Rasmus Brun Pedersen. 2013. Process tracing methods: foundations and guidelines. Ann Arbor: University of Michigan press.

Bennett, Andrew and Jeffrey Checkel. 2014. "Process Tracing Methods". Short course presentation at the American Political Science Association Annual Meeting, Washington DC, August 27, 2014.

Blanc, Ann, and Amy Tsui. 2005. "The Dilemma of Past Success: Insiders' views on the future of the international family planning movement". Studies in Family Planning, 36(4), 263-276.

Bob, Clifford. 2005. The Marketing of Rebellion: Insurgents, Media, and International Activism. Cambridge; New York: Cambridge University Press.

Bradshaw, M., and E. Stratford. 2010. "Qualitative Research Design and Rigour,"iIn Qualitative Research Methods in Human Geography, ed. Hay, I. Oxford: Oxford University Press.

Checkel, Jeffrey T. 2005. "International institutions and socialization in Europe: introduction and framework". International Organization. 594: 801-826.

Cobb, Roger W., and Marc Howard Ross. 1997. Cultural strategies of agenda denial: avoidance, attack, and redefinition. Lawrence: University Press of Kansas.

Della Porta, Donatella, and Mario Diani. 1999. Social Movements: An Introduction. Oxford: Blackwell.

Gamson, William A. 1975. The strategy of social protest. Homewood: Dorsey Press.

Hoodfar, Homa, and S. Assadpour. 2000. The Politics of Population Policy in the Islamic Republic of Iran. Studies in Family Planning, 31, 1, 19-34.

International Family Planning Digest, (IFPD). 1975. Laws and policies in Europe and Latin America spur family planning and population studies. International Family Planning Digest, 1, 1, 3-4.

International Planned Parenthood Federation (IPPF). 1980. Family planning in Cuba: A profile of the development of policies and programmes. London: International Planned Parenthood Federation.

Khan, A. 1996. Policy-making in Pakistan's population programme. Health Policy

and Planning, 11, 1, 30-51.

Kollman, Kelly. 2007. Same-Sex Unions: The Globalization of an Idea. International Studies Quarterly, 51, 2, 329-357. 
Mauss, Armand L. 1975. Social Problems of Social Movements. Philadelphia: Lippincott.

Moore, Richard. 2007. "Family Planning in Iran, 1960-79," in The GlobalFamily Planning Revolution: Three decades of population policies and programs, ed. Robinson, W. C., \& Ross, J. A.Washington, D.C: World Bank.

Robinson, W. C. 2007. "Family Planning Programs and Policies in Bangladesh and Pakistan," in Robinson, W. C., \& Ross, J. A., (ed). The Global Family Planning Revolution: Three decades of population policies and programs. Washington, D.C: World Bank.

Robinson, W. C., and J. A. Ross (eds). 2007. The Global Family Planning Revolution: Three decades of population policies and programs. Washington, D.C: World Bank.

Sanders, T. G. 1974. Cuba and the Bucharest Conference. American Universities Field Staff Reports: North America, 2, 4, 1-11.

Tarrow, Sidney. 2010. "Dynamics of diffusion: mechanisms, institutions, and scale shift." in The Diffusion of Social Movements: Actors, mechanisms, and political effects, ed. Rebecca Givan, Kenneth Roberts, and Sarah Soule. Cambridge: Cambridge University Press.

Tilly, Charles. 1978. From Mobilization to Revolution. Reading: Addison-Wesley.

Tilly, Charles. 2003. The Politics of Collective Violence. Cambridge: Cambridge University Press.

Wood, Elisabeth Jean. 2003. Insurgent Collective Action and Civil War in El Salvador. New York: Cambridge University Press. 


\section{Chapter Four}

\section{The International Movement: Tracing Family Planning Frames Across Time and Venue}

The international family planning movement provides an example of the sweeping global change that can be wrought by a relatively 'quiet' social movement. While the finer points of the movement's influence have been much debated, the broader impact of the movement in 'revolutionizing reproduction' is generally uncontested. Under the influence of an international family planning advocacy coalition, global contraceptive use among couples increased from $10 \%$ to $60 \%$ between the 1960s and 2000s, and — although low-access areas remain—access to reproductive health services has spread extensively throughout the developed and developing world (Sinding 2008). Moreover, "the idea of family planning" has become deeply and irrevocably entrenched in a wide range of cultural, economic and political contexts (Sinding 2008, S5). In order to understand how this dramatic global norms shift occurred, we must first understand how the family planning message was framed and diffused.

Within the circle of researchers who study international family planning, there is some debate over the historical trajectory of family planning framing. Mainstream historical accounts traditionally break family planning into two phases_or, as I term them, generations_of framing tactics. In the first generation, family planning was framed as a solution to overpopulation, underdevelopment, and the environmental concerns related to population growth. By contrast, second generation framing casts family planning as a critical tool for improving women's welfare, health, and human rights. However, a minority of scholars claim that the first generation of family planning frames has not actually been replaced by these second generation frames, and that population and development framing still 
pervades family planning policy and activism. Although these researchers cite select instances of continued first generation frame use, no broader empirical analyses exist to help confirm or reject these claims on a more global level.

Thus, one central goal of this chapter is to provide an empirical account of the shifts in framing strategies as they occurred in several critical venues. Specifically, by employing a content analysis of archival sources reflecting the framing strategies employed in international, NGO, and public forums between 1960 and 2010, I establish an annual measure of frame use in each venue. Through an analysis of this data, I am able to track the rise and fall of various frames in a systematic way, and to contribute to a more exacting historical account of frame use. More critically, however, I then use this data to evaluate my theoretical prediction that social movement issue framing is unified and focused during periods of movement incipiency and coalescence, but more tolerant of the incorporation of diverse framing strategies as the movement enters the phase of institutionalization. Finally, the findings from this chapter will serve as the base of comparison for the framing tactics of dissenting regimes. In order to determine how dissenting regimes interact with or deviate from internationally established issue framing norms, the historical trajectory of these norms themselves must first be firmly established. This chapter provides the outline of that international trajectory.

To establish the foundation for exploring the framing dynamics of family planning, this chapter first proceeds with a review of the mainstream historical accounts of international family planning history, followed by an overview of the opposing alternative historical interpretation. After outlining the specific sources selected for analysis and the methods employed for data collection and coding, the bulk of this chapter is then dedicated to an analysis of the findings and a discussion of their implications for both historical interpretations of international family planning and my theoretical expectations regarding framing strategies during the various social movement stages of development. 


\section{History of the International Family Planning Movement: a Mainstream}

INTERPRETATION.

Although family planning activism certainly predates the 1960s (see e.g. Blanc and Tsui 2005), the emergence of a broad international family planning movement can be traced to this decade, and the rise of the movement in the 1960's is attributable to the confluence of several factors. First, and perhaps most critically, in 1965, the landmark Supreme Court ruling in Griswold v. Connecticut overturned state laws banning contraception, citing their existence as a violation of the right to privacy. Before this 1965 ruling, 31 US states banned the dissemination of information about contraception—effectively rendering illegal any sort of family planning advocacy—and the sale of contraception itself was illegal in 24 states (Bailey 2010, 106). Thus, Griswold helped to pave the way for increased public dialog about contraception and lead to the rise of the pill and IUD on the US public market (Seltzer 2002, 10). Second, after World War II, more complete and accurate census data was becoming available from developing nations for the first time (Seltzer 2002, 11; Blanc and Tsui 2005). This data showed that while modern healthcare improvements were successfully reducing mortality rates in these nations, fertility rates remained high, leading to rapid population growth—as much as 3 percent annually in some nations (Seltzer 2002,11). Such findings reawakened Malthusian fears about planetary overpopulation and led to what can be termed the demographic rationale for family planning policy (Seltzer 2002, 11). Within this demographic rationale, family planning policy was framed as an integral part of population, economic and environmental policy (Seltzer 2002, 11).

Of the three demographic components, the link between family planning and population policy is the most straightforward. In an effort to govern national growth, 75 nations worldwide eventually enacted specific policies establishing desired demographic targets for reducing population growth (Seltzer 2002, 16). Generally, these demographic targets focused exclusively on fertility decline,

although there were policies that also mentioned a need to reduce infant and maternal mortality as well (Seltzer 2002,15). Although there are notorious examples of coercive fertility regulation, most nations 
sought to achieve their population policy goals through the simple provision of access to family planning services. Thus, family planning policies structuring the development and delivery of services became critical. Like population policy itself, most family planning policy formulated under this frame was quite straightforward and focused narrowly on the means of increasing contraceptive availability through nationwide distribution systems, and on the social marketing of these services (Helzner 2002, 49). Thus, within this frame, family planning policy was constructed as a fairly basic solution to a specifically identified problem of population growth.

Of course, examining it in isolation from the other demographic policy areas may give a falsely narrow sense of the motivations driving population policy. Although population policies themselves were concerned with hitting demographic targets, they were certainly motivated by population's perceived relationship with economic and environmental policy. On the environmental front, work by policy entrepreneurs like Lester Brown, Garrett Hardin and Paul Ehrlich helped to emphasize connections between family planning, population growth, natural resources and environmental degradation. Following closely on the heels of Silent Spring, Rachel Carson's 1962 work that helped to launch the environmental movement, Ehrlich published The Population Bomb (1968) to highlight "the fundamental issue of the Earth's finite capacity to sustain human civilization" (Ehrlich and Ehrlich 2009, 63). Although it has been marked by controversy, The Population Bomb started a global dialog about the ecological need to limit population growth and intentionally moved to openly link fertility concerns to growing environmental concerns (Ehrlich and Ehrlich 2009). It also cast family planning as the central solution to these problems, stating: "basically, there are only two kinds of solutions to the population problem. One is a 'birthrate solution,' in which we find ways to lower the birthrate. The other is a 'death rate solution," in which ways to raise the death rate - war, famine, pestilence -find us" (cited by Ehrlich and Ehrlich 2009, 68). Similarly, in his paper "The Tragedy of the Commons", Hardin (1968) links environmental degradation of the global commons to family planning and 
population, and concludes: “perhaps the simplest summary of this analysis of man's population problems is this: the commons, if justifiable at all, is justifiable only under conditions of low-population density. As the human population has increased, the commons has had to be abandoned in one aspect after another" (Hardin 1968, 1248). Thus, particularly on the environmental advocacy front, family planning programs and services became an important component of ideas about environmental policy.

Finally, because of the correlation between high fertility rates and low economic development in many areas of the world, the relationships between family planning, fertility and underdevelopment became an accepted tenet of mainstream 1960s development theory (Blanc and Tsui 2005). Specifically, many economists argued that rapid population growth would "serve as a break" on economic development, as governments would be forced to thin resources over exponentially increasing populations, and individuals would continue to devote their own time and resources to childrearing (Bloom et al. 2003, 2). Rather than using the gains of new innovative technologies to invest in future development, rapid population growth would require that all marginal gains would be consumed merely maintaining a subsistence level of development (Bloom et al. 2003, 14). Overall, 1960's economic policymakers largely agreed that increasing population growth would suppress living standards even as nations modernized. Thus, family planning policy was seen as a critical element in economic planning.

As can be seen in this discussion of the early days of the family planning movement, family planning was framed as integral to population, environmental, and economic initiatives. However, as successfully implemented family planning programs began to achieve noticeable demographic change "the demographic rationale for family planning began to lose strength" (Blanc and Tsui 2005, 265). Fertility rates were dropping and population no longer appeared to be such a pressing problem. Additionally, in the wake of the global recession of the late 1970s and early 1980s, the promised 
economic gains from successful family planning policy were not widely evident, and the belief that lowering fertility would directly increase economic development was shaken (Blanc and Tsui 2005; Bloom et al. 2003, 14).

Instead, once again, various forces were converging to reframe family planning policy—this time in terms of health, women's welfare, and human rights. First, family planning advocacy drew the attention of the growing international women's movement, which claimed "the exclusive focus on population control was destructive of women's health and health services" (Turshen 2007, 156). In its place, the movement called for a more 'woman-centered' focus to family planning, which would give priority to improving women's health and wellbeing (Freedman and Isaacs 1993, 19; Gillespie 2004, 34). Second, global attention to the protection and promotion of human rights, which had been growing since the aftermath of World War II, began to seep into family planning politics (Freedman and Isaacs 1993, 20). Importantly, this attention to individual rights was in direct conflict with population policy, because population planning implies some measure of governmental authority over individual childbearing decisions (Isaacs 1995, 363).

While conceptually it is easier to separate the health and human rights treatment of family planning, in practice it is a bit more difficult. This is because health—and by virtue, health policy—has itself often been framed in terms of human rights (Blank and Burau 2007, 3). Therefore, it is not uncommon to see reference to 'the human right' to basic healthcare provisions. Additionally, while human rights and women's welfare frames emerged separately_—with early UN declarations using gender neutral language to declare that for parents "the opportunity to decide the number and spacing of their children is a basic human right" — a right to reproductive choice also soon became integral to the women's movement (Freedman and Isaacs 1993, 19; Seltzer 2002, 13). Of course, health is also an important component of women's welfare, but health framing is also used in the context of men's sexual health (particularly with regard to vasectomies) and in the context of children's development, 
and the women's welfare frame is additionally used to refer to a woman's social and economic development or human capital. Thus, the rights, women's welfare, and health frame are often collectively bundled, and careful attention should be paid to teasing out their varying implications for the formation and implementation of family planning policy.

While this second generation of family planning framing grew in strength throughout the 1980s, the 1994 International Conference on Population and Development at Cairo is widely viewed as the watershed moment that marked the turning point of decisive shift away from the previously used demographic rationales for family planning (Blanc and Tsui 2005; DeJong 2000; Finkle and McIntosh 2002; Gillespie 2004; Helzner 2002; Lush 2002; McIntosh and Finkle 1995; Seltzer 2002). The Cairo conference continued the broad mission of the 1974 conference at Bucharest and the 1984 conference at Mexico city, but while those UN Population and Development Conferences focused on building a relatively simple 'World Population Plan of Action', Cairo explicitly sought to place that plan within a framework of sustainable development (McIntosh and Finkle 1995, 228). Beyond this difference in goals, the structure of the Cairo conference differed substantially. Both Bucharest and Mexico City were characterized by significant political and ideological tension over population-related issues (McIntosh and Finkle 1995). In order to mitigate this tension and build what they hoped would be a "Cairo Consensus" on population and development, the UN organized an elaborate series of preparatory meetings that intended to resolve significant tensions in advance of the conference (McIntosh and Finkle 1995, 229). For the first time, the UN proactively sought to include NGOs in these planning meetings, and in the conference itself (McIntosh and Finkle 1995, 229, 236). This decision opened the door for the participation of a much wider and more diverse collection of perspectives - especially those from the international women's movement-and was fundamental to the eventual incorporation of a women's welfare, health, and rights agenda in the program at Cairo (McIntosh and Finkle 1995, 236). As a result, it is often noted that Cairo marked a significant 
departure in both which voices were included in family planning dialogs and in how those dialogs were framed. Significantly, “the words 'population problem' do not even appear in the Programme of Action adopted at the conference" (Blanc and Tsui 2005, 265). Instead, the plan of action called for a transformation in family planning programs in order to offer a full range of reproductive and sexual health services and improve quality of care (Helzner 2002, 49). According to one conference observer, "Cairo effectively signaled the end of the family planning movement and replaced it with what we know today as the reproductive health and rights movement... what effectively ended at Cairo was the strong linkage between family planning services and efforts to reduce high birth rates" (Sinding 2008, S4). This new agenda was met with overwhelming support at the Cairo conference, and the conference ended with over 180 countries endorsing the new program of action and the feeling that a historically momentous shift had been realized (McIntosh and Finkle 1995, 224).

Achieving this transformation is the task that domestic governments, advocates and policymakers have been working toward with varying levels of commitment and success over the past two decades. In many nations, there have been significant achievements made in expanding existing family planning policy to develop comprehensive reproductive health programs (Helzner 2002, 56). However, overall, both governmental and NGO financial and political commitment to family planning programs seems to have wavered in the years since Cairo (Blanc and Tsui 2005; Sinding 2008). It has been argued that the shift in family planning from a central tenet of demographic planning to just one of many health and human rights goals has led to a decrease in its prioritization among many governments and advocacy networks (Blanc and Tsui 2005; Gillespie 2004; Routh et al. 2001, 82; Sinding 2008). Furthermore, despite a high unmet demand for access to family planning services in many regions of the world, family planning policy is often viewed as a relative success story that will continue under its own momentum and that does not require significant further advocacy or investment. Nevertheless, a global norm endorsing family planning as an essential component of 
reproductive health and rights has been widely established, and family planning's integration into broader public health movements could help to facilitate its continued support (Blanc and Tsui 2004; Sinding 2008, S6).

\section{FAmily Planning History: An Alternative INTERPRETATION}

While most observers and researchers laud the 1994 Cairo conference's progressive shift away from the demographic rationale for family planning, a minority of individuals maintain that the conference was not the watershed moment that most claimed it to be. First, these counter-claimants argue that although the conference's Programme of Action did not include any direct references to a population problem, the document still has a strong "neo-Malthusian subtext", where the goals of empowering women and providing health services are expressly understood as contributing to population-reduction (Sexton and Nair 2010, 43). Second, they argue that the shift to women's welfare, health, and rights promised at Cairo has not actually been realized in domestic advocacy or policymaking. Rao (2010) suggests that the population and development frames first developed in and disseminated by the Western world have now been 'deeply internalized' in the developing world; as a result, elites in the developing world still attribute development problems to population growth (103, 105). Despite near-universal drops in fertility rates, population anxiety continues-as these fears are now rooted cultural beliefs rather than scientific ones-and actual policy decisions still reflect that anxiety (Rao and Sexton 2010, 6). In addition, population targets continued to find their way into international development initiatives, such as the structural adjustment policies formulated by the IMF and the World Bank (Richey 2010, 267). Meanwhile, the ideas advocated at Cairo have not been widely diffused. Cairo's support for family planning (under a new women-centered banner) legitimated existing but flawed family planning policies by lending a new "politically correct rational to discredited programs", which allowed these programs continue, largely unchanged (Rao and Sexton 2010, 12). As 
a result, women's health and rights continue to be 'undermined' by the ongoing implementation of coercive population policies and by lack of access to high quality reproductive health care (Rao and Sexton 2010, 6). Simultaneously, important measures of women's health care, such as maternal and infant mortality rates, remain virtually unchanged (Rao and Sexton 2010, 6). Although women's reproductive rights have been expanded, much of this expansion is in theory only, as women lack the means to actually exercise these rights (Rosenberg 2010, 158).

Looking at Cairo, the proponents of this alternative interpretation cite the dominance of a US-based white feminist perspective as one of the primary reasons that other voices from the South were excluded, and the measures for real change were not implemented (Rao and Sexton 2010, 12). Within this dominant perspective, women's health and rights were constrained within the context of neo-liberal economic policy and the real needs of the majority of women (living in the developing world) were glossed over (Rao and Sexton 2010, 17). Thus, the depth of understanding and commitment that would be required to realize a true shift in approach to family planning has been absent. In accordance with the more mainstream history, these researchers argue that the drive for empowering family planning programs has faltered and note that, tellingly, the UN's Millennium Development Goals do not emphasize access to reproductive health services (Sexton and Nair 2010, 41). As a result, they argue that the changes heralded at Cairo are more fiction than fact.

\section{METHODS}

Determining the exact historical dynamics of family planning frames requires an empirical examination of the framing tactics employed in international forums, as well as those employed by family planning NGOs and the general public. My analysis of framing in each of these venues begins in 1960. As mentioned, the legalization of nation-wide public discussion of family planning by Griswold in 1965 made way for the full-scale launch of the international family planning movement. By starting 
my analysis several years prior, I will also capture elements of framing strategies leading up to this launch. My investigation ends in 2010, so as to avoid obscuring the analysis with coverage of the Affordable Care Act. Additionally, as the movement history suggests, family planning as an international movement has been relatively dormant in the new millennium.

Because of the marked differences in the type and characteristics of data sources used to trace framing in different venues, the precise methods employed to trace framing strategies also varies by venue. In each case, measurement strategies appropriate for each venue's unique data source were selected. For example, contextually rich qualitative content analysis captures the most nuanced framing language, is well-suited for analyzing mid-length documents, and is particularly useful in cases where author attention to exact phrasing is heightened, such as in UN Plans of Action. ${ }^{4}$ However, such analysis is less feasible for a sample of 5,000 news articles, where word counts are more appropriate. In keeping with the strategy of explaining-outcome process tracing, the analysis of each venue within each case serves to provide an additional (but distinct) piece of evidence for explaining overall movement frames shifts. However, in order to maximize cross-case comparability, I employ the same methods for each venue-type in each of the three empirical case studies. The methods used are described in detail below.

\section{Frames in the Public Discourse: The New York Times}

The international family planning movement has been dominated by US funding and US-based actors, resulting in the widespread impression in narrative histories that "the USA has taken the lead" on global family planning (Cleland et al. 2006, 1910). More concretely, the US government donated the money to launch the United Nations Population Fund, over half of all donor funds addressing reproductive issues worldwide come from the United States, and US federal funding for reproductive health represents about $8 \%$ of official development aid spending, compared to the average donor rate

\footnotetext{
4 The lengthy process of multi-party negotiations over the exact phrasing to be used in these documents is part of UN
} record. 
of 3\% (Finkle and McIntosh 2002, 12; Gillespie 2004, 34). Given the high level of US influence in family planning, the movement's support base of interest is the US public. In keeping with predominant measures of public issue-attention and frame salience (see for example, Baumgartner and Jones 2009), I employ a content analysis of frame usage in New York Times articles as a measure of frame usage in the public discourse. In a comparison of various media sources, Baumgartner and Jones (2009) do not find significant differences in coverage trends between the New York Times and other major news outlets (50). Thus, like prior work, I use this source as a sole measure of publicly salient frames.

To establish the measure of framing in the public discourse, I first used LexisNexis and ProQuest to locate NYT articles on family planning topics. Specifically, I searched all NYT headlines and lead paragraphs for mention of family planning, using the following search terms and their variants: family planning, birth control, contraception, birth prevention, reproductive, pregnancy prevention, birth limitation, child spacing, IUD, condom, diaphragm, vasectomy. ${ }^{5}$ This created a sample of about 5,000 articles on family planning. Then, within each article, I searched for the following keywords related to each frame:

\begin{tabular}{ll}
\multicolumn{1}{c}{ Frame } & \multicolumn{1}{c}{\begin{tabular}{c}
\multicolumn{1}{c}{ Keywords } \\
(This includes all variants of the word.)
\end{tabular}} \\
\hline Population & Population, Overpopulation, Demography \\
Development & Economy, Development, Poverty, Standard of Living \\
Environment & Environment, Resource, Ecosystem, Ecology \\
Women & Women \\
Health & Health, AIDS \\
Rights & Right \\
\hline
\end{tabular}

\footnotetext{
${ }^{5}$ Both the search terms and keywords used for this analysis were developed through a pilot analysis of a smaller sample of New York Times articles. Specifically, I started with the small sample of articles on family planning in the New York Times Index of the Comparative Agendas Project, and used the content of these to generate search terms and expand my search to the full New York. Times archives in 1969, 1981-1983 and 2001-2003. Although I include the more exhaustive list of search terms in every search, in practice, terms such as "birth limitation" rarely (if ever) appear in isolation from one of the other more common terms. Searching headline and lead paragraphs only, I generated a sample of articles $(n=\sim 130)$, and from examination of these, I generated the list of keywords associated with each frame. Finally, in a full text search (rather than headline and lead paragraph search) I used the search terms to locate family planning articles that omitted any reference to the keywords. I then examined the few resulting articles in order to ascertain what alternative frame keywords they might contain, and revised my list accordingly.
} 
I then briefly screened all hits to be sure that the keyword is used in the proper context (eg. "rights" specifically as a right to family planning, and not an unrelated use of the word) and recorded the relevant frame coding. All articles and their coding are preserved in Word documents in order to maintain a record of how each article's frames were coded.

Then, I recorded the total number of articles within each year that used each frame at least one time. ${ }^{6}$ This was repeated for every year from 1960 to 2010. As a result, I obtain an annual measure of the total number of articles that employ each frame over a 50 year period.

\section{International Forum Frames: The United Nations}

Since 1960, the UN has held five International Conferences on Population and Development (ICPD), six international conferences on women's issues, and one international conference on HIV/AIDS. Broadly speaking, the purpose of these conferences is to transmit the goals, strategies and priorities of the UN to an international audience, to set the international policymaking agenda, and to coordinate domestic policymaking efforts. Thus, understanding how family planning is framed in these meetings is critical to charting the framing of the international movement.

The summary reports ${ }^{7}$ from each of these conferences were analyzed for family planning frame use. Specifically, frames were identified and coded using Nvivo qualitative analysis software, which aids in the identification of broad trends in frame usage and allows exploration of the texts in a more organized manner. By employing a qualitative approach to the coding of each conference report, more overt frame usage of in phrases like 'population and development strategies' as well as the more subtle usages in phrases like "[Governments should] use demographic data to promote sustainable resource management, especially of ecologically fragile systems" (ICPD 1995, np) are both captured. Working

\footnotetext{
${ }^{6}$ Because articles vary significantly in length, the low threshold for frame use ensures shorter articles are not discounted.

7 Family planning is a central topic at the ICPDs, and these conferences are widely regarded as critical venues a for setting the international agenda on family planning policy. Thus, for these conferences, the entire summary report was coded.

However, UN women's and HIV/AIDS conferences cover a much broader range of issues. So as not to skew the analysis by coding material unrelated to family planning, for each of these conferences, only the chapters and sections related to family planning topics were coded.
} 
from my list of frames, I read through each report, manually coding each individual phrase according to its frame usage. Individual phrases can be multi-coded to reflect multiple frame use with a single phrase. Phrases that contain only procedural language or recommendations (e.g. "The profit-oriented sector should consider how it might better assist non-profit NGOs in playing a wider role in society by enhancing or creating mechanisms to channel financial and other support to NGOs and their associations" ICPD 1995, np) were left uncoded. A record of the exact coding of each text is preserved in Nvivo.

Nvivo was then used to generate a report detailing the percentage of document coverage commanded by each individual frame. For example, Nvivo calculates that phrases that have been coded as employing a population frame cover $\mathrm{X} \%$ of the entire document. Because each conference report varies in the amount of (uncoded) procedural text, this can skew comparisons of conference coding, as conferences with large proportions of procedural text will have a comparatively smaller percentage of document coverage dedicated to any given frame. For that reason, I eliminated the uncoded procedural text from the final measurement. Thus, the resulting measure is the proportion of each frame's percentage of coverage.

\section{NGO Framing: Population Council and International Planned Parenthood}

To capture NGO framing, I perform a content analysis of the annual reports of both the Population Council and the International Planned Parenthood Federation (IPPF). These are selected both for their high level of international influence and prestige and for their direct involvement in Cuba and Iran. The Population Council began work in Iran in 1966 and was active in the development of their earliest family planning strategies. IPPF began work in Cuba in the 1970s and still provides support for the country's family planning program. IPPF began work in Iran in the mid-1990s and is still active in the country today. Therefore, attention to these two NGOs will give insight into both the framing strategies guiding the international movement and the possible frame insertion by NGOs into 
domestic contexts.

Although they vary in length and format, annual reports from the Population Council were published every year ${ }^{8}$ from 1960 to 2010 . For each year, the general report ${ }^{9}$ was scanned, converted from image to text, and read into Nvivo. These were then coded by first running a word frequency query on all reports. This query generates a word frequency matrix of all words (grouped by stem words and synonyms). I used the results of this query to generate my list of keywords to search and code. This customized process ensures that any major terms that relate to a given frame are not omitted from the keyword list. In addition, the word "population" was removed when used in reference to the organization name, so as to not skew the coding of this frame by repeated reference to the Population Council.

Using Nvivo's text search function, instances of the following keywords and their variants were coded to the appropriate frame:

\begin{tabular}{ll}
\hline \multicolumn{1}{c}{ Frame } & \multicolumn{1}{c}{\begin{tabular}{c}
\multicolumn{1}{c}{ Keywords } \\
(This includes all variants of the word.)
\end{tabular}} \\
\hline $\begin{array}{l}\text { Population } \\
\text { Development }\end{array}$ & $\begin{array}{l}\text { Population, Demography, Birth Rate, Fertility Rate } \\
\text { Development, Quality of Life, Standard of Living, Poverty, } \\
\text { Economic }\end{array}$ \\
Environment & Environment, Natural Resources \\
Women & Women, Female, Maternal \\
Health & Health, Medical \\
Rights & Right
\end{tabular}

I used Nvivo to generate a report detailing the number of coded references to each frame for each annual report, and recorded these to create an annual measure of frame use.

The same process was used for the annual reports from the International Planned Parenthood Federation. However, in the case of this NGO, annual reports vary considerably more in format and availability. ${ }^{10}$ There are eleven years for which no annual report is available for circulation in the US.

8 although1962 and 1963 share an annual report.

${ }_{9}$ Financial, region-specific and divisional reports were not coded.

${ }^{10}$ For a full description of the documents available for coding, see Appendix 1. 
However, available reports follow a fairly even distribution across my decades of interest, and there is no reason to suspect that there is any systematic bias in the content in the reports that are available. Thus, the small, periodic gaps in the data are not overly detrimental to my analysis.

\section{ANALYSIS AND DiSCUSSION}

\section{From Incipiency to Coalescence: Family Planning in the 1960 s}

My analysis of frame usages in the 1960s largely matches my theoretical expectation that, as social movements seek to establish themselves as a coherent mobilizing force, they will pursue a more limited and focused framing strategy. At the 1965 UN conference, Figure 4.1 shows that population and development frames dominated the dialog, while only marginal attention was granted to health and rights, and women are not mentioned at all in the summary report. The characteristics of conference participants also reflects this closed-circle mentality. Rather than individuals representing a wide range of political or social interests, the 1965 conference was led by over 700 scientific experts in population and demography who had been nominated for attendance by UN member nations (Finkle and McIntosh 2002, 12; New York Times 1965). This finding also matches the mainstream historical accounts that family planning in the 1960 s was framed almost exclusively as a population and development issue.

Similarly, the data from the NGO sector also show a heavy use of population and development frames throughout the 1960s. While the Population Council measures in Figure 4.2 and Figure 4.3 show more variation in framing tactics than the $\mathrm{UN}$, and the organization does occasionally frame family planning as a women's, health, or rights issue, a focus on population and development is the overwhelming framing strategy of the decade. 1960 is a notable exception to this trend, with over 50\% of the report relying on second generation frame use. Closer examination shows that in this year the Population Council began a long-term collaboration with Johns Hopkins University, and much of the 
report's discussion was dedicated to how the new alliance "will generate a rapid increase in our knowledge of the ways in which work in the field of maternal and child health can be extended to the area of family planning" (Population Council 1961, 6). Therefore, it is clear that early on, the Population Council did view family planning as a health issue. Nevertheless, the Council largely drops this framing strategy in favor of first generation frames. Although talk about the medical development and health effects of emerging contraceptive technologies somewhat revived health framing in 1964 and 1965, population and development framing dominates the rest of the decade and accounts for between $80 \%$ to $90 \%$ of frame usage in most years.

There is a similar trend in the framing of family planning by the International Planned Parenthood Federation, illustrated in Figures 4.4 and 4.5. Like the Population Council, IPPF starts the decade with a heavier reliance on women and health framing — with health frames alone accounting for over 50\% of frame usage until 1964. Again, we then see a sharp spike in population and development framing, with first generation frame use reaching nearly $90 \%$ by 1966 . However, unlike the Population Council, IPPF's use of the first generation frame strategy is less sticky. Although population and development are more often the dominant frames, beginning in the late 1960s, IPPF bounces between higher and lower levels of use. Examination of the reports shows that much of the emphasis on women and health framing during these early years revolves around IPPF efforts to aid nations in "integrating family planning with maternal and child health services" (IPPF 1969, 1). Additionally, in 1967, IPPF convened an international conference with the motto, "Planned Parenthood—a Duty and Human Right" (IPPF 1968, np). From that point forward, IPPF fairly consistently puts more emphasis on human rights than any other venue, reflecting a particular focus of their organization. Thus, IPPF demonstrates an early understanding of family planning as a health and women's and human rights issue in their activities on-the-ground, but does more frequently discuss family planning in terms of first generation frames in their general reports. 
The initial switch from more diversified framing tactics to an emphasis on population and development framing by both NGOs in the early 1960s supports my theoretical predictions that framing efforts become more focused and unified during social movement incipiency and coalescence. However, while the Population Council's switch is more decisive, IPPF's variation in framing from year to year shows that this commitment may be incomplete-especially if it is at odds with how programs are working to integrate themselves in actual practice. Although there is an undeniable movement to put more emphasis on first generation frames-which syncs NGO framing efforts with broad international UN framing trends - there is some variation strength of this emphasis. Therefore, focused framing efforts by NGOs and the UN during this period are evident, but are not overwhelmingly rigid.

Analysis of frames in the public discourse, shown in Figures 4.6 and 4.7, adds another level of nuance to 1960s framing trends. Although population, development and the environment— the first generation frames - are the more prominent in the 1960s, combined, they account for only slightly more than half of frame usage. Meanwhile, I find that in between $20-35 \%$ of news articles, family planning is framed as a health issue, that the women's welfare frame grows in usage from less than $10 \%$ to over $20 \%$ in the 1960 s, and that human rights frames account for a small but persistent proportion of framing. Thus, while historical accounts of the family planning movement have more accurately described family planning framing at the international and NGO level, they seem to have overlooked and important trend in the public discourse - that is, that while first generation frames were certainly central to early public dialogs, the second generation frames were far from absent or insignificant. Rather, while more formal venues may have been moving to focus the discussion of family planning around more limited frame narratives, the public discussion employed a much broader (and increasingly expanding) set of frames. This is a critical insight, given our theoretical understanding of the public's influence over NGO and governmental agenda setting processes (e.g. 
Baumgartner and Jones 2009; Bob 2005).

Therefore, overall, during the 1960s period of movement incipiency and coalescence, NGOs and the UN-the more coordinated and formal venues-behaved as expected in that they largely moved to focus on a narrower range of framing strategies and created a more unified family planning dialog. However, attention to the public discourse, as well as imperfect commitment by the IPPF to first generation frames, demonstrates that alternative frames were already vying for a place in the discussion. Moving forward-especially as the movement institutionalizes—we should see efforts to incorporate these varied framing tactics into more formal dialogs, both because firmly established movements can afford to employ more disparate framing tactics and because it would seem critical to retaining public support.

\section{Movement Institutionalization: the 1970s and 1980s}

As the international family planning movement institutionalized in the 1970s and 1980s, I find the theoretically predicted shift in UN framing tactics. At the 1974 ICPD, framing strategies diversify to include both women's and environmental frames. At the same time, framing of family planning as a health issue increases, while population and development framing decreases. This same trend continues at the 1984 ICPD, with health, women's and rights frames all expanding in usage, while population and development framing decreases slightly. However, at both of these conferences, first generation framing still accounts for well over $70 \%$ of total frame usage. Thus, although this period sees both greater variation in framing tactics and a decrease in population and development framing that corroborates historical accounts of the movement, these conferences are still relying firmly on first generation framing of family planning.

Meanwhile, in 1975, the UN held its first quinquennial conference on women's issues, which was attended by family planning stakeholders and dedicated substantial discussion to family planning topics. My content analysis of this discussion, and those at the 1980 and 1985 conferences, also 
demonstrates a shift in family planning framing. While venue clearly matters to how the discussion is framed-the women's conferences use an unsurprisingly large proportion of women's welfare framing-over time, these conferences also follow a similar pattern of decreasing emphasis on population and development frames, and an increasing emphasis on health and rights frames. Despite the strong emphasis on women, at the 1975 conference, population and development account for over $30 \%$ of framing; by 1985 , this share has decreased to less than $10 \%$. Therefore, although the ICPDs still give priority to population and development during these decades, this women's forum leads a more decisive UN shift to second generation frames.

On the NGO front, similar trends in frame usage are less immediately apparent. With regard to the Population Council, there is little to no diversification of framing tactics, and overall, population and development framing actually appears to increase slightly in the 1970s and 1980s. There are, however, a few outliers in this subtle trend. In 1977, we see a sharp spike in the use of second generation frames, which is largely attributable to a dramatic increase in women's frames and a decrease in population frames. An examination of the 1977 report shows that the Population Council's organizational theme for 1977 was "including women in development efforts" (Population Council 1978, 15). Thus, the Council demonstrates an awareness of the shifting ideas surrounding women's welfare and family planning and gives it full attention in 1977. However, rather than maintaining this focus, the Council reverts back to its usual population and development heavy framing in 1978. This framing focus is interrupted by another spike in second generation frames in 1988, when an increase in both women and health framing account for the change. For this year, the Population Council's theme was "facing critical issues in reproductive health" (Population Council 1989, 6). Thus, once again, the Council acknowledges the growth of family planning as a women's and health issue in its focus for the 
year. ${ }^{11}$ However, this time, the dramatic shift in frames does precipitates a small but noticeable change in the NGOs framing. Although population and development frames continue to dominate, after 1988, the Population Council does not return to previously used levels of second generation frames. Therefore, while the Council lags behind other venues in making any shift, and while this change is relatively small and appears suddenly, rather than slowly over time, it is not completely at odds with the overall trajectory of framing in the 1970s and 1980s.

Similarly, the analysis of the IPPF reports does not show a departure from the pattern of frame usage employed in the 1960s. Although use of first generation frames never quite matches the peak level from 1966, IPPF population and development framing across the two decades continues to reach between $60 \%$ and $80 \%$ of total frame usage, and is occasionally punctuated by years with high use of second generation frames. Despite the fact that in these punctuating years, the use of second generation frames exceeds $50-60 \%$ of total frame usages, this usage follows the same pattern from the 1960s, and overall there is no sustained decline in the use of first generation frames. Even the period's lowest peak of first generation frame use, at 1989, exceeds similar peaks in the 1960s. Thus, unlike the findings from the Population Council, if we cut off the analysis at 1989, there is no compelling evidence to suggest that IPPF is shifting subtly away from first generation frames.

Meanwhile, frames in the public discourse show a fairly steady continuation of their 1960 s trends during the 1970s and 1980s. As use of first generation frames declines from about 50\% in 1970, to about $40 \%$ in 1980 , and about $20 \%$ in 1989 , the use of women's and health frames grow dramatically. Health framing nearly doubles during this time period, from about $25 \%$ in 1970 , to almost $50 \%$ in 1989, and women's welfare frame moves from about $20 \%$ to about $30 \%$. Additionally, use of the human rights frame increases slightly overall, although it appears stronger in some years than in others.

11 It should be noted that few years in the 1970s and 1980s have any stated theme. When they do, they are usually more general ideas, such as "reflections on a decade" (1986) or "a year of exploration and change" (1976). The use of more programmatic themes, like those in the 2 outlying years, does not appear regularly until the 1990s. 
While there are two spikes in first generation framing during this time-one in 1974 and another in 1984 - these correspond exactly with periods of news coverage around the 1974 and 1984 UN International Conferences on Population and Development. Given the comparatively high focus on first generation frames in these ICPDs, it is not surprising that discussion in the public forum would briefly reflect this population and development frame usage. Framing then continues its previous trends in the years immediately following these outlying observations. These findings support both historical accounts of the movement, as well as theoretical predictions about frame diversification during the period of institutionalization. Once again, however, it appears as though the public discourse is leading this shift in framing, while the more formal NGO and international venues experience a bit of lag time before they follow suit.

\section{The 1990s: $A$ Watershed Moment?}

The 1994 ICPD marks the moment when the majority of historical accounts claim that the international arena broke with first generation framing strategies, and analysis of the 1994 summary report does show a marked decline in population and development framing. However, this shift appears to be more closely a continuation of prior framing trends, rather than a dramatic break. Moreover, although the proportion of environmental frames remains relatively small, environmental framing increases in 1994, and first generation frames still account for nearly $50 \%$ of total frames. A closer examination of the text suggests that although the UN is signaling an intentional shift to the inclusion of second-generation frames, it is also reluctant to give up the old frames. For example, consider the following excerpt:

[The UN] endorses a new strategy which emphasizes the numerous linkages between population and development and focuses on meeting the needs of individual women and men rather than on achieving demographic targets. Key to this new approach is empowering women and providing them with more choices through expanded access to education and health services and promoting skill development and employment. (UN 1995, np)

Here, there is a clear attempt to promote the importance of second generation frames. However, the 
text remains silent on how the 'numerous population and development linkages' fit into this goal, given that demographic targets are no longer favored. This pattern of promoting new frames, while somewhat disconnectedly paying lip service to population and development is repeated throughout the text — and, in fact, in the name of the conference itself. Thus, more than marking the decisive shift to second-generation frames, it seems that the report from the 1994 conference is somewhat awkwardly attempting to reconcile the two groups of frames. The 1999 ICPD framing continues the trend of increasing attention to women, health, and rights and decreasing use of first generation frames. Again, however, there is no dramatic break with the previous frame use trajectory, and first generation framing still accounts for over $30 \%$ of frames.

Meanwhile, the 1995 UN women's conference does all but eliminate the discussion of family planning as a population issue. However, once again, this is not exactly a bold new framing strategy, as first generation frames accounted for less than 10\% of frame usage at the previous 1985 meeting. Interestingly, this is the first women's conference where health replaces women as the dominant frame; this trend is also reflected in the ICPDs, where framing family planning as a health issue becomes more pronounced in the 1990s.

Taken together, these findings more closely support the alternative historical interpretations that refute the notion that the 1994 conference marked a 'paradigm shift' in family planning framing. Rather, it seems that the ICPDs reflected greater diversification of frames, and a continued slow progression away from population and development. This diversification of frames occurs in conjunction with an explicit decision to include of a wide range of participants in the organization of the ICPD. Movement histories discuss this decision, but a closer examination of the ICPD reports give an even clearer picture of the magnitude of change. At the 1984 ICPD, 131 NGOs were represented at the conference (UN 1984, 89-93). Of these organizations, 30 reference population or development directly in their organizational title, while only 16 reference women or health. By 
contrast, over 1,500 NGOs were represented at Cairo in 1994, and women' interests groups made up the majority of participants (UN 1994, np). This diversification in both participants and frames supports my theory that a broadly institutionalized movement can afford to incorporate varying perspectives without jeopardizing the movement's integrity. However, even a shift in participants_-while likely to have impacted framing language-did not cause an abrupt upheaval in ICPD frames. Moreover, barring some crisis event, it seems improbable that a deeply institutionalized movement could switch its framing tactics dramatically within the scope of a single conference. ${ }^{12}$ Instead, the accommodation of alternative perspectives may slowly lead to a shift a movement's framing tactics over time_-as we see with the slowly increasing reliance on health framing.

As noted in the discussion of the previous decade, changes in NGO framing in the 1990s are more subtle. Although the Population Council does move to greater use of second generation frames and begins to favor development framing over population framing, these first generation frames remain dominant in the 1990s. Additionally, from year to year, there is quite a bit of variation in levels of first versus second generation frames, but nothing in the reports themselves (such as a theme or new program introduction) seems to explain this oscillation. Rather, the pattern reflects the same level of variation from year to year that is present in most of the Council's reports. The small and subtle shift in framing that occurred in the 1980s was not followed by more dramatic change in the 1990s-and thus, the only noteworthy change in Population Council framing was realized before the 1990's 'watershed moment.' ${ }^{13}$

By contrast, the IPPF does exhibit significant change in its framing strategies during the 1990s. Between 1989 and 1992, use of second generation frames rises from about 35\% to around 75\% — the

\footnotetext{
12 Suggesting that policymaking theories of rapid change that discuss focusing events and tipping points (e.g. see Baumgartner and Jones 2009, 88; Birkland 1998; Downs 1972; Kingdon 1995; Wood 2006) may also apply to social movement framing strategies.

13 Given the subtly of the change and the lack of continued change, it is also unlikely that the Population Council contributed to any larger order framing shifts.
} 
highest level recorded thus far. However, this trend is briefly interrupted again in 1997 and 1998, when population and development frames resurface in both reports' discussion of the "International Conference on Population and Development+ 5 review" (IPPF 1999, np). Although this discussion reflects on the early decade's stronger focus on population and development, this framing subsides again in 1999, with women, rights, and health framing returning to over $70 \%$, marking the final departure from the preponderance first generation frames use. Therefore, although the change is not initially as dramatic or resolute as mainstream movement histories would suggest, I do find a definite shift in IPPF framing in the 1990s.

In the 1990s, public framing of family planning continues its general shift away from first generation frames. Again, the highest spike in population and development framing occurs during coverage the 1994 ICPD, and then declines again after that. As in the other venues, there is no decisive break with first generation frames during this decade, but rather a continuation of previous trends. With the exception of the UN women's conference, the public discourse uses the largest proportion of second generation frames, with health, followed by women, gaining the largest share of frame usage. Thus, in the public sphere, we see more consolidation around the framing of family planning as a women's and health issue, as the mainstream movement history suggests. This consolidation suggests that the diverse group of stakeholders noted for advocating a change framing at the 1994 ICPD were in reality simply reflecting changes in framing in the public discourse, which had been incrementally moving toward second generation frames for decades.

\section{Family Planning Frames in the New Millennium: 2000-2010.}

There has been no UN ICPD since the 1990s. It is possible that, in a continuation of framing trends, the UN's era of 'population and development' has ended, and the lack of new conferences 
reflects that. ${ }^{14}$ It is also possible that a general decline in attention to family planning has made way for other conference priorities—like the meeting on HIV/AIDS in 2001. Both the 2000 UN conference on women and the $2001 \mathrm{HIV}$ /AIDS conference still include discussions of family planning. In 2000, the women's conference report relies exclusively on second generation framing of family planning. As in 1995, health frames are the most prevalent, but women's frames have increased again to over 30\%, while rights framing remains present but marginal. At the HIV/AIDS conference, unsurprisingly, the discussion of family planning is confined exclusively to these programs' positive health impact in the fight against the epidemic. Again, we see that venue matters in how family planning is framed, but this reliance on health framing is also congruent with broader trends in the discussion of family planning. Overall, although the 1994 conference at Cairo did not mark a dramatic change in how family planning is discussed in UN forums, it does seem to mark the beginning of the end of first generation framing. Thus, in noting the decline and eventual elimination of population, development, and environmental framing, the mainstream movement history correctly characterizes framing in this venue.

By contrast, population and development framing has not disappeared from the NGO world. While Population Council framing may have experienced a slight decline in first generation frames in the 2000 s, use of these frames generally ranges between $30 \%$ to $70 \%$. Nevertheless, while use of development frames often remains high, there is a drop in the use of population frames. This suggests an effort to uncouple population and development-and perhaps to recast development efforts in terms of women's welfare, health, and rights. Thus, although they still bear 'population' in their name, the Population Council has slowly begun to deemphasize population concerns. The Population Council explicitly recognizes this shift, and the 2004 report asks, "does the world still need the Population Council?” (Population Council 2005, 1). In answer, the report quotes the Population Council's founder, John D. Rockefeller III, stating “"there is only one reason for concerning ourselves

${ }_{14}$ Narrative histories similarly point to the end of this era. See, for example, Blanc and Tsui 2005; Finkle and McIntosh 2002; Gillespie 2004; Sinding 2008. 
about population - to improve the quality of people's lives, to help make it possible for individuals everywhere to develop their full potential"' (Population Council 2005, 1). The report goes on to stress that 'improving the quality of people's lives' is still the organization's mission, but that programs now focus more heavily on stopping HIV/AIDS, ${ }^{15}$ improving maternal mortality rates, and guaranteeing better access to a broader range of reproductive health services (Population Council 2005, 1-2). Therefore, although population consciously remains a part of the Population Council dialog, programmatic goals increasingly emphasize second generation frames through the lens of economic development. Nevertheless, even if this trend continues, it is impossible to claim that first generation frames have not been carried forward into this century. When examining this venue, the alternative movement history more accurately characterizes frame development.

The shift in IPPF frame use is more absolute, and in the 2000s, first generation framing follows the same downward trend initiated in the 1990s. By 2010, population framing has all but disappeared, and combined first generation framing accounts for less than $20 \%$ of total frame use. Meanwhile, health has become the predominant frame-covering over $40 \%$ of total frame use-while women's and rights framing also each account for nearly $20 \%$ of frames. Interestingly, environmental framing remains most persistent in this venue, and although its presence is marginal, its continued use makes IPPF the most diversified in terms of framing tactics. Finally, it is evident that although development framing has decreased substantially, it generally continues to hover between $10 \%$ and $15 \%$ throughout the 2000s. Thus, like the Population Council, IPPF appears to be de-linking a concern for development issues from population concerns. Thus, while population and development decrease more simultaneously in other venues, the same is not true in the case of the NGOs, and this facet of first generation framing persists.

\footnotetext{
15 The focus on HIV/AIDS is largely responsible for the spikes in second generation framing in 2000 and 2003 , where reports describe how "the Council's expertise in operations research on reproductive health programs is being applied to develop ways of promoting use of condoms, preventing mother-to-child transmission, engaging youth in HIV/AIDS prevention, and improving the prospects for children orphaned by AIDS" (Population Council 2001, 9).
} 
Perhaps more surprisingly, given the strength of prior trends, first generation framing also has not disappeared from the public discourse. In fact, although usage does not exceed $20 \%$, first generation framing actually appears to experience a small resurgence in the late 2000s. Use of first generation frames is marginal-but not negligible - in this venue, and because they continue to resonate with the public, NGOs' continued use of these frames stands to reason as well. Health frames, followed by women's frames, experience the highest proportion of usage, but once again, alternative interpretations of the movement history stand correct in noting that they have not entirely won out. Therefore, although the broad trend is toward consolidation around women's and health framing, analysis of this venue shows that mainstream histories have again overlooked framing strategies in the public discourse.

\section{CONCLUSIONS}

This chapter supports the overall existence of two generations of family planning framing, but it also adds a new level of nuance and additional insights to the discussion of the history of international family planning frames. Outlined below are the key points that this more comprehensive empirical analysis of international family planning frames has provided.

\section{Framing tactics vary by venue.}

Frame variation across venue is not a novel theoretical concept, but it is one that has been ignored in the discussion of family planning. At best, there is acknowledgment of the variation in how family planning is addressed within different national contexts. However, neither the mainstream nor the alternative historical accounts of the movement discuss the possibility that different actors in the international arena have varying framing strategies. Rather, 'the movement' is treated as a homogeneous entity that moves with perfect coordination. By contrast, this analysis has demonstrated that precisely how family planning is framed depends on the particular type of venue where it is being 
discussed. Family planning framing by the UN differs depending on the type of conference that is being convened. Framing in the NGO arena varies between organizations with otherwise similar goals and capacities, while the public discourse follows its own balance of framing tactics. Although the broadest trends in each of these venues are roughly alike, taken together they show a more diverse range of framing tactics than a simple historical overview would suggest.

\section{Movement histories are wrong on two accounts.}

First, mainstream histories are incorrect in their claim that the ICPD at Cairo marked a watershed moment in the shift of family planning framing strategies. As my analysis demonstrates, changes in the discussion of family planning were already underway-particularly in the public sphere and in the UN women's conferences. Additionally, as the frame analysis of the Cairo conference shows, first generation frames were still heavily employed at that meeting, and the diminishing of first generation frames post-Cairo was also not rapid or dramatic; rather, analysis shows a slow and steady continuation of previous trends. Moreover, population and development frames have not disappeared from either the public or NGO sphere. In this regard, my findings align with alternative historical interpretations that note the continued presence of first generation frames-albeit at a reduced level.

Second, both mainstream and alternative movement histories overlook the fact that second generation frames were not absent from the earliest discussions about family planning. On the contrary, second generation frames account for a substantial proportion of the earliest frame use in the public discourse, and increase fairly steadily over time. Meanwhile, although NGOs drop their earliest constructions of family planning around second generation frames, their use points to an NGO acknowledgment of their appropriateness and utility in the discussion of family planning. Thus, it is incorrect to conclude that family planning was exclusively constructed as a solution to population and development problems during the 1960s.

Overall, it seems that the mainstream movement histories most closely reflect framing tactics at the 
UN ICPDs. This is not particularly surprising, as these conferences were a highly visible and powerful venue in the formation of international family planning strategies. However, by overlooking framing tactics in other venues, movement histories have mischaracterized the extent to which first generation frames dominated early dialogs, and have (in the case of the mainstream movement) been too quick to pronounce them extinct in more recent years. This more nuanced history serves as an important foundation for future analysis.

In formal venues, framing tactics are less diverse during periods of movement incipiency and coalescence than during institutionalization.

The analysis shows that the UN and NGOs move to a greater focus around first generation frames during the 1960s, and then very slowly diversify framing tactics across the 1970s to 1990s. Additionally, the field of actors who were permitted to participate in UN discussions increased substantially over this time period. These findings correspond to my theoretical prediction that movements will seek to create more unified discussions during incipiency and coalescence, but can afford to be more inclusive of a range of perspectives once a movement becomes institutionalized.

This conclusion is further supported by my finding that use of these second generation frames did exist during the 1960s. As analysis of the public discourse shows, it is not possible to claim either that second generation frames were not yet dreamed up or that they were wildly unpopular during this time period. Rather, although they had a heavy presence in public discussions, they were simply not incorporated into the formal dialog — a fact that points to an intentional limitation of framing in formal venues. Nevertheless, the existence of these second generation frames in the public discourse is important. As the literature argues, advocacy coalitions will not adopt framing strategies that lack salience among the general public, but will model their framing strategies around ideas that produce resonance. Thus, the growing public use of second generation frames demonstrates the existence of alternative framing perspectives and suggests an eventual need to incorporate them in order for the 
movement to continue to resonate with the public. NGOs behavior, then, follows as theory would predict—first abandoning previously used first generation frames in order to align with focused movement goals during incipiency and coalescences, and then returning to second generation frame use as second generation frame salience increases and movement institutionalization occurs. Meanwhile, UN framing also expands to incorporate these tactics.

In conclusion, this chapter provides a refined account of historical framing trajectories within the international family planning movement, which provide a sound basis for comparison with movements from dissenting political contexts. Moreover, the analysis also provides evidence in support of both existing theoretical claims regarding social movement behavior and the new theoretical propositions offered within my dissertation. Further analysis in the following chapters will help to more thoroughly evaluate these claims. 


\section{Chapter 4 Tables}

Figure 4.1

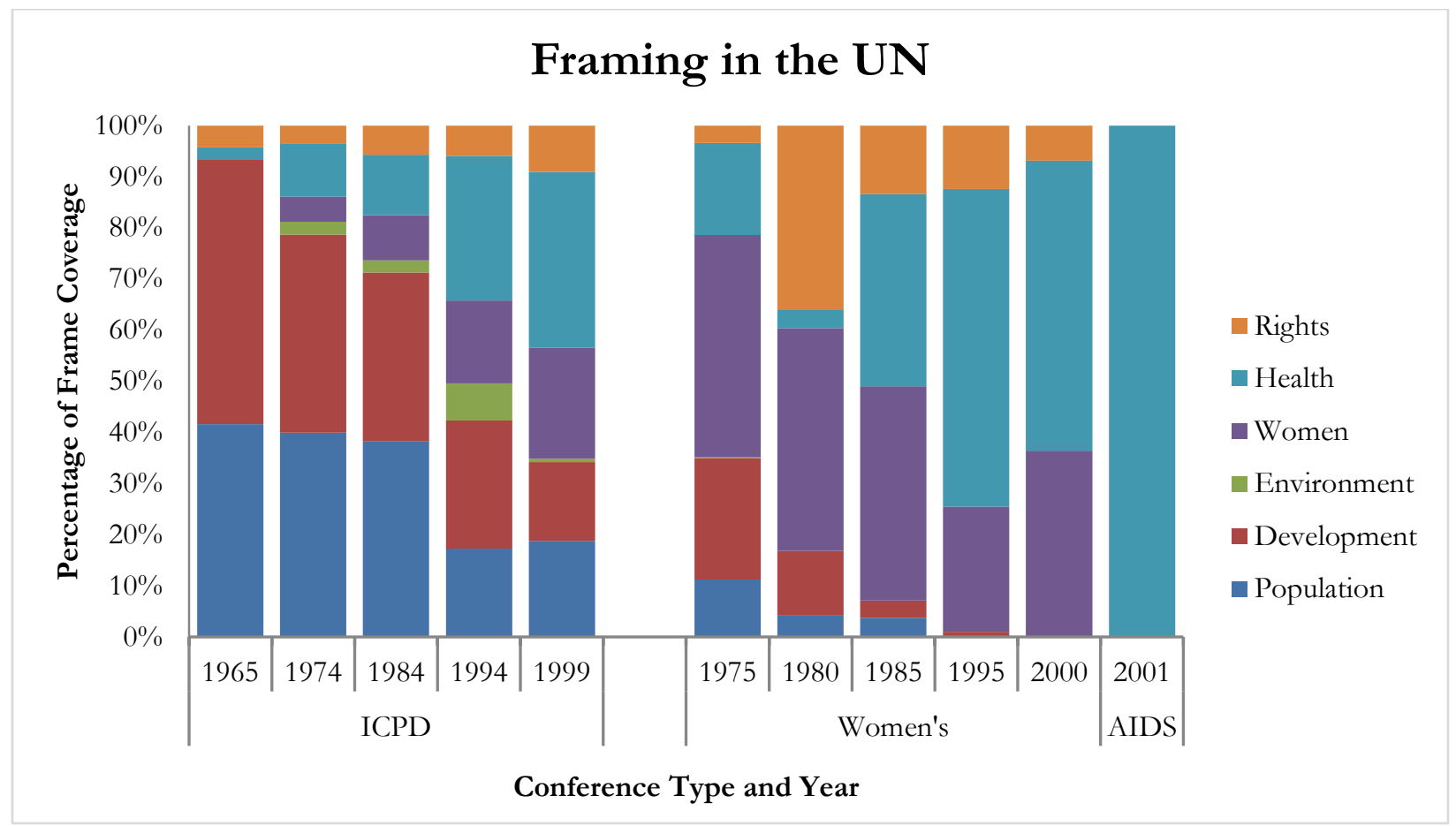

Figure 4.2

\section{Population Council Framing}

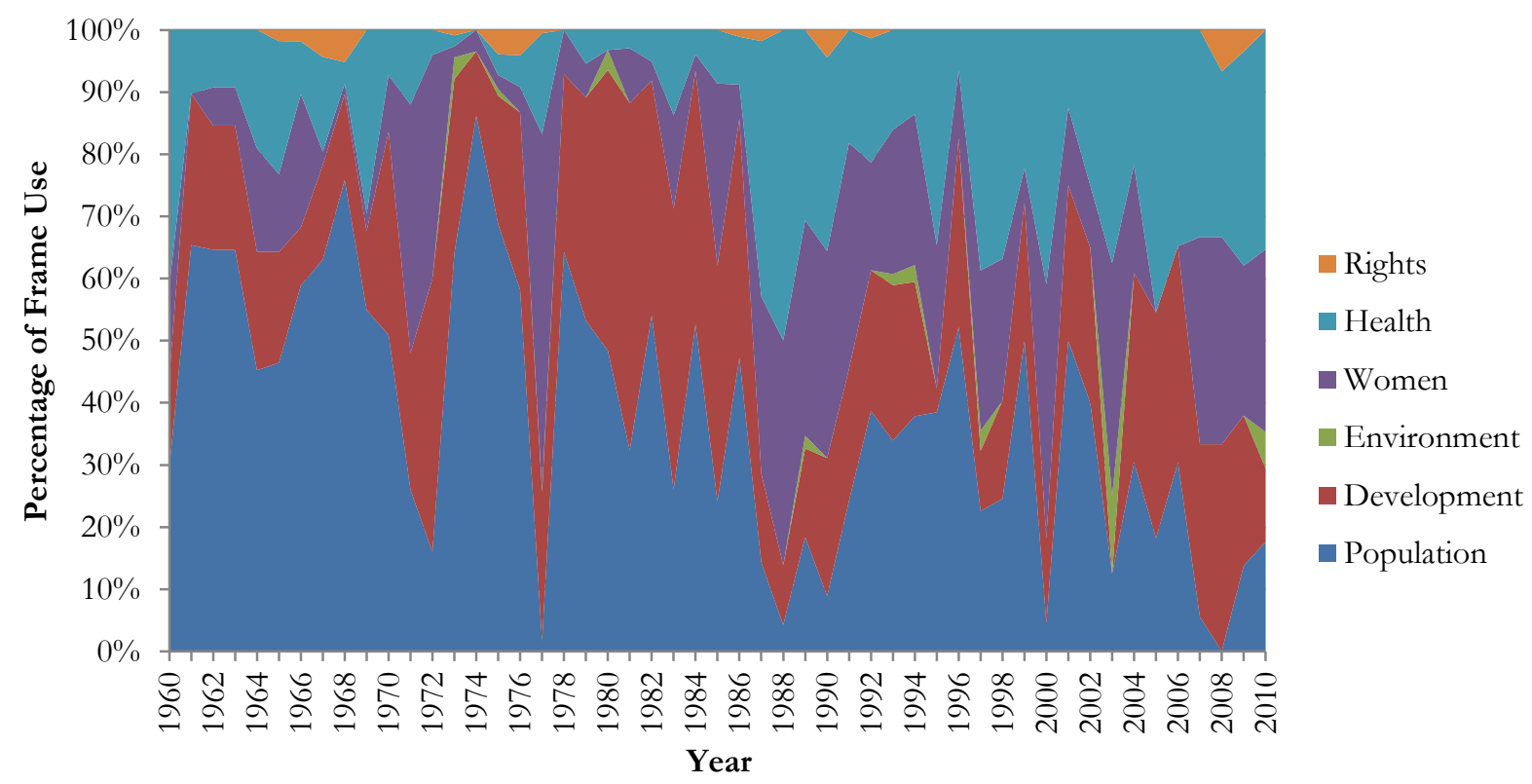




\section{Population Council: First vs. Second Generation Framing}

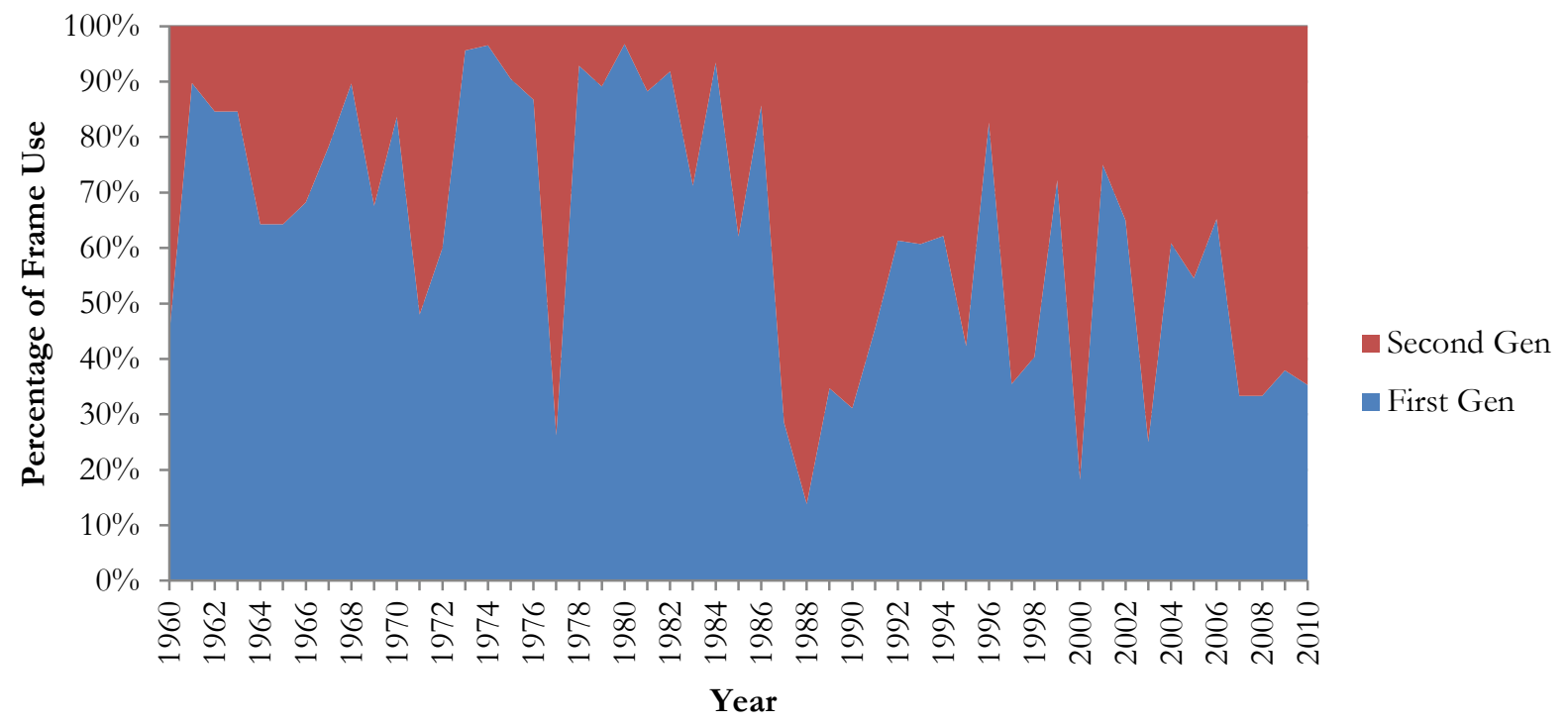

Figure 4.4

\section{IPPF Framing}

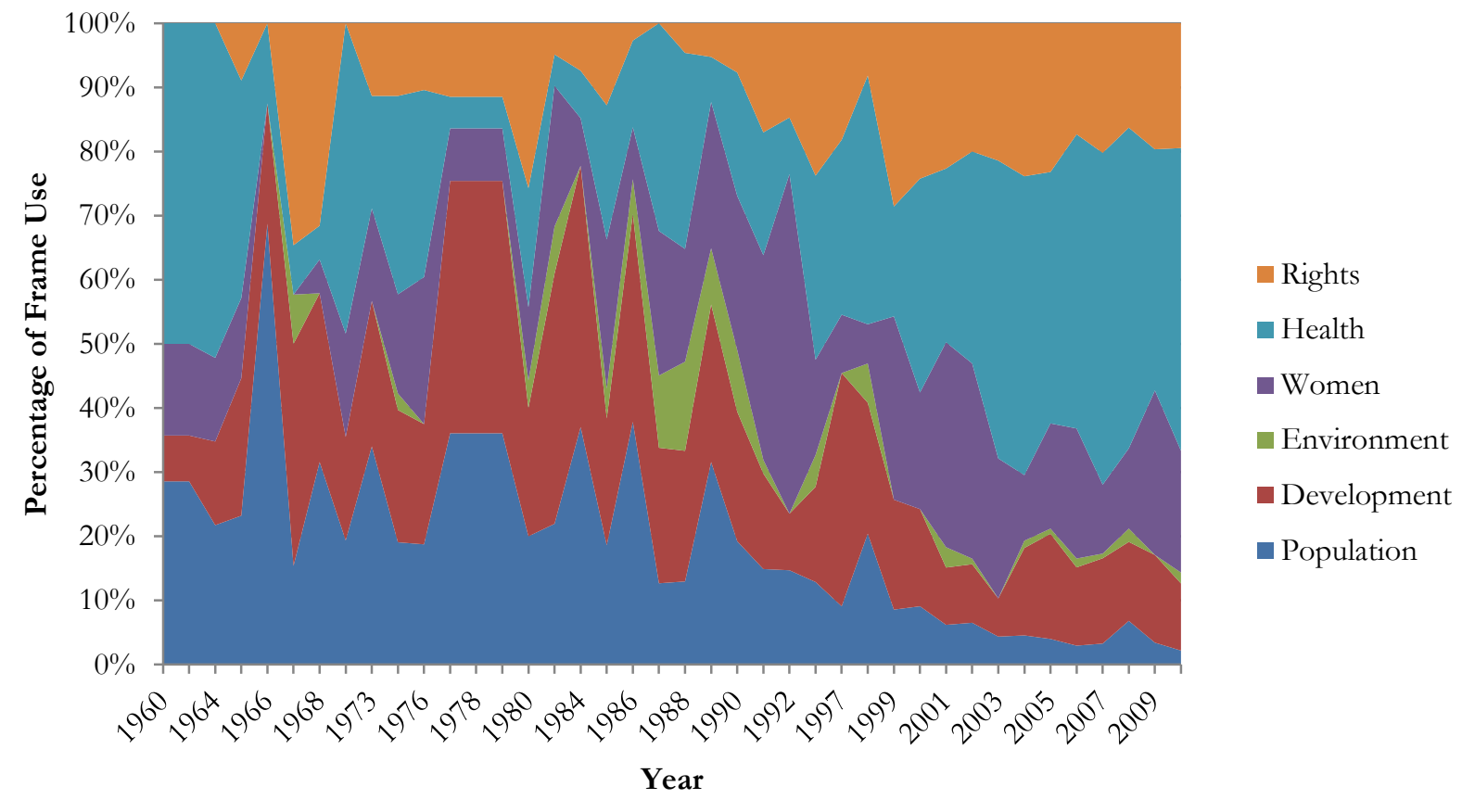




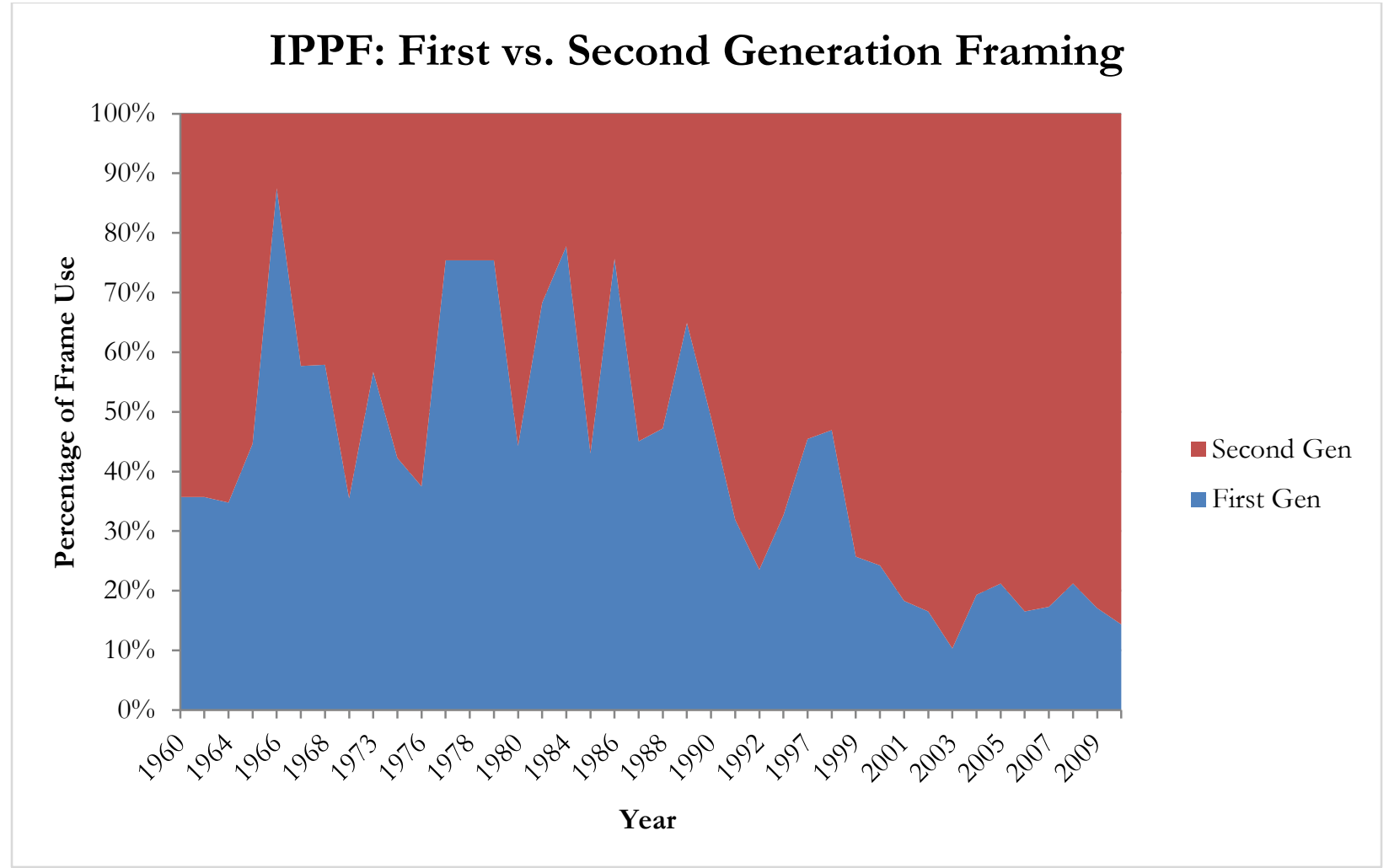

Figure 4.6

\section{Framing in the New York Times}

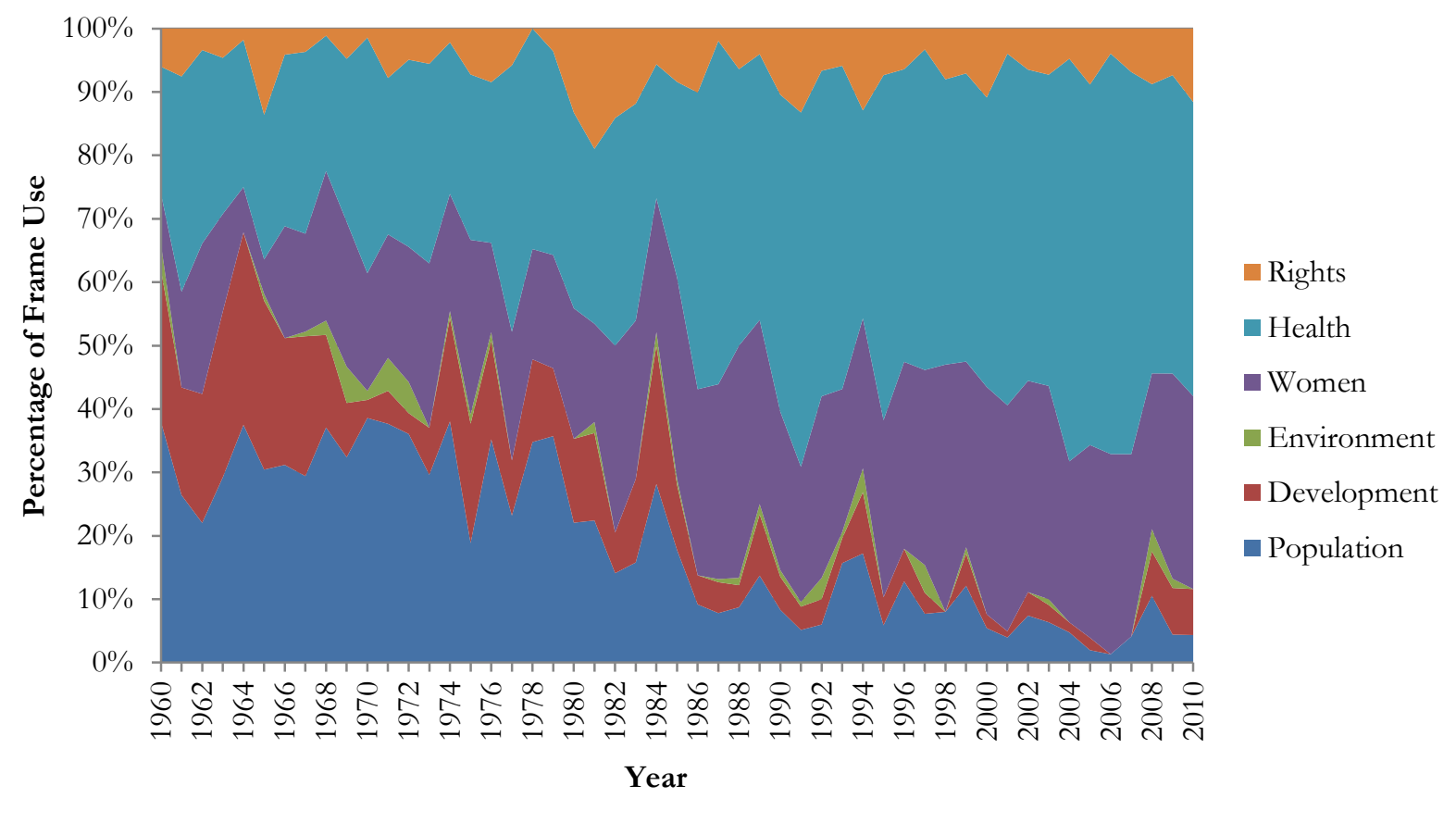




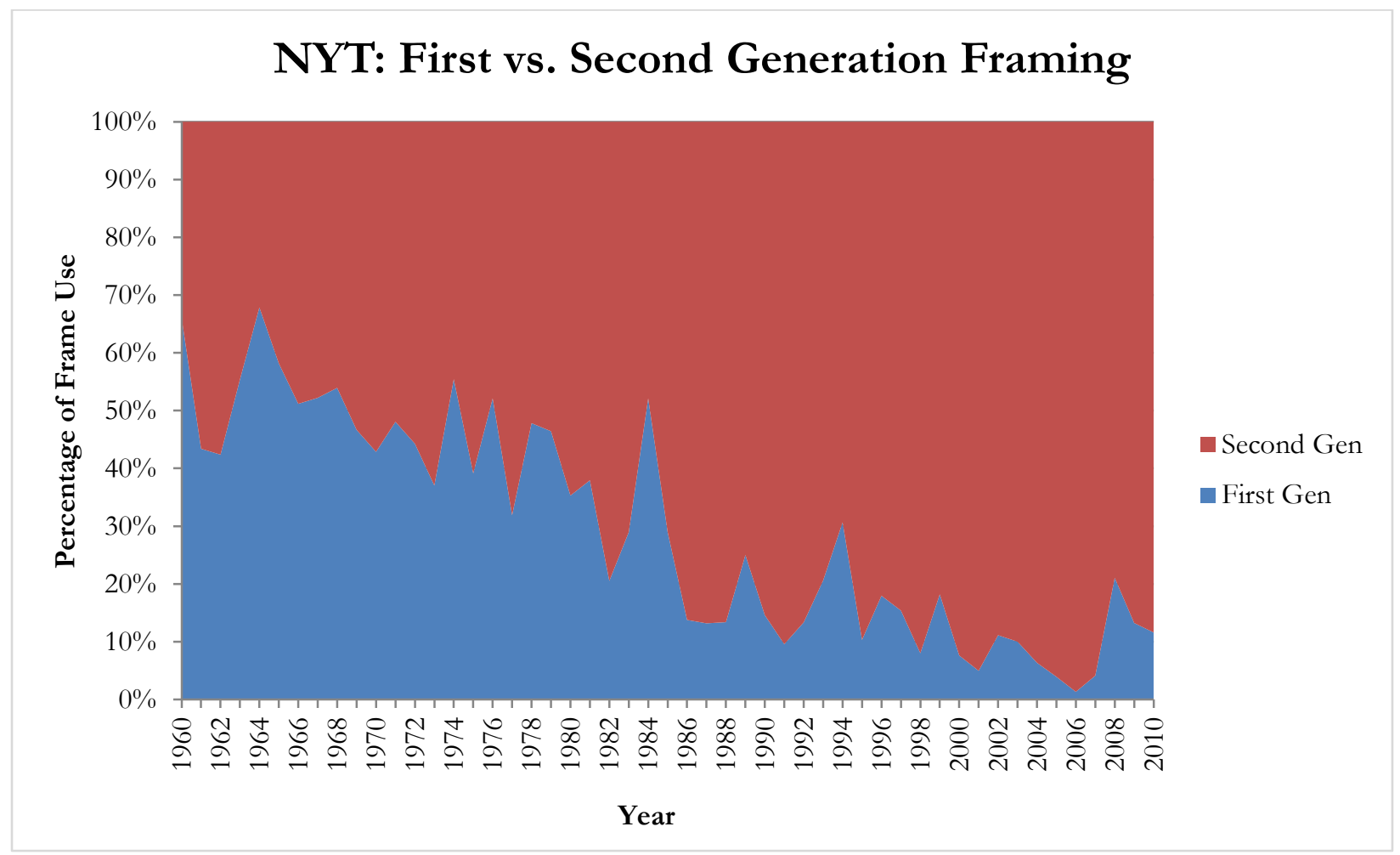




\section{References}

—. 1965. "U.N. Belgrade Conference to Study Family Planning." The New York Times, June 26.

Bailey, Martha J. 2010. "'Momma's Got the Pill": How Anthony Comstock and Griswold v. Connecticut Shaped US Childbearing". The American Economic Review. 100 (1): 98-129.

Baumgartner, Frank R., and Jones, Bryan D. 2009. Agendas and Instability in American Politics. Chicago: University of Chicago Press.

Blanc, Ann, and Amy Tsui. 2005. "The Dilemma of Past Success: Insiders' views on the future of the international family planning movement". Studies in Family Planning, 36(4), 263-276.

Blank, Robert H., and Viola Desideria Burau. 2007. Comparative health policy. Houndmills, Basingstoke, Hampshire [England]: Palgrave Macmillan.

Bloom, David E., David Canning, and Jaypee Sevilla. 2003. The Demographic Dividend a New Perspective on the Economic Consequences of Population Change. Santa Monica, Calif: Rand.

Bob, Clifford. 2005. The Marketing of Rebellion: Insurgents, Media, and International Activism. Cambridge; New York: Cambridge University Press.

Cleland, John, Stan Bernstein, Alex Ezeh, Anibal Faundes, Anna Glasier, and Jolene Innis. 2006. "Family Planning: The Unfinished Agenda." The Lancet 368 (9549): 1810-27.

DeJong, Jocelyn. 2000. "The role and limitations of the cairo international conference on population and development". Social science \& medicine, 51 (6): 941-953

Ehrlich, Paul and Anne Ehrlich. 2009. "The Population Bomb Revisited". The Electronic Journal of Sustainable Development, 1(3), 63-71.

Finkle, Jason L., and C. Alison McIntosh. 2002. "United nations population conferences: shaping the policy agenda for the twenty-first century". Studies in Family Planning. 33 (1): 11-23.

Freedman, L. P., and S. L. Isaacs. 1993. "Human Rights and Reproductive Choice". Studies in Family Planning. 24 (1): 18.

Gillespie, Duff G. 2004. "Whatever Happened to Family Planning and, for That Matter, Reproductive Health?" International Family Planning Perspectives. 30 (1): 34-38

Hardin, Garrett. 1968. “The Tragedy of the Commons”. Science. 162 (3859): 1243-1248.

Helzner, Judith F. 2002. "Transforming family planning services in the Latin American and Caribbean region". Studies in Family Planning. 33 (1): 49-60. 
International Planned Parenthood Federation (IPPF). 1968. Ninth Report of the International Planned Parenthood Federation 1967-68. London: International Planned Parenthood Federation.

International Planned Parenthood Federation (IPPF). 1999. 1998 Annual Report. Available at: http://web.archive.org/web/20000919040325/http://www.ippf.org/annualreport1999/ [13 July 2015].

International Planned Parenthood Federation, and Howell, Catherine. 1969. IPPF World Survey, Factors affecting the work of family planning associations. London: International Planned Parenthood Federation.

Isaacs, S. L. 1995. "Incentives, Population Policy and Reproductive Rights: Ethical Issues". Studies in Family Planning. 26(6): 363-367.

Lush, Louisiana. 2002. "Service Integration: An Overview of Policy Developments".InternationalFamily Planning Perspectives. 28 (2): 71-76.

MacIntosh, C. A. and Jason Finkle. 1995. The Cairo Conference on Population and Development: A new paradigm? Population and development review 21, (2): 223-260

Population Council. 1978. The Population Council Annual Report 1977. New York: Population Council.

Population Council. 1989. The Population Council Annual Report 1988. New York: Population Council.

Population Council. 2001. The Population Council Annual Report 2000. New York: Population Council.

Population Council. 2005. The Population Council Annual Report 2004. New York: Population Council.

Rao, Mohan. 2010. "An Entangled Skein: Neo-Malthusianisms in Neo-liberal Times," in Markets and Malthus: population, gender, and health in neo-liberal times, ed. Mohan Rao and Sarah Sexton. Los Angeles: Sage.

Rao, Mohan and Sarah Sexton. 2010. "Introduction: Population, Health and Gender in Neo-liberal Times," in Markets and Malthus: population, gender, and health in neo-liberal times, ed. Mohan Rao and Sarah Sexton. Los Angeles: Sage.

Richey, Lisa Ann. 2010. "Reproductive Health, Family Planning and HIV/AIDS: Dangers of (Dis) Integration in Tanzania and Uganda," in Markets and Malthus: population, gender, and health in neo-liberal times, ed. Mohan Rao and Sarah Sexton. Los Angeles: Sage

Rosenberg, Martha. 2010. "A Decade After Cairo In Latin America: An Overview," in Markets and Malthus: population, gender, and health in neo-liberal times, ed. Mohan Rao and Sarah Sexton. Los Angeles: Sage 
Routh, Subrata, Ali Ashraf, and John Stoeckel. 2001. "Consequences of the Shift from

Domiciliary Distribution to Site-Based Family Planning Services in Bangladesh". International Family Planning Perspectives. 27 (2): 82-89.

Seltzer, Judith R. 2002. The origins and evolution of family planning programs in developing countries. Santa Monica, CA: Rand.

Sexton, Sarah and Sumati Nair. 2010. "A Decade and More after Cairo: Women's Health in a Free Market Economy," in Markets and Malthus: population, gender, and health in neo-liberal times, ed. Mohan Rao and Sarah Sexton. Los Angeles: Sage.

Sinding, Steven W. 2008. What has happened to family planning since cairo and what are the prospects for the future? Contraception 78, (4): S3-S6

Turshen, Meredith. 2007. 'Women's Reproductive Rights," in Women's Health Movements: A global force for change. New York: Palgrave Macmillan.

United Nations (UN). 1984. Report of the International Conference on Population: Mexico City, 6 - 14 August 1984. New York: United Nations.

United Nations (UN). 1994. "Highlights Of NGO Forum International Conference on Population and Development". United Nations. Available at:

http://www.un.org/popin/icpd/newslett/94_19/icpd9419.eng/4ngos.html [15 July 2015].

United Nations (UN). (1995). Summary of the Programme of Action of the International Conference on Population and Development. New York: United Nations, Dept. of Public Information. 


\section{Chapter Five ${ }^{16}$}

\section{Cuban Family Planning: Dissent and Diffusion in Castro's Regime}

In 1959, the Cuban Revolution established a socialist regime in Cuba that challenged Western political ideology and decried the forces of Western imperialism and neocolonialism, particularly as propagated by the United States. Despite this dissent to dominant global norms and US doctrine, Cuba did not disengage from the international community. Although this is true on many levels, Cuba's continued engagement with the international family planning movement is most relevant and important to my research questions. For example, consider the following: Cuba continued to be an active participant in UN conferences discussing population, development, and family planning, and even hosted the 1983 Latin American Regional Preparatory Meeting for the International Conference on Population; in 1966, the Cuban National Medical Congress invited renowned obstetrician and Planned Parenthood leader Alan Guttmacher to address their annual meeting and give advice on family planning (Kaiser 1975); and starting in the 1970s, Cuba maintained a formal relationship with and accepted aid from both the United Nations Population Fund (UNFPA) and the International Planned Parenthood Federation (IPPF). However, as this chapter will detail, Cuba also frequently voiced its dissent to prevailing international family planning frames and generally refrained from incorporating them within their own domestic dialogues. An analysis of the balance between Cuba's engagement and dissent is the subject of this chapter.

Specifically, this chapter uses the Cuban case to answer the core questions posed in my research — that is, how do international and domestic actors negotiate the tension between divergent framing tactics in both domestic and international venues? Does the international movement shift to

16 The research for this chapter was supported by a fellowship from the Cuban Heritage Collection at the University of Miami. 
accommodate these divergent frames, or do the dissenting regimes themselves conform? Does prolonged engagement eventually lead to frame convergence? To answer these questions, I rely on a wide variety of data that highlight the Cuban family planning frames employed in both international and domestic arenas between 1960 and 2010. A description of these data sources, as well as the methods employed for collecting and coding this data, are outlined in the following section. The analysis portion then traces Cuban framing across this 50 -year period in order to determine how various frame strategies were employed by different actors and venues in both international and domestic contexts. This enables us to detect patterns of diffusion and dissent developed within the Cuban case, and to form a deeper understanding of how dissenting regimes approach advocacy and policy programs in varying political environments.

\section{METHODS}

Although the revolution came in 1959, my analysis of Cuba begins in 1960, which aligns with my analysis of the international movement and also captures the earliest regime activity around family planning. As with the international movement, I give attention to frames in the public discourse, the NGO sector, and activity at the UN. However, in order to more fully capture domestic activity, I also add attention to state-level framing and street-level implementation. A detailed description of the methods and sources of data collection and coding strategies for each of these venue-types follows in the remainder of this section.

\section{International Forum Frames: The United Nations}

In order to trace the frames forwarded by Cuba in the international arena, I employ an analysis of Cuba's statements at the UN population conferences. ${ }^{17}$ These include the formal written

\footnotetext{
17 Statements from Women's and HIV/AIDS conferences were not considered because, with the exception of the 1995 Beijing conference, no statements or references to statements could be located in the UN archives or in other conference-related material. I conclude that they may not exist.
} 
statements endorsed by Cuba at the 1974, 1984, 1994, and 1999 meetings, as well as the full transcript of the Cuban delegate's speech at the 1974 conference.

These statements were coded using Nvivo in the same manner as the general UN conference reports in the preceding chapter, with one important difference. Initial coding revealed that Cuba often discusses population and development in neutral or positive terms, in much the same way that the general UN reports employ this frame. For example, the following statement from Cuba's 1974 speech clearly endorses attention to population and development issues:

This World Population Conference is of significant and momentous importance, since it is the first time that representatives of governments from around the world meet to discuss this issue, which is a serious problem in light of the international economic situation and, particularly, the situation in developing countries, which are those with the highest rates of population growth and the most desperate economic situations. (Gutiérrez Muñiz 1975, 3, translated by author.)

However, it became clear that, in many instances, Cuba mentions population and development exclusively to condemn the use of these frames. ${ }^{18}$ In the same speech, for example, the Cuban delegate notes that, "we repudiate any attempt to impose population policies on the populace against the will of its citizens, such as mass sterilization practiced by the colonial government of Puerto Rico at the insistence of US imperialism" (Gutiérrez Muñiz 1975, 9, translated by author). Coding this simply as use of the population frames would misconstrue the intent behind the language being employed in these statements and problematically inflate the proportion of framing language dedicated to these frames. Thus, I amended my coding categories to include a 'population-dissent' and 'development-dissent' classification that is used for text that discusses these frames in order to challenge them; positive and neutral use $\mathrm{e}^{19}$ is captured in the original 'population' and 'development' categories.

As with the general UN conference reports, I used Nvivo to calculate the total percentage of

18 The same is not true of the environmental frame, which is largely unused.

${ }^{19}$ For example, discussion of population growth rates without any judgement of the positivity or negativety of these trends. 
document coverage for each frame, and eliminated uncoded procedural text, so that the final measure reflects the proportion of each frame's percentage of coverage.

I supplement this analysis with excerpts from an interview conducted with two program directors at the Cuban branch of the United Nations Population Fund in Havana, Cuba. A copy of the IRB-approved interview schedule can be found in Chapter 5 Appendix 1.

\section{Media Frames and the Public Discourse}

According to the World Press Freedom Index, Cuba currently scores a 70.21, which places Cuba in the index's least-free category, along with other nations such as China, North Korea, and Iran. Lugo-Ocando (2008) describes a system where the media "is managed from the very top of the country's leadership, which decide what sort of information is available to the public, through which channels and in which style of presentation" (121). In practice, this is accomplished not through an official policy of censorship, but through the appointment of "politically reliable" individuals to all management and editorial positions, and through oversight by the Ideological Department of the Central Committee (Lugo-Ocando 2008, 123). As a result, although the frames used in the media influence and inform the general public dialogue around family planning, they are also frames that are first endorsed by the state. Therefore, these frames are more top-down, whereas it may be argued that the media frames employed by the New York Times are more bottom-up. Nevertheless, these media frames capture an important dynamic of the family planning debate, as they are reflective of the way that family planning is discussed in informal domestic contexts and the types of frames that are diffused in public dialogues.

To measure media framing, I collected and coded articles from four sources-Mujeres, Granma, 
Bohemia, and Somos Jovenes — as detailed below. ${ }^{20}$ Together, these cover a broad audience and range of topics, including discussion of family planning in varying contexts.

Mujeres is a monthly women's magazine that is produced by the feminist Cuban Women's Federation (FMC). Mujeres began in November 1961, but was shut down in 1993 during Cuba's economic crisis. The magazine resumed publication in 2001 and currently distributes about 60,000 print copies quarterly, and has an estimated readership of 130,000 (Niekamp 2012). Although other magazines possess wider readership, Mujeres has been recognized as a primary provider of information on reproductive health topics (Sanders 1974). Therefore, its inclusion in this study is critical.

A nearly comprehensive collection of bound volumes of Mujeres is housed in the Cuban Heritage Collection (CHC) at the University of Miami. Using this resource, I began revision of the magazine in 1961 and paged through every available issue through 1992, ${ }^{21}$ searching for, and then copying, any articles discussing family planning topics. The $\mathrm{CHC}$ collection does not resume until 2010. ${ }^{22}$ However, Mujeres archives are available online starting in 2007 . The online issues were searched using the following keywords and their variants, which are translations ${ }^{23}$ of those terms used to search the New York Times: planificación familiar, control de la natalidad, anticonceptivo/a anticoncepción, prevención de nacimiento, reproductivo/a, prevención del embarazo, limitación de la natalidad, espaciamiento de los nacimientos, DIU, intrauterino, condón, preservativo, profiláctico, diafragma, vasectomía. Thus, Mujeres articles are missing from 2001-2006. Overall, the search yielded 33 articles.

Founded in 1965, Granma is the official daily newspaper of the Cuban Communist Party and is

\footnotetext{
${ }^{20}$ By relying on multiple sources, I am able to increase the sample size of articles available for analysis. Additionally, the articles in this broader sample move beyond a narrow target audience of women or youth to encompass a more well-rounded target audience (with greater comparability to the broader audience of the New York Times).

21 See Appendix 2 for a brief list of missing issues.

${ }^{22}$ This gap is due to an absence of a procurement chain during these years that does not reflect a systematic bias in material content.

${ }^{23}$ I verified these translations with the Cuban staff at the CHC in order to confirm that I did not overlook any alternative, commonly used term translations.
} 
Cuba's most widely read media publication (Lugo-Ocando 2008). Given the volume of material and time constraints, a full manual revision of this source was not possible. However, the Latin American Network Information Center (LANIC) provides a comprehensive online index of bibliographic references for Granma articles from 1965 to 1992. Using this index, I used the above set of keywords to search article titles and subject indexes for articles about family planning. I then located and copied the full text for each article from the CHC collection. Granma came online in 1997 and archived articles are available from that year forward. Again using the set of keywords, I searched and stored Granma articles from 1997 to 2010. Thus, the gap in Granma data is from 1993-1996, and there are 34 total articles on family planning.

Bohemia began as a popular, weekly 'general interest' magazine in 1908, and covers a wide variety of political, cultural, economic, and scientific topics. Issues from the 1960s are approximately 150 pages long, but overtime the length has gradually decreased to about 80 pages per issue. It is one of the few media sources that did not shut down during the economic crisis of the 1990s, but continued to publish on a biweekly basis. ${ }^{24}$ Bohemia appeared online in 2002, and according to its website, currently distributes about 100,000 print copies per week. The continuity of this source and its national popularity were key factors in its selection.

The CHC houses a nearly complete collection of Bohemia from 1960 to 2010. Due to time constraints, from 1960-1969, I search a random sample of $25 \%$ of Bohemia's issues on microfilm. ${ }^{25}$ Between 1970 and 2005, I paged through every available print issue of Bobemia in the CHC's bound volume collection. ${ }^{26}$ For 2006 to 2010, I used online searches of my keywords to locate articles, saving copies of all findings. In total, I located 102 articles covering family planning.

Finally, I include an analysis of Somos Jovenes, a monthly teen-oriented magazine whose stated

\footnotetext{
${ }^{24}$ During this 'special period', Cuban media was reduced from 733 newspapers, magazines and journals, to 53 newspapers and magazines, and 212 semiannual scientific journals (Lugo-Ocando 2008, 129).

${ }^{25}$ For a list of issues sampled, see Appendix 2.

26 There are some scattered missing issues. For a complete list, see Appendix 2.
} 
goal is 'to illustrate how Cuban youth live, study, work, think, love and dream'. Given Cuba's efforts to intensify sex education among its youth—a topic that will be covered in later discussions-the inclusion of a media source targeting adolescents adds a valuable perspective. Somos Jovenes opened in 1977, shut down in 1992, and reopened in 1999. In order to diversify sources, Somos Jovenes was chosen over two other equally popular youth magazines: Muchacha, which is also published by the FMC starting in 1980, and Juventud Rebelde, which is the CCP's youth-oriented publication. The CHC collection of Somos Jovenes covers 1981 to 2010, and as with other sources, I searched each issue page by page looking for articles on family planning, which I copied and saved. This produced a collection of 27 articles.

In order to maximize comparability with international movement data, these articles were coded following the same method as the New York Times articles. That is, I read each article and recorded the frames that appear in each, and then record the total number of articles within each year that used each frame. As with the NY'T, the result is an annual measure of the total number of articles that employ each frame over a 50 year period. However, as with the United Nations statements, I also differentiate between whether population and development are being used in a positive/neutral or negative context. To avoid double-counting population and development framing, I subtract the number of dissenting population and development articles from the total number of population and development articles in each year. In other words, a single article cannot be coded as both population and population-dissent; rather, any clear dissent to the frame within the article qualifies it to be coded as population-dissent. Although coding for each source was completed separately, I combine all coding in the final analysis. Combining media sources gives me more continuity and a larger sample size for analysis, and because of Cuba's media oversight, we can expect that media framing choices are all reflective of a common political orientation.

\section{Domestic State-level Frames}


In order to examine formal state framing of family planning in domestic contexts, I examined speeches by Fidel Castro. ${ }^{27}$ Cuba is a one party state with an elected legislative body that chooses the nation's president—which, until 2008, was Fidel Castro. Despite the perhaps “democratic and broadly participatory" legislative elections, the state is still structured firmly around "one political party, and within that party, Fidel Castro's authority was hegemonic, total, and uncontested. Dissent was tolerated only on a limited basis, and only within the confines of officially sanctioned institutions" (Sweig 2009, 45). Thus, Castro's agenda was the fundamental guiding force behind Cuban state politics. The role of Castro's speeches in promoting his agenda is also critical. Castro was a legendary speaker and the "larger-than-life, impassioned Fidel Castro leaning forward to address a pulsing sea of a million or more exuberant Cubans" has become an iconic symbol of the revolution (Guerra 2012, 37). As a political tool, however, speech rallies were more than a symbolic representation of the people's support. Specifically, speeches were a principal means through which Castro constructed the revolutionary narrative, and they positioned "Castro [as] the primary protagonist in an unfolding drama of national redemption as well as a self-appointed prophet empowered to define the process of change" (Guerra 2012, 38). As a result, the issue frames employed in these speeches give key insights into state-level framing strategies

Portal Cuba (www.cuba.cu) houses a complete, digitized collection of 'all speeches and some reflections of our Commander in Chief published from 1959 until February 22, 2008, ${ }^{28}$ Using the family planning keywords, I searched this collection for Castro's speeches that mention family planning. In all, Castro talks about family planning in eight speeches, which were all given

${ }^{27}$ In addition, I reviewed the formal reports from the Cuban Communist Party Congresses. The CCP held five conferences between 1960 and 2010, in 1975, 1980, 1986, 1991, and 1997, and I examined the full reports from each of these conferences. However, although the reports review many women's, health, and development policies at length, I found no references to family planning. I also searched for public policies dealing with family planning. However, although I found policies establishing the primary care consults that dispense family planning services, I again found no explicit references to family planning.

28 The LANIC database also contains English translations of many of these speeches, which were employed where available. 
domestically. Castro is known for his lengthy speeches that cover a wide variety of topics, and these speeches are no exception. Therefore, I limit coding of these speeches only to the entire section or entire paragraph(s) that deal directly with family planning. I performed this coding in Nvivo, using the same method employed to code the UN statements, and the final measure shows the proportion of each frame's percentage of coverage within the section of coded speech.

\section{NGO Framing: The FMC}

To identify the frames used by domestic NGOs, I employ an analysis of FMC publications that discuss reproductive health, family planning, and contraceptive use. The FMC has been recognized by the International Planned Parenthood Federation (1980) as the central advocacy force for women's issues within Cuba. Additionally, the reach of the organization is extremely pervasive. According to a UN survey, by 2004, FMC membership had reached 4 million women—or $86.3 \%$ of Cuba's adult female population-who are active in the 74,000 FMC chapters that operate throughout the nation (UN). The FMC also runs a "nationwide network of 175 women and family counselling centres [that] contributes to the important function of providing a discussion and advisory service for women and families," and has become "an essential and mandatory source of reference for the Government in the design of policies, programmes and legislation targeted at women or having an impact on them" (UN, 14). It received consultative status at the UN in 1997. As mentioned, Mujeres is published by the FMC, and so I employ an independent examination of this source as the more quantitative portion of my analysis, and supplement this with a review of other FMC publications. FMC conference reports, ${ }^{29}$ bulletins, pamphlets, books, interviews, and statements vary widely in their style, audience, and content, and only rarely mention family planning. Thus, coding in Nvivo would not produce a consistent measure that can be meaningfully compared over time. Instead, I supplement the Mujeres

${ }_{29}$ I reviewed the general reports from FMC congresses 1-6, and 8, spanning 1962 to 2009. I was unable to locate a report for Congress 7 from any source. Although the reports discuss various development, health, women's, and rights achievements, only the report from Congress 6 in 1995 mentions family planning. 
analysis with a review of pertinent excerpts from these sources. Finally, an interview I obtained with a former official from the FMC provides supplementary details.

\section{Family Planning On-the-ground: Interviews}

In order to gain an understanding of the frames and practices guiding the actual, street-level delivery of family planning services I conducted voluntary, confidential, semi-structured interviews with Cuban doctors and women in Miami, Florida. ${ }^{30}$ A network of contacts was accessed through Jorge Perez Lopez at the Association for the Study of the Cuban Economy (ASCE) and through the Cuban Heritage Collection. Using a snowball sampling strategy, I identified participants with direct knowledge of the provision of family planning services. In total, I obtained interviews with five doctors, with medical careers in Cuba spanning the 1970s to 2010s, and five women whose lives in Cuba span the 1960s to the 2010s. Copies of the IBR-approved interview schedules for these interviews can be found in Chapter 5 Appendix 1.

The insights gained from these interviews are critical to understanding family planning program operations in Cuba, and excerpts and analysis of these participants' experiences are included in each section.

Together, the analysis of these sources allows me to construct a model of Cuban family planning framing tactics that spans multiple decades and levels of analysis, and which accounts for framing choices in both domestic and international, and formal and informal contexts.

\section{ANALYSIS AND DISCUSSION}

\section{The 1960s: Emergent Family Planning and Dissent}

Although Cuban representatives attended the 1965 UN World Population Conference in

\footnotetext{
30 There is undoubtedly some selection bias introduced by the decision to rely on interviews with the Cuban
} exile community. In depth attention to specific biases will be given in the analysis portion of this chapter. 
Belgrade, there is no record of a statement being offered by Cuba. ${ }^{31}$ Thus, I can conservatively suggest that at the international level, there is participation without dissent. This suggestion is bolstered by an account from Alan Guttmacher. In 1965, Guttmacher was the president of Planned Parenthood-World Population, a division of the IPPF. At the conference in Belgrade, Guttmacher had lunch with three of the Cuban delegates, including chief delegate Celestino Lajonchere (Guttmacher 1966; Kaiser 1975). Lajonchere was a Cuban obstetrician and one of the most powerful figures in the development of Cuba's reproductive health programs. Beginning in 1962, he served as the Ministry of Public Health's Director of Obstetrics and Gynecology, and later became the president of the National Group on Sex Education (Ochoa 2006). ${ }^{32}$ In Belgrade, Lajonchere invited Guttmacher to address the Cuban National Medical Congress, and followed up in order to secure Guttmacher a formal invitation, which he accepted. Guttmacher positively describes an 'overflowing' attendance of his talk and a high level of interest in family planning among the 3900 Cuban physicians and 180 international delegates attending the congress (Guttmacher 1966, np). For its part, the Cuban media also gave favorable coverage to both Guttmacher's participation and the participation of other Western specialists. In an issue of Bohemia that covered the congress, the magazine ran two photographs of the Guttmacher address with captions noting that Guttmacher gave "an extraordinary report on modern contraceptive methods" that "sparked exceptional attention" (Bohemia March 1966, 60, 70)..$^{33}$ In addition, Bohemia included remarks from Castro thanking the foreign participants for the honor of their presence (Bohemia March 1996, 67). Thus, here we have a description of a relationship developing out of Belgrade with little tension, and a focus on cross-national collaboration.

Concerning state-level frames, it is during the late 1960s that Castro gives the most attention to family planning; four out of the eight of speeches that mention family planning are given in 1966 and

${ }^{31}$ I searched all 4 volumes of the full conference report and the UN online database.

32 His name also appears frequently in the Cuban media articles I collected, and one of the doctors I interviewed knew him personally and spoke of his influence.

33 This issue was not included in the random sample of Bohemia from the 1960s. 
1968. The coding shows that an overwhelming proportion of family planning framing revolves around population and development, both in dissenting and positive/neutral contexts. Here, it is worth mentioning that although the Cuban government outwardly decries population control, this should not be mistaken for a lack of interest in or concern for population and development. However, in the 1960s, Cuba begins to differentiate itself by framing socialism and revolution as the solution to population and development problems. As a clear example of this trend, consider the following two statements:

Gentlemen, some countries maintain that the solution lies in birth control. This can be said only by the capitalists, the exploiters. No one who is aware of what man can achieve with technology and science will ever establish a limit upon the number of human beings who can exist on this earth, and much less a country which has enough land to supply a much greater population than ours. (Castro 1966)

Now there comes another problem relating to this increase of the population--let no one be frightened, for we are not promoting planning or control. Those are measures being proposed by the imperialists to the underdeveloped world. The measures that we want-the only ones that resolve-are different. (Castro 1968, March)

In both cases, Castro is discussing challenges related to population and development, but raises the question of family planning only to note that it is a false solution. He then goes on to describe how Cuba will engage in a system of economic investment that will mitigate any population and development problems. Importantly, Castro does not focus on family planning as an important health, women's welfare, or human rights goal in and of itself. Rather, he mentions family planning only in speeches that are expressly centered on population and development concerns. Moreover, during this era Castro appears to treat family planning in general with a certain level of derision or skepticism. For example:

For children are going to be born at any rate, because I do not believe they will pay much attention to Johnson and his colleagues when they talk of birth control and family planning. It is ridiculous! For anyone who knows our fields and our peasants, what kind of story are they going to give to our peasants with this kind of thing? They are going to send the planners to the devil. [laughter] Well, that has never been planned. [laughter]. (Castro 1968, April)

Here, more than simply dismissing family planning as a solution to population and development, 
Castro seems to be dismissing it altogether. Between the overall scarcity of speeches that mention family planning, and a lack of attention to family planning in the CCP congresses, it is clear that the highest levels of government are putting little emphasis on the family planning development. Therefore, at this level of analysis, there is clear dissent to the frames being employed by the international movement, but also a general lack of support for family planning.

From the media sources during the 1960s, only five articles from Bobemia discuss family planning. These articles employ both first and second generation frames, and the largest proportion of positive/neutral population and development framing is employed during this decade. The first article, from 1966, ${ }^{34}$ is a piece discussing family planning and population in India, and there is no condemnation of the practice of employing contraception to slow demographic growth. However, dissent emerges in 1967 in a lengthy article discussing a new contraceptive-an early version of the contraceptive implant — that will be used by the United States to exterminate the world's impoverished societies in the name of reducing population growth. By contrast, another article the same year mentions both the implant and population growth, but without any dissenting commentary. The article from 1968 discusses decreasing birth rates, abortion, and contraception use in Bulgaria. Tangentially, the paragraph about abortion notes that abortion is prohibited in Bulgaria during a woman's first pregnancy and that "these measures tend to protect the health of the woman and her ability to give birth" (Bohemia 1968). There is neither objection to an abortion policy that is likely intended to influence population growth, nor a suggestion that women have abortion rights. The article goes on to discuss the use of contraception and, somewhat incongruously, states that there is no doubt that women should have the ability to determine their family size. In 1969, focus shifts away from population and development in an article discussing women's health and the pill. Thus, even in this small selection of articles in the 1960 s, it is possible to note both the emergence of dissent to first

34 An article from 1961 discusses abortion rates and vaguely mentions "the problem of preventing pregnancy" without ever mentioning contraception. 
generation frames and an early (albeit sometimes contradictory) use of second generation frames. Analysis of the larger article sample size in later decades will aid in the further understanding of these trends.

On the NGO front, there is no family planning activity in the archival data collected from the FMC. One interviewee - an FMC officer during the era-notes that although Vilma Espin, ${ }^{35}$ the president of the FMC, was interested in women's health and initiated informal relations with the IPPF, action on family planning was limited until the 1970 s.

As far as actual family planning services are concerned, my interview with a Cuban sex educator provides a few details. During the 1960s, nylon IUDs were the primary means of contraception used in Cuba, which doctors I spoke with referred to simply as the anillo or ring. These were a Cuban imitation of the Grafenberg IUD, but, due to resource shortage, they lacked the silver used in Grafenberg's design. Nurse volunteers produced these nylon rings by hand, and they were used by 'thousands and thousands' of Cuban women (female participant, interviewed November 2015). Nearly every Cuban I interviewed mentioned the use of these rings. During the 1960s, the IPPF sought to aid in the importation of contraceptives, but this was made difficult by the embargo. IPPF workers would bring supplies—spiral and copper T IUDs and the pill—in their personal luggage via Mexico (female participant, interviewed November 2015). From my interview, it is not clear whether this type of clandestine aid really had a widespread effect. Also during the 1960s, Cuba imported 'mediocre quality' condoms from China, which Cuban men largely rejected (female participant, interviewed November 2015). Finally, in 1968, Cuba liberalized its abortion laws and, in a theme that is repeated across these interviews, abortion began to rise as a primary means of limiting births (female participant, interviewed November 2015). These accounts demonstrate action on family planning in the 1960 s, but point to the lack of a comprehensive and coordinated programming. When taken

35 Espin was also a central leader in the revolution, and was married to Raul Castro from 1959 until her death in 2007. She is almost undoubtedly the most powerful female figure in post-Revolutionary Cuba. 
together, analysis from all of these venues demonstrates an emerging engagement with family planning politics, but frames and policies are still largely in a developmental stage. Moreover, dissent to international frames is beginning to occur in domestic venues, but international cooperation-with the UN and the IPPF - is evident. Meanwhile, no clear alternative or uniquely Cuban framing strategies were developed.

\section{The 1970s: Tactful Divergence on the World Stage}

After the gradual emergence of family planning dialogues in the late 1960s, and the early development of a domestic language of dissent to international frames, Cuban family planning and related frames progressed rapidly in the 1970s. At the UN World Population Conference at Bucharest in 1974, the nature of Cuba's participation contrasts starkly with the passivity employed in 1965. At Bucharest, Cuba's dissent to the frames prevailing in the international movement forcefully entered the international arena. As mentioned, two statements from Cuba were coded for analysis. The first is a joint statement issued by Cuba and ten other socialist nations, labeled 1974a in Figure 5.1. Here, the coding reveals heavy use of first generation frames-over $90 \%$. Within this statement, dissent to population frames is non-existent and dissent to development framing is less than $10 \%$. In fact, the main focus of dissent in this statement, which was left uncoded due to its deviance from family planning and related frames, is to the exclusion of the government of South Vietnam from the conference. Thus, the level of dissent to family planning frames demonstrated by Cuba in the speech made by the Cuban delegate, illustrated in 1974b, is noteworthy even when compared to other nations in the socialist bloc. Although about $80 \%$ of the speech revolves around first generation frame use, nearly half of this is from a dissenting perspective. Meanwhile, health and women's welfare frames account for less than $20 \%$ of total framing. When I compare this to the general 1974 conference framing in Chapter 4, the coding is strikingly similar. The proportion of engagement with each frame is

nearly identical, although the international conference report dedicates a small percentage (about 5\%) 
to human rights, whereas Cuba does not.

This is an important finding because it shows that, even though Cuba objects to first generation framing and, as analysis from other venues in this decade will show, is moving away from first generation framing in domestic contexts, Cuba is not substituting new frames in international dialogues. Despite its differing domestic values, goals, and understanding of family planning, we do not see a disconnect in the dialogues between Cuba and the UN. Cuba is protesting the UN framing from within the framing strategies that the UN itself employs, and not by advancing alternative (and internationally non- or less-resonant) frames. Although the delegate notes that access to contraception should be "guaranteed to the whole population" (Gutiérrez Muñiz 1975, 8), Cuba is not demanding a shift in focus to women's, health, or rights frames. Moreover, Cuba is negotiating a balance between engagement and dissent, which is reflected in the coding. As stated above, the split between positive/neutral and dissenting population and development frames is about 50/50. The delegate's speech opens with a long statement noting the positive aspects of the conference, which concludes with the assertion that, "we are sure that the Bucharest Conference will help us to gain depth and understanding of population factors, which Cuba understands should be considered as an element and an integral part of the process of economic development" (Gutiérrez Muñiz 1975, 3, translated by author). The remainder of the speech goes on to voice both agreement with and objection to international norms, and despite the often-used language of conciliation, the dissent is not subtle. For example, consider the following statement:

Cuba rejects the pretension of the ideologues of imperialism who associate underdevelopment with the population explosion, and who designate underdevelopment as the cause of this outcome. My country believes, on the contrary, that high rates of population growth, and therefore the population explosion, are companions and, in a certain sense, the consequence of underdevelopment and oppression and exploitation imposed by imperialism. The true origins of underdevelopment are particularly linked to the colonialist and neo-colonialist policies of the imperialist powers. (Gutiérrez Muñiz 1975, 5, translated by author)

Here, Cuba is not tentative in its criticism of Western norms, and yet, overall, dissent at the UN is far 
from absolute. This effort to maintain a certain level of agreement is also evident in Cuba's relationship with the UN outside of the conference. In 1971, Cuba invited UNFPA to begin work in Cuba, which consisted mainly of offering training courses in Havana and a few other provinces (interview, male participant, UNFPA Cuba, November 2015). At the close of the 1974 conference, Cuba negotiated a \$3.8 million grant agreement with UNFPA, which strengthen the relationship even further, and paved the way for the establishment of regular, formal relations with the organization (IFPD 1975). An interview with a Cuban UNFPA officer offers more detail about this collaboration and the framing strategies employed by both parties:

First [UNFPA] organized training on population issues and family planning issues. Really, UNFPA has an agenda that has been, I would say, that has been enriched by conceptual advances-with gender issues, with the concepts of reproductive health, which expanded to dimensions that do not have to do with access to contraception, which aren't seen only as family planning but also sexual rights, reproductive rights, and which also extended to many types of couples. They are associated not only this type of service, say, more associated with the 70s, the $60 \mathrm{~s}$, that had to do with birth control. In Cuba, really there has always been more of a 'rights' connotation, although obviously I think we also have much to improve. (Female participant, UNFPA Cuba, November 2015, translated by author.)

The process of conceptual enrichment and the evolving focus of UNFPA described here suggests that during the 1970s, the UN's work in Cuba was still more motivated by birth control and population issues, which makes sense given the dominant UN framing strategies of the decade. However, there is also an assertion that Cuban family planning has always been rights-based. When asked about this use of rights, the UNFPA official offered the following observation:

In Cuba, you are going to find-it's something you have to keep in mind-you are going to find the word "rights" very seldom used... We know that [Cuba] is a country that has guaranteed rights like no other. A right to education, a right to health. That is to say, Cubans feel assured. It wouldn't occur to me to think that I don't have a right to health services because I have had them since I was born... But you'll find little explicitly about that, perhaps, in the media... When I think in reality, Cuba has had its [family planning] services based in rights since the beginning. With their limitations, obviously. (Female participant, UNFPA Cuba, November 2015, translated by author.)

Here, the suggestion is that, although the UN was still focused on population and development, Cuban 
family planning was always implicitly understood as a rights issue. Although it is plausible that rights frames were not explicitly used in domestic contexts because they were taken as a given, in this case, we might still expect to see Cuba calling for the right to family planning internationally. This is particularly true since, in the 1970s, the UN itself very occasionally uses rights frames. Thus, mentioning rights would not be in conflict with the UN understanding. However, although the UN delegate at Bucharest speaks of a "guarantee" to contraception, this is the closest Cuba comes to expressing a right to family planning. Although it is a strong argument and one that will be later incorporated at the $\mathrm{UN}$, dissent to population control because it violates an individual right to determine fertility is not employed.

Domestically, there is no activity on family planning discussed in Castro's speeches in the 1970s, but media coverage increases sharply, with 23 articles on family planning during this decade. As Figure 5.2 illustrates, in 1970 and 1972 there is non-dissenting use of population and development frames; however, most use of these frames in the early 1970s, especially around the time of the 1974 conference, is focused on dissent. Between 1970 and 1975, about 50-65\% of the framing language revolves around first generation frames, but $77 \%$ is of this use is dissenting. Thus, in the early 1970 s, Cuban media is making a shift away from positive/neutral first generation framing and is also aligning with Cuba's international dissenting framing activity. Nevertheless, the beginning of a broader trending in media framing can be seen in 1976, when the media drops first generation frames altogether. In the late 1970s, the popular discourse frames are divided between women, and a slightly heavier use of health frames. By contrast, rights framing appears only once, in 1974. Over time, this reliance on women and health framing becomes the norm, as later sections will discuss in detail.

From the FMC, Mujeres magazine published its first article on family planning in 1972. The articles from the 1970s are all published in the magazine's popular "Health Debates" section, which were specifically designed to promote health education among Cuban women (Justice Ministry 1977, 
38). The content of these early articles tends to be heavily informational, focusing on explaining varying types of contraception, their use, and the pros and cons of various methods. As the coding for Mujeres shows in Figure 5.4, women and health framing dominate the discussion, with health having an edge until the late 1970s. The FMC official I interviewed discussed how participation in the 1975 UN Global Women's Conference in Mexico City catalyzed the FMC's support for family planning-leading to the organization's initiation of a wide scale sex education campaign and greater collaboration with UNFPA, the IPPF, and the Ministry of Health in the creation of family planning consult centers-because the conference's Plan of Action called for attention to 'women's reproductive health and reproductive rights' (female participant, November 2015). Although rights frames were certainly employed at that conference, as the analysis in Chapter 4 shows, it was not a prominent framing strategy. In addition, rights frames are not employed in the FMC's Mujeres in the 1970s. Thus, I probed the participant's use of the phrase "reproductive rights", questioning whether she thought the organization had been developing an understanding of family planning as a human right as early as the 1970s. Similarly to the UNFPA official, she responded:

In Cuba this term "reproductive rights" was hardly used, but in addressing the issue of family planning and women's reproductive health, women's rights were always emphasized. The right to decide how many and when to have a child; the right to receive the information required to make decisions; the right of recourse to abortion; the right to have access to contraceptives. This does not mean, however, that these rights have resulted in appropriate services. There were, and there are, gaps in production and a lack of products, or the products didn't have, or don't have, the required quality. (Female participant, November 2015, translated by author.)

Again, there is the assertion that a right to determine fertility was always part of the Cuban (and FMC's) understanding of family planning, and that this understanding was fostered by the relationship with the UN. Nevertheless, the only evidence of rights-based language is coming from the UN itself and not from within the FMC.

An alternative explanation for the lack of human rights frames was offered in an interview with a Cuban doctor who began medical practice in the early 1970s. The doctor began with the following 
story:

A woman, 45 years old, came and requested a delivery with me. It was her $18^{\text {th }}$ baby, so the highest risk for delivery. We were 37 kilometers from [the city], where the maternal hospital was. I had less obstetric experience, less knowledge of instruments, because I'm a GP trained in internal medicine and pediatrics. I told her it was impossible. The risk was too high for her, and the risk was too high to me. There was no ambulance. I sent her with a note to look for sterilization after the birth, and she was sterilized. At the time, there was a policy for the sterilization of women with a lot of babies. This was specifically in order to reduce maternal and infant mortality. Cancer and other diseases were ignored, but we were to reduce infant and maternal mortality at any cost. (Male doctor, September 2015.)

When asked about this sterilization policy, we had the following exchange:

-[Officials would say that] Cuba was reducing the birth rate because the Cuban people were developing, and [family planning] was an option that they had, and they were doing this because they had this option, and they were more cultural and informed. But in the practice, they were compulsorily inducing the abortions and contraception and sterilizations.

\section{-How was this enforced?}

-The physician, talking with the women, would try to convince the woman that it was the important thing because she was sick, or had some diseases, or was high risk, and that she could increase the infant mortality.

-And what if the woman disagreed?

-They tried to convince the woman, they say, if you don't use some method, you will make some children die, and they confused the women to be subject of the method of abortion or contraception or sterilization...Look, if you don't understand that the Cuban government is giving you the food on a ration card, giving you medicine in a ration card, giving you everything because they don't let you have this in a free way, you have to receive that from them... [the government is] the only owner that is in the country, and the doctor is representing the only owner of the country, that is Fidel Castro. And then they are saying that the Revolution, and Cuba, and the Ministry of Public Health, and the problem of the reduction of the problem of infant mortality needs that you do this, you are obliged, because you are receiving everything, supposedly for free. ... Because you will receive the health care for that baby from that doctor, and you are obliged to cooperate with that doctor. If you don't go, and you have the baby, that doctor could be not very happy with your pregnancy and could be dangerous for you. Because you don't have any other option, you don't have private options, you have those that the state is giving you supposedly for free... And the doctor is not free to do what he wants, he is a tool of social control. (Male doctor, September 2015).

Chronologically speaking, this is the first of several interviews suggesting that a female right to

reproductive freedom is being compromised by a state drive to avoid or eliminate high risk 
pregnancies and thereby reduce infant and maternal mortality. However, unlike many countries where coercive tactics were employed in the name of population control, the individuals I interviewed reject the notion that these policies in Cuba were intended to halt population growth. Rather, the doctors repeatedly note that a shrinking population has posed a greater challenge to the government, and that with regard to family planning, maternal and infant mortality rates were the central element of concern; reducing these rates was one of the most important health goals in the entire nation. Cuba's pervasive health framing of family planning is consistent with this analysis. However, this particular doctor also has an alternative explanation for the motive behind these healthcare priorities:

Because of JFK's 'plan for progress in the Americas' [the Alliance for Progress], which was pushing for democracy in Latin America and giving money to governments who pushed this US plan, Castro had to respond with his own figures. And then Lenin mandated that "the first thing of a socialist country is health". So it was not because Cuba was more humane [that it cared about maternal or infant mortality]. Political deaths abounded. There were lots of political executions without trial...[reducing infant and maternal morality] were political goals, not humanitarian goals. (Male doctor, September 2015)

The statement from this doctor offers one explanation for Cuba's desire to engage the UN while pursuing a strategy of moderated dissent and tactful divergence-namely, defending the socialist political strategy pursued by Cuba in the face of pressure to democratize.

It is clear from each of these excerpts the doctor interviewed here is an outspoken critic of the Castro regime, as are many (although not all) of the Miami exiles. Thus, many of the explanations offered here should be evaluated with this knowledge in mind. This critical perspective is also useful, however, because, for example, we can be fairly certain that if Cuba had been involved in a project of population control, these doctors would likely be forthcoming with that information. Thus, I can assert with some confidence that Cuba's rejection of population and development framing in relation to family planning is genuine. Moreover, even population control advocates would agree that Cuba did not have a 'population problem'. Before the revolution, private means of obtaining contraception contributed to comparatively low fertility rates relative to the region (Díaz-Briquets and Pérez 1982, 
515). In addition, large waves of emigration__ first during the Great Depression and then again after the revolution-have had a substantial influence on limiting the island's overall population growth (IPPF 1980, 1). Furthermore, the island itself was not densely populated and did not suffer from resource shortages. Thus, interest in family planning is unlikely to have resulted from a desire to reduce fertility, but makes more sense as a strategy to boost Cuba's healthcare reputation.

As far as the actually availability of contraception in the 1970s is concerned, this doctor and the FMC official both affirm that the nylon ring IUDs and condoms were freely available, and that abortions-and especially early term 'menstrual regulations'-were also common. Thus, although method choices remained limited, in the 1970s, the basic provision of family planning services was being realized. One impetus driving the provision of these services seems to be a concern for health indicators, balanced with perhaps a genuine (and perhaps an occasionally paternalistic) concern for women's health. Whether any meaningful conceptualization of human rights is occurring in the 1970s is an issue that seems doubtful.

\section{The 1980s: A Human Rights Paradox}

At the 1984 UN World Population Conference in Mexico City, Cuba’s perspective is again offered in a joint statement with other socialist nations. Thus, the 1984 proportions of frame use, shown in Figure 5.1, are most directly comparable to the 1974a coding. Here, we see a combination of very high first generation frame use and increased first generation frame dissent. Use of first generation frames is similar to 1974 , at about $95 \%$ - compared to about $75 \%$ in the general conference use of first generation frames, which had begun to decline in the 1980 s - and about $30 \%$ of that is dissenting. Although the use of rights frames makes its first (very marginal) appearance, women's frames are still absent, and there is no push to replace first generation frames with new framing strategies. Thus, it cannot be argued that Cuba is taking advantage of the opening space for second 
generation frames at the UN or pushing the envelope in terms of introducing new frames, but rather is still pursuing the same strategies of tactful divergence from first generation frames.

In the domestic media, there is a heavier reliance on second generation frames in the 1980s, and less emphasis on first generation frames, dissenting or otherwise. Overall, there is a small spike (about 20\%) of population and development framing surrounding the 1984 conference, but only minor dissent to development frames. The rest of the decade is characterized by nearly exclusive reliance on second generation framing, and we also see the most substantial reliance on rights framing during this period. The articles discussing family planning as a reproductive right are largely from Bohemia and are often contributions by various government ministry figures, including Lajonchere. Thus, to some extent, this focus on rights is being initiated within the government and being diffused outward through the media. However, this observation is a bit paradoxical when compared to actual program implementation, as discussed below.

The FMC's framing in Mujeres likewise introduces rights framing in this decade, but only briefly in 1988, and otherwise continues its pervasive focus on women and health framing. In a 1985 FMC publication entitled Cuban Women and Public Health, the FMC further details its understanding of its role in family planning. The publication details how, through both Mujeres and the National Working-group on Sexual Education (GNTES), ${ }^{36}$ the FMC seeks to "prepare new generations for relationships, love, marriage, and family, under conditions of equality between men and women" (Martinez 1985, 8, translated by author). The focus throughout this bulletin is on improving women's welfare and health, and with regard to family planning, and the FMC sees its role as establishing 'education, orientation, and assistance measures' that "help the couple to plan the opportune number of desired children, as well as the right moment of their birth" (Martinez 1985, 8, translated by author). Newspaper interviews with FMC president Vilma Espin in both 1984 and 1987 also stress the promotion of

36 This later becomes the National Center for Sexual Education (CENESEX). 
women's equality in conjunction with the provision of family planning services, but in these there is also a central and explicit rights-based dialog. In the 1984 interview, Espin stresses the importance of education, asserting that "in order for every couple to be able to exercise the fundamental human right to decide whether or not to have a child, we are obligated to educate them, to give them guidance on the mechanisms of human reproduction and the contraception possibilities that permit the avoidance of an inopportune pregnancy" (Espin 1990, 57, translated by author). In this statement, the FMC's educational contributions to the promotion family planning are thus constructed as part of a commitment to reproductive rights. In the 1987 interview, Espin notes that it was Cuba's commitment to these rights that made the nation a key contributor at both the 1974 and 1984 UN World Population Conferences (Espin 1990, 169). This is an interesting perspective, given the lack of discussion of human rights by Cuba in these venues, but it nevertheless demonstrates that by the mid- to late-1980s, the head of the FMC is familiar with rights-based frames and is expressing a desire to make them a central part of family planning dialogues. Moreover, in a 1989 analysis of Cuba's progress on family planning goals established at the 1984 UN women's conference, the FMC again recognizes this 'fundamental human right', which, although connected to a discussion about other health programs is not necessarily connected to the right to health care, but which is rather recognized an independent right to determine fertility (FMC 1989, 41). However, this framing language is not generally reflected in more far-reaching FMC debates in Mujeres, and a further example of the FMC's inattention to reproductive rights is discussed below. A final critical observation can be drawn from this 1989 report. The report is structured around quotes from the UN conference resolutions, followed by measures taken in Cuba to achieve UN goals, and the title of the report itself is "diffusion and evaluation of Nairobi's strategies to forward the advancement of women". Thus, it can be concluded that the FMC sees the UN as the international agenda setting venue, but it is also careful to point out where these priorities align with domestic activities that Cuba has been pursuing since the 1960s. Generally, the 
goal of the publication seems to be to demonstrate Cuba's natural alignment with UN norms promoting women, health, and rights, while also recognizing the UN's work in promoting and diffusing these priorities.

Although official-level framing shifts considerably in the 1980s, Castro himself does not employ rights frames in the discussion of family planning. Instead, as shown in Figure 5.3, his speech in 1985 relies on health frames less than $20 \%$ of the time and otherwise focuses on population and development framing, largely with dissent. This is in stark contrast to his 1987 speech, which closely mirrors the UN framing a decade earlier. Here, there is no dissent to first generation frames, which account for over $90 \%$ of the speech's frame use. This speech marks a permanent break with dissenting frame use; however, framing here lags behind the transitions to second generation frames being initiated in other domestic and international venues. Overall, the shift in tone between the two speeches is perhaps partially explained by the audience. In 1985, Castro is addressing the Latin American and Caribbean Trade Union Conference on Foreign Debt, while the 1987 speech addresses an international student conference. Although both speeches target a mix of domestic and international participants in Havana, the more political trade union speech is more critical of outside political trends than is the future-building speech to the students. In either case, however, it is clear that Castro is not at the forefront of establishing new frame narratives on family planning.

In practice, little seems to have changed in the 1980s in terms of service availability. Both doctors and women that I interviewed discussed the difficulty of obtaining methods other than widely available condoms or nylon rings, which seems to be due to resource shortages. As one woman noted, "the most used [method in the 1980s] was the ring. It was the easiest to get. Then, the T was not easy to get. For the T, you had to have a friendship with a doctor, and if the doctor was a friend of yours, they would find you one" (female participant, October 2015, translated by author). Because T-shaped IUDs were made of copper, they were more effective, but also more expensive. Similarly, the pill was 
also hard to find, and one doctor suspects a discrepancy in the official versus unofficial reason for their absence, stating: "in [about] 1979, the government said that it didn't endorse the use of contraceptive pills because they were suspicious of the ethics of the pills. So Cuba was not using them. Really, they weren't suspicious of the pills. They didn't have them because there was no money" (male doctor, September 2015). Ongoing accounts of reproductive rights violations support the claim that these concerns were based more on economics than ethics. In addition to the pressures for abortions and sterilizations, a number of stories began to surface from this period of IUDs being inserted after an abortion, without the knowledge or consent of the female patient. One middle-class woman (an accountant) I interviewed described her first-hand experience as follows:

I got pregnant while using the ring. What happened was, I had an abortion, and during that abortion, they put in a ring, right there. During the same procedure, they put in a ring. I didn't ask for it. I don't remember having asked for it. I didn't think I had anything in there, but later when they gave me an exam, they told me I had one. The thing was, I was always someone with a very regular period, every 28 days, always, always. And what happened was, after they put in the ring, I didn't have a period, and to me that signaled that I was pregnant. So I went to the doctor-a very good doctor in Cienfuegos - and he told me that he was sure I wasn't pregnant, because I had a ring in, and so I wasn't pregnant. But he was wrong! I was pregnant, and that's the child I had, who is now 29. (female participant, October 2015, translated by author). ${ }^{37}$

There are no official statistics on the pervasiveness of this practice, but in the course of my interviews, similar stories were recounted by five unrelated sources. One doctor described the motives and frequency of these practices, saying:

If I do this to a women, I don't have to defend myself to anyone, because in Cuba there is no right to informed consent. And these were not just a few cases, but it also wasn't an [officially] established policy either. It was really a way for doctors to protect themselves, because the doctors are the ones who are responsible for infant mortality rates. If a baby dies in its first year, the doctor involved is questioned by all levels of the Ministry of Health, by the government, and many times they will have problems. Serious problems, like prison or invalidation of their medical license. Anyone who affects the maternal and infant program is questioned from head to toe, and nobody wants that. (Male doctor, November 2015, translated by author.)

${ }^{37}$ It is worth noting that this participant cites economic (rather than political) reasons for her emigration from Cuba, and that the tone of this interview was not critical of the regime. She praised most aspects of the Cuban healthcare system and also communicated several favorable maternal healthcare experiences. 
As with pressure for abortions and sterilizations, the forces driving this process appear to be a top-down concern with lowering infant and maternal rates, but this explanation suggests that the Cuban government does not explicitly support policies that violate reproductive rights (as has certainly been the case in other nations). Rather, political pressure led to a system wherein support for reproductive rights is subordinated in the pursuit of other political or health goals, and where violating these rights is not punished. I noticed a similar lack of concern over rights violations in responses in Mujeres to questions from women who had been sterilized without realizing (or having been informed) that the process is permanent. ${ }^{38}$ In one, a woman hopes for another child despite having "submitted" to sterilization after her third Cesarean birth, at age 21. Here, the magazine expresses no concern that her right to informed consent may have been violated, but rather advises that a pregnancy in anyone who has had three C-sections would constitute too much of a health risk anyway. Thus, once again, maternal health indicators are prioritized.

A final development in family planning programming in the 1980s that deserves attention is the shift in attention to condoms. As mentioned previously, condoms, although available, were unpopular in Cuba, and "the word condom was, until the end of the 1980s, a 'prohibited' word, a word that decent people did not use" (interview with a Cuban sex educator, November 2015, translated by author). However, with the onset of the AIDS epidemic, the Ministry of Public Health recognized the need to increase condom use, and relied on IPPF to supply new, higher quality products. Media attention to condom use also increased. For example, in February 1988, Mujeres ran its first article promoting condom use in order to prevent STDs. This is the beginning of turn toward emphasizing condoms as the birth control of choice for young people because of the added benefit of STD protection, and more generally, a norms shift making condoms a more accepted method.

\section{The 1990s: Toward Frame Harmonization}

38 See Mujeres June 1984, pp. 46; May 1989, pp. 49 
Across the 1990s, Cuban framing in both international and domestic venues continued to shift, reaching greater harmony with, and less dissent to, international movement frames. At the UN meeting in Cairo in 1994, shown in Figure 5.1, Cuba's population frames drop to less than 10\% of total frame usage, and nearly all of this usage is dissenting. Here, Cuba appears ahead of the international trend in dropping population frames, but overall, Cuba employs more first generation framing than the UN as a whole- just under 70\% compared to the UN's 50\%. Most of this is attributable to both neutral and dissenting use of development frames, which claim the largest percentage of frame use overall. However, we also see a marked increase in women's framing, which reaches $15 \%$ in 1994, as does health framing. Additionally, rights frames continue to be employed, although at a very low level. One factor that is almost certainly driving this framing shift is Cuba's choice of delegate for the Cairo meeting, which is none other than the FMC's Vilma Espin. In and of itself, the selection of Espin is significant as the decision to send an NGO activist deviates from the selection medical doctors and public health ministers, like Lejonchere in 1965 and Gutiérrez Muñiz in 1974, and an increase in attention to women's welfare would be expected from this actor. Overall, her participation is reflective of the more inclusive nature of the Cairo conference, as discussed in Chapter 4, and framing tactics reflect the inclusion of these new perspectives.

This trend toward less dissent continues at the 1999 UN meeting in New York in the statement from the Vice Minister of Foreign Investment and Economic Cooperation. Here, despite similar levels of first generation frame use hovering around $65 \%$, only about $25 \%$ of this is dissenting. Meanwhile, rights frames increase slightly, while women's frames decrease slightly, and health framing remains fairly constant. Combined, however, second generation frames are still the minority at the end of the 1990s and still trailing behind the international movement in their shift.

In the media, there are two distinct spikes in first generation framing around both the 1994 and 1999 UN meetings, shown in Figure 5.2, which account for about one-third of frame use during those 
periods. Although there is a mix of neutral and dissenting framing in the early 1990s, in 1999, all use of second generation frames is in dissent. However, this use is overshadowed by the focus on second generation frames. As with the international movement as a whole, in the Cuban media, health framing is becoming more clearly established as the dominant framing tactic. At the same time, rights frames are used only sporadically, and women's frames also decline. Some of this decline in women's frames is likely explained by the 1993 disappearance of Mujeres and its somewhat more woman-heavy framing; however, women's frames do not make a consistent comeback even once all media venues resume in the 2000s, so this explanation is likely only accounting for part of the shift.

With the early 1990s decline of Mujeres, there are only two available FMC publications in this decade that discuss family planning. The first is a 1995 report detailing the organization's "realities and challenges". Here, the FMC includes several pages detailing progress on sexual and reproductive health issues, and highlights the organization's work promoting family planning education. Most of this work is discussed in terms of promoting women's welfare and health, and the organization states that, "since 1959, all action inherent to family planning has been developed on a foundation of criteria for diminishing maternal-infant risk and supporting the free exercise of women's equality on the principle of the free decision of the couple (or of the woman) over reproduction" (FMC 1995a, 24, translated by author). Here, there is an unambiguous link between family planning and the specific goal of reducing infant and maternal mortality; however, in contrast to assertions found in the interviewee testimonies, the FMC emphasizes the goal of promoting reproductive freedom and women's welfare in this process. Although the overarching focus is on women and health, there is also a nod to first generation frames in the acknowledgment of development goals and the assertion that these health programs will "allow human development and fullness of family" (FMC 1995a, 25, translated by author). Finally, in this report, there is also a single, explicit use of the term "reproductive rights", but in reference to abortion rather than contraception. The 1995 FMC congress report also 
briefly discusses family planning, and links this discussion to a broader overview of sex education programs $^{39}$ and the UN conference at Cairo. In the report, the FMC contends that, since 1962, their organization has pursued "the establishment and promotion of family planning methods and the legalization of abortion as a right of the family and, in first place, of the woman" (FMC 1995b, 45). Of course, the FMC's construction of family planning as a rights-based issue in the 1960s and 1970s is not well supported by my analysis of those periods, and was not part of Cuba's advocacy strategy at those early UN population conferences, but the FMC nevertheless expresses mild concern that it has taken the UN 30 years to come around to this way of thinking. Although this section of the report relies mostly on second generation frames, there is also one of the clearest examples of non-dissenting use of first generation framing in the FMC's assertion that "it was made clear at Cairo that without the presence of the woman [in development plans], there is no possibility of slowing the highly preoccupying advance of planetary over-population" (FMC 1995b, 45, translated by author). Overall, then, although the FMC focuses on second generation frame use, there is still a clear affinity for international population and development concerns.

In the 1990s, Castro discusses family planning in 2 speeches at the end of the decade. In 1998, his framing strategies very much resemble those used in 1987, with no dissent, and heavy use of first generation frames. Health framing has increased to about $20 \%$ of total frame usage, but women and rights frames are absent from this dialog. The family planning-related content in this speech is brief-2 short paragraphs — and is brought up in the context of a discussion about sustainable development and the economic pressures related to family size. As Figure 5.3 illustrates, compared to his speeches in the 1960s, Castro takes a different tone when discussing population and development. For example, he asserts "the rich do not multiply, they have one child, two at most, or none, and maintain a balanced population. The poor have not been able to go to school, and they have not been able to become

39 Sex education programs are discussed in other congresses, and yet these discussions fail to include references to family planning. 
aware of these problems" (Castro 1998, translated by author). Thus, a poverty-driven lack of education is cited as the source of population growth, and he similarly expresses the need to increase education around family planning, which is large departure from his perspective three decades earlier. Here, it is important to note that he is addressing problems that he identifies outside of Cuba. The 1999 speech reflects an even more abrupt shift in framing tactics, where first generation frames are dropped altogether, and health becomes the primary focus. Again, however, the theme of this speech is education, as Castro emphasizes that individuals must have "sufficient education and social responsibility" to protect against STDs and unwanted pregnancies (Castro 1999, translated by author). In contrast to the previous speech, HIV/AIDS, STDs, and high abortion rates are all problems that Castro sees as affecting Cuba domestically. Thus, within Cuba, family planning is a tool for addressing women's welfare and health, while outside, it may still be applied to population and development issues.

From the perspective of women and doctors I interviewed, the economic crisis of the 1990s, or 'special period', wrought changes in family planning services in Cuba. At the most basic level, there was a shortage of contraceptive supplies, but it is hard to pinpoint exactly how grave this shortage was. On one hand, domestic funding for family planning services and education programs may have diminished, but in the early 1990s, UNFPA's involvement in Cuba increased with the opening of a formal office in Havana and renewed monetary support (female participant, UNFPA Cuba, November 2015). In 1992, Granma reported on UNFPA's construction of a contraceptive pill factory in Havana that would have the capacity to produce 250 million pills per year (Granma 1992, March). In addition, Granma reported an \$800,000 grant from UNFPA for family planning in 1992, and in 1994 Bohemia reports that between 1990 and 1994, UNFPA invested \$4 million in Cuba family planning programs (Granma 1992, May; Bohemia 1994, B7). Correspondingly, two interview participants—one woman and one doctor-noted the availability of the pills in the 1990s. However, this availability 
seems to be far from uniform, and as one would expect, areas outside of the capital were hit the

hardest. A younger doctor who practiced medicine between 2001 and 2014 in both Havana and Las

Tunas, a small landlocked city 400 miles east of Havana, describes the situation in the 1990s as follows:

There was a period in which they were trying to organize [about] 17 health programs, and sometimes, [family planning] was not a priority...The desire, the directive to focus on family planning - there is a political desire. The problem was the economic situation. Some of the programs deteriorated, including this one, and they had a hard time trying to focus resources on the whole population. [Between Las Tunas and Havana] there are differences in resources. The capital has most of the resources and most of the information about their access...Those that are less socially developed have less access to services. These are the places that suffered the most. (Male doctor, October 2015, translated by author).

Even in the capital, however, resources were not guaranteed. As a doctor who practiced in Havana in the late 1990 s noted regarding condoms, "sometimes they are there in the pharmacy, and sometimes they aren't. It's like everything, sometimes it's in the store, and sometimes it's not" (Male doctor, November 2015, translated by author). These observations are also reflected in the experiences of the women I interviewed. The middle-class woman from a city in Villa Clara province who spoke of needing connections to get a T obtained one in 1989 and kept it throughout the 1990s, and had friends who reportedly had no issue obtaining pills. By contrast, a tobacco factory worker from a tiny village in Villa Clara describes much greater obstacles to service access. She explained,

For a woman who wants to avoid a pregnancy in Cuba, it is very difficult in the sense that in the pharmacy, there is a lack of appropriate medications for that end. They don't exist, or they exist in very little quantities. Many years ago...there were also rings or loops... But these have been used less because they also don't exist. Instead, the practice that we've used the most in recent years is abortion... It's the most practical method of those that exist, the most convenient. (Female participant, October 2015, translated by author.)

It is not a secret that Cuba has one of the highest abortion rates in the world. In 1998, Bohemia reported that there were about 9 abortions for every 10 live births in Cuba. Doctors I interviewed cite abortion rates that averaged from 6 to 8 per woman, and the participant above describes long lines (of mostly 
adolescents) that form outside of clinics. ${ }^{40}$ A joint publication from UNFPA and the FMC reports an abortion rate that climbed from 36 per 1000 women in 1970, to 42 in 1980, to 46 in 1990 (FMC and UNFPA 2010, 63). ${ }^{41}$ This is the case despite Castro's expressed concern over abortion rates and the prevalence of media articles that affirm a woman's right to abortion, but repeatedly note that abortion should be a final recourse of action and never used in place of effective contraception. When I asked doctors why abortion rates were so high, they cited a mix of reasons-most commonly poor sex education, but also ambivalence, convenience, 'abortion culture, ${ }^{42}$ and pressure to abort high risk pregnancies-but generally do not point to contraceptive access problems. From the interviews, it seems that this may be because contraception of one type or another was almost always freely available to anyone with the means and motivation to pursue it. However, the reality is that ease of access to information and services varied in the 1990s, and family planning did not rank highly in the list of health sector priorities.

\section{The 2000s: Convergence on Health Frames}

In the absence of UN population conferences and speeches from Castro on family planning in this decade, my analysis focuses here on media treatment, FMC framing, and street-level perspectives on family planning. In the media, the shift to second generation frames is almost absolute. Only two articles in 2003 employ population and development framing in a discussion of UNFPA's activities and World Population Day, and there is no dissent in this framing. As in the New York Times, health framing has become the most prevalent tactic, but Cuba's near-exclusive reliance on these frames is

\footnotetext{
40 See also AZAM "Plenty of Romance but Too Few Babies Means a Demographic Crisis for Cuba." The New York Times. (October 28, 2015 Wednesday ): 1441 words. LexisNexis Academic. Web. Date Accessed: 2016/01/29.

${ }^{41}$ For comparison, the global rate in 1995 was about 35 per 1000 women. (https://www.guttmacher.org/pubs/journals/Sedgh-Lancet-2012-01.pdf)

${ }^{42}$ For a recent study exploring "abortion culture" and the factors driving abortion rates in Cuba, see Bélanger, Danièle, and Andrea Flynn. 2009. The persistence of induced abortion in Cuba: Exploring the notion of an "abortion culture". Studies in Family Planning 40 (1): 13-26. Critically, these authors do not cite a lack of service access as a factor and note high contraceptive prevalence rates.
} 
more dramatic than the international movement's shift. Interestingly, women's welfare frames are used sporadically and infrequently, and rights frames appear only in a spike from 2003 to 2005. Although rights framing appears in only a few articles, the topic of each article is explicitly focused on rights, and rights framing has spread for the first time in this decade to the teen magazine Somos Jovenes, in an article titled "We Have Sexual Rights". Here, varied media venues are taking a more direct approach to talking about rights, and this corresponds with the UNFPA-Cuba interview participant's claim that "we have to improve people's knowledge about the rights they have, and I think this has been changing recently-that today the Cuban population knows more about this" (Female participant, UNFPA Cuba, November 2015, translated by author). This increase in knowledge may be accompanied by changes in service provision, as discussed below.

Although there are few insights that can be drawn from Mujeres in this decade-only one article, which exclusively relies on health frames, was located-there are two statements from the FMC to the UN in the 2000s that illustrate framing strategies being forwarded by the FMC in the international arena. Although FMC members previously participated in UN conferences, these are the first statements from the organization itself that discuss family planning in these forums. The first, in 2004, is to the Human Rights Commission, and although the whole document is rights-focused, reference to family planning appears in a paragraph discussing women's health care as a human right (FMC 2004). The second, from 2010 to the Human Rights Council, mentions the scope of the Cuban family planning program in a section focused on more general health achievements. Thus, in its international activism, the FMC is relying on second generation frames, and health frames in particular. A similar trend is demonstrated in the organization's domestic activism. Besides Mujeres, a 2010 publication by the FMC discusses contraceptive use, failure rates, and resulting abortions among adolescents strictly through health frames. However, given the decline of Mujeres articles discussing family planning and the fact that the FMC often discusses women's and sexual health at length—for 
example, in its 2009 Congress-without mentioning family planning, it seems that advocacy around this issue is less of a priority. As in the international movement as a whole, following the burst in activity around Cairo, overall advocacy attention to family planning in Cuba appears to have decreased somewhat in the 2000s.

A decrease in advocacy does not necessarily correspond to a decrease in service provision, and if anything, family planning services seem to be on the rebound in Cuba. According to interviews with doctors and women who most recently departed the island, street-level service provision has improved since the 'special period'. A recently departed professional from Havana described how anyone can go to the doctor now for an IUD, or buy pills in the pharmacy (Female participant, August 2016). A young doctor who worked in Havana in the late 2000s told me that although many social programs in Cuba 'don't work', in her experience, family planning is one of the programs that is well run and contraception is widely available (Female doctor, October 2015). In her opinion, the current problems result from a lack of information and the censorship of the internet in Cuba. As she observed:

The information for everything in Cuba is limited. I give the answers to you from what I know in the medical field, but then I remember that what I know in the medical field and in my case is not the same thing as everyone else. Because I have access, I have my books, I had internet in Cuba. But mostly other people in Cuba don't have access to that information...Y You need to know what AIDS is, you need to know what a pregnancy is, you need to know what is everything in order to avoid it...Because when you have a 15 year old girl that gets to your consult having chlamydia, having gonorrhea, and also being pregnant, and you say, Where were the parents? What does she know? And actually when I'm questioning her, she doesn't know anything...If people had the information on all that they should, it would be better...There are some days that I've gone to the pharmacy in Cuba with 10 Cuban pesos, that is around 50 cents, and I bought like 30 condoms and 2 packs of pills. So it's not even expensive, it's not that you can't go and find it, and the point is that there isn't a lot of information...It's a good program, but what we have to do is get people informed about it. (Female doctor, October 2015.)

Thus, despite official claims that sex education is a priority, it is not clear that this education is being realized, even in more developed regions. Describing her high school experience with sex education in Cienfuegos city in the early 2000s, one woman explained, "our discussions were more disease-focused 
than pregnancy-focused. A lot of focus on STDs and HIV/AIDS-how to prevent it, how it's transferred, and about condom use, with demonstration on how to use condoms. But it was all more theoretical than practical--there was no information about treatment if you got an STD. Pregnancy was not really mentioned" (Female participant, October 2015). In addition, the quality of the information being conveyed varies depending on the interest-level of the district's official 'health promoters'-the volunteers responsible for teaching sex education (Male doctor, November 2015). Overall, it is the privileged populations who are most likely to have the information required to access family planning services, and adolescents are particularly vulnerable to lapses in educational offerings.

However, beyond basic service provision, doctors and women also expressed interesting sentiments about more macro-level cultural and economic conditions that affect the practice of family planning. As the tobacco factory worker explained, "planning like what I've seen here-'in two years we'll have a child' — that culture doesn't exist in Cuba" (Female participant, October 2015, translated by author). The young doctor elaborated, noting that, "from the point of view of the doctors' office, yeah, people have access there. It's not like here that you have a few barriers to get to see a doctor...But before that, and after that, people in Cuba don't have what they need to have--I mean, it's not like you can plan your whole life, like you can get to have your house, or the things that you need for raising your child. And it's not like you can be completely responsible because you have all the means" (Female doctor, October 2015). Another doctor, who worked in Havana in the early 2000s echoed this sentiment, stating:

The whole family planning situation is a reaction to the socio-political-economic situation...to the inability to plan for life, to say 'in 5 years I'll finish my schooling, buy a house, and in 6 years we'll have a baby'... Here, any couple can have a house... a car, diapers, baby food, milk. There, no...And another important aspect is among the youth, the most widespread desire is to leave the country. And when you are hoping to leave the country, you aren't thinking about giving birth. (Male doctor, November 2015 , translated by author).

From these accounts, it seems clear that family planning, in the narrowest sense, is available in Cuba 
in this decade. However, what is lacking is a broader ability to effectively plan for family life, and for that reason, all of the doctors roundly rejected Cuba's 1994 claim at Cairo that the nation has pursued "a comprehensive approach to development that provides for interlinking economic and social aspects to the benefit of all people" (Espin 1994). Cubans have small families — the birth rate in the 2000s was about 1.5 children per woman — and they have the means to prevent births, but the decision to have fewer children is stemming from a position of economic hardship, rather than a truly "comprehensive approach to reproductive health and rights adopted in Cuba" (Espin 1994).

Finally, according to the doctors, attention to mortality rates continues to be a chief concern motivating family planning policy and still in the 2000s they note that "what interests the government the most is that people classified as high risk avoid pregnancy" (Male doctor, November 2015, translated by author). As even the young doctor observed, "with pregnant [women] and with little children under 28 days old, if you mess with that, oh my God. That's like the worst thing that you can do in the medical field. It's well protected and I'm happy it happens that way" (Female doctor, October 2015). As a result, the rights violations mentioned in previous decades continue in the 2000s, although perhaps with less frequency (Male doctor, November 2015, translated by author). Because the practice of inserting IUDs without consent was an 'unofficial policy' and not a formal state directive, increased attention to sexual rights in the public discourse may help to continue to drive this shift.

\section{Tracing Family Planning Frames}

Establishing empirical measures of frame use by both the international and Cuban movement across five decades and in multiple venues lays the foundation for an examination of diffusion and convergence of framing tactics in family planning. As discussed in chapter three, I follow Kollman (2007) by employing a timeline to visually organize key shifts in framing tactics, shown in Figure 5.5. From this analysis, several key conclusions can be drawn. 
First, it is clear that the promotion of family planning occurs first at the international level, and that Cuban attention to family planning began a few years later From this, I conclude that Cuba was not a primary agenda setter on the topic of family planning.

Second, Cuban attention to family planning in the 1960s began by adopting frames being diffused by the international movement. At the same time, there is limited use of women and health frames and no conception of human rights framing in any Cuban venue. Dissent to these international frames emerges in the late 1960s only in domestic contexts-beginning with Castro and later appearing in the media-while international activity is characterized by increased collaboration and a lack of dissent. Specifically, international interactions during this decade were characterized by Cuba's quiet participation at the 1965 UN conference and the simultaneously development of a congenial relationship with international advocates, which led to the positive reception of Alan Guttmacher in domestic Cuban venues. In the early (non-dissenting) use of population and development frames, the lack of dissent in international contexts, and the development of non-confrontational relationships, there is support for my first hypothesis, which predicts that during the international movement's incipiency and coalescence, international recognition and support of dissenting regimes requires frame matching by the dissenting regime. However, the second part of this hypothesis, which predicts that no relationship of support will develop during this phase, is clearly incorrect. Instead, at the end of the 1960s, we see the beginning of a two-level game, in which Cuba balances an understanding of and conformity with international frames with dissenting tactics. During the 1960s, when the international movement would be most sensitive to disruptions in the formation in a cohesive frame narrative, this balance is achieved by simply refraining from dissent in the international sphere.

Third, when dissent does emerge in international venues in the 1970s, Cuba employs a strategy of tactful divergence by equally balancing support for and dissent to international framing tactics. Again, there is support for my second hypothesis that as the international movement institutionalizes, 
divergent framing tactics will appear. However, there is little evidence of an effort by Cuba to 'push the boundaries' of alternative frame use and introduce new (second generation) frames. Rather, this divergence materializes in an effort to criticize existing frames, and perhaps open a space for the later insertion of new frames. At the same time in domestic venues, Cuba utilizes the second generation frames — women's welfare and health—that more closely match its own political and social priorities. Domestically, this shift in framing occurs as Cuba is increasing efforts to provide widespread access to family planning. First generation frames do not fit the Cuban rationale for promoting family planning, and simply dissenting to this frame use does not provide justification for supporting the development of family planning programs. Rather, a shifting focus to women's and health frames during this decade seems contextually appropriate and establishes a clear motivation for the need to expand services.

Fourth, by the 1980s and into the 1990s, it appears that Cuba is actually lagging behind in the international arena in terms of making the shift to second generation frames. Again, rather than taking advantage of the changing climate around family planning to campaign for women's and health priorities, Cuba continues to pursue high first generation frame use, coupled with decreasing levels of dissent. Therefore, once again, we can conclude that second generation frame use in the international movement is not being diffused by Cuba. Given that the shift to second generation frames occurred very slowly within the international movement, and was more pronounced in some venues than others, it is possible that it takes domestic regimes some time to recognize that a shift is underway and to adjust frame strategies accordingly. Thus, we see Cuba finding less reason for dissent, but still not taking advantage of new opportunities for frame matching-perhaps because, as my second hypothesis predicts, this matching is less necessary to collaboration now that the international movement is deeply institutionalized.

Domestically, the focus on women and health becomes more institutionalized across each venue in the 1980s and 1990s, but the record on human rights is mixed. Despite some insistence that family 
planning has always been a rights issue in Cuba, this is not born out in the frame measures or participant statements. It is possible this insistence stems from a longstanding Cuban emphasis on a right to health care, and a tacit assumption that family planning is part of this right. However, a right to health care and a right to determine fertility are two interconnected but distinct rights, and recommendations for improving health outcomes may not always align with an individual's desired fertility outcomes. Thus, we see the violation of reproductive rights in an effort to improve maternal and infant health indicators. Although recognition of a right to determine fertility emerges from the FMC in the 1980s, there is also the assertion by FMC officials and publications that this frame is being diffused by the international movement, and therefore, it is possible that it is being given lip-service, but is not meaningfully employed in policy due to its conflict with other domestic health and social goals. Thus, the international diffusion of reproductive rights in this period does not permeate actual program implementation specifically because of an overwhelming focus on health outcomes.

Finally, by the 2000s, dissent disappears and the Cuban movement makes the shift to second generation frames in all venues in both domestic and international contexts. Clearly, a reliance on health and women's frames has dominated FMC and Cuban media discussions of family planning since the 1970s. However, both state-level framing and international-level framing from Cuba were slow to follow this trend. According to diffusion theories, NGOs and the media act as more ready pathways for diffusion, and seeing a closer parallel in framing between the international and domestic movement in these venues - and particularly between groups that work together, as do the FMC, IPPF, and UNFPA - is not surprising. As far as the direction of diffusion is concerned, multiple sources from the FMC itself note that it sees the international movement as the agenda setter on women and health issues. ${ }^{43}$ However, the only frames that become widely diffused in domestic

${ }^{43}$ With regard to the media, it seems highly unlikely that the New York Times is picking up on framing trends within the Cuban media. By contrast, Cuban media often cites international sources, interviews international family planning experts, and covers international conferences and events. 
contexts are those that match FMC goals and ideology; that is, women and health frames. In domestic venues, the Cuban movement selectively employs the second generation frames that match its broader political goals, while generally omitting explicit reference to the more problematic rights frames. In international venues, Cuba initially responds to ideological mismatch not with the promotion of alternative, domestically salient frames, but with dissent. However, when these first generation frames begin to disappear from international dialogues, dissent to the use of these frames becomes a less viable tactic, and as predicted by my third hypothesis, dissent is dropped and framing strategies begin to harmonize around the use of women's and health frames.

\section{CONCLUSIONS}

In drawing conclusions, it is helpful to revisit the core questions posed by my dissertation and review the answers suggested by my analysis of the Cuban movement. They are as follows:

\section{How do international and domestic actors negotiate the tension between divergent framing tactics in both domestic and international venues?}

As the literature predicts, the Cuban movement engages in selective fitting of outside ideas, or domestication. This is evident in the adoption of women and health frames, for example, even when domestic priorities may differ somewhat from international goals-i.e. the reduction of maternal and infant mortality indicators. However, I find little evidence of the reverse process, global framing, where movements match their own goals to outside frames. Cuba is not pressing the second generation frames that it employs domestically within the international arena. Rather, I find an effort to balance dissent to and support for dominant frames, which I have called tactful divergence. Here, dissenting regimes acknowledge value in existing frames that they disagree with, while also challenging their use. From the international movement's side, we see the slow decline of these contested frames. Challenges to first generation frames came from many different types of groups, and the movement responds by 
slowly incorporating a new framing strategy. However, while Cuba can be counted among the challengers to first generation frames, it does not appear to have been influential in forwarding this new strategy.

Does the international movement shift to accommodate these divergent frames, or do the dissenting regimes themselves conform?

Initially, there is evidence of Cuba adopting population and development frames both domestically and internationally without dissent. However, this brief conformity is replaced with tactful divergence to first generation frames and the domestic adoption of second generation frames as the international movement institutionalizes. In this process, we see accommodation by both movements. For its part, Cuba dedicates a significant proportion of its activism to finding support for first generation frames; dissent to these frames in the international arena is never greater that $50 \%$ of total frame engagement. In turn, the international movement moves away from contested framing strategies to frames that are more universally appealing.

\section{Does prolonged engagement eventually lead to frame convergence?}

In short, there is clear evidence of convergence. Both Cuba and the international movement converge around second generation framing strategies, and health frames in particular. Dissent to old frames has disappeared as their use internationally declines. Activist collaboration on family planning remains strong, there is more agreement over movement goals, and there is even initial evidence to support more consistent agreement with human rights framing. Thus, after decades of dissent and disagreement, Cuban family planning framing and international movement framing bear a close resemblance to one another.

In addressing these questions, the analysis here contributes to an enhanced understanding of the politics of dissent and its influence on global activism and program development. Importantly, it shows that by moderating dissent, regimes can simultaneously contest dominant norms and build 
cooperative partnerships with the international community. Over time, through continued engagement and accommodation by both movements, movements can converge on less contested framing strategies that harmonize in their pursuit of common goals. 
Figure 5.1

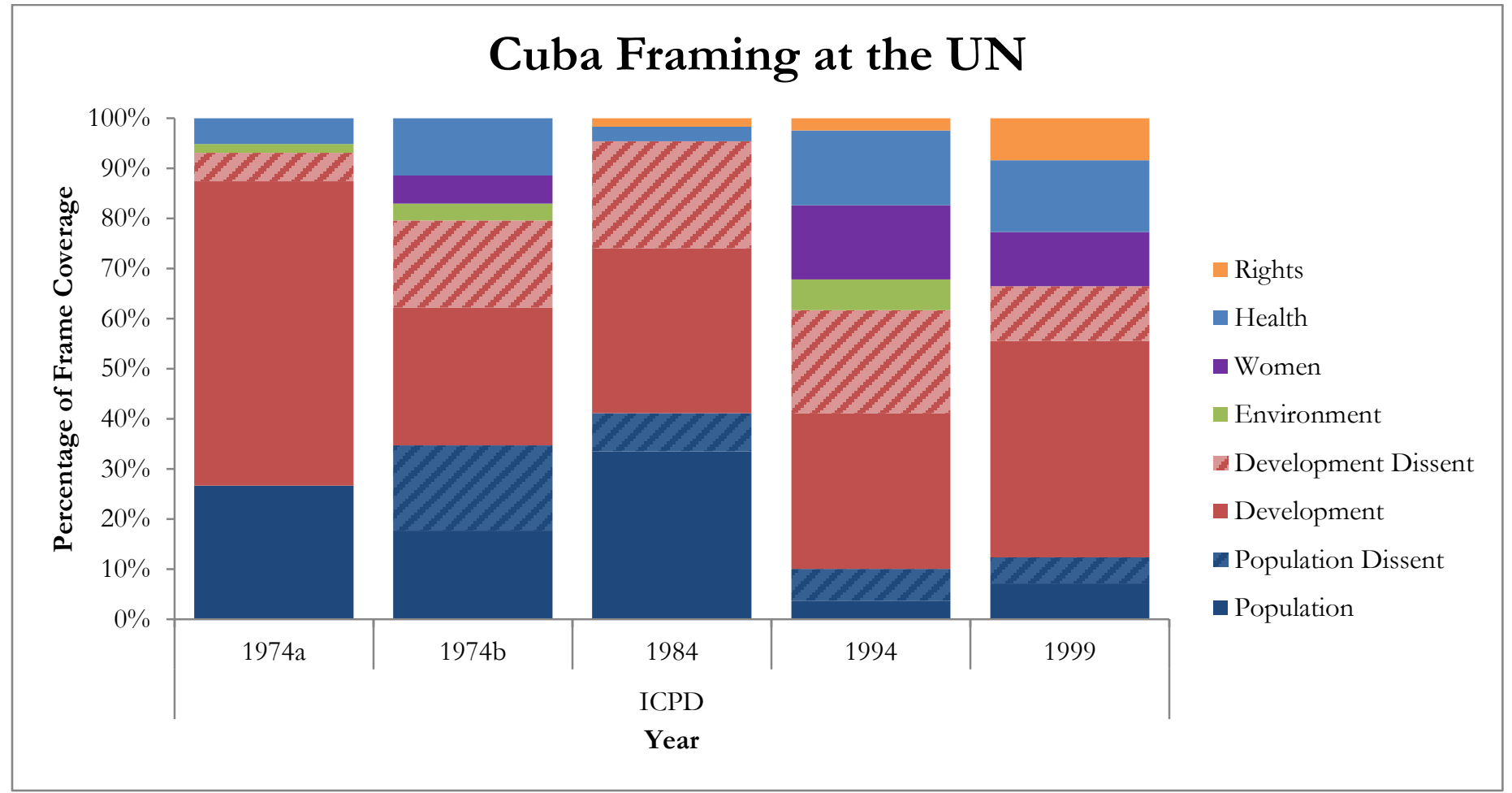

Figure 5.2

\section{Cuban Media Framing}

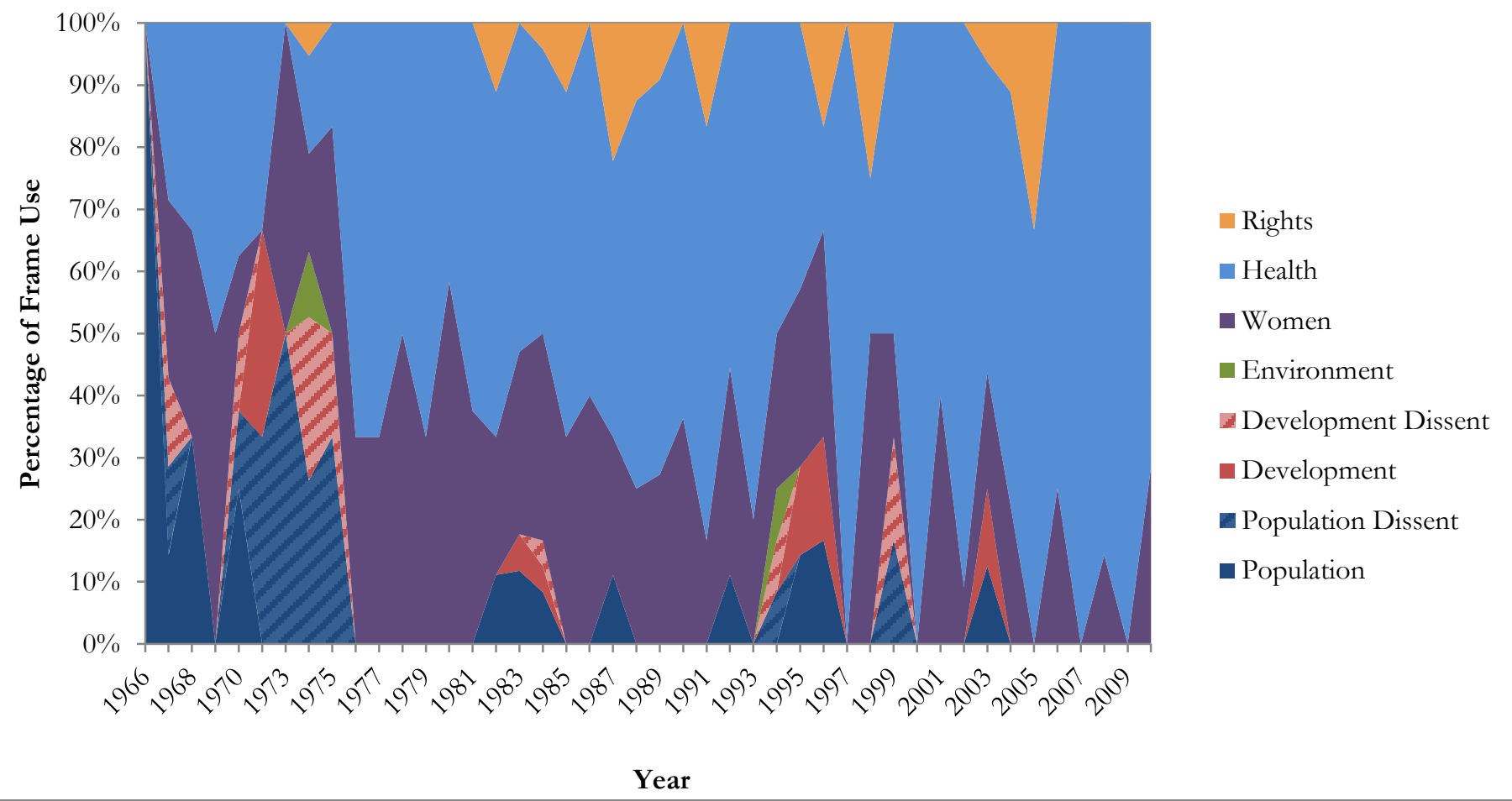




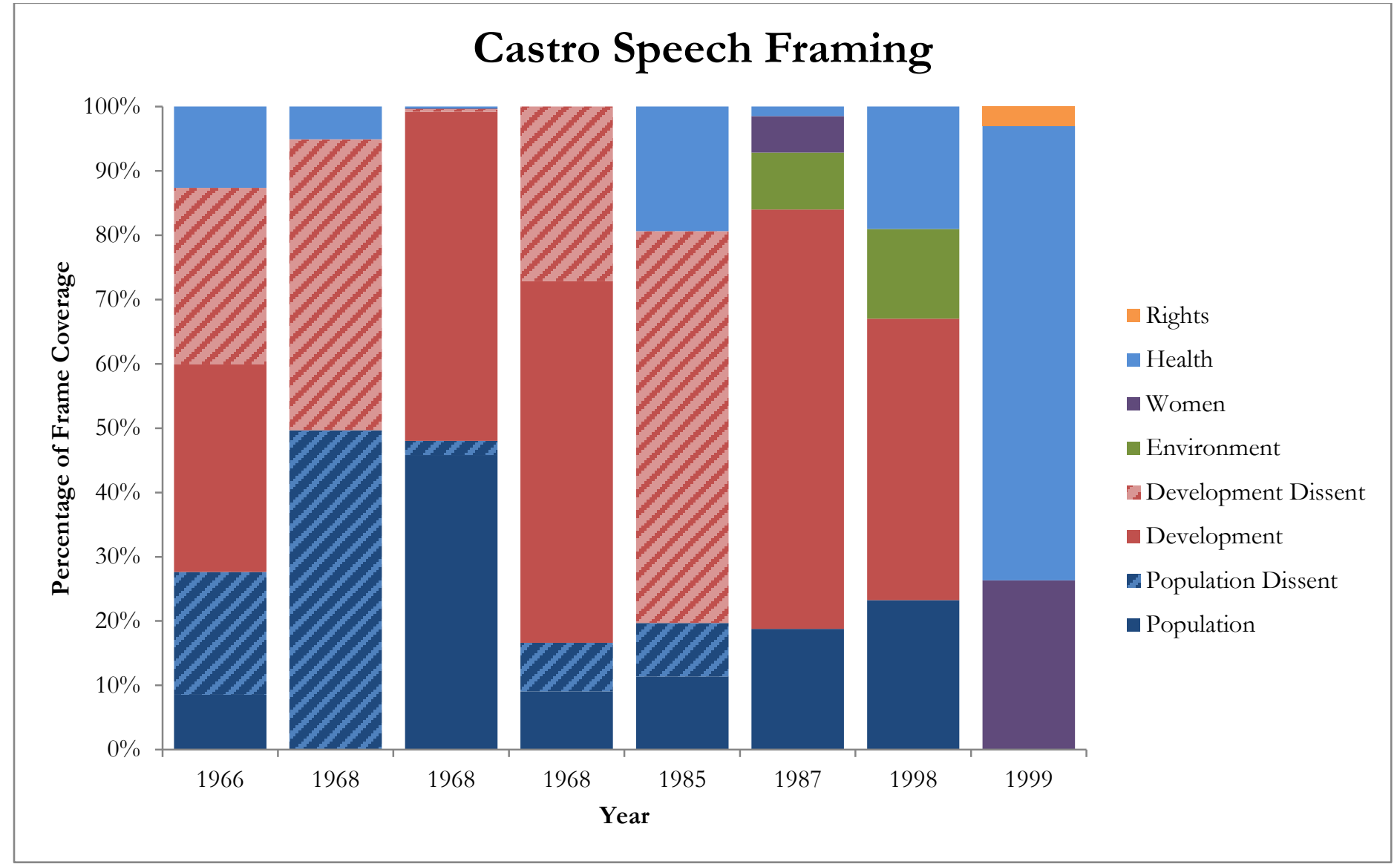

Figure 5.4

\section{FMC (Mujeres) Framing}

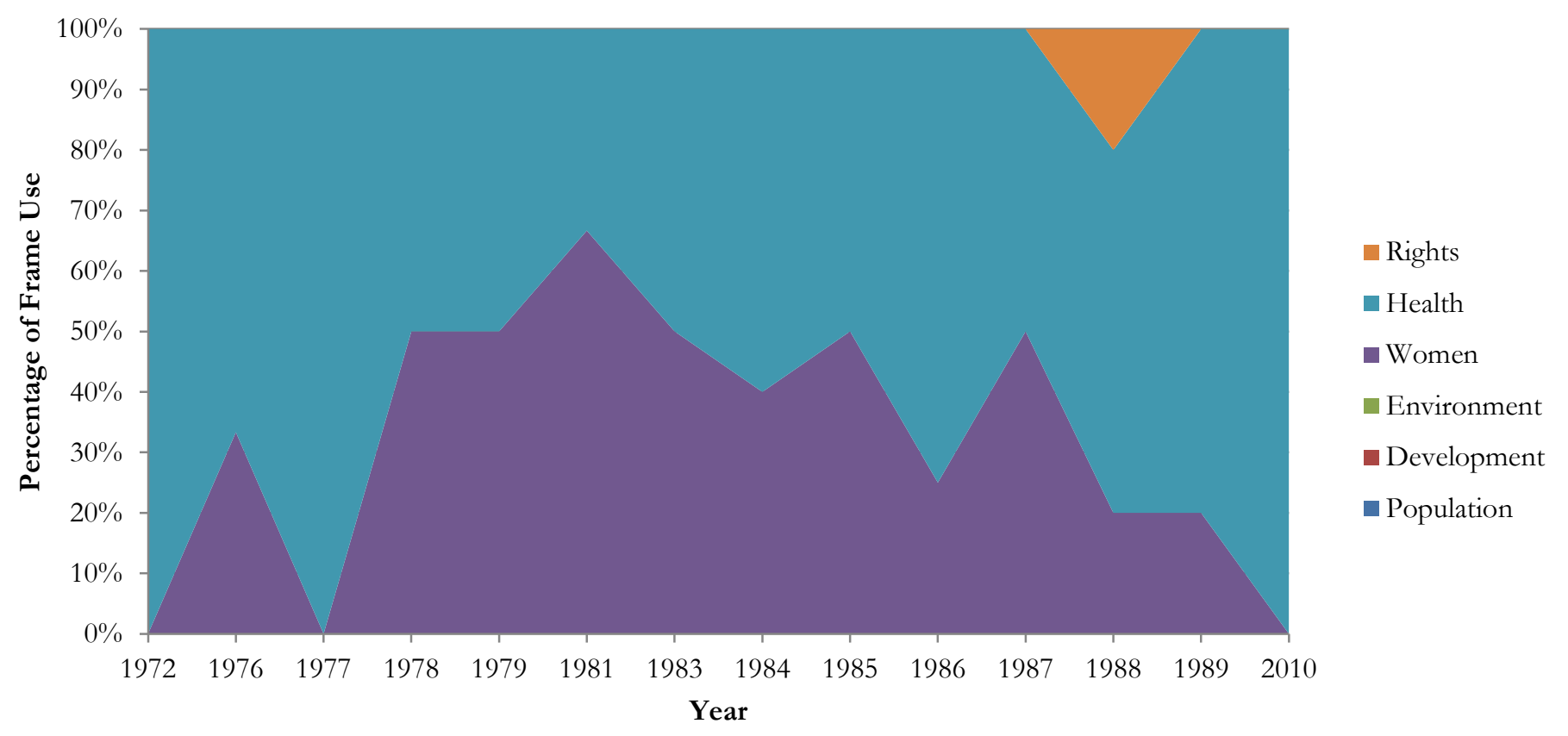




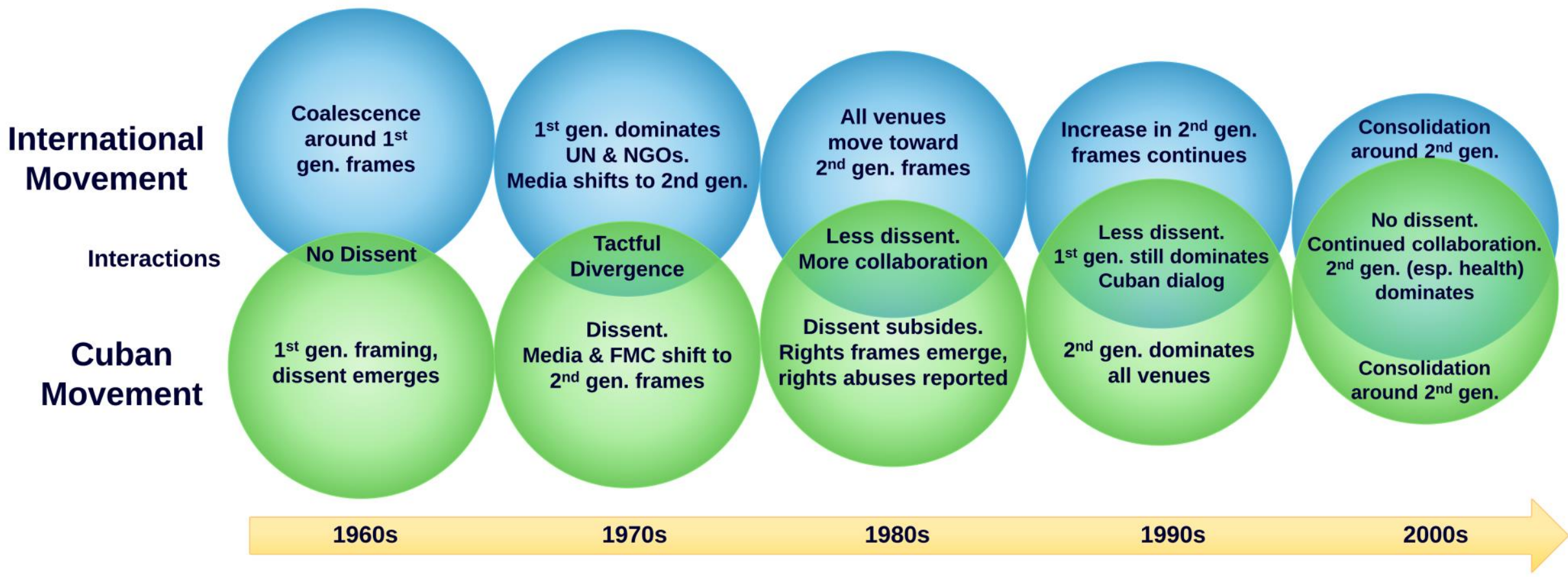




\section{References}

—. 1977. La Mujer en Cuba Socialista. Justice Ministry. Ciudad de La Habana: Empresa Editorial Orbe.

Bélanger, Danièle, and Andrea Flynn. 2009. "The Persistence of Induced Abortion in Cuba: Exploring the Notion of an 'abortion Culture."' Studies in Family Planning 40 (1): 13-26.

Bohemia. 1966, March 4. "No es la lucha revolucionaria lo que cuesta más vidas, sino la miseria y la explotación”. 58-71.

Bohemia. 1968. “Comprimidos”. Np.

Bohemia. 1994, April 29. "Demasiados en Casa?” B4-B7.

Bohemia. 1998, April. "Baja tasa de fecundidad”. Np.

Castro, Fidel. 1966, September 18. "Fidel Castro Speech to School Monitors". Available at http://lanic.utexas.edu/project/castro/db/1966/19660918.html

Castro, Fidel. 1968, March 14. “Text of Castro Havana University Speech”. Available at http://lanic.utexas.edu/project/castro/db/1968/19680314.html

Castro, Fidel. 1968, April 20. "Castro Speech Commemorates Giron Victory". Available at http://lanic.utexas.edu/project/castro/db/1968/19680420.html

Castro, Fidel. 1998, September 5. "Discurso pronunciado por el Comandante en Jefe Fidel Castro Ruz, Primer Secretario del Comité Central del Partido Comunista de Cuba y Presidente de los Consejos de Estado y de Ministros, en el Memorial "Héctor Peterson", por la matanza de Soweto, Sudáfrica, el día 5 de septiembre de 1998, "Año del aniversario 40 de las batallas decisivas de la guerra de liberación"”'. Available at http://www.cuba.cu/gobierno/discursos/1998/esp/f050998e.html

Castro, Fidel. 1999, January 5. "Discurso del Presidente de la República de Cuba, Fidel Castro Ruz, en el acto por el aniversario 40 de la constitución de la Policía Nacional Revolucionaria, efectuado en el teatro "Carlos Marx", el día 5 de enero de 1999". Available at http://www.cuba.cu/gobierno/discursos/1999/esp/f050199e.html

Diaz-Briquets, S., \& Pérez, L. 1982. Fertility decline in Cuba: A socioeconomic interpretation. New York: Population Council.

Espín Guillois, Vilma. 1990. La mujer en Cuba. discursos, entrevistas, documentos. La Habana: Impr. Central de las FAR.

Espín Guillois, Vilma. 1994. Discurso de la Jefa de la Delegacion Cubana En La Conferencia Internacional Sobre la Poblacion y el Desarrollo. Available at http://www.un.org/popin/icpd/conference/gov/940913123342.html 
International Family Planning Digest (IFPD). 1975, January 1. Laws and policies in Europe and Latin America spur family planning and population studies. International Family Planning Digest 1 (1): 3-4.

International Planned Parenthood Federation. 1980. Family planning in Cuba: A profile of the development of policies and programmes. London, England: International Planned Parenthood Federation.

Federación de Mujeres Cubanas (FMC). 1989. Difusión y evaluación de las estrategias de Nairobi orientadas hacia el futuro para la promoción de la mujer: seminario. [Havana]: Federación de Mujeres Cubanas.

Federación de Mujeres Cubanas (FMC). 1995a. Realidades y desafios. Ciudad de La Habana, Cuba: Federación de Mujeres Cubanas.

Federación de Mujeres Cubanas (FMC). 1995b. Memorias. La Habana, Cuba: Federación de Mujeres Cubanas.

Federación de Mujeres Cubanas (FMC). 2004. Integración de los derechos humanos de la mujer y la perspectiva de género.E/CN. 4/2004/NGO/84. Ginebra: Naciones Unidas.

Federación de Mujeres Cubanas (FMC). 2010. Written statement submitted by the Federation of Cuban Women (FCW), a non-governmental organization in special consultative status. A/HRC/13/NGO/2. Geneva: United Nations.

Federación de Mujeres Cubanas (FMC) and United Nations Fund for Population Activities (UNFPA). 2010. Mujeres cubanas: estadísticas y realidades, 1958-2008. Cuba: Oficina Nacional de Estadísticas.

Granma. 1992, March 21. "Funcionarios de la ONU recorren fábrica de anticonceptivos". Vol. 28 ; 59.

Granma. 1992, May 7. “Aporte de la ONU al Programa Alimentario”. Vol. 28; 92.

Guerra, Lillian. 2012. Visions of Power in Cuba: Revolution, Redemption, and Resistance, 1959-1971. Chapel Hill: University of North Carolina Press

Gutiérrez Muñiz, Jose. 1975. Intervención del jefe de la delegación cubana Dr. José A. Gutiérrez Muñiz, Ministro de Salud Pública, en el debate general de la Conferencia Mundial de Población. Revista Cubana De Salud Pública 1(1): 3-9. 
Guttmacher, Alan F. 1966. "Planned Parenthood-World Population, President's Letter from Alan Guttmacher," Center for the History of Medicine: OnView, accessed December 21, 2015, http://collections.countway.harvard.edu/onview/items/show/6662.

Jones RK and Kooistra K. 2011. Abortion incidence and access to services in the United States, 2008. Perspectives on Sexual and Reproductive Health 43(1):41-50.

Kaiser, I. H. 1975. Alan Guttmacher, and family planning in Cuba, 1966 and 1974. The Mount Sinai Journal of Medicine, New York 42 (4).

Kollman, Kelly. 2007. Same-Sex Unions: The Globalization of an Idea. International Studies Quarterly 51 (2): 329-357.

Lugo-Ocando, Jairo. 2008. The media in Latin America. Maidenhead, England: Open University Press. http://public.eblib.com/choice/publicfullrecord.aspx?p=345138.

Martínez, Miriam. 1985. La mujer cubana y la salud pública/Cuban women and public health/Les femmes cubaines et la sante publique. La Habana, Cuba: Editorial Letras Cubanas.

Niekamp, Gwen. The publication of Mujeres and Muchacha and the workings of Editorial de la Mujer. In Cuban Transitions [database online]. 2012 Available from http://pages.vassar.edu/cubantransitions/the-publication-of-mujeres-and-muchacha-and-th e-workings-of-editorial-de-la-mujer.

Ochoa, Francisco Rojas. 2006. Mis recuerdos del Profesor Lajonchere. Revista Cubana De Salud Pública 32 (1): 156-158.

Sanders, T. G. 1974. Cuba and the Bucharest Conference. American Universities Field Staff Reports: North America 2 (4): 1-11.

United Nations (UN). Cuba Questionnaire to Governments on Implementation of the Beijing Platform for Action (1995) and the Outcome of the Twenty-Third Special Session of the General Assembly. Available at http://www.un.org/womenwatch/daw/Review/responses/CUBA-English.pdf 


\section{Chapter 5 Appendix 1: Interview Schedules}

Below are the interview schedules used in my interviews with doctors, lay women, and NGO activists, respectively. The schedules, as well as the interview protocol, were all reviewed and granted exemption by the West Virginia University Institutional Review Board IRB.

Doctors

Interview Questions on Cuban Family Planning

This first set of questions is designed to gather basic information about your professional experience. (Estas primeras preguntas están formuladas para recoger unos datos básicos sobre su experiencia profesional.)

During what years did you practice medicine in Cuba?

(¿Usted ejerció medicina en Cuba durante qué época?)

In which regions did you work?

(¿En qué regiones trabajó usted?)

What is your professional specialization?

(¿Cuál es su especialización profesional?)

In which types of medical settings have you worked (hospitals, rural clinics, etc.)?

(¿En qué clase de establecimiento medical trabajó usted (hospitales, clínicas rurales, etc.)?)

When did you leave Cuba?

(¿Cuando salió de Cuba?)

The following questions ask about your experiences with and knowledge of family planning in Cuba. (Las preguntas que sigan preguntan por sus experiencias con y su conocimiento de la planificación familiar en Cuba.)

To what extent have you been professionally involved in providing family planning services or counseling? What are your experiences in this area?

(¿En qué medida ha estado usted involucrado profesionalmente con la provisión de servicios o consejos de la planificación familiar? ¿Cuáles son sus experiencias en este campo?)

I would like to discuss the principles or values that guide the provision of family planning services in Cuba. Can you talk about your perception of the principles or values forwarded by the government (or official policy) with respect to family planning?

(Quisiera hablar de los principios o los valores que guían la provisión de los servicios de la planificación familiar en Cuba. ¿Puede hablar de su percepción de los principios o valores transmitidos por el gobierno (la política oficial) con respeto a la planificación familiar?)

To what extent do these official values align with the provision of services that you have witnessed in practice? Can you give me some examples?

(¿En qué medida alinean estos valores oficiales con la provisión de servicios que usted ha presenciado en práctica? ¿Puede darme unos ejemplos?)

Below is part of an official statement on family planning submitted by Cuba to the UN in 1994. Can you comment on how the actual implementation of family planning programs compares to the principles outlined in this statement?

(A continuación se incluye parte de una declaración oficial sobre la planificación familiar, que Cuba presentó a la ONU en 1994. ¿Puede comentar sobre como la implementación de los programas de la planificación compara a los principios resumidos en esta declaración?) 
Cuba adopto a partir de 1959 una concepción integral del desarrollo que prevé una intervinculacion de los aspectos económicos y sociales en beneficio de toda la población, sin que haya sido necesario formular una política de población explicita. Como parte de su estrategia general de desarrollo y, con el objetivo fundamental de satisfacer las necesidades materiales y espirituales de nuestro pueblo, el país puso en práctica desde hace 35 años un conjunto de políticas que, sin plantearse específicamente metas de control o limitación de la natalidad, persigue mejorar las condiciones de vida para la población y ha logrado cifras de crecimiento poblacional compatibles con nuestro desarrollo económico y nuevas perspectivas.

$[\ldots]$

En la concepción de salud integral y derechos reproductivos adoptada en Cuba, se presta especial atención, ante todo, a la vida y salud de la mujer, a su realización en todos los ámbitos, al desarrollo de su talento y creatividad. Se valora a la mujer como sujeto especialmente implicado en las políticas de población y, como tal, se considera necesaria su preparación y su decisión en este sentido.

[Translation:

After 1959, Cuba adopted a comprehensive approach to development that provides for interlinking economic and social aspects to the benefit of all people, without it being necessary to make an explicit population policy. As part of its overall development strategy and with the primary objective of satisfying the material and spiritual needs of our people, for 35 years the country implemented a set of policies that, without specifically setting goals to control or limit births, aims to improve living conditions for the population and has achieved figures of population growth compatible with our economic development and new perspectives.

$[\ldots]$

In the comprehensive approach to reproductive health and rights adopted in Cuba, special attention is given, above all, to the life and health of women, to their realization in all areas, the development of their talent and creativity. The woman is valued for her particular role in population policies, and as such, her preparation and her decision in this respect is deemed necessary.]

Women

\section{Interview Questions on Cuban Family Planning}

This first set of questions is designed to gather very basic information about your life in Cuba. (Estas primeras preguntas están formuladas para recoger unos datos muy básicos sobre su vida en Cuba.)

During what years did you live in Cuba?

(¿Usted vivió en Cuba durante qué época?)

In which regions did you live?

(¿En cuales regiones vivió usted?)

In Cuba, what kind of professional work did you (or your husband or family) engage in?

(¿En Cuba, en qué tipo de trabajo profesional estaba involucrado usted (o su esposo o su familia)?)

Why did you leave Cuba?

(¿Porque salió usted de Cuba?)

The following questions are concerned with services that support women's health in Cuba. Overall, I am particularly interested in the services or methods of family planning (contraception) that are available as part of women's health care. (Las preguntas que sigan se tratan de los servicios que apoyan la salud de la mujer en Cuba. Sobre todo, tengo interés particular en los servicios o los 
métodos de la planificación familiar (los métodos anticonceptivos) que están disponibles como una parte de la asistencia médica de la mujer.)

If a woman wishes to avoid or delay a pregnancy, what options are available to her in Cuba? Feel free to answer generally or personally from your experience.

(Si una mujer desea evitar o posponer un embarazo, ¿qué opciones están disponibles para ella en Cuba? Siéntase en libertad de responder con carácter general o personal de su experiencia.) What differences in family planning services have you noticed occurring over time?

(¿Qué diferencias en los servicios de la planificación familiar ha notado usted que ocurren con el paso de tiempo?)

In your opinion, does the government seek to influence childbearing decisions? If so, how?

(En su opinión, ¿el gobierno se trata de influir en las decisiones de la maternidad? ¿Si es así, cómo?)

Do you have any other experiences on this subject that you would like to share?

(¿Tiene usted algunas otras experiencias sobre este tema que le gustaría compartir?)

NGO Activists

\section{Interview Questions on Cuban Family Planning}

This first set of questions is designed to gather basic information about your professional experience. (Estas primeras preguntas están formuladas para recoger unos datos básicos sobre su experiencia profesional.)

How many years have you worked for this organization? ¿Durante cuantos años ha trabajado usted en esta organización?)

What is your professional role here? ¿Cuál es su papel profesional aquí?)

The following questions ask about your experiences with and knowledge of family planning in Cuba. (Las preguntas que siguen preguntan por sus experiencias con y su conocimiento de la planificación familiar en Cuba.)

Currently, what is the role of this organization in providing family planning services, information, or counseling? (En este momento, ¿Cuál es el papel de esta organización con respecto a la provisión de servicios, información, o consejos de la planificación familiar?)

How has this role changed or evolved over time? (¿Cómo ha cambiado o evolucionado este papel con el paso de tiempo?)

I would like to discuss the principles or values that guide the provision of family planning services. Can you talk about your perception of the principles or values that motivate or support family planning dialogs and services within this organization?

(Quisiera hablar de los principios o los valores que guían la provisión de los servicios de la planificación familia. ¿Puede hablar de su percepción de los principios o valores que motivan o apoyan los diálogos y servicios de la planificación familiar dentro de esta organización?) 
Mujeres:

\section{Chapter 5 Appendix 2: Sample Notes}

The CHC is missing the following issues of Mujeres from their collection: March and July 1967, June and July 1972, March 1973, June and September 1979, January 1985, November and December 1989. There is no reason to suspect systematic bias in these omissions. In 1990, presumably under financial strain, the magazine begins publishing on a bimonthly basis. In 1992, one issue is released covering January-March, and another from July-September.

\section{Bohemia:}

As noted in my methods section, given time constraints, I employed a random sample of $25 \%$ of the issues of Bohemia from 1960-1969. In practice, as another time saving measure, I sampled full months, ${ }^{44}$ or reels of microfilm, rather than individual issues. This eliminated time spent loading and searching through individual reels for a given issue. The exception to the random sample is 1963, where the 3 months sampled were simply the only ones available, as all of the other reels of film were off-site for repair. There is no evidence to suggest that damage to these reels and their exclusion from random sampling should significantly bias my results.

The list of sampled months is as follows:

\begin{tabular}{ll}
\hline Year & \multicolumn{1}{c}{ Sample } \\
\hline 1960 & January, November, December \\
\hline 1961 & July, August, November \\
1962 & May, June, November \\
\hline 1963 & July, November December \\
\hline 1964 & January, September, October \\
1965 & May, June, July \\
\hline 1966 & January, February, August \\
\hline 1967 & February, March, Sept \\
\hline 1968 & March, June, July \\
\hline 1969 & October, November, December \\
\hline
\end{tabular}

In hardcopy, the $\mathrm{CHC}$ is missing a few scattered weekly issues from the following bound volumes from the 1970s and 2001-2002:

\begin{tabular}{l} 
AP63 .B7 v.62:pt.4 (Jul-Aug 1970) \\
\hline AP63 .B7 v.63:pt.3 (May-Jun 1971) \\
AP63 .B7 v.64:pt.3 (May-Jun 1972) \\
AP63 .B7 v.65:pt.3 (May-Jun 1973) \\
AP63 .B7 v.65:pt.5 (Sep-Oct 1973) \\
AP63 .B7 v.67:pt.1 (Jan-Feb 1975) \\
AP63 .B7 v.67:pt.2 (Mar-Apr 1975) \\
AP63 .B7 v.67:pt.3 (May-Aug 1975) \\
AP63 .B7 v.67:pt.4 (Sep-Oct 1975) \\
AP63 .B7 v.67:pt.5 (Nov-Dec 1975) \\
\hline
\end{tabular}

${ }^{44}$ I have no reason to believe that coverage of contraception issues would vary with systematic bias according to calendar month. 


$$
\begin{aligned}
& \hline \text { AP63 .B7 v.68:pt.3 (May-Jun 1976) } \\
& \text { AP63 .B7 v.68:pt.5 (Sep-Oct 1976) } \\
& \text { AP63 .B7 v.68:pt.6 (Nov-Dec 1976) } \\
& \text { AP63 .B7 v.69:pt.3 (May-Jun 1977) } \\
& \text { AP63 .B7 v.92-93 (2000-2001) }
\end{aligned}
$$

Overall, these missing issues represent a very small proportion of the total holdings, and again, there is no reason to suspect that there is a systematic reason for their omission. In the future, this could be verified by checking these issues in microfilm, as the collection in this format is complete. 


\section{Chapter Six ${ }^{45}$}

\section{Family Planning in Iran: Frame Convergence and Divergence in the Islamic Regime}

In the early 1960s, Iran became one of the first countries in the world to develop a national family planning program. Although the early advocates of Iranian family planning under Mohammad Reza Shah Pahlavi (henceforth, the Shah) worked closely with the West and received much outside NGO advice and financial support, the 1979 revolution broke this pattern of direct outside influence and engagement (Moore 2007). Initially, the government's family planning division was shut down and all foreign NGOs were expelled (Moore 2007; Hoodfar and Assadpour 2000). The new Islamist government officially took a pronatalist stance, which in practice meant limiting family planning to a small, exclusive private sector market and rewarding couples with many children with land and stipends (Afary 2009). Although contraceptive use is not prohibited in the Muslim faith, the regime viewed the use of contraceptives as an un-Islamic, Western imperialist practice (Hoodfar and Assadpour 2000).

By 1988, some government ministers and private intellectuals were beginning to question the wisdom of policies that led to rapid population growth. Thus, the regime began to reexamine family planning as a means for strengthening an independent, Islamic state, and became determined to build a program that reflected the nation's distinct religious and political values. However, despite this nationalist vantage point, by the mid-1990s, the Iranian government had developed a strong program that collaborated closely with the Western advocates. This chapter examines the rationales behind post-revolutionary family planning in Iran, and gives particular attention the pattern of international engagement that balances a commitment to independence and Islamic values with strategies to

\footnotetext{
45 The research for this chapter was supported by a Distinguished Doctoral Scholarship from West Virginia University.
} 
facilitate collaborative partnerships.

Through an analysis of the Iranian case, I return to the key questions driving this dissertation: how do international and domestic actors negotiate the tension between divergent framing tactics in both domestic and international venues? Does the international movement shift to accommodate these divergent frames, or do the dissenting regimes themselves conform? Does prolonged engagement eventually lead to frame convergence? In this case, I examine data that illustrates the frames employed by Iran in both international and domestic venues between 1988 and 2010. The following section details these data sources and describes the methods employed for collecting and coding this data. Then, in the analysis section, I trace the framing tactics used by Iran in order to understand how dissent and collaboration were balanced in this context.

\section{METHODS}

For Iran, I coded all instances of the 6 original frames-that is, population, development, environment, women, health and rights. However, historical accounts of the Iranian family planning program suggest the need to be attentive to the use of two additional frames: Islam and nationalism. The Islamic frame coding captures instances of family planning being promoted as a tool for strengthening Muslim values. The literature notes that through Islamic frames, Iran promoted the idea that concentrating parental and societal resources on a smaller number of children would help to develop a society of "healthy, well-trained, and moral Muslims" (Hoodfar and Assadpour 2000, 28). In practice, this frame also sometimes manifests itself in reference to an Islamic society's obligation to provide family planning services, as in the following statement: "it suffices for us to know that Islam, for example, makes it the duty of every Muslim to satisfy the essential needs of the community" (UN 1995a, np). With regard to the nationalism frame, coding captures references to family planning as a

means for increasing Iran's independence, or freedom from reliance on outside support. The 
following statement that explicitly links population control to self-sufficiency is a good example of this: "having agricultural self-sufficiency as its major objective in the country's first five-year social and economic plan as well as other long term projects, implementing population control plans will become a must for Iran" (FBIS-NES-89-223, 66). Throughout the coding process, I was conscious of the possible need to include population-dissent or development-dissent frame coding, like those employed in the Cuban case; however, for reasons that will be explained, these frames are less relevant to the Iranian context.

\section{International Forum Frames: The United Nations}

As with the Cuban case, I measure Iranian frames in the international arena through analysis of Iran's statements to UN population and development conferences. Although it attended the International Population Conference in Mexico City, Iran did not make a statement to the UN in 1984. This is not surprising when one considers the lack of domestic family planning development at that time. Thus, the coding includes statements only from 1994 and 1999. These are coded using NVivo in the same manner as the UN reports and Cuba statements, where the output is a measure of the proportion of each frame's total percentage of coverage in each statement.

In addition to these statements, I include one additional resource from the 1994 ICPD. The Foreign Broadcast Information Service (FBIS) ${ }^{46}$ published a special supplementary digest with extensive coverage of the 1994 ICPD. This digest includes several transcripts of interviews with and statements by Mohammad Ali Taskhiri, an Iranian health minister and the chief delegate to the 1994 conference. These were published or broadcast in international forums for an international audience and are thus representative of the messages the Iran delegation wished to convey in the international arena. All direct statements from delegate Taskhiri were collapsed into a single document and coded according to the same procedures used to code the other UN statements. The result is a supplementary

\footnotetext{
${ }^{46}$ More information about this source is included in the description of media sources.
} 
measure of Iran's frame use at the 1994 ICPD.

\section{State-level Frames: Domestic Family Planning Policy}

In Iran, the government's explicit policies regarding family planning are incorporated into the Five Year Economic, Social and Cultural Development Plans, which begin in 1989. However, detailed policies are only included in the first two plans, while later plans merely note that there is no change to family planning policy. Thus, I code only the 1989 and 1995 plans. Relying on the same method used to code the UN statements, I employ Nvivo to complete the coding, and the result is a measure of the proportion of each frame's percentage of coverage in each policy.

\section{State-level Frames: Ministry Reports and Dialogues}

The Ministry of Health and Medical Education (MOHME) published two lengthy reports on family planning programs — one in 1994 and the second in 1998. These reports provide two snapshots of state-level framing of family planning during a period of rapid program development. In addition, in 2000, Iran hosted an international workshop on family planning issues. Segments of the workshop report, which record speeches by state officials, also give insight into how various state family planning leaders were constructing family planning at this later date. With the exclusion of sections detailing demographic data, I coded the entirety of both MOHME reports in NVivo. For the Integrated Approach to Reproductive Health and Family Planning in Iran workshop report, I coded the introduction, opening statement, and welcoming remarks, but omitted the topical reports from workshop sections. As with other documents coded in NVivo, the final measure reports the proportion of each document dedicated to the use of each frame.

\section{Frames in the Public Discourse: Tebran Times and FBIS}

Founded in 1979, the Tehran Times is Iran's leading English-language newspaper. In this phase of the analysis, I used the list of family planning keywords to search the online archives for articles about family planning, which is available beginning in 1998. This search, from 1998 to 2010, yielded 36 
articles. These were then coded according to the same method as the news articles in the two preceding cases, so that the final result is an annual measure of total articles that employ each frame.

To capture earlier instances of frame use, I employed a search of the Foreign Broadcast Information Service (FBIS) archives. FBIS was a federal agency, founded in 1941 and run by the Central Intelligence Agency until 2004, with a mission to "to monitor, record, transcribe and translate intercepted radio broadcasts from foreign governments, official news services, and clandestine broadcasts from occupied territories" (FBIS 2012). In 2005, the CIA's Open Source Center absorbed the FBIS, and continued to publish similar reports. The archives contain a range of domestic news articles published in various venues, which are translated directly into English on a daily basis. Access to the FBIS collection was made available by West Virginia University in various formats, described below.

From 1941 to 1996, the FBIS archives are cataloged on microfiche, first by region and then by day, month, and year. For the Near East and South Asia region, which contains the articles from Iran, I first manually searched each monthly table of contents fiche for article titles that mention family planning. ${ }^{47}$ I then located the identified articles within the archives and copied them for future coding. For months where the table of contents fiche was unavailable, I searched the headlines for each day individually. I began this search in 1988, when histories note that family planning dialogs first emerged in the public discourse, and ended in 1996, when the archives move to a digital format. From 1996 until July 2004, the FBIS collection is available on CD-ROM in a text-searchable format. For these years, I used the family planning keywords to locate articles in the Iran sub-section. ${ }^{48}$ After 2005 , Open Source Center archives are available on the World News Connection database, and I again used the family planning keywords to locate articles. Importantly, for the years captured on microfiche, my

\footnotetext{
47 Because Iran officially includes family planning within population policy, I also included references to population policy within this search.

48 The following months are missing from the CD-ROM archives: July-September 1998; March-June and September-October 2002.
} 
search strategy only enabled me to locate articles that explicitly mentioned family planning in the article title, while the CD-ROM and World News Connection queries searched the full text as well.

The FBIS searches yielded a sample of about 90 articles. All articles were coded using the same method employed for the Tehran Times, and the final measure shows an annual count of articles employing each frame.

As with the Cuban case, I merged the FBIS and Tehran Times data into a single measure of media framing, which increases continuity and provides a larger sample size for analysis.

\section{Frames Employed by Religious Leaders: the Friday Prayer}

Histories of Iranian family planning repeatedly note the importance of Iranian imams in family planning advocacy efforts. Thus, including a measure that reflects how these leaders framed family planning is critical. One advocacy tool used by the imams is the Friday Prayer, which is given every week in various venues, and which is broadcast on the radio (and more recently via television and webcast) and is published in domestic newspapers and magazines. These prayers routinely include a mix of political and religious messages, are considered a critical component of religious leadership in Iran, and have been documented as a tool of "indoctrination and mobilization" (Laursen 1996, 650). Former Iranian president Akbar Hashemi Rafsanjani described the importance of these prayers, stating "if someone, without any excuse and reason, shuns three Friday prayers...this is the state of a hypocrite; a hypocrite does that...Therefore Muslims, revolutionaries, believers, especially civil servants, government managers and heads, personalities, prominent people and religious scholars, should feel obliged to take part in Friday prayers in such a way that all the people realize that they give importance to Friday prayers. This is a duty" (FBIS-NES-93-141, cited by Laursen 1996, 651). Thus, Friday Prayers are widely observed and the discussion of family planning in this venue serves as an important resource for understanding the framing tactics employed by religious leadership. FBIS publishes translations of the Friday Prayer, and using the method employed for FBIS news articles, I 
searched the table of contents of each month, and located and copied each Friday Prayer from 1988 to 1996. I then skimmed each prayer for references to family planning. Although 12 prayers mentioned population issues, only 3 explicitly discussed family planning and birth control. In the text-searchable archives, I found one additional prayer that mentioned family planning in 2000. I coded each of these 4 using NVivo, and as with the UN statements, the result is a measure of the proportion of the percentage of each frame's use.

\section{Street-level Perspectives: Interviews}

As with the Cuban case, I rely on voluntary, semi-structured interviews with Iranian doctors and laywomen to gain insight into the program rationales that manifest themselves in the day-to-day functioning of family planning services. In total, I obtained 3 interviews with doctors whose career activity in Iran ranged from 1988 to present, and 10 interviews with women whose lives in Iran spanned 1949 to 2014. In the case of the doctor interviews, I was fortunate to have participation from two individuals who entered family planning work in the early days of the program, before rising through the ranks to the highest levels of program leadership. These provide invaluable perspectives on programming; however, unlike the Cuban participants, these doctors very much represent officially sanctioned voices in family planning. Interview participants were drawn from a snowball sample that tapped into diverse networks. Specifically, professors at the Johns Hopkins Bloomberg School of Public Health and the Tulane University School of Public Health and Tropical Medicine provided contact information for the doctor interviews.

Many individuals and organizations with professional interests in Iran and/or family planning were contacted to generate the sample of laywomen, but recruitment of this population was more difficult. Often, my inquiries were met with non-response, or women declined to participate. Ultimately, participants were identified through the University of Virginia ESL community, the West Virginia University Iranian Student Organization, and a few personal contacts. As a result, the sample 
is skewed somewhat toward greater inclusion of younger, university-educated women. The mean age in my sample is 38.7 (with a standard deviation of 12.9). Thus, these women largely came of age in the 1990 s and 2000s, which is a good fit for gauging family planning patient perspectives during some of the family planning program's most active years, but an ideal sample would include a few more women with experiences in the late 1980s. All of the women in my sample had at least some university education, although several did not complete their studies. It should be noted that female university attendance rates are high in Iran. In 2014, 66\% of high schoolers continued their education in a tertiary education program, and $64 \%$ of those enrolled were women. ${ }^{49}$ Thus, the higher level of education in my sample is not wholly unreflective of population dynamics. Finally, these women represent a mix of regional backgrounds, with participants with experiences from small villages in more remote regions, mid-size cities, and the capital.

Copies of the IBR-approved interview schedules for these interviews can be found in Chapter 6 Appendix 1

\section{ANALYSIS AND DISCUSSION}

\section{The 1980s: Delayed Action on Family Planning}

The Islamic regime that came to power in 1979 explicitly outlined a right to health care in the new constitution and began the construction of an elaborate, multi-tiered health network. In the most rural areas, health houses staffed with public health workers provide the most basic services. Above the health houses, rural health centers run by medical workers, including at least one doctor, provide higher level medical care. Each rural health house is linked to an urban health center or hospital, where patients with more serious medical conditions have access to services. These centers

49 See "Gross Enrolment Ratio, Tertiary, Both Sexes (\%) | Data." 2016. Accessed November 21. http://data.worldbank.org/indicator/SE.TER.ENRR?locations=IR; and "School Enrollment, Tertiary, Female (\% Gross) | Data." 2016. Accessed November 21. http://data.worldbank.org/indicator/SE.TER.ENRR.FE?locations=IR. 
report to the medical university located in the capital of each province, which falls directly under the jurisdiction of the Ministry of Health and Medical Education. Thus, the system is designed to give patients easy, coordinated access to the level of services they require. However, family planning was not initially included in these services. The rebounding total fertility rate (TFR), which had begun to decline under the previous regime, reflects this absence of services. See Figure 6.7.

Histories of the modern family planning program in Iran generally point to both the 1986 census_-which revealed an increase in population size from 33.7 million to almost 50 million in a ten year period-and economic pressure the war with Iraq placed on the government's stated commitment to providing a growing population with social services as the catalysts for rethinking pronatalist policies (Moore 2007, 55). As a result, we see the emergence of family planning that is explicitly embedded within national population policy. However, at the same time, family planning services themselves were integrated into and governed by existing health programs. One of the doctors I interviewed, who eventually rose to the highest ranks of family planning program management, described the dual focus of the program saying,

So they encouraged people to decrease the number of children through different ways and one of them was expansion of health services to the people. There was no obligation for use of the services, for use of the health services or use of the family planning services. Just providing information to the people and making the services accessible through the expansion of the health system network. (Interview, male doctor, May 2016).

Another doctor, also a leader in family planning programming, suggested an even more central concern for health in program development. In particular, he described the entrepreneurial role of a particular minister, whom he described as:

A religious man, but at the same time a visionary leader who understood the importance of public health. He approached family planning programs and approached the religious leaders from a different angle - from the health angle. So basically, he justified the sanctity of marriage and life and saying that we need to save the lives of women, and save their dignity, and as a result the health is the cornerstone of all our programs...And this includes family planning. (Interview, male doctor, April 2016).

Finally, changes in the religious framing of family planning during this time-and particularly the 
delivery of a fatwa by Ayatollah Khomeini that declared that contraceptive use was not prohibited-was also critical. ${ }^{50}$ Essentially, this decree from the highest level of Islamic authority in Iran overrode arguments that framed family planning as a hindrance to good Islamic practice and, practically speaking, eased the implementation of family planning programs. As the same doctor describes, "so the founder of the revolution issued a fatwa. And he was an awesome power in terms of religious authority, and he issued a fatwa nobody else could... So the fatwa was there, and the minister advised the senior people that from now on, we have the fatwa, you don't need to talk to one of us, move on it " (Interview, male doctor, April 2016). Also as a result, frames that linked family planning use to Islamic values could grow. Given these competing interpretations of the most important frames driving the expansion of family planning, the analysis below will help to determine the extent to which early programming was motivated by population, religious, health, or other concerns.

In the First Five Year Economic, Social and Cultural Development Plan, which was developed in the late 1980s and ratified by the legislature on January 31, 1990, family planning policy is first formulated within a section entitled “1. Population 1-1. National Birth Control Policy Outline”. As would be expected from this categorization, Figure 6.2 shows that at this time, family planning was overwhelmingly framed as a tool to halt population growth, with population frames accounting for nearly $70 \%$ of frame usage. At slightly over 10\%, development frames are the second most prevalent frame. Thus, at a time when international framing tactics are beginning to shift slowly away from first generation frame use, we see the emergence of an Iranian policy that is firmly grounded in these frames. As suggested by the program leaders above, health frames do factor into this policy; however, their use accounts for only about $10 \%$ of total frame content. Thus, a larger role for health rationales is not confirmed by this policy analysis, nor is the role of Islamic frames, which do not appear in this policy. Finally, attention to women's welfare accounts for the remainder of frame use, albeit at a low

50 I have searched extensively for the original text of this widely cited fatwa, but cannot locate it. 
level (less than 10\%).

The attention of religious leaders as captured in the Friday Prayers is similarly focused on first generation frames, and primarily population. In June 1989, Ayatollah Khamenei himself gave a Friday Sermon on the subject of birth control, in which he notes that he will "not reject or insist on birth control to slow down the population boom" (FBIS-NES-89-110, 43). Nevertheless, he goes on to detail the problems of a growing population, to stress the compatibility of Islam with the promotion of family planning and small family sizes, and to lament the impact of population growth on the destruction of the environment. In total, first generation frames account for over $75 \%$ of the frame usage, as shown in Figure 6.5. Given the venue and actor, it is not surprising that Islamic framing accounts for the remaining portion; however, the discussion of family planning is mostly constructed as an issue of population control, development, and environmental preservation.

Given the lack of a statement to the 1984 ICPD and the absence of other state documents in this period, media sources provide the only other archival record of frame use during this period. In the FBIS collection, I found just one article discussing family planning in 1989. The subject of this article is a meeting between the UNFPA executive director and Iran's foreign minister, in which they discuss plans for beginning collaboration "on the planning of population control in Iran" (FBIS-NES-89-223, 66). The article is largely focused on population issues, but as shown in Figure 6.3, also employs development frames. Thus, this article provides evidence of the early development of a relationship with Western collaborators — initiated "at the invitation of the [Iranian] Health Ministry"-where action on family planning according to the first generation rationale is the central priority. Although first generation frame use is beginning the decline in the international movement, we see the initiation of a relationship with Iran constructed around these frames.

\section{The 1990s Family Planning Booms}

After initial efforts to reinstate family planning programs at the end of the 1980s, family planning 
efforts were increased significantly in the 1990s. On May 23, 1993, the government passed a law "pertaining to population and family planning" that revoked many social security privileges for a family's fourth (or subsequent) child and increased public education programs related to family planning, child and maternal health, and population (MOHME 1994). In addition to incorporating education on these topics into formal school curricula, the law instructs the Ministry of Islamic Culture and Guidance to seek the "active and effective participation of journalists, film makers and other artists" as well as the Islamic Republic of Iran Broadcasting (IRIB) system, to develop efforts "to increase the general awareness of people regarding the population and family planning programs" (MOHME 1994, 21). Several women, from both rural and urban areas, recalled the prevalence of these messages in the media and other advertisements. As one woman who grew up in a small village in the late 1980s and 1990s noted, "I remember when I was a kid, there were a lot of signs about having one or two children would be enough. If you have less kids, you'll have a better life, and this kind of stuff' (Interview, female participant, November 2016). Thus, in these educational outreach efforts, it is clear that state action on family planning is tightly linked to population concerns.

With regard to the actual provision of family planning services, dissemination through existing health care networks became the central strategy. By 1993, as one doctor describes:

The situation of the whole health regime was that the whole chain was working...So when the fatwa was issued, all the Ministry of Health, managers, middle level, higher level, all there was was to simply add the family planning program to the ongoing program, which was working perfectly. So I didn't have a problem at the district level. I simply, simply trained my public health workers on family planning and the provision of services. Simple. And they added at the central level, when I was there, just to add contraceptives to the flow of the supply chain, as simple as it is. Easy, easy, piece of cake. And the family planning program applied, overnight, all over the country. So that is the first reason for the success of that family planning program. The functioning health system absorbed easily family planning. (Interview, male doctor, April 2016)

Clearly, it is very generous to claim that an entire health system is working "perfectly". Nevertheless, with regard to family planning, there is a lack of evidence suggesting that services were not widely available. Iran's dramatic decrease in fertility in the 1990s - from a TFR of 4.8 children per woman in 
1990 to 2.2 in 2000 - is well-documented and widely cited in demographic literature (World Bank, illustrated in Figure 6.7). Beyond this data, women I interviewed from all regions routinely described the availability of a wide range of methods_-including pills, IUDs, condoms, sterilization for both men and women, and even legal abortion in the first trimester - and the ease of accessing these services, especially for married couples. ${ }^{51}$ A woman from southern Iran, who left the country in 1987 when she was in her late 20s and returned in 1997, gave a particularly insightful description of the changes in programming that had occurred in the intervening decade:

When we went back in 1997, I had my 3 babies and I didn't want any more, so I noticed we have clinics which was free. They give you birth control or condoms, or even IUDs, do you know? They used to give IUDs and the privilege to close up their tubes, like the surgery they do. But different methods and all were for free. They even used to give you gifts if you go to do the surgery because the population was so much at that time. But before 87 when [my husband, child, and I] came [to the US], it was religious prohibited to do those things. You could go and buy things but they just give the privileged to use, and let's have babies. Because of the war many people died, and they want population to raise up. So at that time it was prohibited, but later when we went back home, I noticed it was okay...And everything was free, you can visit whenever you want. It was very nice at that time...All of them were available, whatever you decide. IUD didn't work for me. It was making me bleeding, things like that. But everything was available and anyone want to do anything, they can do it. I didn't like to do the surgery even though I didn't want any more babies, I wasn't agreed to do that. Also, I think they do it even for men, I don't know actually the term, to close up the tube. Many people, they did it...I think maybe the pills [were most popular], it's easier, convenient. I think they use mostly that. It's different. Some people, they really like IUDs, they put it up, they just go for checkups, and no problems, it was easy. But for some people, it was not working, even though they have it from different brands, from different countries, whatever you want...At that time, everything was available. At the beginning, I didn't know because I was [in the US]. I thought I would have to go to a private doctor and ask permission to get these things. But they came to my door, gave us the address of the clinic, they do these services, they introduce what they do, and they do everything. (Interview, female participant, November 2016).

In this account, the participant describes a clear reversal in policy and the resulting changes in broad service availability, which in her understanding is directly connected to population concerns. However, unlike various other countries with intensive population programs, there is also a lack of evidence for coercion in family planning. As a young doctor who practiced in a conservative, rural area noted, "I never experienced any pressure to use a certain method. I never experienced any pressure, like, even

51 Difficulties encountered by unmarried couples are discussed in more detail below. 
I've never heard of anything like that. Using any method or even putting pressure to use methods. So, everybody was free to use it or not to use it" (Interview, male doctor, August 2016). Similarly, although the women quoted above describes incentives for sterilization programs and the practice of sending health workers door-to-door to spread information about available services, she also captures the interviewees' prevailing sense that women are free to do 'whatever they decide'. Across the board, female interview participants agreed that the government seeks to influence childbearing decisions—mostly with the goal of reaching population targets—but none of these women described direct patient pressure. Rather, they commonly describe the financial and social incentives and types of government-sponsored media campaigns outlined here, or the discussion of population concerns in required university courses on 'family management' and mandatory premarital counseling sessions on family planning. In general, women agree that individuals ultimately make childbearing decisions based on their own preferences, not government policy, but that incentive structures, family size norms promoted by the government, and the overall economic condition of the country have an impact on this decision. Therefore, street-level perceptions of family planning services highlight the importance of population concerns in motivating government action, but also confirm that these concerns have resulted in widely accessible, comprehensive, and voluntary family planning services.

Beyond the measures described above, understanding government success in implementing family planning programs requires mention of one additional development. Although the government took responsibility for establishing family planning programs, the provision of services was aided by collaborative efforts with international partners. In 1993, Iran partnered with the World Bank in a $\$ 294$ million project — where half of the money was provided by Iran and the other half was loaned by the World Bank — to provide family planning supplies and training (World Bank 1993). This program ran until 2001, and was specifically intended to "(i) improve health conditions in rural areas where health conditions were particularly poor and existing health services relatively inadequate, and (ii) 
reduce population growth in the country. To support these general objectives the project would contribute by improving the quality and coverage of health care and family planning services" (World Bank 2002). Thus, we see a relationship forged with the international community dually grounded in population and health concerns. Similarly, in 1994, UNFPA distributed \$10.4 million to Iran for “(a) carrying out maternal and child health and family planning $(\mathrm{MCH} / \mathrm{FP})$ activities in peri-urban and hard-to-reach areas; (b) enhancing population awareness through incorporation of population education into formal and informal education systems; (c) strengthening the institutional capacity of government agencies by developing human resources; and (d) integrating women's concerns into all population and development policies and programmes" (UNFPA 1998). Here, we see a greater diversity of priorities, which include a population and health focus, but also explicitly includes concern for development and women's welfare. Finally, in 1995, Iran developed a relationship with the IPPF and set up the Family Health Association (FHA) as an IPPF affiliate designed to "complement well-established services provided by the government." 52 A former FHA manager described the political climate around the creation of the organization and its early functions, stating:

What happened, the space was a bit more open in Iran [in the 1990s]. It was now 15-20 years after the revolution and a reformer president is in place, so civil society started to grow. And the most innocent area for civil society to start to grow and mushroom around is health. So, a group of like-minded people came together and established the Family Planning Association of Iran [the FHA], which is affiliated or associated with the IPPF. This was to address issues around family planning and sexual, reproductive health that are not covered by the public sector, and at the same time the idea was to link Iran to the international community through - including the family planning sector-through the health sector. So that's how it started...I worked for the Family Planning Association and our role was mainly focusing on elements that are not focused on in the public sector, such as adolescent sexual and reproductive health, STD and HIV, which was very much a sensitive area. So what we did-in addition to the policy briefs and dialogs and annual conferences and committees and things like that - we also started something that picked up very rapidly and was welcome and very popular, actually we reached the 14th or 15th edition, we developed self-learning material. And this picked up very fast after a couple years of sexuality education. It was basic information for different age groups, so we planned something for primary school and middle school, and something for parents, something for young adults, and different age groups' self-learning material. The initiatives were to get youth participation and engagement. It was an innocent topic for expanding the use of participation and youth involvement within the policy setting.

52 See http://www.ippf.org/about-us/member-associations/iran. 
We arranged meetings with the youth and policymakers to exchange ideas on family planning, and usually it goes beyond that. (Interview, male doctor, April 2016).

Here, the doctor is describing a partnership that was strategically built around health issues, both because these issues were a ready area for international collaboration and because domestically, these issues were less politically sensitive. As a result, the activities described here have a broad health focus and tie into the IPPF's shifting strategy that is more focused on health than population at the end of the 1990s (see Chapter 4). Greater insight into Iran's particular priorities as reflected in the framing of family planning — and how those priorities are articulated in Iran's collaboration with the international movement - is established through the coding and analysis of archival material below.

Although the government's official family planning policy changed to reflect the needs of a more advanced family planning structure, we see very little difference in framing tactics between 1989 and 1995. As Figure 6.2 shows, first generation framing still accounts for about $85 \%$ of total frame use, which is a slight increase from 1989. Here, development framing accounts for this increase, while women's, health, and population framing all decrease very slightly. However, overall framing change in the Second Development Plan is minimal and suggests that population and development concerns continue to motivate the government's commitment to family planning.

The 1994 MOHME report on the status of family planning shows a similarly high reliance on first generation frames, with these accounting for about $75 \%$ of total frame use. However, as illustrated in Figure 6.6, the report also employs a more diverse selection of frames, including use of environmental, Islamic, and nationalist frames. By contrast, use of first generation frames in the 1998 MOHME report is sharply reduced, with first generation frames accounting for less than half of total frame usage. Here, health has become the most widely used frame, accounting for nearly $40 \%$ of total framing, and women's and rights frames increase slightly. Thus, it appears that MOHME framing is slowly following the same trend as the international movement, although at a noticeably delayed rate. In the early 1990s, when the international movement's shift to second generation frames is more fully 
underway, Iran's commitment to these framing strategies is still high; however, by the end of the 1990s, more harmonization — and a decrease in nationalist frames - is evident within the government health sector. Moreover, as the account above details, this greater harmonization coincides with the post-1994 increase in collaboration with the international community.

With regard to the domestic media, coverage of family planning issues increases in the 1990s, with about 40 articles appearing in the FBIS or Tehran Times between 1990 and 1999. Importantly, Iran's participation in the 1994 ICPD was also widely covered in the domestic media, with 14 stories dedicated to the topic; however, the majority of these stories do not directly mention family planning and are therefore not included in the media analysis. Rather, they are discussed separately within the broader discussion of the decade's ICPDs below. As Figure 6.3 shows, the early 1990s are marked by a downward trend in the use of first generation frames. The highest peak in second generation frame use, which reaches about $80 \%$ in 1994, reflects coding of only 2 articles. Nevertheless, these articles are distinct in their use of broader framing strategies, an omission of development frames, a more pervasive focus on health framing, and greater reliance on Iran's more unique framing tactics. Closer examination of these articles reveals that they are more overt in their inclusion of the framing language being promoted by the international movement, while also retaining a distinctive perspective. For example, consider the following excerpt:

Ever since the conference was inaugurated, Iran and some other Islamic countries have sought to advocate the profound Islamic viewpoint with regard to family planning, individual rights, and women's rights in particular, based on an international, wise, effective, and judicious perspective in supporting the family and women. (FBIS-NES-94-177, 82).

Here, very direct inclusion of second generation framing - including the first rights frames identified in this venue-is combined with a clear effort to show both that Iranian and Islamic stakeholders have been at the forefront of promoting these values and that there is an explicit desire harmonize domestic priorities with international ones. However, after the 1994 ICPD, first generation framing increases again. Although these frames do not dominate the dialogue to the same extent that they did in the late 
1980 s and early 1990s, they hover between about 30\% to $60 \%$ of total frame use. Thus, first generation framing in the media clearly decreases from the program's earliest days, but does not become insignificant.

In the Friday Prayers during the early 1990s, family planning is mentioned twice. Both of these occasions occur in 1994, around the time of the ICPD, which is also referenced in the sermons. In the first sermon, given in August, the focus is entirely on population, with the imam asserting that "sociologists deem the current situation and the world conditions to be dangerous. They believe the rate of population growth is catastrophic and the future is bleak. In view of this, the problem of birth control must be pursued with greater care" (FBIS-NES-94-167, 58). In the second sermon in December, population is again a central frame, accounting for just over half of total frame use. However, in this sermon, the difference is that population problems and birth control are discussed as an important issue for imams to address, and thus includes more Islamic framing. Nevertheless, in this venue, the primary frame motivating family planning dialogues is population.

At the UN in 1994, the statement from Iran is brief_-just under 200 words — and is focused on designating a role for Islam in the management of health and development concerns. Thus, although with $45 \%$ coverage development frames are the most prominent, the short statement is fairly balanced between health, Islamic, and development frames. The effort to demonstrate the importance of the Islamic perspective in family planning is even more evident in ICPD chief delegate Taskhiri's international statements. As the coding represented in Figure 6.1 shows, the statements incorporate a wide range of framing strategies. Moreover, if we eliminate Islamic and nationalist frames, the framing distribution looks fairly similar to that of the general UN report in 1994, albeit with a somewhat higher reliance on first generation frames - about $70 \%$ versus about $50 \%$. Nevertheless, when all frames are included, Islamic frames account for about half of all frames employed. Therefore, the importance of engaging with internationally salient frames while simultaneously stressing the Islamic perspective in 
Iran's international advocacy is clearly demonstrated here. By comparison, domestic Iranian coverage of the 1994 ICPD, illustrated in Figure 6.4, shows a slightly different framing strategy. Again, without the nationalist and Islamic frames, the framing distribution of ICPD domestic coverage looks quite similar to the international distribution. However, there is a significant increase in the use of nationalist frames, from less than $10 \%$ in the internationally disseminated statements to about $25 \%$ in the domestic coverage. On one hand, the domestic media is highly critical of the West's perceived agenda and communicates the need to mount opposition to international incursions. For example, the Tehran-based Jombouri-e Eslami newspaper noted that,

In a surprising move, the United States has threatened that every country which opposes the proposed ICPD resolution and the proposals incorporated in it based on unbridled sexual freedom, freedom to abort fetuses, and freedom to indulge in homosexual behavior will be deprived of U.S. economic assistance. This U.S. threat is precisely aimed at the Islamic and Third World countries, who will probably display the most serious and principled opposition in this regard. (FBIS-NES-94-168, 56).

At the same time, coverage emphasizes the importance of outward engagement, with sentiments like the following: "In some international gatherings many issues would be figured out for many countries of the world, President Rafsanjani said and stressed Iran's failure in having an active presence in such meetings would be to its disadvantage" (FBIS-NES-94-178, 34). Thus, we see a clear distinction between media framing strategies depending on venue. In domestic coverage, participation in the ICPD is largely framed as a way to assert Iran's views in the international arena and to help ensure that the national interests are protected from outside forces. In international statements, however, most of this nationalist rhetoric is replaced with a more conciliatory approach that emphasizes the compatibility and importance of the Islamic perspective. Although the majority of the framing distribution stays the same, the most controversial nationalist framing language is visibly moderated in the international context.

At the 1999 UN meeting, Iran issued a much longer (1816 words) and more detailed statement. Although by 1999 first generation framing is much diminished in UN reports, the Iranian statement 
still relies heavily on these frames, with nearly $70 \%$ of frame coverage split between population and development. Thus, at the end of the 1990s, first generation frames remain an important part of Iranian activity on the world stage, and although the level of second generation frame use is not insignificant, Iran is clearly not making a shift to reliance on these frames as the same rate as the international community.

Overall, although decreases in some venues can be detected, for example in some media coverage and in the MOHME reports, population and development continue to be a central component of framing strategies, and these frames generally appear with more frequency than they do in the international movement.

\section{Equilibrium in Family Planning in the 2000s}

While the 1990s were characterized by increased advocacy and rapid service expansion, family planning programming in the 2000s reached an equilibrium point in terms of policy and program development. Programs continued to run under the direction of MOHME and policymakers did not incorporate changes to the existing policy into subsequent Five Year Development Plans. In general, interview participants suggest that increases in the method mix and emphasis on education were the primary changes of the decade. A current MOHME program director described the government's more recent priorities as follows:

So actually one of our programs was for increasing the quality of the service provision to the client through the improvement of the counseling, so we worked on it for about 13 years in the counseling area...And also in the program development, of course, [we have worked on] service development in the different categories you can think about, for example: providing guidelines, developing guidelines and tools and forums, service provision and increasing the availability of the contraceptives - working on the quality of the contraceptives inside the country and outside of the country. (Interview, male doctor, May 2016).

As far as actual services go, participants confirm efforts to increase contraceptive options, noting that "when time passes we have more options, because there were more options available scientifically" (Interview, female participant, November 2016). In addition, an interview with a doctor who practiced 
from 2006 to 2009 in one of Iran's poorest regions highlights the functioning of MOHME's outreach and education program even in remote, less-developed, and religiously conservative areas. As he asserted,

One of the very important, at that period of time-I should insist I don't know if it's like that anymore-one of the very important programs was the family planning program...Each of the women of reproductive age has a profile in the health house. So they know everybody, they have a list. They should go to them, like practically, they should go to them and talk to them. And ask them if they want more children or not, and if they have a newborn, they should consult and tell them that you have to space and use the methods. And they give them a proper contraceptive method. And most of the time, there's no complication, but if they have a problem they should consult the midwife of the health center or the doctor. So this is how it works there. So the doctor and midwife usually supervise the health workers to see how many women they have, how many are using contraceptive methods, how many are not using, is there any reason for those who are not using, are they going to have more kids, or like, these things... [The methods women choose are] really different from area to area, from province to province. So in the place I used to work it was a majority of Sunni Muslim. Sunni imams and Sunni religious leaders comply with family planning as long as it is not really permanent, like sterilization. And also so long as it is not really long acting...However, in that area, injection was one of the most popular ones. Condoms. And IUD and sterilization were not so popular...Supplies are free. The government provides supplies and they are free for everybody. And they provide even the same brands everywhere. (Interview, male doctor, August 2016).

Thus, evidence points to the government's continued commitment to broad service provision and suggests that by the 2010, family planning services and counseling are easily available in even very remote areas.

However, as coverage and options continue to increase in the early 2000s, it is important to note an important population left out of public family planning programming — that is, unmarried men and women, and adolescents in particular. Premarital sex is not permitted in Iran, which, domestically, leads to an official policy that reserves services only for married couples. In the international arena, Iran challenges the international movement's understanding that service access should not depend on marital status. For example, in its 1994 ICPD statement, Iran notes that, "there are some expressions that could be interpreted as applying to sexual relations outside the framework of marriage, and this is totally unacceptable. The use of the expression 'individuals and couples' and the contents of principle 8 demonstrate this point. We have reservations regarding all such references in the document" (UN 
1995a, np). Nevertheless, this position does not inhibit Iran's ratification of the ICPD agenda, nor its continued collaboration with the international community. For its part, the international community does not change its stated programmatic focus; however, there is some evidence of accommodation in the international community's work in Iran. In a follow-up email to the doctor who worked with the IPPF in the 1990s and 2000s, I asked how international NGOs negotiated the boundaries between marriage and service provision in Iran. Although his recollection was not precise, he noted that "if I am not mistaken, the provision of services was only limited to married women in the past" (Email from male doctor, January 2017). Thus, disagreement on this point may have been overcome by the international community's willingness to tailor its usual focus and work within Iran's parameters in domestic program development.

Of course, an official focus on marriage and the limitation on domestic programming does not mean that unmarried couples are not obtaining contraception. One interview participant noted the availability of black market contraceptives. Another described a more nuanced situation, stating:

If you are not married, it would be very hard to-so you can always buy pills or condoms in the pharmacy, you don't even need a prescription, ${ }^{53}$ because these kinds of things are really cheap in Iran. But if, let's say you get pregnant or whatever, having an abortion if you are not married would be really difficult. And if a doctor does that, it's actually against the law, so there are some doctors that do that but it would cost you a lot of money... A lot of people actually [start contraception] by themselves, so they don't even go to the doctor...not most people maybe, but in Tehran, a lot of people are having premarital sex. So a lot of doctors are I think trying to provide them with whatever they need, even if they aren't married. Unless they're pregnant, there is nothing against the law to provide those services. I think it's getting better, more information out there. But with the internet, a lot of people can do a lot of searches by themselves even if they don't want to go to a doctor. (Interview, female participant, October 2016).

Several women described similar increases in the social permissibility of premarital sex and the patchwork means that these couples use to prevent pregnancy. However, individuals who are unable to overcome the social, educational, or logistical barriers to contraceptive access fall through the

53 Birth control pills are available for purchase without prescription in Iranian pharmacies. In rural areas without pharmacies, they are obtained instead through public health clinics, where access is free. See below for more detail. 
cracks. This situation is exacerbated by a public sex education system that focuses on universalizing family planning education in premarital counseling sessions and university-level course requirements, but that overlooks adolescent populations. As a result, one woman noted "there have been many cases where unmarried pregnant girls have committed suicide, usually by throwing themselves off a building" (interview, female participant, October 2016). Therefore, there are actually two different systems for obtaining family planning operating during this decade-one, a comprehensive, well-funded, and wide-reaching public system for married couples, and the other, an under-the-table and disjointed selection of services for unmarried couples.

With regard to the framing of these programs, less policy activity and innovation leads to the production of few documents available for analysis. However, insights can be drawn from discussion of family planning that continued in the media, sermons, and state official activities.

As shown in Figure 6.3, media coverage in the 2000s varies in terms of the proportion of first and second generation frame use. In the first half of the decade, first generation frame use rises slowly from about $45 \%$ in 2000 to about $65 \%$ of total frame use in $2006 .{ }^{54}$ Overt connections between family planning and population growth are easy to identify in this period; for example, in one article's report that "the representative of the United Nations Population Fund (UNFPA) in Iran, Mohammad Mosleheddin, said, 'The baby boom is endangering Iran since Iran is a young country.' He noted that Iran's family planning program has been successful in reducing the birthrate, adding that Iran is a model for other developing countries" (Tehran Times 2002, July 13). Although in the 2000s the international movement continues to move away from population frames, this example shows continued emphasis on the frame by an Iranian official who works closely with the international

\footnotetext{
54 The anomalous data point in 2004 reflects a lack of data availability, rather than a radical departure from normal framing activity. As mentioned, FBIS articles are unavailable from July to December 2004. Thus, the sample size for this year is 1 article. Unlike the majority of news articles, which focus on the status of Iranian family planning, this article is an interview with a religious scholar, who mentions family planning only in passing as part of a discussion about sovereignty and religious norms.
} 
community. The peak in first generation frame use in 2006 is the highest since the early 1990s, and demonstrates that, despite periodic declines, population and development continue to be durable and salient framing strategies in the popular discourse. Although there is a fairly sharp increase in second generation frames in 2010 as women's and health frames increase, it is difficult to predict whether this is the beginning of a decreasing commitment to population and development frames in the media, or whether this represents just another temporary oscillation toward increased second generation frame use. Thus, although they are on the decline at the end of the decade, first generation frame use is still very present in the media analyzed here.

Similarly, the statements from governmental officials analyzed in the IRPD report, shown in Figure 6.6, also demonstrates a continued commitment to population and development frames, which fall just below $50 \%$ of total frame usage. Here, health is the single most-used frame, accounting for about $30 \%$ of frame use. Thus, state actors are certainly not ignoring this rationale in support of family planning, yet first generation frames still occupy a prominent place in the dialogue. However, this report also ties these frames to international goals. For example, the document states:

ICPD achieved unprecedented consensus on population and development principles, objectives and actions. Among other things, it stressed the importance of individual welfare and the need to invest in people as a basis for improved human welfare and sustainable development. The Islamic Republic of Iran has had significant success in achieving the goals of ICPD Program of Action. Impressive achievements in some worth mentioning indicators are the reductions in the population growth rate, infant and maternal mortality rates, total fertility rate and increase in the contraceptive prevalence rate, primary school enrolment rate and literacy rate. (IRPD and Mehryar 2001).

So despite a heavy reliance on frames that are decreasing in the international movement, the officials quoted here are also clearly signaling their cooperation with international movement objectives.

With regard to the Friday Prayers, like sermons in previous decades, the sermon issued in 2000 omits any use of second generation frames. Rather, as the coding in Figure 6.5 illustrates, the imam ties use of birth control to population size and national strength. Although reference to family planning in the Friday Prayers is found briefly in only one sermon at the beginning of the decade, this reference 
gives some evidence that conceptualization of family planning in this venue is not moving toward advocacy grounded in women, health, or rights framing.

Finally, an additional argument in support of the continued linking of family planning with population initiatives comes from policy changes implemented after 2010, beyond the time frame analyzed throughout this dissertation. Although full extension of the analysis of family planning frames into the next decade is beyond the scope of this project, these dynamics warrant some brief attention here.

In 2014, Ayatollah Khamenei issued a new policy position on population, which promoted several initiatives "with the purpose of making up for population decreases in recent years" (Khamenei 2014). Indeed, in the 2000s, Iran's TFR slowly dropped below replacement-level, or about 2.3 children per woman, which could lead to negative population growth in future decades (See Figure 6.7). As a result, Khamenei's position statement focuses on initiatives to support families with more children. However, there is no mention of changes to family planning programs. Nevertheless, this position followed several years of governmental concern over the problems commonly faced by nations with aging, contracting populations, which the government does connect to family planning. This linkage is evident even by the end of 2010; for example, one article captured in the media analysis notes that:

Ahmadinejad had previously spoken against the family planning and called for an increase in Iran's population from 70 to 120 million. 'I am against saying that two children are enough. Our country has a lot of capacity for many children to grow in it. Westerners have problems. Because their population growth is negative, they are worried and fear that if our population increases, we will triumph over them,' he said. (Tehran Times 2010, December 30).

Here, we see the revitalization of nationalist frames in conjunction with changing ideas about the role of family planning and the need for population control. As a result, there have been changes to family planning services since 2010. In a piece published in The Lancet, a MOHME official explicitly makes the connection between low population growth and changes to family planning services:

Despite Iran's successful family planning and population control policies, serious concerns now exist that Iran has overshot the target, which has led to a total fertility rate of 1.92 -less 
than the replacement fertility level 2.3. Such a low population growth rate and demographic transition, and their potential socioeconomic consequences have driven the shift in policies. Moreover, access to contraception and permanent sterilisation is not banned completely. Most contraceptive methods are still available in pharmacies, and condoms are sold in supermarkets. Access to all contraceptives remains free for vulnerable populations through service-providing centers (eg, drop-in centers). The main restriction and penalty is on surgical sterilisation, which is still accessible under some circumstances. (Karamouzian and Haghdoost 2015).

A MOHME official I interviewed gave a more nuanced description of the changes in policy and stressed that although the government is easing away from the universal provision of free contraception, commitment to family planning, health, and women's welfare is still high, and access

will not be compromised. In general, he stressed that achieving improved health outcomes will still be prioritized within the new policy, even as the government seeks to nudge the total fertility rate (TFR) a bit higher. As he describes:

You know that in the last 3 to 4 years we had a change in our population policy. But it is very important to look at, even in the new population policy, it is said that we should improve reproductive health and childbearing situations in the country. And we also have another 5 items in the population policy which address the health issues. So I think, to the population policy, there are a lot of principals that help to improve the health of all of the people, especially mother and child. So, right now, the reducing of the births of children in the country is not a priority, because the total fertility rate in the country is about 1.9, it is below replacement level. So the first principle in the population policy is to achieve 2.1 -we should achieve the replacement level for our TFR. But that doesn't mean that we should not provide services to the people who in the case of pregnancy, their health, or the children's health, is in danger. We are continuing to provide the free services of contraceptives to the people whose pregnancy could be at risk for them or for their children or for their newborn. So the free services will continue for them and it is established completely in the last 2 or 3 years. Or even if we have tubal ligation for the people who will in the case of pregnancy will be very high risk; it is again free of charge. For the other people, they have access to the information and they have access to different types of contraceptives. The price of the contraceptives is too low [sic]. ${ }^{55}$ For example, the price for one pack of low dose pills is about 16 cents. It is cheaper than 1 bread. So, it affordable for the people to pay for the contraceptives because they are too cheap. And also they have access to the information. So, we don't continue the free services of the contraceptives to all people, as I mentioned, we continued free services for the people that are at risk, but for the other people the services are affordable and accessible. The counseling is again, free, they shouldn't pay for the counseling, but if they want the contraceptives, they should pay and it is cheap and affordable. It is very important, I want to emphasize, that the new population policy in Iran is not to push people to have more children. (Interview, male doctor, May 2016)

Thus, it is clear that population concerns are behind the new shift, but that the health rationale for

55 The verbal tone in this statement suggests that the participant wishes to stress that prices are 'very low', not that he believes that prices are lower than they should be. 
family planning is also important. This official perspective that the new population policy and resulting changes in services provision do not affect access is supported by the testimonies of the women I interviewed. When asked directly about changes to family planning services over time, women do not mention problems with access. Of these women, 8 came to the US after 2010, and although there are some differences in how they describe the provision of services-those from rural areas talk about free clinics while those from urban areas talk about the ease of purchasing pills at the pharmacy, for example-there is no sense that contraception is difficult to obtain. Instead, the answer to this question almost always involves a discussion of changes in government promotion of population growth. As one woman from a small city commented,

In our country, our government at first they announced you have to have 2 kids. Like China, you know? And if you have 4 kids they stop the benefits, or something like that. But now when the government change, they encourage people to have more kids. I don't know what happened with that, but they announced that you don't prevent pregnancy, or something like that, and encourage people to have babies on advertisements. It's changed during the time, but before, yeah, the government announced that for the 4th child, you don't get insurance or something like that. But now it's changed. (Interview, female participant, November 2016).

Government advertising of ideal family sizes is a recurrent theme, and the association of family planning with population policy is evident these women's statements. Overall, population is still very important to the regime, and its original connection with family planning has never been erased either in state decision making or in public perceptions. Although family planning is a key component of the larger health system, and the connection to women's empowerment is also recognized, these frames have not become fully entrenched, and family planning policy is still influenced by fluctuations in the desire for population control. Whether this connection will ultimately affect future service access remains to be seen.

\section{Tracing Family Planning Frames}

Although the use of second generation frames is not insignificant in Iranian family planning, and has grown since the earliest days of the program, it is clear that this movement has been built primarily 
around population framing strategies. With regard to how this frame dominance influences interactions with the international movement, it is important to remember that population and development frames were once the most salient frames in this arena as well. Although they have been slowly replaced with women's, health, and rights frames, population and development framing strategies still appear in the media and NGO sector until at least 2010. Thus, although these are not the international movement's preferred frames, they are frames that the international movement still recognizes. This recognition may help explain both why international collaboration with Iran has found common ground on population issues and why Iran has not shifted to second generation frames. Moreover, this finding is in keeping with my theoretical predictions, articulated in my second hypothesis, that an institutionalized movement—like the international family planning movement in the 1990s and 2000s_ — will tolerate divergent framing strategies in dissenting regimes. Given both the international movement's institutionalization and familiarity with these frames, Iran has not been forced to change its framing language in order to obtain support. The following section builds on the foundation laid in the preceding frame analysis in order to parse the dynamics of the relationship built with the international movement and to gain a fuller understanding of the process of frame convergence, as it can be applied to this case. Figure 6.8 provides a visualization of the broader trends evident in this relationship.

When attention to family planning emerges in Iran in the 1980s as a response to population concerns, the international movement is still often constructing family planning as means for addressing population growth as well. Thus, although sectors within the international movement are beginning shift to second generation frames, there is little tension with regard to the heavy use of first generation frames in this decade. As a result, it is not surprising that Iran's 1989 meeting with UNFPA centers on population problems, and the relationship grows from this common concern. The analysis shows that relationships with international organizations continue to have a strong population 
component in the $1990 \mathrm{~s}$, but that health and women's welfare framing is also incorporated into program charters. Here, it is important to recognize that although population and development are the dominant frames used in policy and advocacy to support family planning in Iran, there is no objection to the use of second generation frames. Population is the primary motivation behind the development of family planning, but Iran is also comfortable with the understanding of family planning as a health, women's, and rights-based issue, as long as it occurs within the context of marriage. Therefore, even as the international movement begins to shift toward more second generation frame use and to incorporate this into program language, there is still little tension in framing strategies.

Rather, the more intricate strategizing occurs in Iran's use of Islamic and nationalist frames. Domestically, religious leaders, MOHME, and the media employ Islamic frames to promote family planning, but use of these frames tends to be low across venues. As the previously cited doctor suggests, this may be because, after the fatwa, public controversy about the ability of family planning to support Islamic values is low. Moreover, in terms of actually promoting family planning use (or non-use), development planners recognize that religious values are a weak motivator. As that same doctor notes:

In my current work, I emphasize that in any part of the world, no matter what the religion is, they don't make the fertility decisions based on faith. We know that. If you look at the whole context, the reason for not using contraceptives, when we ask them, the last one is the religious aspect...Religion has nothing to do in the bedroom of the people, they make their decisions based on something else. It was the case in Iran" (interview, male doctor, April 2016).

Thus, recognizing that family planning is compatible with Islam is important for the legitimacy of the program, but domestic advocacy tends to stress other concerns more heavily. However, at the international level, this frame becomes more politicized as Iran seeks a niche area for leadership in the international area. At the 1994 ICPD, emphasizing the ability of the Islamic perspective to enhance commitment to other internationally salient goals—such as the promotion of health, reproductive rights, and women's welfare-is a central component of Iran's advocacy strategy. Here, the chief 
delegate notes that "the Iranian delegation insisted on participating in the ICPD to defend Islam", while at the same time advancing areas of agreement, such as the "the emphasis on women's role in political and social decisionmaking" (FBIS-NES-94-181-S, 25; 38). Thus, we see more use of the Islamic frame here than in any other venue, where it is employed to demonstrate the validity and compatibility of Islamic values in family planning. In addition, conference reporting provides evidence of how Iran politicizes this frame in order to build a more influential coalition. For example, one report relays that "Shayk Taskhiri noted that there is cooperation with the various humanity-loving nations, Islamic states, including Egypt, and the Vatican to bridge the points of weakness in the Plan of Action] document" (FBIS-NES-94-181-S, 38). Indeed, the Vatican is the only other participant that voices a shared concern over marital status, and there are multiple references in the data to Iran's interest in working with this important ally to shape the ICPD. Thus, a commitment to promoting religious values serves both as a key reason for participation in the conference and as a means of building a more powerful advocacy coalition. At the same time, as evidenced by a heavy reliance on the other internationally salient frames, Iran is placing the use of this frame within a broader language that the international movement recognizes and accepts. As previously noted, without Islam or nationalist frames, the frame distribution in chief delegate Taskhiri's advocacy is very similar to the framing employed by the international movement. Thus, by engaging in the global framing of the Islamic frame, Iran is not seeking to radically alter the dialogue. Instead, the strategy employed is clearly a balancing of the Islam frame with frames that resonate in the international community.

With regard to nationalist frames, there is much less evidence of efforts at global framing. In the international arena, nationalist frames appear in Taskhiri's statements, but they account for less than $10 \%$ of frame use. Internationally, Iran asserts its intention to remain free from outside domination, but this is not a primary focus. Thus, Iran relies more on promoting Islam and integrating this frame into existing international frame narratives than it does on condemning encroachments on Iranian 
independence. By contrast, in domestic coverage of the 1994 ICPD, the nationalist frame is much more prevalent and is employed by $25 \%$ of articles. Here, the media describes how both Iran's international leadership efforts and its responsible demographic policies will help to ensure that Iran is neither marginalized on the world stage nor dependent on the West for aid. Although, ordinarily, media coverage of family planning only sporadically contains nationalist frames, these frames are particularly high in the general 1994 media coverage as well. Thus, concerns about independence are clearly heightened by the events surrounding the ICPD. However, Iran's activities at the ICPD are positively framed in the domestic media and include many of the same references to Islamic leadership on family planning issues that are present in Taskhiri's international statements. Therefore, domestically, nationalist frames are widely used to promote a domestic narrative that links family planning to strong leadership and independence, while internationally Iran strategically limits their use in favor of less confrontational frames.

As the Iranian family planning movement develops in the late 1990s and 2000s, subtle shifts to second generation frames are evident, but the program maintains a close link to population. However, collaboration continues with an institutionalized international movement that is still willing to work on family planning within the context of population and development frames. In Chapter 4 it was evident, for example, that although the international movement has come to rely on second generation frames, first generation frames persist in most venues. In particular, there is evidence that not all internationally focused NGOs have moved decisively away from these framing tactics. Thus, rather than Iran shifting significantly to match with dominant trends in the international movement, we see more accommodation by international players that are still comfortable framing family planning as a population and development issue. Moreover, there is some minor evidence of accommodation on religious and independence issues as well. For example, the official 1994 ICPD Plan of Action states that "implementation of the recommendations contained in the Programme of Action is the sovereign 
right of each country, consistent with its national laws and development priorities, with full respect for the various religious and ethical values and cultural backgrounds of its people" (UN 1995b, np). In the conference reporting, Taskhiri comments that this is an inclusion that he and other nations in his coalition were pleased to see as a result of their advocacy (FBIS-NES-94-181-S, 44); however, while it is clear that the $\mathrm{UN}$ is expressing the importance of religious values and domestic sovereignty, it cannot be determined how much Iran's advocacy truly impacted the final statement. Overall, the ICPD final report and Plan of Action stop short of mentioning any special role for Islam. Therefore, we see that the institutionalized international movement is willing to accept and incorporate some divergent frames proposed by Iran in the international area, but that this incorporation results only in minor levels of convergence over time in the frames used by each movement. Despite a willingness to tolerate Iran's divergent strategies, higher degrees of harmonization have not been observed to date.

\section{CONCLUSIONS}

To conclude, I again revisit the central questions that motivate this dissertation and review the answers that can be applied from the Iran case. These are as follows:

\section{How do international and domestic actors negotiate the tension between divergent framing tactics in both domestic and international venues?}

Generally, there is no direct tension in the way Iran and the international movement utilize first and second generation frames. Despite varying levels of commitment to each set of frames over time, both sets are recognized as legitimate framing strategies by both parties, and there is no objection from either party over the other party's use of these frames. With regard to Iran's more unique frames-nationalism and Islam-tension is mitigated by strategic use of these frames. Specifically, although domestically Iran employs nationalist frames more heavily during periods of increased collaboration (i.e. during the 1994 ICPD), it restricts their use in the international arena. Instead, 
internationally, Iran focuses on balancing use of internationally salient frames with the promotion of Islamic frames. In this way, Iran is able to appeal to international norms, while also promoting its national ideology and building a religion-based advocacy coalition. For its part, the international movement shows some minimal accommodation of Islamic frames in the international area by including a nod to the importance of respecting religious values in the ICPD Plan of Action.

Does the international movement shift to accommodate these divergent frames, or do the dissenting regimes themselves conform?

In addition to accommodation of religious frames, the institutionalized international movement accommodates Iran's predominant focus on first generation frames by explicitly addressing population concerns in domestic-level programing within the country. In turn, Iran is willing to build more health-centric partnerships with the international community, as in the relationship with the IPPF, when politically expedient. However, overall, we see only minor shifts made by Iran toward the broader use of second generation frames, as in recent years, family planning programming remains closely tied to population issues.

\section{Does prolonged engagement eventually lead to frame convergence?}

In short, this case presents less evidence of frame convergence. As the international movement continues to move more firmly to the (often exclusive) use of second generation frames, Iran has reaffirmed its commitment to population frames. Within the time period analyzed here, this divergence has not impeded engagement. A strong legacy of population and development framing within the international movement has perhaps prolonged the movement's willingness to continue to recognize these frames within varying domestic contexts, as has the ability of a firmly-established institutionalized movement to absorb divergent perspectives. In Iran, family planning is recognized as an important means for improving health and promoting women's welfare, even if health policy decisions are altered depending on population goals. Thus, there has still been room for meaningful 
collaboration between these movements. However, it is possible to imagine a future where the international movement no long prioritizes work on population-focused family planning programs, particularly in a country that is decreasing its commitment to the goal of providing free, universal access to family planning. In this case, we would expect to see either Iran increasing reliance on second generation frames_and greater frame convergence-or decreased collaboration in family planning. Thus, looking forward, prospects for continued engagement may depend on how polarized each movement becomes in their use of first and second generation frames, and how Iran works to prioritize the provision of services.

The answers the analysis of the Iran case provides for these questions give a distinct view of the nature of the relationship between international advocates and dissenting regimes. Again, the regime's work to balance unique or contested frames with internationally salient frames proves key to developing international partnerships. At the same time, a willingness of the international movement to create space for domestic framing strategies is also critical. The mutual accommodation that helps to overcome diverging perspectives does not, however, necessarily lead to high levels of overall frame convergence, at least in the time period studied here. Future work should continue to examine the extent to which these cases move toward greater convergence and how this process influences inter-movement collaboration 


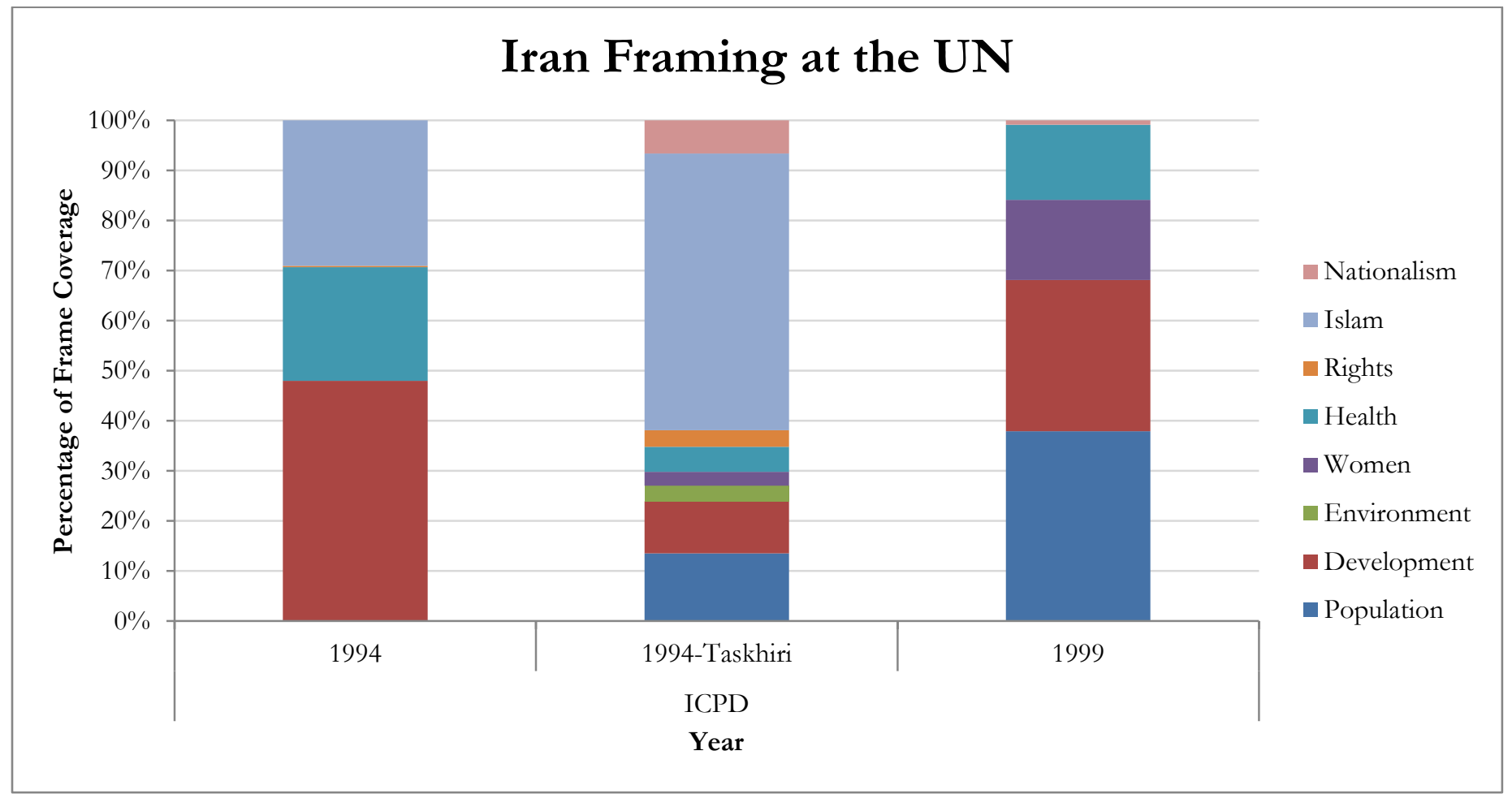

Figure 6.2

\section{Iranian Domestic Policy Framing}

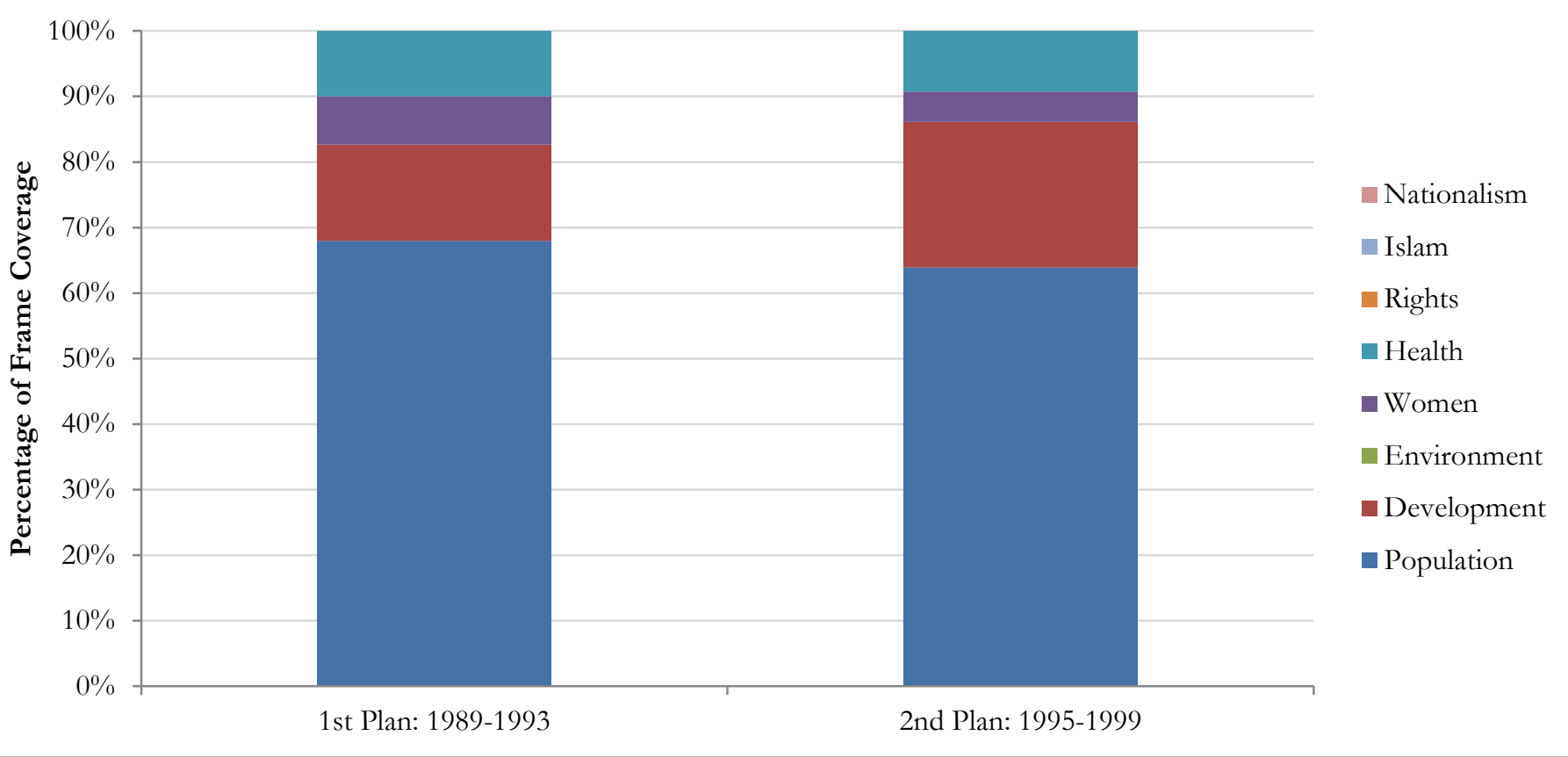




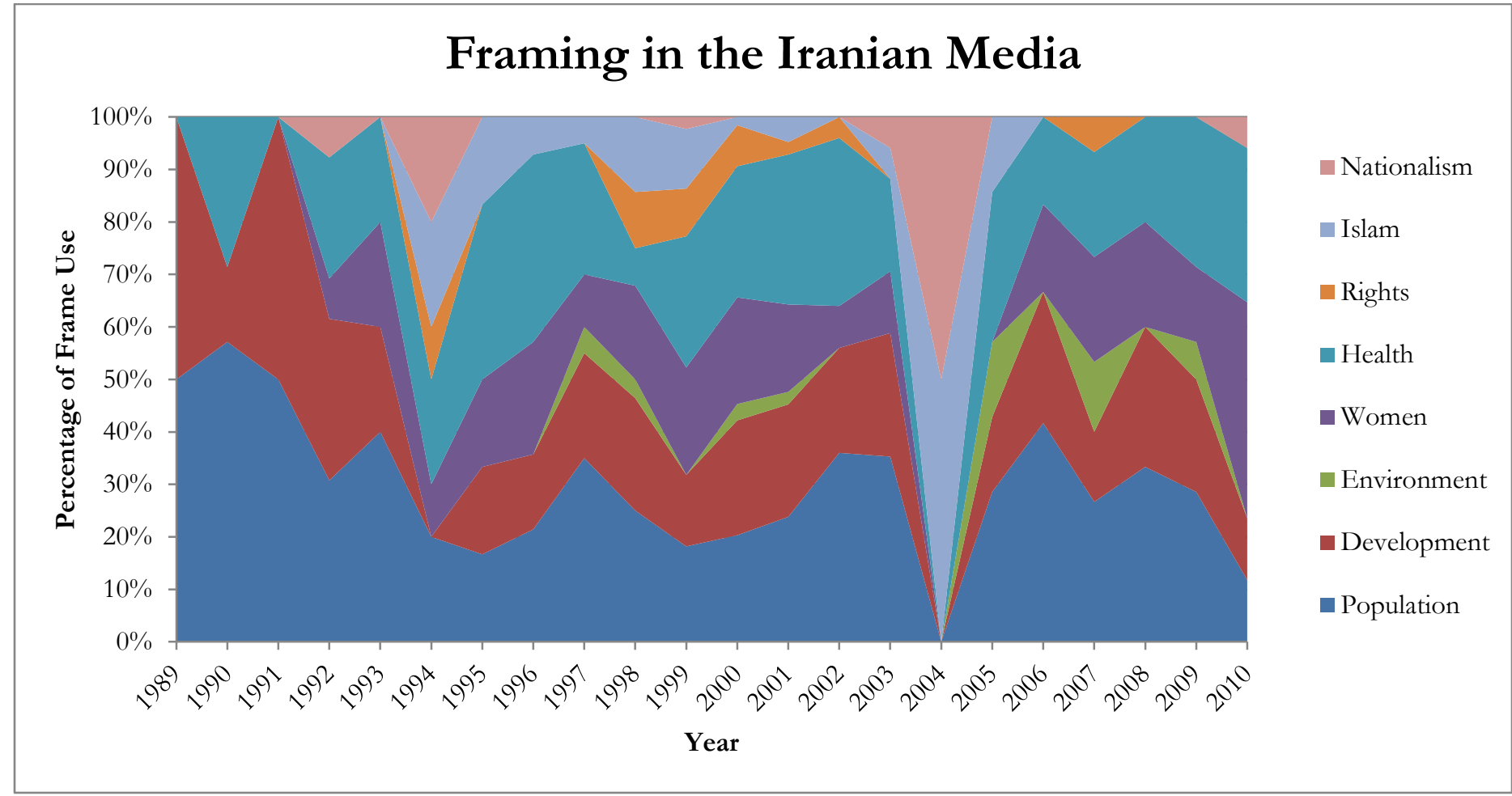

Figure 6.4

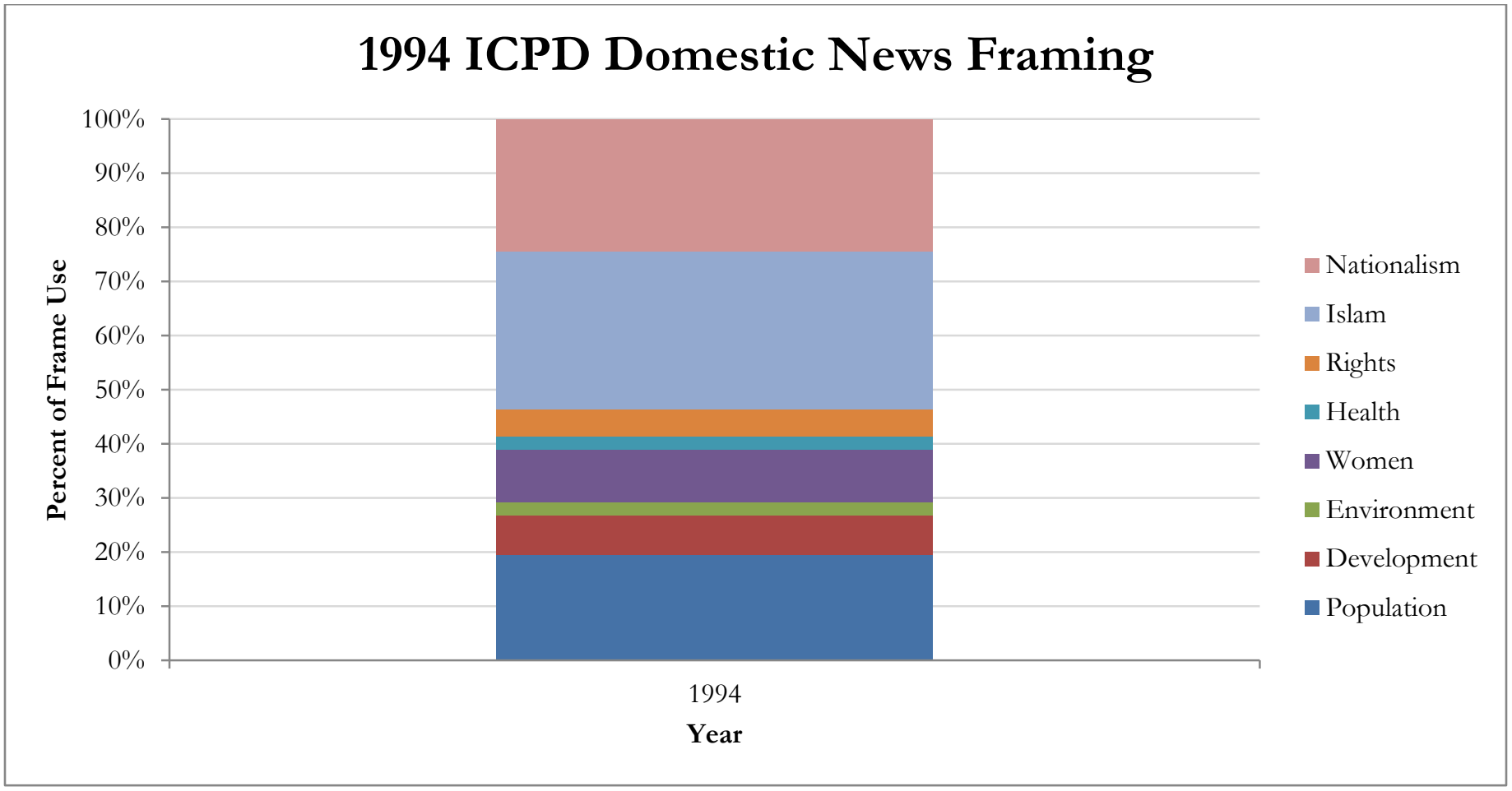




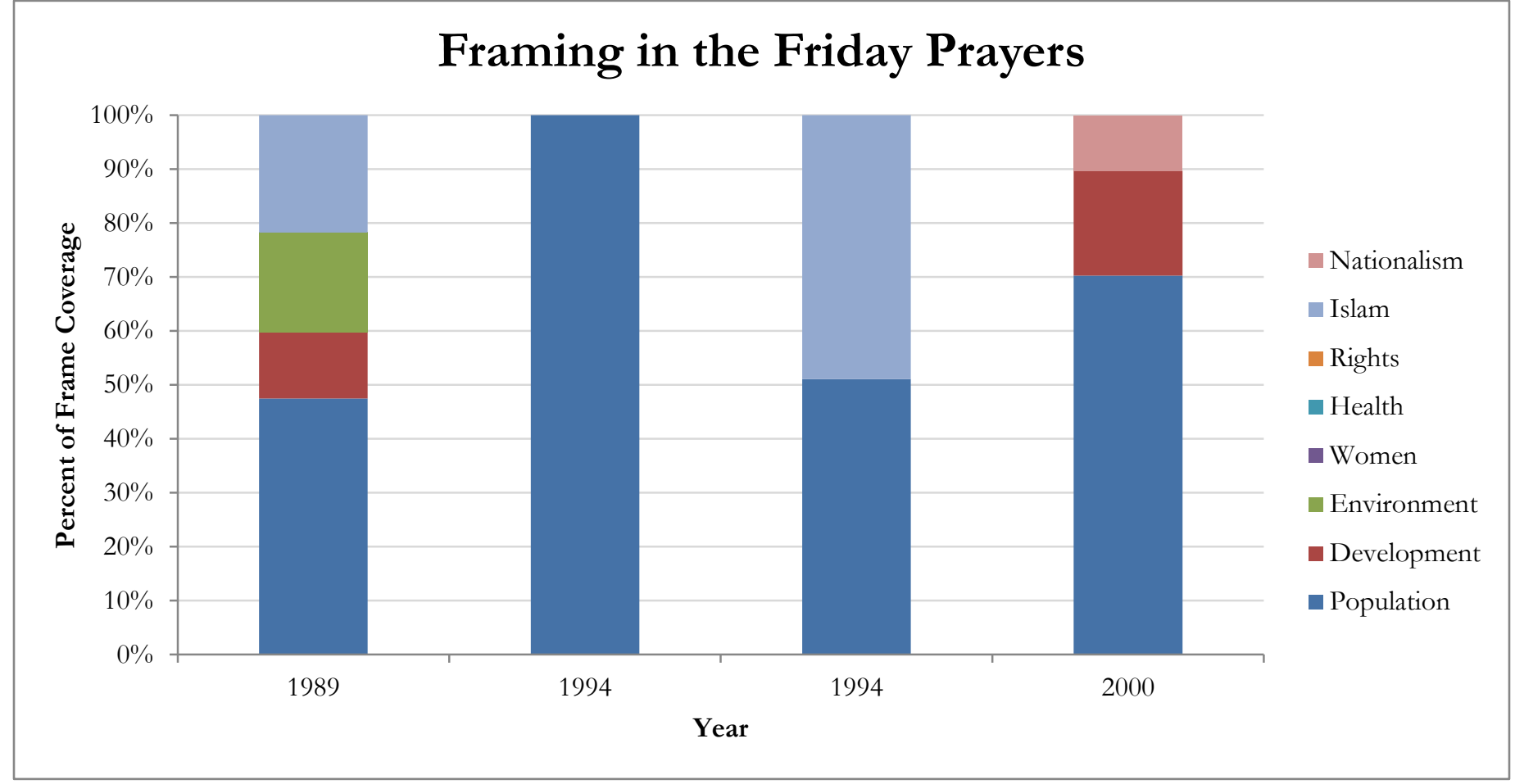

Figure 6.6

\section{MOHME and Domestic Conference Reports}

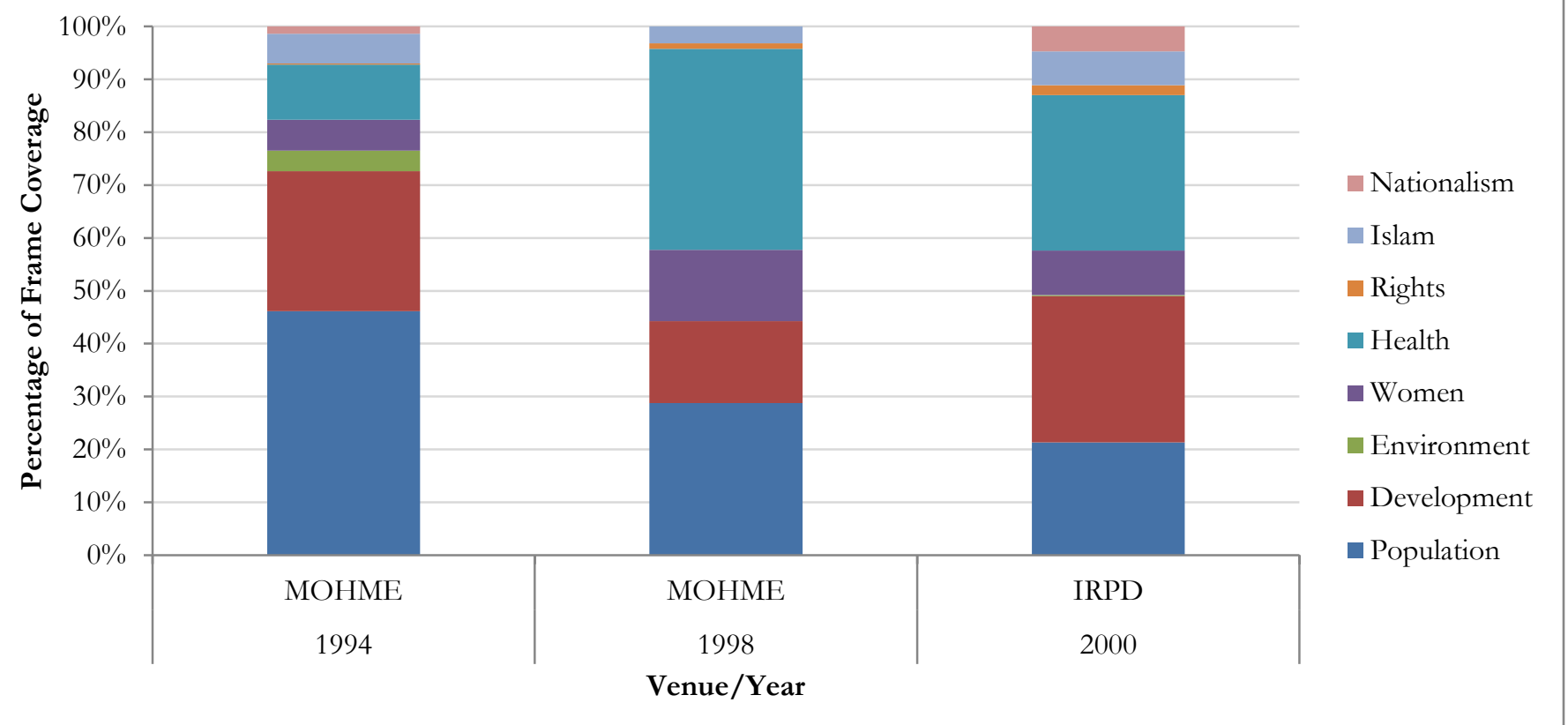




\section{Iran, Total Fertility Rate}

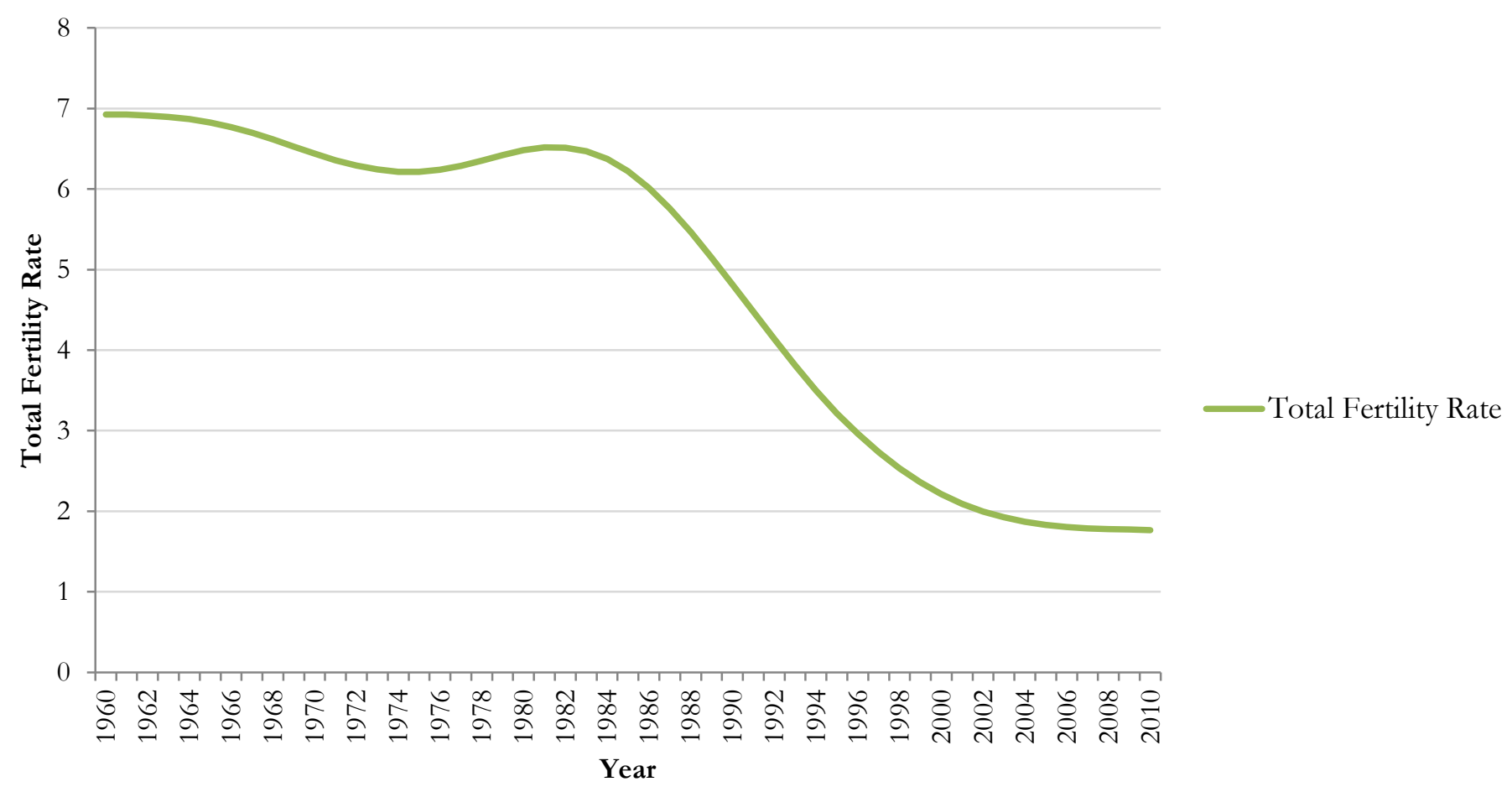




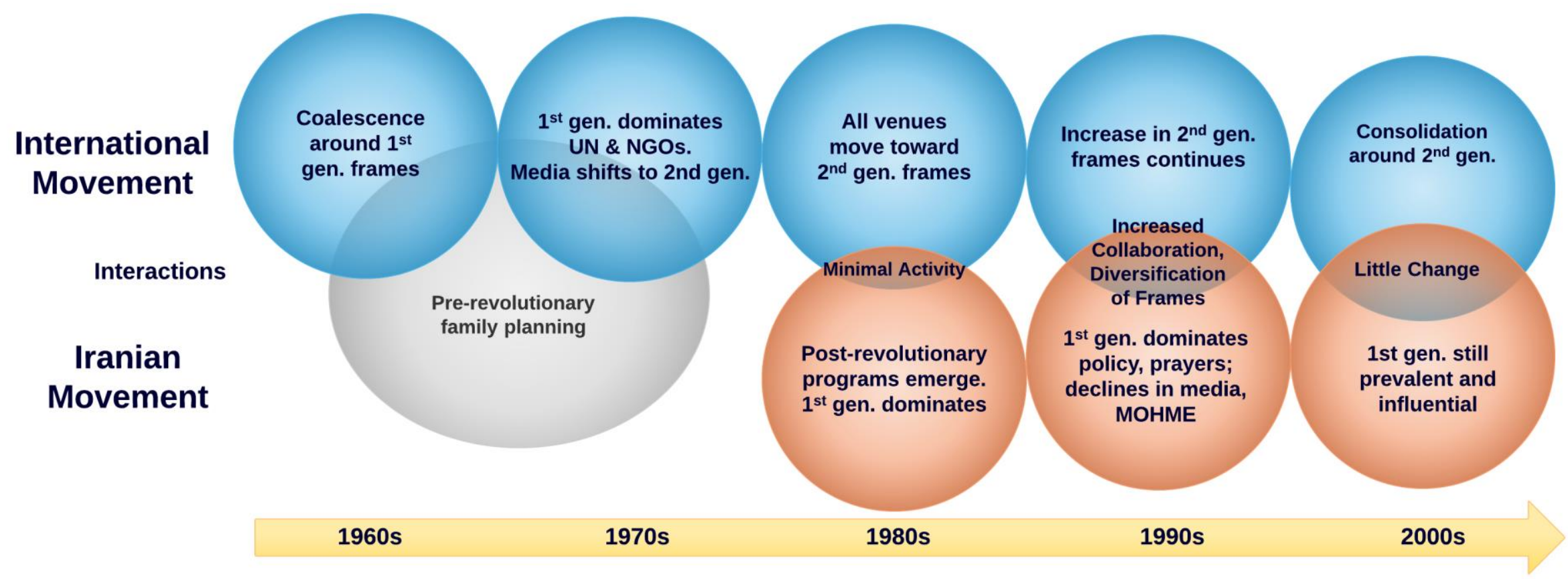




\section{References}

-- “Iran’s Family Planning Program Successful." 2002. Tehran Times. July 12. http://www.tehrantimes.com/news/84123/Iran-s-Family-Planning-Program-Successful.

-- "Ahmadinejad Says Family Planning Should Be Jettisoned." 2010. Tehran Times. December 29.http://www.tehrantimes.com/news/233170/Ahmadinejad-says-family-planning-shouldbe-jettisoned.

--“Foreign Broadcast Information Service (FBIS) Daily Reports, 1941-1996.” 2012. Readex. April 19. http://www.readex.com/content/foreign-broadcast-information-service-fbis-daily-reports-1 941-1996.

Afary, J. 2009. Sexual politics in modern Iran. Cambridge, UK: Cambridge University Press.

Foreign Broadcast Information Service (FBIS). Foreign Broadcast Information Service (FBIS) Daily Reports 1974-1996. Near East and South Asia. Washington, D.C.: FBIS.

Hoodfar, Homa. 1994. "Devices and Desires: Population Policy and Gender Roles in the Islamic Republic.” Middle East Report, no. 190(September): 11. doi:10.2307/3012460.

Hoodfar, Homa, and Samad Assadpour. 2000. The Politics of Population Policy in the Islamic Republic of Iran. Studies in Family Planning. 31 (1): 19-34.

International Workshop on Integrated Approach to Reproductive Health and Family Planning in the Islamic Republic of Iran, and Amir H. Mehryar. 2001. Integrated approach to reproductive health and family planning in the Islamic Republic of Iran: proceedings of an International Workshop held Isfahan, Iran, 31 April-13 May, 2000. Tehran, Iran: Institute for Research on Planning \& Development.

Khamenei, Ali. 2014. In“ Leader Announces General Policies on Population.” Khamenei.ir. May 20. http:/ / english.khamenei.ir/news/1911/Leader-Announces-General-Policies-on-Population.

Karamouzian, Mohammad, and Ali Akbar Haghdoost. 2015. "Population control policies in Iran". The Lancet. 385 (9973): 1071-1071.

Laursen, Andreas. 1996. "Modernity and Islamic discourse: attitudes towards modernity found in Friday prayers delivered in Tehran, 1989-1995.” Orient. 37 (4): 647-672.

Ministry of Health and Medical Education, Iran (MOHME). 1994. Iran. National Report on Population, the Islamic Republic of Iran. Tehran: Ministry of Health and Medical Education.

Moore, Robert. 2007. "Family Planning in Iran, 1960-79," in Robinson, W. C., \& Ross, J. A., (ed). The Global Family Planning Revolution: Three decades of population policies and programs. Washington, D.C: World Bank.

United Nations. 1995a. Population and Development: Programme of action adopted at the International Conference on Population and Development, Cairo, $5-13$ September 1994. New York: United Nations, Dept. for Economic and Social Information and Policy Analysis. Available at http://www.earthsummit2002.org/toolkits/women/un-doku/un-conf/population2.html

United Nations (UN). 1995b. Summary of the Programme of Action of the International Conference on Population and Development. New York: United Nations, Dept. of Public Information.

United Nations Population Fund (UNFPA). 1998. Request for Extension of and Additional Resources for the UNFPA Country Program for the Islamic Republic of Iran. DP/FPA/IRN/2/EXT1. Available at http://web.undp.org/execbrd/archives/sessions/eb/2nd-1998/DP-FPA-IRN-2-EXT1.pdf

World Bank. "Fertility Rate, Total (Births per Woman) | Data." Iran. Accessed 2016 November 23. http://data.worldbank.org/indicator/SP.DYN.TFRT.IN?locations=IR.

World Bank. 1993. "Loan Agreement (Primary Health Care and Family Planning Project) between 
Islamic Republic of Iran and International Bank for Reconstruction and Development." Loan Number 3584 IRN. Available at

http://documents.worldbank.org/curated/en/954651468262779265/pdf/1CAFFD7A6F83 530185256F0300053AEF.pdf

World Bank. 2002. "Report No: 24313 Implementation Completion Report (Cpl-35840; Scpd-3584s) on a Loan in the Amount of US\$141.4 Million to the Islamic Republic of Iran for a Primary Health Care and Family Planning Project." Available at http://documents.worldbank.org/curated/en/618741468052772925/text/multiOpage.txt 


\section{Chapter 6 Appendix 1: Interview Schedules}

Below are the interview schedules used in my interviews with doctors and laywomen, respectively. The schedules, as well as the interview protocol, were all reviewed and granted exemption by the West Virginia University Institutional Review Board IRB.

\section{Doctors}

\section{Interview Questions on Iranian Family Planning}

This first set of questions is designed to gather basic information about your professional experience.

During what years did you practice medicine in Iran?

In which regions did you work?

What is your professional specialization?

In which types of medical settings have you worked (hospitals, rural clinics, etc.)?

When did you leave Iran?

The following questions ask about your experiences with and knowledge of family planning in Iran.

To what extent have you been professionally involved in providing family planning services, counseling, or program development? What are your experiences in this area?

I would like to discuss the principles, values and rationales that have guided the provision of family planning services in Iran. Can you talk about your perception of the principles or values forwarded by the government leaders (or official policy) with respect to family planning? Over time, have you noted any changes in the rationale for supporting family planning?

How do these official values align with the provision of services that you have witnessed in practice? Can you give me some examples?

Below is part of an official statement on family planning submitted by Iran to the UN in 1999. Can you comment on how the actual implementation of family planning programs reflects the principles outlined in this statement?

Relying on the three bases of Islam, nationality and republicanism, the Constitution of the Islamic Republic of Iran while respecting the rights and dignity of the individual, considers family as the basic unit of society and social life, in which the respective rights, functions and roles of both parents and children are defined. The formulation and implementation of population policy, including family planning, in the Islamic Republic of Iran has been based on such a definition and with due regard for the socio-cultural characteristics as well as development needs and requirements of the society.

Women

\section{Interview Questions on Iranian Family Planning}

This first set of questions is designed to gather very basic information about your life in Iran.

During what years did you live in Iran?

In which regions did you live? 
In Iran, what kind of professional work did you (or your husband or family) engage in? Why did you leave Iran?

The following questions are concerned with services that support women's health in Iran. Overall, I am particularly interested in the services or methods of family planning (contraception) that are available as part of women's health care.

If a woman wishes to avoid or delay a pregnancy, what options are available to her in Iran? In what ways are family planning services provided?

Feel free to answer generally or personally from your experience.

What differences in family planning services have you noticed occurring over time?

In your opinion, does the government seek to influence childbearing decisions? If so, how?

Do you have any other experiences on this subject that you would like to share? 


\section{Chapter Seven}

\section{Conclusion: Dissent and Diffusion in Policy and Advocacy}

Through this project, I examine the shifting advocacy and policy framing tactics of regimes that espouse non-Western ideologies, but which are nevertheless active in the global community. I then compare these shifts to trends in international advocacy in order to generate a fuller understanding of the relationship between international social movements and the policy and advocacy trajectories of dissenting regimes. Because existing theory suggests that the development of productive and cooperative partnerships between international and domestic actors requires the use of similar framing tactics, advancing an explanation for dissenting regimes' ability to retain their distinct-and sometimes confrontational—frame narratives while simultaneously building international relationships is critical to more clearly understanding policy and advocacy processes in diverse political contexts. In the effort to develop such an explanation, the findings of this research, broadly outlined below, provide a more nuanced account of the importance of frame matching and the implications of divergence and dissent in international contexts.

\section{SUMMARY OF FINDINGS}

In the case of family planning, Iran and Cuba share many similarities. Both nations worked to develop strong family planning programs that extend services to a broad population base, and both nations engaged with actors from the international movement, who provided financial and technical support for these programs. At the same time, both Cuba and Iran openly rejected certain international movement norms and pursued domestic framing strategies that suited their own specific domestic values and goals. However, despite these similarities, Cuban and Iran differ somewhat in 
both the types of framing strategies pursued and in how they negotiated these frames in the international arena. As Chapter Five details, the Cuban movement was first initiated around non-dissenting use of population and development frames, but soon began to challenge the dominance of first generation frames in the international movement. At the same time, reliance on women and health frames became increasingly common in domestic contexts. The study of Iranian family planning in Chapter Six also highlights an early reliance on population and development frames and domestic actors retain use of first generation frames even as these increasingly lose salience in the international movement. In addition, Iran demonstrates a commitment to the use of Islamic frames and nationalist frames that challenge Western intervention in non-Western family planning programs.

Therefore, as existing theory predicts, each nation pursued a unique set of framing tactics that were best suited for promoting family planning in their own unique socio-political contexts. The finding of greater interest, however, is that both Cuba and Iran were able to generate international support for these domestic narratives (and resulting programs) by strategically balancing divergent frame use and dissent with the uncontested use of internationally salient frames. In the case of Cuba, advocates in international forums condemned first generation frames and affirmed the importance of population and development in equal measure, and employed these frames in international dialogues both with and without dissent. This process of tactful divergence allowed Cuba to voice its criticism of international norms while simultaneously developing relationships with international partners. Similarly, Iran balanced dissent and frame divergence, but accomplished this through somewhat different strategies. Specifically, Iran did not reject first generation frames, but rather used these as an early point of common ground with the international movement. At the same time, Iran limited their international use of confrontational nationalist frames-which were more popular in domestic contexts-while favoring the heavier use of Islamic frames. In this case, Islamic frames were used as a more gentle signal of Iran's divergence from Western norms, as well as to help build a broader 
advocacy coalition that challenged dominant trends in international movement frames and objectives. In sum, although there are nuanced differences in the tactics of dissent, which reflect each nation's particular socio-political context, both Iran and Cuba strategically balanced their open challenges to international movement frames with frames that allowed them to affirm and uphold the values and norms of the international movement. As a result, both nations were able to simultaneously challenge and draw support from the international movement. Nevertheless, this strategic balancing was only observed during periods of international movement institutionalization, the implications of which are reviewed in the next section.

\section{REVIEW OF HypotheSES AND THEORETICAL IMPLICATIONS}

In the effort to reconcile the behavior of dissenting regimes with existing work on the importance of international and domestic movement frame matching, I have incorporated the well-established literature on social movement lifecycles and proposed that the importance of frame matching varies according to the particular stage of a social movement's development. Existing theory assumes that, in order to receive recognition and support, domestic movements must employ frames that resonate with the international community. Similarly, in order for international movement goals to be realized in domestic contexts, the framing of those goals must resonate with local values. Thus, for productive collaboration between movements to occur, frame matching between movements is critical. However, given that dissenting regimes often directly challenge international frames and forward their own particular mix of framing strategies while securing international support, some revision to existing theory seems necessary. In this project, I have therefore examined the possibility that frame matching is more important when a movement is in its incipiency or coalescence than it is when a movement has

become broadly institutionalized. In accordance with this theory, Figure 7.1 recapitulates the 
stage-dependent dynamics that are expected in the interactions between international and domestic movements.

Figure 7.1

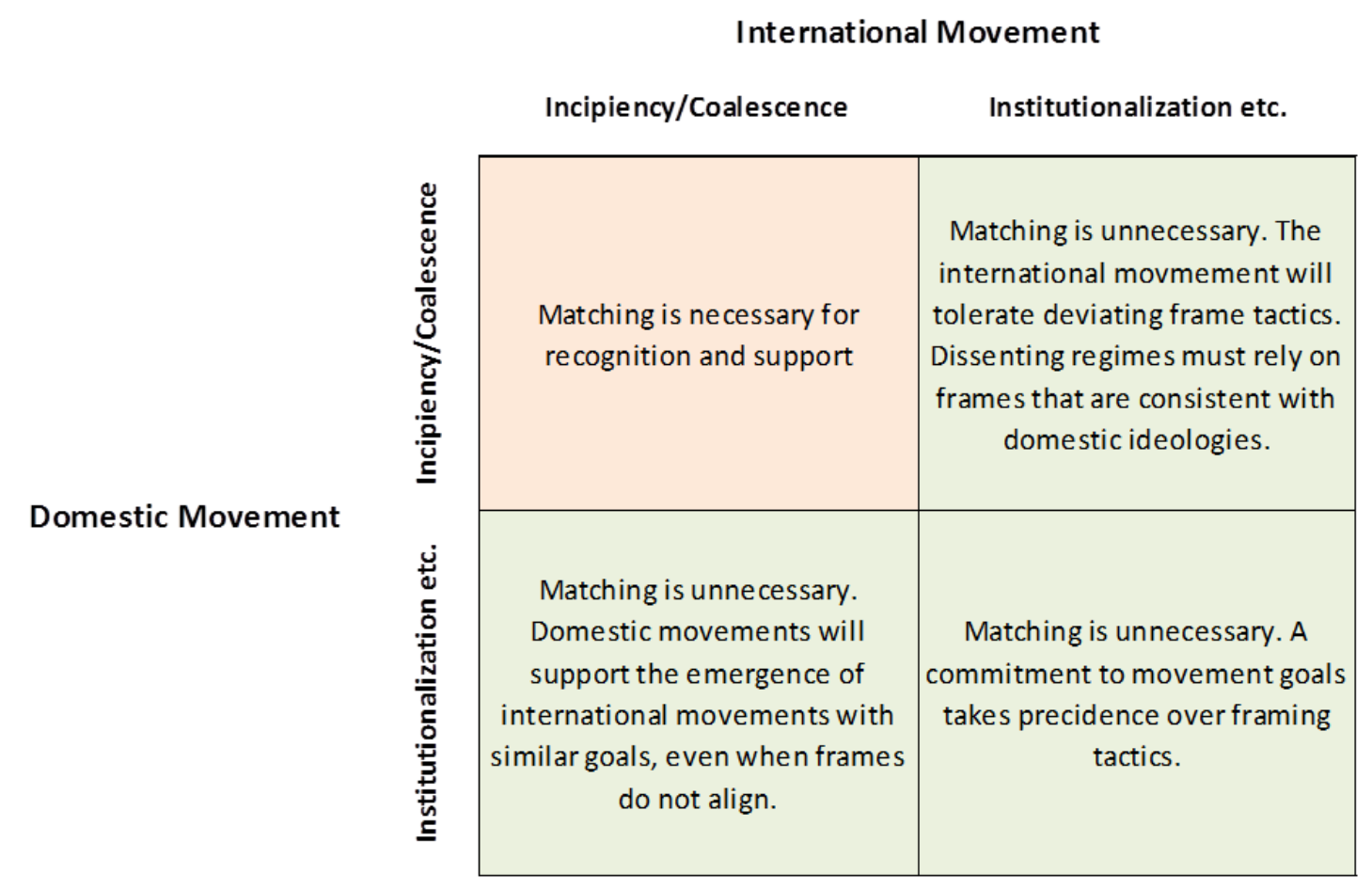

In Chapter Three, I outlined three specific hypotheses resulting from my theoretical

propositions, and these have each been tested through analysis of the international movement, Cuban,

and Iranian case studies. Below, I revisit each hypothesis and review the outcomes of my analysis.

H1: During the international movement's incipiency and coalescence, when the movement is working to focus, coordinate, and develop its messages and strategies, dissenting framing tactics will not be recognized or supported by the international movement. Funding and technical support will not be granted and collaborative partnerships will not develop. Thus, any international recognition and support of dissenting regimes that does occur during this phase requires frame matching by the dissenting regime. However, given the need for dissenting regimes to market themselves through ideologically inconsistent frames to draw international support, it is more likely that no relationship of support will develop during this phase.

In the international movement, we see the transition through incipiency and coalescence during the 1960s, when the movement was heavily dominated by population and development framing. Although 
I predicted that an absence of dissenting regime engagement with international actors would be the more likely outcome during this stage, this did not hold true in the case of Cuba. Rather, the first scenario-frame matching and a lack of dissent—were observed. In this decade, Cuba was slow to challenge population and development frames and widely employed these frames domestically without dissent. In its international interactions, Cuba also refrained from dissent and worked to develop partnerships with international family planning activists that were built on praise for and acceptance of international movement strategies. Thus, I find support for hypothesis 1 in the interactions between Cuba and the international movement in the 1960s. However, because Iran's Islamic family planning movement ${ }^{56}$ did not begin until after the international movement's institutionalization was complete, the Iranian case cannot provide evidence to confirm or reject this hypothesis.

H2: As the international movement institutionalizes, support will be extended to dissenting regimes despite divergent framing tactics. This is both because the institutionalized movement-having achieved high levels of support, resources, and legitimacy—is less threatened by dissenting framing tactics, and because domestic adherence to domestically salient (and ideologically divergent) frames is critical as the dissenting regimes themselves move through movement incipiency and coalescence.

Existing literature demonstrates that the international family planning movement began institutionalization in the 1970s and had become fully institutionalized by the end of the 1980s (Blanc and Tsui 2005). In the 1970s and 1980s, we see behavior from Cuba and the international movement that support hypothesis 2. Specifically, we see the emergence of tactful divergence from international movement frames that does not impact the international movement's extension of support to the Cuban domestic movement. Thus, as the international movement institutionalizes, pointed but moderated dissent is tolerated. In the case of Iran, frame mismatch is more prevalent than outright dissent in the 1980s, as Iran placed heavy reliance on the first generation frames that were increasingly

\footnotetext{
${ }^{56}$ Narrative accounts of Iranian family planning in the 1960s suggest that levels of both frame matching and non-dissenting collaboration were high during this decade. However, because pre-revolutionary Iran cannot be considered a dissenting regime, this matching and collaboration do not signal support for hypothesis 1.
} 
losing salience internationally. In the 1990s, this mismatch continued to grow, as did Iran's use of internationally marginal Islamic frames. However, again in support of hypothesis 2 , I find that this divergence in framing tactics during the period of institutionalization does not impede Iran's ability to build strong partnerships with the international movement during this decade. Rather, strategic balancing leads to the formation of a durable relationship with the international movement. Thus, both cases demonstrate that a well-institutionalized movement may readily extend support to movements that express objections to its framing tactics, particularly when these objections are balanced with support for internationally salient frames.

H3: As dissenting regimes continue to interact with the international movement and its related organizations, and their own movements become institutionalized, both activist and policy frames will converge with those employed by the international community.

Looking at the most recent developments in family planning activism, I find support for hypothesis 3 in the case of Cuba, but less so in the case of Iran. In Cuba in the 2000s, we see continued high levels of collaboration, the disappearance of dissent, and convergence around second generation frame use. By contrast, despite a strong relationship with the international movement, Iran has retained more of its early focus on family planning as a tool of population control and economic development. Although Iran does not dissent to second generation frame use and has incorporated more of these frames over time, in the 2000s, these frames are not clearly dominant. I have suggested that this may be due, in part, to the institutionalized international movement's willingness to continue to work on population and development issues. Whether the slow increase in second generation framing is the beginning of a longer trend in Iran is a question that future research will need to address.

Overall, these findings support the theory that the stage of social movement development impacts the importance of frame matching in the development of inter-movement collaboration and aid. During international movement incipiency and coalescence, I find higher levels of frame matching and an absence of dissent, but as the movement lifecycle progresses through institutionalization, 
divergence and dissent emerge without threatening the ability to build inter-movement relationships. Beyond support for my theoretical proposition, my analyses also show that even during periods of institutionalization, dissenting regimes never fully oppose dominant trends in international frame narratives. Rather, as dissenting regimes express their clear objection to international movement norms and frames during institutionalization, they still strategically balance this dissent with support for international framing tactics.

\section{ADVOCACY AND POLICY IMPLICATIONS}

A better understanding of the relationship between international movements and dissenting regimes can enable activists, aid donors, and political leaders to develop advocacy strategies and policy programs that more consciously and judiciously account for the effects of their underlying differences. Moreover, by deepening awareness of where and when collaboration between groups with seemingly incompatible ideologies results in desirable policy outcomes, this work can assist in the often difficult process of identifying areas where transnational partnerships will be most welcome and effective. Specifically, looking toward the practical application of theory, this work suggests several concrete insights.

First, significant divergence in ideological orientations (and related frames) need not represent an intractable problem for groups that seek to develop a productive working relationship. Rather, this research suggests that grave differences in values and perspectives can be overcome when 1.) dissent to opposing frames is balanced a willingness to engage with those frames in a non-dissenting manner, and 2.) institutionalized movements provide a tolerant space for dissenting views. Although compromise is a hallmark of transnational collaboration, the observations from these cases do not fit into a traditional model of give-and-take. For example, in the 1970s, we do not observe compromising shifts in Cuba's domestic approach to family planning to accommodate population and development 
dynamics, nor do we observe an international movement that concedes to arguments regarding neocolonial subjugation. In place of compromise, these cases are characterized by a willingness to offer space for the development of opposing viewpoints and ultimately to affirm the validity of varying approaches to common goals.

Second, although 'hijacking' of domestic activist or policy agendas by powerful international actors certainly occurs — and has occurred frequently within the history of family planning - the external imposition of international norms is not the inevitable result of extensive collaboration. In both Cuba and Iran, domestic actors remain firmly in control of their internationally-supported family planning programs and the frame narratives used to develop them. In these cases, the provision of international support coupled with the freedom to run programs that are consistent with domestic values has resulted in some of the strongest examples of family planning success in both Latin America and Western Asia. Thus, it is possible for regimes with the political will to develop and administer their own programs to do so even while relying on significant international aid.

Third, although these cases provide positive examples of collaboration, there is some evidence that timing matters. Dissent may not be tolerated by movements that have not yet institutionalized, and regimes that express diverging perspectives may be excluded from international partnerships. Thus, we should not expect that the forging of productive relationships is always a viable possibility, and it may be necessary to wait until an advocacy campaign is securely established before attempting to engage dissenting regimes.

Overall, these cases suggest that tolerance of dissent during movement institutionalization, tactful divergence by dissenting regimes, and the freedom to retain control of domestic narratives are important determinants of the ability build diverse coalitions and develop sound policies and programs that benefit individual citizens. In judging how universally these lessons may be applied, it is important to first recognize that while the strength of qualitative analysis and 'explaining-outcome' process 
tracing rests in their ability to provide nuanced explanations of puzzling outcomes, the limit lies in their generalizability. Nevertheless, while the more detailed analysis of events is specific to these particular cases, these general conclusions have much greater potential to be more widely applied. Thus, we may not find other cases where the sequence of events exactly mirrors the strategies employed by Iran in Cuba in the case of family planning, but there is nothing about 'tolerance of dissent during movement institutionalization, tactful divergence by dissenting regimes, and the freedom to retain control of domestic narratives' that suggests that these factors must be unique to these cases. Rather, we might first look for evidence of their broader applicability in cases that share features of a strong international movement and clashing domestic perspectives, but where activist goals are quite similar. Strong international coordination that sets the tone for global action is a prominent feature in the theory described here, and thus, cases that exhibit this coordination—whether from a Western or alternative perspective—are most likely to fit within my theoretical framework. Additionally, recognition from both international and domestic actors that the ultimate goals of the movement are valid or important is likely needed in order to motivate any action on the issue, even if the rationales and motives for pursuing those goals might be quite different. For example, analysis of the international women's movement or climate change advocacy-where Western transnational actors (and particularly the UN) have taken lead in guiding activist activity and setting global norms, but where there are many conflicting domestic interpretations about how to frame and interpret movement goals and incorporate them into policy-could provide a fruitful starting point for additional tests of the trends identified here. Several additional avenues for future research are explored in the conclusion. 


\section{CONCLUSIONS AND FUTURE RESEARCH}

Although prior research has suggested that domestic groups entering the international arena must frame their claims in a way that is compatible with international norms, this conceptualization leaves little space for challenges by regimes that seek to collaborate with the international community, but that object to the activist and policy ideas that dominate international venues. By demonstrating that, in the effort to build inter-movement partnerships, domestic actors can balance their objections with support for movement norms, and that institutionalized movements offer more flexibility in the degree to which outside actors must match existing frame narratives, this dissertation outlines a path through which dissenting regimes can retain their distinctive, divergent perspectives while not compromising outside recognition and support. These findings show that dissenting regimes do not need to abandon their criticism of international trends in order to collaborate with international actors. Instead, this work highlights the potential for dissenting regimes to criticize existing frames, to open space for new frame narratives, and to insert domestic frames into international dialogues. As existing literature predicts, over time this process may lead to frame convergence; however, in these cases, convergence is the outcome of accommodation by both international and domestic actors, and not simply a product of divergent movements conforming to international norms.

Further research investigating the impact of social movement lifecycles and reliance on tactful divergence would help to strengthen our understanding of how actors with diverse perspectives develop positive and productive inter-movement relationships. In particular, beyond broader testing to determine generalizability, future research should focus on testing this theory across additional cases in order to verify that additional explanations for the dynamics of dissent observed here have not been omitted.

With regard to testing additional cases, an examination of different social movements, a wider selection of dissenting regimes, and other time frames could help to strengthen support for the theory 
proposed here. The international family planning movement was undoubtedly a powerful movement that radically transformed family planning norms and practices across the world. However, it was also a fairly tame movement that was characterized by relatively low levels of contention and an absence of collective violence. Although its impact was revolutionary in terms of demographic influence and women's health and welfare improvements, the repertoires employed to achieve this change were not particularly unconventional. Testing this theory across a range of cases with varying levels of contention and different movement repertoires would help to determine how universally the theory might be extended. Similarly, examining whether the behavior of a wider selection of regimes fits the pattern of strategic balancing and expressions of dissent that are linked to movement stage would be beneficial. Although both Iran and Cuba fit the definition of dissenting regime in the context of family planning activism and programming, these regimes are ideologically and culturally disparate. Thus, their selection as test cases helps to demonstrate that the trends identified in this work are not particular to a very narrow set of regime characteristics. Nevertheless, extending the sample size could help to bolster this claim. Finally, the theory presented here should be tested among movements that progressed through the social movement stages during a wider range of decades. Literature on frame matching does not suggest that the importance of matching is decreasing over time; rather, as claimant access to and competition for international support increases over time, the importance of strategic frame marketing increases. Nevertheless, it seems marginally plausible that general tolerance of deviant frame tactics is increasing over time, across all movements. Thus, the general decade of movement activity, rather than the particular social movement stage, would be the greater predictor of tolerance of frame mismatch. A test of movements that progressed through the social movement stages in a wider range of time periods would help to determine whether this is the case.

More generally, additional research would help to address the possibility of additional or alternative explanations for the ability of dissenting regimes to draw support and build partnerships, 
and would help to offset the qualitative approach's tradeoff between context-rich explanations and pinpointing the generalizability of the theory proposed. For example, although the outcome of this research supports the importance of movement stages, it is possible that my findings regarding the balancing of dissent hold higher explanatory power. Documenting the appearance (or absence) of this strategy across other cases would help to determine the impact of such tactics. Moreover, the regime test cases employed here are highly instructive, but have clear limitations. In particular, because pre-revolutionary Iran was not a dissenting regime and the Islamic Iranian movement did not begin until the late 1980s, testing of hypothesis 1 was not possible within this case. In addition, my evaluation of this case was impacted by language barriers and the more diffuse nature of the Iranian expatriate population in the US. Specifically, securing interviews with English-speaking Iranian women, whose lives in Iran spanned the 1980s-2010s, proved more challenging than obtaining interviews with Cubans. In part, the dense Cuban social networks in Miami and my ability to conduct native-language interviews certainly facilitated the interview process for this case. ${ }^{57}$ However, although family planning and family size is a matter of widespread public discussion in Iran and activism on health issues is viewed as relatively harmless, Cubans also have a more open approach to discussions of sexual activity and reproductive health in general. Given that I was ultimately able to generate a sizeable sample for Iran —albeit of comparatively young and well-educated women — it is possible that the extent to which this cultural difference influenced my findings is negligible. Nevertheless, the evaluation of additional cases could help to offset limitations posed by individual cases and increase confidence in my theory.

Overall, this work provides a firm foundation for understanding the relationship between dissenting regimes and international activists and suggests various opportunities to extend research on the complex relationship between these actors. Importantly, the analysis of the three cases presented in this dissertation advances our understanding of how international and domestic actors negotiate the

57 In Miami, the central challenge to gathering interviews was time-related, as my two month fellowship required a full-time commitment to archival research. 
tension between divergent framing tactics in both domestic and international venues, how and where accommodation of these divergent frames occurs, and how prolonged engagement impacts frame convergence. As a result, this dissertation highlights the pathways through which activists and policymakers may negotiate a relationship that bridges divergent values and norms, and collaborate to develop sound, context-appropriate policies and programs that benefit individual citizens. 